University of Louisville

ThinkIR: The University of Louisville's Institutional Repository

$5-2011$

\title{
Validation of an instructional observation instrument for teaching English as a foreign language in Spain.
}

Maria Gómez-García

University of Louisville

Follow this and additional works at: https://ir.library.louisville.edu/etd

\section{Recommended Citation}

Gómez-García, Maria, "Validation of an instructional observation instrument for teaching English as a foreign language in Spain." (2011). Electronic Theses and Dissertations. Paper 514.

https://doi.org/10.18297/etd/514

This Doctoral Dissertation is brought to you for free and open access by ThinkIR: The University of Louisville's Institutional Repository. It has been accepted for inclusion in Electronic Theses and Dissertations by an authorized administrator of ThinkIR: The University of Louisville's Institutional Repository. This title appears here courtesy of the author, who has retained all other copyrights. For more information, please contact thinkir@louisville.edu. 


\title{
VALIDATION OF AN INSTRUCTIONAL OBSERVATION INSTRUMENT FOR TEACHING ENGLISH AS A FOREIGN LANGUAGE IN SPAIN
}

By

\section{María Gómez-García}

B.S., Instituto Tecnológico y de Estudios Superiores de Monterrey, 1982

M. A., California State University at Fresno, 2000

M. A., Western Kentucky University, 2001

\author{
A Dissertation \\ Submitted to the Faculty of the \\ Graduate School of the University of Louisville \\ and \\ Graduate Studies and Research at Western Kentucky University \\ in Partial Fulfillment of the Requirements \\ for the Degree of \\ Doctor of Philosophy \\ Department of Education and Human Development \\ University of Louisville \\ and \\ College of Education and Behavioral Sciences \\ Western Kentucky University
}

May 2011 


\section{Copyright 2011}

by

María Gómez-García

All rights reserved 



\title{
VALIDATION OF AN INSTRUCTIONAL OBSERVATION INSTRUMENT \\ FOR TEACHING ENGLISH AS A FOREIGN LANGUAGE IN SPAIN
}

\author{
By
}

Maria Gómez-García

B.S., Instituto Tecnológico y de Estudios superiors de Monterrey, 1982

M. A., California State University at Fresno, 2000

M. A., Western Kentucky University, 2001

A Dissertation Approved on

December 14, 2010

By the following Dissertation Committee:

Christopher Wagner

Dissertation Director

Cynthia Houston

Marge Maxwell

Namok Choi

Pradeep Kotamraju 


\section{DEDICATION}

To my husband Yuca and my children: Mariela, Rodrigo, and Valeria.

A special dedication to my dear friends: Dr. Barbara Burch and Dr. Cynthia Houston. 


\section{ACKNOWLEDGEMENTS}

"Gracias a la Vida, que me ha dado tanto"

Through the long journey of our lives, we weave a long tapestry of experiences which intertwine until it becomes a unique and beautiful pattern. Each person that is part of such experiences represents a thread which forms part of the whole motif.

This dissertation is an intrinsic piece of my pattern, and it has become a reality thanks to the accompaniment, advising, support and motivation of many people. Each and every one of these people has left an imprint not only in these pages, but in my heart and journey.

I would like to thank first and foremost my husband, Yuca, for all his encouragement, his unconditional love and his company while walking by my side through our long venture, my three children, for always supporting me and helping me along the way; and my mother, parents-in-law and siblings, for all the help and encouragement throughout the years.

To my dear friend Dr. Barbara Burch, who has always been there, with an unbreakable faith in me. To my unconditional friends Yolanda Rebollar, Kelly BurchRegan, and Roxanne Spencer that with their care have made Bowling Green my home. To my dear friend, Dr. Berta González, whose support all the way through all these years has been very important to me. To my two beloved friends, Liz Romero-Fuerte and Lily 
Zhuhadar, whose help was crucial for my progress. I would also like to thank Anurag Anthati, whose support meant a relevant part of this work came to be.

I would of course like to thank my advisor, Dr. Christopher Wagner, whose help, patience, and faith allowed this study to come true. I would like to thank each and every one of the members of the committee; Dr. Marge Maxwell, Dr. Namok Choi, and Dr. Pradeep Kotamraju for all of their suggestions, valuable contributions and willingness to help me.

A very special thanks to my dear friend and member of the committee, Dr. Cynthia Houston and her husband Jim Houston. Had it not been for Dr. Houston's great support, guidance, and priceless friendship I would have never finished this project. Thank you to all, may the God-Life bless us all and allow for more opportunities in this life to coincide with one another.

\section{RECONOCIMIENTOS}

"Gracias a la Vida, que me ha dado tanto"

En el caminar de la vida vamos tejiendo un gran telar que se compone de cada una de nuestras experiencias, y al final ese gran telar está compuesto de hermosos estampados. Cada persona que participa en cada una de nuestras experiencias se convierte en uno de los hilos de cada estampado.

Esta disertación es uno de los estampados de mi telar y gracias al acompañamiento, asesoramiento, apoyo y motivación de un sin número de personas esta disertación se ha vuelto una realidad. Todas y cada un de estas personas no solamente han quedado plasmadas en este reconocimiento sino han quedado grabadas en mi corazón y en mi caminar. 
Quiero agradecer en primer lugar a mi esposo Yuca, por todo su apoyo, su amor incondicional y su caminar a mi lado durante este largo viaje. A mis tres hijos por siempre estar a mi lado dándome ánimos y ayudándome en todo lo que iba necesitando. A mi madre, suegros y hermanos por su apoyo durante tantos años.

A mi queridísima amiga Dra. Barbara Burch, quién siempre estuvo ahí, con una fe inquebrantable en mí. A mis incondicionales amigas Yolanda Rebollar, Kelly BurchRegan y Roxanne Spencer quienes hicieron de Bowling Green mi hogar. A mi queridísima amiga Dra. Berta González quién ha sido un gran apoyo a través de todos estos años. A mis dos queridísimas amigas, Liz Romero-Fuerte y Lily Zhuhadar cuya ayuda fue crucial para mi desempeño. Quiero también agradecer a Anurag Anthati, quien gracias a su apoyo una parte importante de este trabajo lo pude realizar.

Por supuesto quiero agradecer a mi director de tesis Dr. Christopher Wagner que gracias a su apoyo me fue posible la realización de este estudio. También quiero agradecer a cada uno de los miembros de mi comité; Dra. Marge Maxwell, Dra. Namok Choi y Dr. Pradeep Kotamraju por todas sus sugerencias, valiosas aportaciones y disponibilidad para apoyarme.

Un muy especial agradecimiento es para mí siempre amiga, miembro de mi comité Dra. Cynthia Houston y su esposo Jim. Definitivamente gracias al gran apoyo, guía y valiosa amistad de la Dra. Houston me fue posible finalizar este doctorado. Gracias a tod@s, que el Dios-Vida nos siga bendiciones y proveyendo de oportunidades para coincidir. 


\section{ABSTRACT \\ VALIDATION OF AN INSTRUCTIONAL OBSERVATION INSTRUMENT FOR TEACHING ENGLISH AS A FOREIGN LANGUAGE IN SPAIN María Gómez-García}

December 14, 2010

The design and validation of a classroom observation instrument to provide formative feedback for teachers of EFL in Spain is the overarching purpose of this study. This study proposes that a valid and reliable classroom observation instrument, based on effective practice in teaching EFL, can be developed and used in Spain to enable teachers to move from where they are in their actual teaching performance to an improved level of performance. This instrument is intended to be used as part of the teachers' professional development and for formative purposes. Few instruments have been developed to assess effective practices in EFL/ESL instruction and none have been developed for use in Spain.

The issues investigated through this study concerned the extent to which the observation and evaluation instrument is both valid and reliable. However, there are certain conclusions that may be drawn for each of the research questions posed.

Some of the significant conclusions reached in this study were: (a) a majority of the items included in the final survey are associated with effective EFL teaching practices and are valid for use in an observation instrument; (b) this instrument can help educators, 
supervisors as well as cooperating teachers provide teachers with formative evaluation on their teaching behaviors in EFL instruction; (c) the instrument developed in this study exhibits appropriate content, as determined by a panel of experts; (d) construct validity was determined by internal consistency of the items using exploratory factor analysis; (e) the items that will comprise the observation instrument were shown to have reliability as well as stability; and (f) the instrument can be used by educators, supervisors, or teachers with relative ease and high degree of reliability. Some recommendations will be important to pursue: (a) conduct a inter-rater reliability study by the actual use of the instrument observing EFL teachers, (b) design a training course for the observers, and (c) conduct a longitudinal study to assure formative evaluation as a strategy for teachers 'professional development. 


\section{TABLE OF CONTENTS}

PAGE

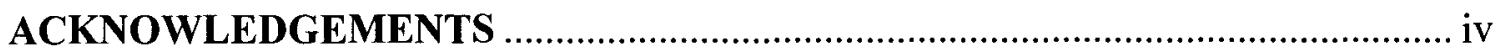

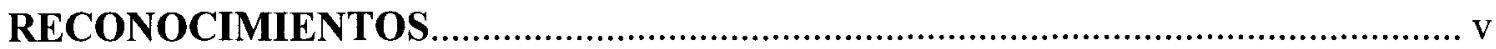

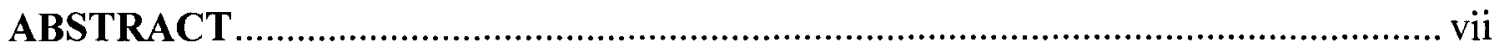

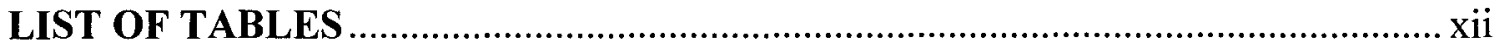

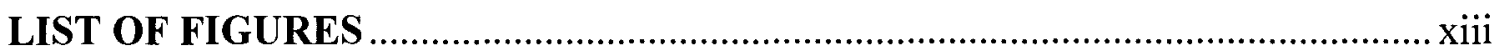

INTRODUCTION ……........................................................................................................ 1

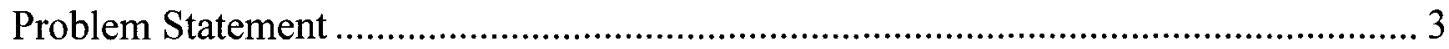

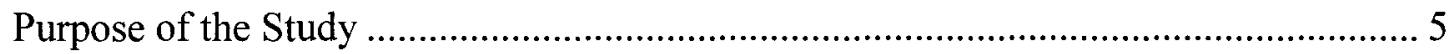

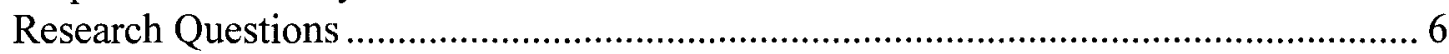

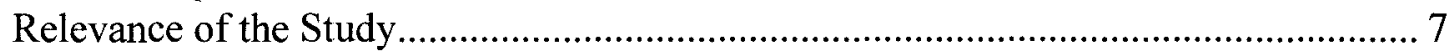

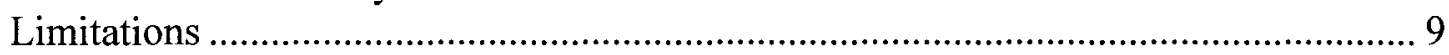

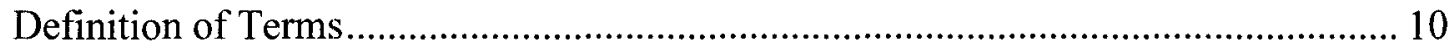

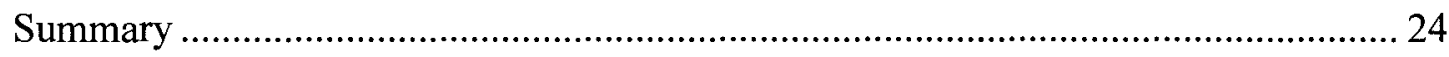

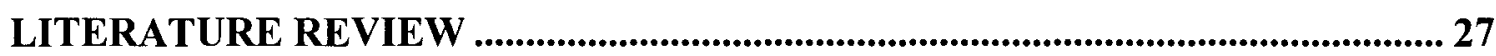

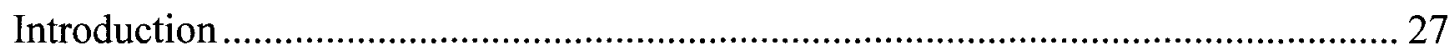

Language Acquisition Theory..................................................................... 28

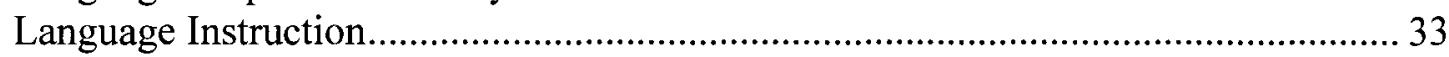

Research on Effective Teaching Practices ................................................................ 40

Research in ESL/EFL Instruction ..................................................................... 49

Classroom Observation for Teacher Improvement ................................................... 57

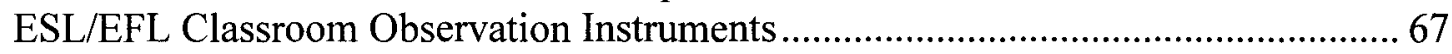

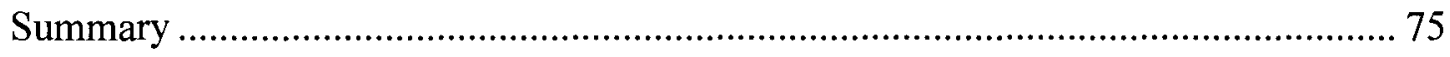

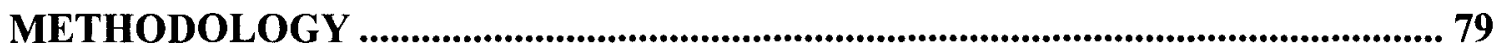

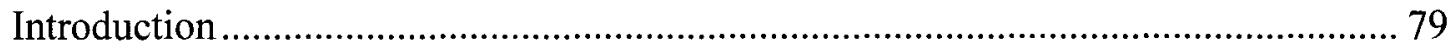

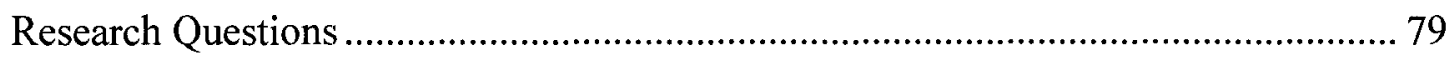

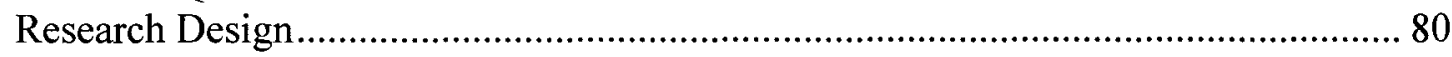


RESULTS AND ANALYSIS ......................................................................................93

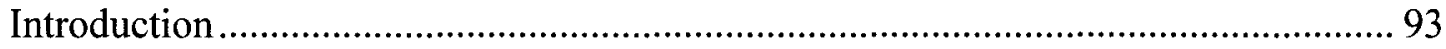

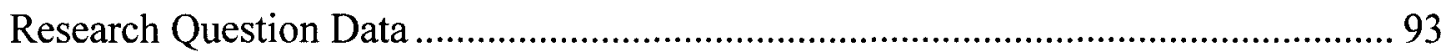

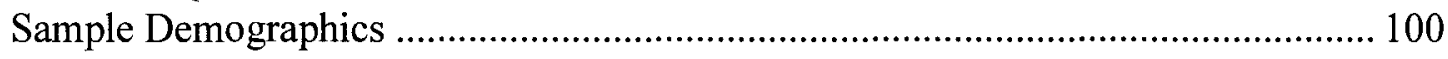

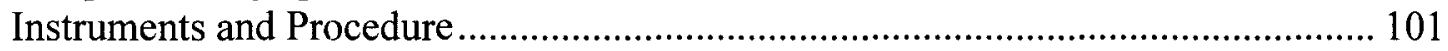

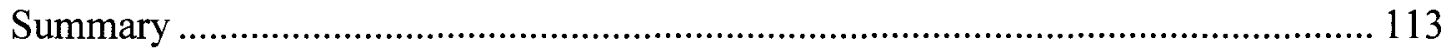

CONCLUSIONS AND RECOMMENDATIONS..................................................115

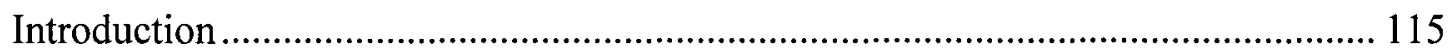

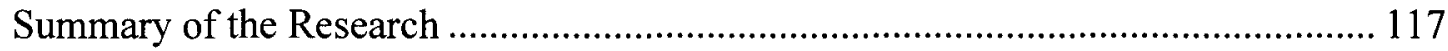

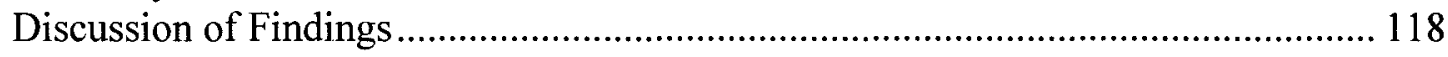

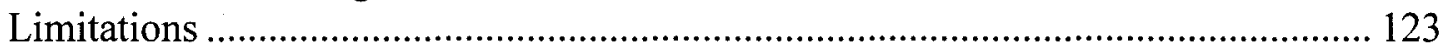

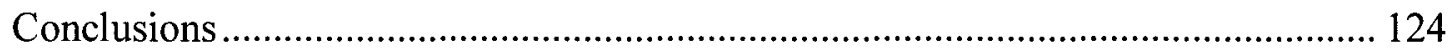

Recommendations for Future Research ......................................................... 126

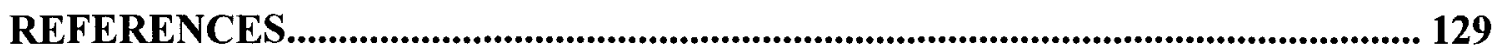

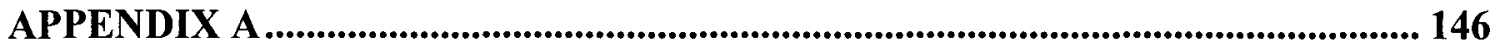

Research-based Items ...................................................................................... 146

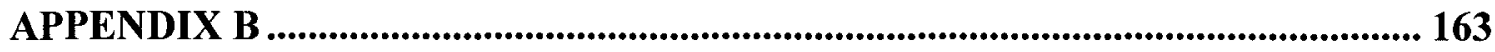

B1. Expert Survey Instructions ............................................................................ 163

b2. Expert Survey Informed Consent Form ................................................................ 164

b3. Expert Survey for Content Validity ……………………………………….... 165

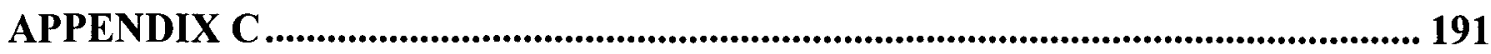

C1. Experts Suggestions for Items Modifications …………..................................... 191

c2. Each Expert Suggestions for Items Modifications ................................................ 198

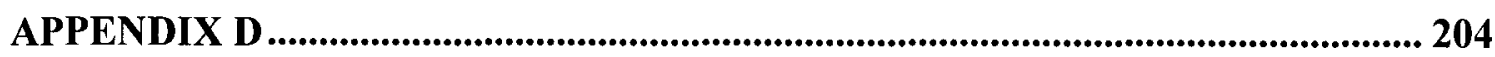

D1. Participants Survey Informed Consent Form ..................................................... 204

d2. Participants Demographics Survey .................................................................... 205

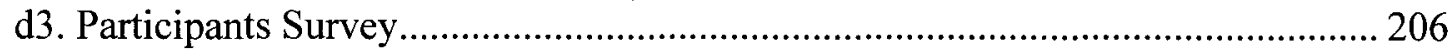

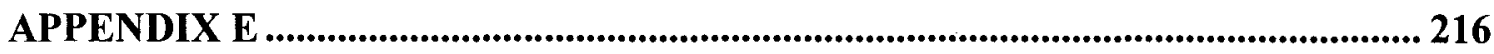

E1. Faculty Invitation Letter ……………………………................................ 216

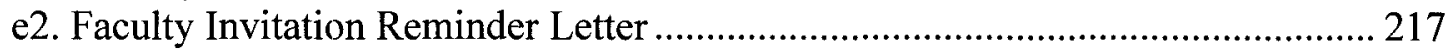

e3. Faculty Invitation Reminder Letter ................................................................. 218

e4. Faculty Invitation Letter to Participate in a Test-Retest Study .............................. 219

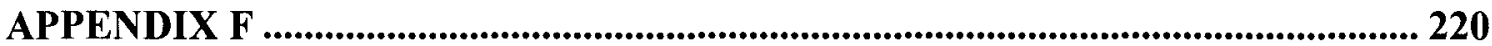

Factorial Factor Analysis Data Analysis.................................................................. 220

APPENDIX G............................................................................................................. 228

Factorial Five-factor Analysis Data Analysis .......................................................... 228 


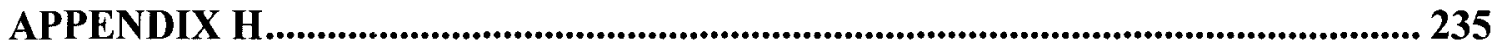

Reliability Data Analysis for the Five Final Factors............................................ 235

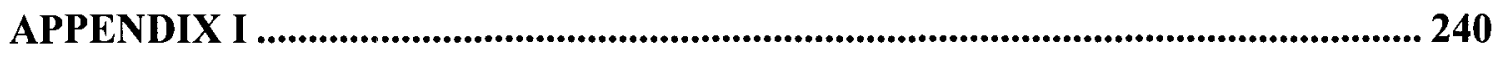

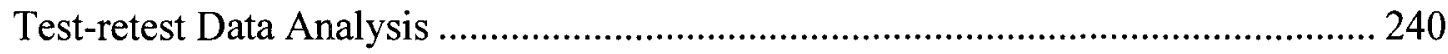

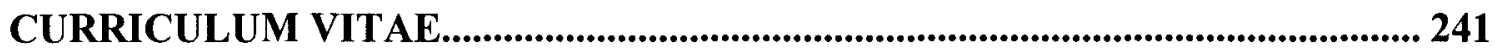




\section{LIST OF TABLES}

TABLE

PAGE

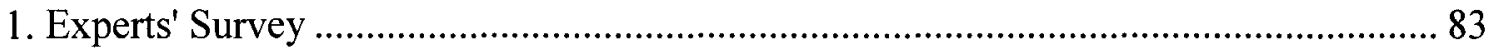

2. Initial and Final Items after Experts' Suggestions ........................................................ 94

3. Items that were Eliminated by the Panel of Experts .................................................... 95

4. Domains and Items for the Survey after Experts' Suggestions for Modification..........98

5. Descriptive Statistics for all 46 Items of the Final Survey $(N=192) \ldots \ldots \ldots \ldots \ldots \ldots \ldots \ldots . . .102$

6. Factor Loadings and Communalities Based on a Principle Components

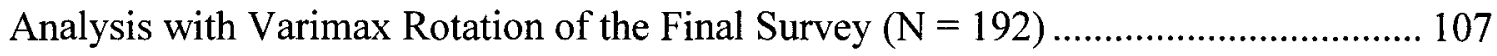

7. Survey with the 5 Factors and Their Items ................................................................. 109

8. Reliability Statistics for the 5 Factors with all the Items $(\mathrm{N}=192) \ldots \ldots \ldots \ldots \ldots \ldots \ldots \ldots \ldots . .112$ 


\section{LIST OF FIGURES}

FIGURE

PAGE

1. Factor Scree Plot Based on a Principle Components Analysis for the

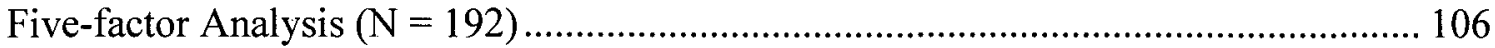




\section{CHAPTER I}

\section{INTRODUCTION}

As educators we know that good teaching plays a critical role in student learning; however, the specific teacher characteristics that impact student learning are difficult to identify and measure (Darling-Hammond, 1999; Goldhaber, 2002; Wenglinsky, 2000). According to Goldhaber (2002), "Good teaching is clearly important for raising student achievement. In fact, most research suggests that the benefit of improving the quality of the nation's teaching workforce is far greater than other policy interventions, such as lowering class size. However, while we know that good teaching is important, it's far less clear what makes for a good teacher" (p. 55).

According to Roberson (1998), classroom observation is one of the premier data collection methods available to those interested in teaching behavior. The use of classroom observation instruments in evaluating teacher performance is a widely accepted practice in teacher education for evaluating instructional effectiveness (Chism, 1999; Griffee, 2005). Observation instruments with good properties provide a framework for educational professionals to assess the effectiveness of teachers' classroom performance and enable them to make the necessary changes to meet accountability standards. Researchers have found that classroom observation gives the supervisor or evaluator a view of the interaction, climate, and dynamics of a classroom that are available from no other source (Peterson, 2000; Roberson, 1998; Stronge, 1997; 
Valentine, 1992). For example, thanks to the information gathered from observations as part of pre-service student teaching programs, institutions of higher education can better know if their graduates are able to link theory with practice and provide universities with an opportunity to improve their teacher education programs (Loghram, 2002; Ludy, 1995).

Evaluation of teacher performance using classroom observation has been a wellstudied field for many years. However, evaluation of teaching in English as a Second Language (ESL) instruction is a relatively new field in the United States and is an emerging field of study in Spain. Recently, English as a Foreign Language (EFL) instruction has become a very important part of the curriculum in many Spanish public and private schools. Furthermore, the Spanish government has been encouraging the growth and development of EFL instruction throughout the country, particularly in the early and primary grades (Reichelt, 2006). A wide variety of teaching methods are used in EFL instruction in Spain, but currently no objective instruments have been developed to observe, assess, or evaluate the extent to which effective EFL instructional practices are being used.

The imperative set forth by these national educational initiatives in Spain has given rise to the need for developing valid and reliable methods to assess teacher performance in English language instruction. Developing valid and reliable observation instruments specific to EFL instruction in Spain will make a contribution to these national initiatives (Rowan, Correnti, \& Miller, 2002). 


\section{Problem Statement}

Although research shows repeatedly that teacher quality is the essential factor in student learning, the continual problem is to identify the significant characteristics of teacher quality and help teachers to develop these characteristics (Darling-Hammond, 1999; Wenglinsky, 2000). If, as education proponents often assert, the emphasis should be placed on equipping educators with the skills necessary to make a meaningful impact on student learning, then Egelson and McCoskey (1998) assess that "an evaluation system designed to encourage individual teacher growth is not a luxury but a necessity" (p. 14). Viewing the problem of improving student performance from this perspective makes the development of systematic and objective methods of classroom observation a critical component in improving teacher quality in every subject area.

When we take for granted that good teachers make a difference in student achievement, but are aware of the fact that traditional criteria we often use to judge a teacher have a minimal impact on improving student learning, the problem we face is: how can any teacher, experienced or not, improve their teaching performance in order to become a good or better teacher? (Goldhaber, 2002; Wilson, Floden, \& Ferrini-Mundy, 2002). This does not imply that teacher preparation and other teachers' attributes are not important. In fact, there is substantial evidence indicating that teachers with more preparation for teaching are more confident and successful with students than teachers who have little preparation or none (Darling-Hammond, 2000). Nevertheless, given the imperative faced by educational professionals to prepare students for the $21^{\text {st }}$ century, methods to evaluate and improve teaching performance must be explored and 
incorporated into the teacher development process both before and after they enter the profession.

The design and validation of a classroom observation instrument to provide formative feedback for teachers of EFL in Spain is the overarching purpose of this study. This study proposes that a valid and reliable classroom observation instrument, based on effective practice in teaching EFL, can be developed and used in Spain to enable teachers to move from where they are in their current teaching performance to an improved level of performance.

It is known that teachers have the greatest impact on student achievement (Ashton \& Webb, 1986), but the evaluation of teaching by observing their lessons has been the subject of much debate in the field of teacher education. In teacher education, the use of classroom observation, along with student achievement data, is among the means by which effective instruction has been evaluated. Observation techniques and instruments that have not undergone the rigor of systematic peer review and validation have shown to be unreliable (Chism, 1999). Often these instruments suffer from such problems as inconsistency, lack of objectivity, unclear item definitions, and variability over time in both observers and subjects (Simmons et al., 1999).

Although a host of instruments has been developed for observing pre-service and practicing teachers in the classroom, not all of them are valid for observing EFL/ESL instruction because many of these teaching methods are not specific to foreign language instruction. Few instruments have been developed to assess effective practices in EFL/ESL instruction and none have been developed for use in Spain. The question remains, therefore: Can an observation instrument be developed to evaluate the quality of 
EFL instruction in Spain? It is precisely this problem that this study is designed to address.

\section{Purpose of the Study}

The purpose of this study is to design, develop, and validate items for an effective, easy-to-use tool, based on research in effective practice, for observing EFL instruction in Spain as part of a formative evaluation process. The design, development, and validation of items is the first step in developing an observation instrument. Therefore, this study will focus on the development and validation of classroom observation items related to effective practices for EFL instruction for use in providing formative evaluation to EFL teachers in Spain. This instrument will allow administrators, cooperating teachers, and university supervisors to efficiently and effectively guide the development of skill levels and competencies of EFL teachers.

The researcher will design and document the validity and the reliability of the items that will compose a comprehensive, easy-to-use, and practical observation instrument designed to measure effective ESL/EFL Teaching Practices. The instrument items will be based on effective practices in ESL/EFL instruction identified in the research literature. These items will be tested for content validity using a panel of experts, construct validity using factor analysis, and reliability using Cronbach's alpha. The stability of the items will be obtained by running a test-retest procedure. The researcher envisions the outcome of this study will provide the most relevant items for an observation instrument that will improve the effectiveness of individual teachers' EFL instructional activities in Spain and, ultimately, improve students' English language learning. 
This instrument will be designed to be used by cooperating teachers, professional observers, evaluators, or supervisors when student teachers or professional teachers are engaged in EFL instruction. The primary emphasis of the proposed instrument will be on tracking the professional development of EFL teachers and providing them with assistance on improving their instructional performance and development through reflection and analysis. Reliable consistent data provides insight into teacher practices that can be used to assess not only the effectiveness of training activities, but also to make informed decisions concerning future efforts about teacher preparation and professional development (Wilson, Floden, \& Ferrini-Mundy, 2001). This data can be used to evaluate teachers' growth in EFL instruction. This tool should improve teachers' content knowledge in the area of effective EFL instruction resulting in higher student achievement in English language learning.

\section{Research Questions}

To design and determine the construct validity and reliability of items for an observation instrument for formative evaluation of EFL instruction in Spain, the following questions are proposed:

RQ1. Do the items have content validity as demonstrated by the judgment of experts in the field of ESL/EFL instruction?

RQ2. Do the items demonstrate construct validity?

RQ3. Do the items demonstrate internal consistency?

RQ4. Do the items demonstrate stability as a measure of effective ESL//EFL teaching practices? 


\section{Relevance of the Study}

It is broadly accepted that knowing foreign languages is very important in both the academic and professional arenas (Almarza, 2000; Alonso, 2006; Bluford \& Dillon, 1995; Díaz, 2004; Silveira, 2000; Puyal et al., 2005; Sanchez, 2009a; Sanchez, 2009b). According to Roldán-Tapia (2005), the document, Teaching and Learning: Toward the Learning Society 1997, issued by the European Commission emphasizes the need for European citizens to acquire at least three languages besides their native language in order to improve their employment opportunities and European cultural interrelationships. One of the strongest statements from the European Community in this document is that language learning should occur in the early school years. The fast technological development in the English speaking countries, especially in the United States, has caused the English language to play a very important role in international communications in both English speaking and non-English speaking countries (Graddol, 1997). English is now an indispensable means for communication in the business sector as well as in the scientific world (Broca-Fernández \& Escobar-Montero, 2002; Graddol, 1997; Kindelán-Echevarría, 2007; Silveira \& Carlos, 1998).

Currently, more than $40 \%$ of the European population speaks English at some level. At present, 91\% of European students learn English, 34\% learn French, 15\% learn German, and 10\% learn Spanish. European English speakers are $47 \%$ of the European Union population, of whom $16 \%$ are native speakers and $31 \%$ speak English as their Second or Foreign Language (Graddol, 1997).

Recent studies indicate the number of English speakers in Europe is on the rise. Miret (2003) and Aragonés (2002) suggest that increasing the number of European 
citizens who are learning English should become a priority. English is the most frequently used language in all European countries, and being able to use it has become a must for professional success (Berg, Hult, \& King, 2001; Hyrkstedt \& Kalaja, 1998; Labrie \& Quell, 1997; Petzold \& Berns, 2000; Phillipson, 2001). According to Miret (2003), Spain is last among all the European countries in terms of language knowledge other than the native language (Eurobarómetro, 2007). In response to this issue, the Asociación Española de Promotores de Cursos en el Extranjero (ASEPROCE) reports that, in Spain, $90 \%$ of students are now required to learn English. Consequently, English is the language in the most demand for foreign language classes (Aragonés, 2002).

Since English has become the preferred language for the European community, the Spanish government is concerned about how to improve English language learning by students. The challenge faced by Spain in developing a competent workforce of English teachers will require the implementation of a rigorous system for improving teaching effectiveness in English as a Foreign Language. The design of an evaluation system for teachers' growth is an important challenge to accomplish (Egelson \& McCoskey, 1998). Nonetheless, in Spain, appropriate supervision and evaluation systems for teacher performance in EFL instruction are scarce or nonexistent. According to Dr. Muñoz (personal communication, July 7, 2010), studies related to EFL classroom observations in Spain are just now being conducted; therefore, no observation instruments for teaching EFL in early years of school have yet been developed. This study intends to fill the void in the literature by developing and validating the items of an observation instrument based on effective practice in EFL instruction to improve the professional development of English teachers in Spain. 


\section{Limitations}

Because this study is comprised of statements about the complex concept of effective practice, it has limitations based on the subjective nature of the subject matter. In essence, whether or not an instructional practice is effective is dependent on the person who carries out the behavior. Furthermore, whether or not an instructional practice is perceived as effective is dependent on the person doing the classroom observation and evaluation. It is for this reason that this study is predicated on subject matter that is entirely relative and, therefore, results can be discussed only as far as researchers agree that the concept of effective practice is a valid concept.

Limitations of this study also include the following very specific issues:

1. Teacher behaviors are very diverse and often particular to the practice of an individual teacher. In a study such as this, the selection of teacher behaviors defined as effective practice in this study may not encompass all teaching practices that result in student learning.

2. This study consists of only the identification and validation of items associated with effective practice in ESL/EFL and does not include a study of the practical application of the observation instrument, which should be the subject of a later study. Because the concept of effective practice as a teaching behavior is rather subjective, there will be some variance in how these behaviors are interpreted by participants in the study.

3. The instrument being developed based on this study is for the PreK-2 grade levels, and items included in the present study include effective practice behaviors found those classroom settings that limit the classroom behaviors 
included in the study. The population used to validate items in this study was comprised of teachers of English as a Foreign Language in Spanish universities belonging to ANECA and not PreK-2 teachers, which may bias results of the study.

4. The teacher behaviors defined as effective practice included in the study were obtained from studies conducted in the United States and may contain teacher behaviors not relevant to the population of this study in Spain. Because the intention of the observation instrument is to identify teaching behaviors that reflect effective practice and does not focus on any specific teaching methodology, some of the described behaviors may be very general statements and lack specificity.

\section{Definition of Terms}

$\underline{\text { AMTB }}$ - Attitude Motivation Test Battery. Proposed by Gardner (1985) as a multicomponent motivation test made up of over 130 items. Working as the main element of Gardner's theory, the test also includes language anxiety measures (L2 class anxiety and L2 use anxiety) and an index of parental back-up. Adaptations of the test have been used in several data-based studies of L2 motivation all over the world, and at the moment it is still the only published standardized test of L2 motivation (Dörnyei, 2001).

ANECA - Agencia Nacional de Evaluación de la Calidad y Acreditación (National Agency for Quality Assessment and Accreditation). The Spanish Organic Law on Universities lays down by means of a Resolution by the Council of Ministers and subsequent to a report by the Universities Coordinating Council, which the Government shall authorize the setting up of the National Agency for Quality Assessment and 
Accreditation. ANECA was set up as a public trust on 19 July 2002. The ultimate goal of the Trust is to contribute to the quality improvement of the higher education system through the assessment, certification, and accreditation of university degrees, programs, teaching staff, and institutions.

ASEPROCE - Asociación Española de Promotores de Cursos en el Extranjero (Spanish Association of Promoters of Overseas Courses). A non-profit Spanish organization founded on 1987 whose objective is to promote the quality and professionalism of the sector's companies and to defend the students' interests.

$\underline{\text { BEST}}-$ Behavioral Evaluation Strategy \& Taxonomy. A software program provides users with an effective way to collect, store, and analyze real-time observational data. The program is comprised of two distinct applications: BEST Collection and BEST Analysis. $\underline{\mathrm{CD}}-$ Classroom Dynamics. For this study, CD is one of the selected domains. According to Omatsu (2006), CD refers to the building of a classroom community and the creation of a positive classroom culture. Helping students develop skills in working together and creating an atmosphere in the classroom where students feel safe enough to take risks in grappling with new and difficult ideas are essential factors for good learning outcomes. $\underline{\text { CIS }}$ - Center for Immigration Studies. An independent, non-partisan, non-profit research organization. Since its founding in 1985 , it has pursued a single mission - providing immigration policymakers, the academic community, news media, and concerned citizens with reliable information about the social, economic, environmental, security, and fiscal consequences of legal and illegal immigration into the United States.

CLT - Communicative Language Teaching. An approach to the teaching of second and foreign languages that emphasizes interaction as both the means and the ultimate goal of 
learning a language. It is also referred to as "communicative approach to the teaching of foreign languages" or simply the "communicative approach."

$\underline{\mathrm{CM}}$ - Classroom Management. For this study, $\mathrm{CM}$ is one of the selected domains where, according to Jones and Jones (1986), it refers to the use of methods to facilitate positive student behavior and achievement, replacing the concept of school discipline, based on controlling inevitable student misbehavior. Four aspects are typically considered: students' personal, psychological, and academic needs; interpersonal relations and school and home interactions as key factors influencing student behavior and achievement; research-supported, practical strategies for improving classroom organization and instruction, including techniques to maximize on-task behavior, creating interesting lessons, and motivating students to increase their learning; and methods for handling classroom and school-wide discipline problems.

Construct - Construct is an individual characteristic that can explain some aspect of behavior (Linn \& Gronlund, 1995). The construct in this study is the measurement of EFL effective teaching practices as represented through specific teaching behaviors Construct validity - The degree of fit of a measure and its interpretation with its underlying explanatory concepts, theoretical rationales, or foundations (Wheeler, Haertel, \& Scriven, 1993).

Content validity - The degree to which an instrument logically appears to measure an intended variable; it is determined by expert judgment (Fraenkel \& Wallen, 1996). Domain - A field of action and influence of instructional practice. Normally, a classroom or group of scholars (apprentices) measured to get statistical meanings. For this study, a domain will be a field of action and influence of instructional practice, as the major 
category on the related items will be organized. Normally, a classroom or group of scholars (apprentices) measured to get statistical meanings.

EFL - English as a Foreign Language. The use of English language in a non-Englishspeaking country or region. Study occurs in the student's home country, as part of the normal school curriculum or as special intensive language class program. ELCOI - English Language Learners Classroom Observation Instrument. A 30-item moderate influence Likert-type scale proposed by Baker, Gersten, Haager, Dingle, and Goldenberg (2004). It is composed of six empirically derived subscales: explicit teaching, instruction geared toward low performing students, sheltered English techniques, interactive teaching, vocabulary development, and phonemic awareness and decoding. ELLA - English Language and Literacy Acquisition. A five-year longitudinal study funded by U.S. Department of Education (USDOE) that followed a group of students from kindergarten through third grade to determine which instructional delivery model was most effective in promoting English language acquisition and literacy by studying under what circumstances certain students respond more favorably to a specific model. ELLIE - Early Language Learning in Europe. A transnational, longitudinal study of the introduction of second/foreign language learning in primary school classrooms in seven European countries. The study has been set up in response to the rapid expansion of provision for early languages learning that has recently occurred in Europe and many other parts of the world.

ESL - English as a Second Language. The use of English language in English-speaking country or region: the United States, Canada, and Australia (known as ESOL in the United Kingdom, Ireland, and New Zealand). It is learned to function in the new host 
country, e.g., within the school system (if a child), to find and hold down a job (if an adult), and to perform the necessities of daily life.

ETP - Effective Teaching Practices is the idea that asserts that there is an activity, technique, method, approach, procedure, or process which helps teachers to effectively achieve particular outcomes that benefit students (Tell, 2001).

Feedback - The information and recommendations provided to a teacher about his/her performance based on the results of that teacher's evaluation and designed to help the teacher improve his/her performance and make decisions concerning professional development and improvement (Wheeler, Haertel, \& Scriven, 1993). Formative evaluation - Evaluation used to improve classroom instruction (George \& Cowan, 2004).

FPMS - Florida Performance Measurement System. The FPMS was compiled initially in 1982 from the research on effective teaching performance. Since that time, a number of studies conducted with the FPMS instruments developed from this knowledge base have documented the validity and reliability of the system for measuring teacher performance (Reliability Study, 1983; Norming Study, 1984; Predictive Validity Studies, 1987).

IALLT - International Association of Language Learning Technology. A professional organization dedicated to promoting effective uses of instructional technology for language teaching, learning, and research. Professionals in the field of language learning technology, including language media center directors and foreign language instructional technologists, require knowledge from a broad range of disciplines.

IATEFL - International Association of Teachers of EFL. Organization whose mission is to link, develop, and support English Language Teaching professionals throughout the 
world through a range of regular publications, an Annual International Conference, offering members the chance to join any number of 14 Special Interest Groups, providing members with reduced rates on a number of selected professional journals, offering scholarships to specific groups of teachers to enable them to attend our Annual Conference, linking with associated professional organizations in other countries, and providing help to others in forming or developing a local teachers' organization. Instrument - A device used to collect data, information, and evidence; these devices can include tests, questionnaires, application forms, interview schedules, checklists, rating scales, and observation records (Wheeler, Haertel, \& Scriven, 1993). Instrument reliability - Instrument reliability refers to the notion that the instrument documents accurately, consistently, predictably, and dependably (Peterson, 2000). It is a way of ensuring that any instrument used for measuring experimental variables gives the same results any time.

Internal consistency - Measures the degree to which a set of items measures a single onedimensional latent variable (Carmines \& Zeller, 1991).

Inter-rater reliability - The degree to which the measure yields similar results for the same teacher at the same time with more than one assessor (Wheeler, Haertel, \& Scriven, 1993).

$\underline{\text { Item }}$ - For this study, an item will be an instructional teacher behavior.

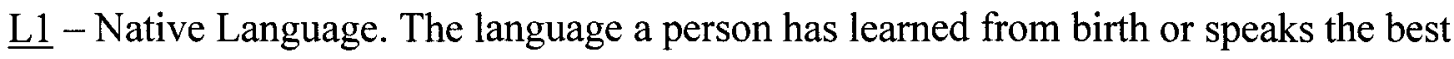
and is often the basis for a person's sociolinguistic identity. In some countries the term is known as mother tongue, and it also refers to the language of one's ethnic group rather than one's first language. 
L2 - Target Language. A language that is the focus or end result of certain processes. In applied linguistics and second-language pedagogy, the term "target language" refers to any language that learners are trying to learn in addition to their native language. The same concept is often expressed as "second language."

LAS - Language Arts Strategies. For this study, LAS is one of the selected domains. According to Chamot and O'Malley (1987), LAS refers to a cognitive approach to teaching that helps students learn conscious processes and techniques that facilitate the comprehension, acquisition, and retention of new skills and concepts. The use of learning strategy instruction in second language learning is based on four main scenarios: mentally active learners are better learners, strategies can be taught, learning strategies transfer to new tasks, and academic language learning is more effective with learning strategies.

$\underline{\text { LAD }}$ - Language Acquisition Device. Part of Chomsky's acquisition hypothesis. The LAD is a system of principles with which children are born that helps them learn language and accounts for the order in which children learn structures and the mistakes they make as they learn. Second language learning theory proposes that acquisition is possible in second and subsequent languages, and that learning programs have to create the conditions for it.

Observation - The unobtrusive watching of behavioral patterns of people in a certain situation to obtain information about the phenomenon of interest (Johnson \& Christensen, 2000); observations typically occur in the teacher's own classroom, but may also be based on audio tapes or videotapes (Wheeler, Haertel, \& Scriven, 1993). 
PACES - Professional Assessment and Comprehensive Evaluation System. Personnel evaluation and assessment system designed to improve the professional skills of all personnel. Standard PACES information sessions are offered to teachers at their school site by its administration (Ellet, 2000; Ellet, Annunziata, \& Schiavone, 2002). Pre-K - Previous to kindergarten. It is also called PK, refers to the first formal academic classroom-based learning environment that a child customarily attends in the United States. It begins around the age of four or five in order to prepare for the more didactic and academically intensive kindergarten, the traditional "first" class that school children participate in. Currently Pre-K is not required.

Preservice teacher - An individual enrolled in a formal teacher education program prior to having teacher certification. A preservice teacher may be completing coursework, an internship, and/or working under provisional status as a teacher (Hinrichsen \& Thaler, 2003).

Reflection/reflective thinking - The process by which a teacher reviews his or her past performance as a means of improving future performance (Wheeler, Haertel, \& Scriven, 1993).

Reliability - The consistency across parts of a measurement instrument. $\underline{\text { SD }}$ - Student Dynamics. For this study SD is one of the selected domains. According to Biggs (1987), SD refers to the ways in which students go about learning. A theory of learning accentuates the interaction between the person and the situation. Research evidence implies a form of meta-cognition called meta-learning, the awareness of students of their own learning processes, and their increasing control over them. 


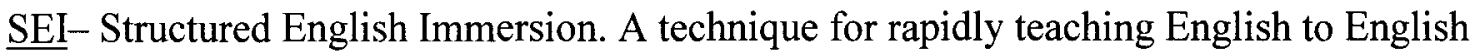
Language Learners. The term was coined by Keith Baker and Adriana de Kanter in a 1983 recommendation to schools to make use of Canada's successful French immersion programs (Baker, 1998).

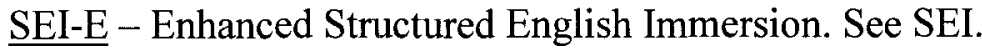

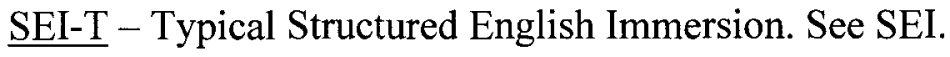

$\underline{\text { SIOP }}$ - Sheltered Instruction Observation Protocol. A research-based and validated instructional model that has proven effective in addressing the academic needs of English learners throughout the United States. The Model consists of eight interrelated components: Lesson Preparation, Building Background, Comprehensible Input, Strategies, Interaction, Practice/Application, Lesson Delivery, and Review/Assessment. Using instructional strategies connected to each of these components, teachers are able to design and deliver lessons that address the academic and linguistic needs of English learners.

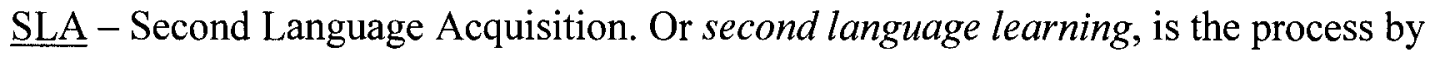
which people of a language can learn a second language in addition to their native language(s). "Second language acquisition" refers to what the student does; it does not refer to what the teacher does.

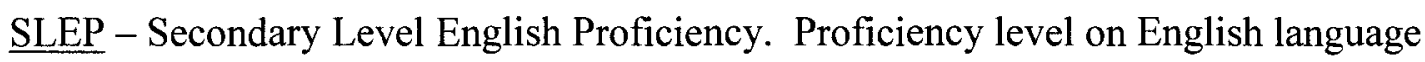
measured by a test created by Educational Testing Service and administered by American middle and high schools to applicants whose first language is not English.

$\underline{\text { SLL }}-$ Second Language Learning. See SLA. 
$\underline{\text { SPSS }}$ - Statistical Package for the Social Sciences. A computer program used for statistical analysis. Between 2009 and 2010, the premier vendor for SPSS was called PASW (Predictive Analytics Software) Statistics, while copyright issues for the name were settled. The company announced on July 28, 2009 that it was being acquired by IBM for US $\$ 1.2$ billion. As a result, on January 2010 it became "SPSS: An IBM Company."

Stability - The state of firmness and continuance on an instrument (i.e., a test, survey, etc.). Permanence or constancy on the purpose (results) of searching through experimental meanings over time, ensuring that the same test performed upon the same individual gives exactly the same results.

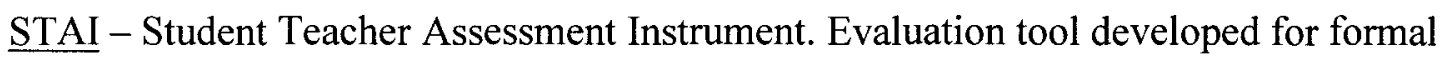
performance assessment at different stages during a student teaching experience.

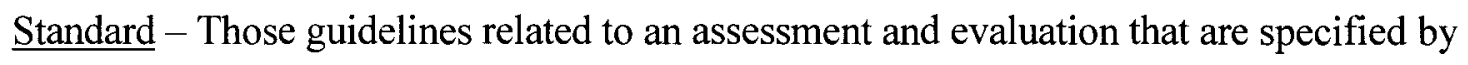
the individuals and associations in the career area affected, directly or indirectly, by the assessment (Wheeler, Haertel, \& Scriven, 1993); a standard is a succinct statement of one aspect of the practice of accomplished teachers (National Board for Professional Teaching Standards, 2010).

$\underline{\text { STAR }}$ - System for Teaching and Learning Assessment and Review. A conceptual and empirical analysis of findings from the development of a comprehensive classroombased, direct observational measure of classroom environment. The STAR differs from traditional instruments of direct, systematic classroom observation in that it assesses elements of both teaching and learning. Observation is based on four performance dimensions: preparation, planning, and evaluation; classroom and behavior management; 
learning environment; and enhancement of student learning (Ellett, Loup, \& Chauvin, 1989).

Supervision - The function or process of working with teachers to improve instruction; the process of supervision involves observing teachers by utilizing predetermined observation guides and conferring with teachers on how to plan and use essential teaching elements more wisely and judiciously (Glickman \& Bey, 1990).

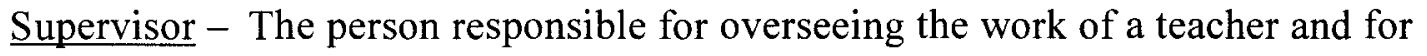
ensuring that the teacher performs his other duties and professional responsibilities; this person can be either "university-based" or "school-based" (Wheeler, Haertel, \& Scriven, 1993) A university-based supervisor is a member of a higher education teacher education faculty who supervises the activities of student teachers as part or all of his other workload; the term is also used to refer to non-faculty personnel (school-based supervisor) employed by the college or university either part time or full time for this specific function (Ludy, 1995). A school-based supervisor may also have joint appointment with a school system and higher education institution.

Systematic Observation - A process in which a classroom observer records the visible performance of a teacher and analyzes the record using some conceptual framework (Peterson, 2000)

$\underline{\text { TA }}$ - Teaching Approaches. For this study TA is one of the selected domains. According to Fraser and Walberg (1995), TA refers to a trend of bringing the tools and learning opportunities to learners.

$\underline{\text { TADS }}$ - Teacher Assessment and Development System. An instrument used to evaluate teachers. It is utilized specifically to discriminate between high performing versus other 
teachers. The TADS form is used to observe teaching behaviors under performance indicators in four categories: knowledge of subject matter, techniques of instruction, classroom management, and student-teacher relationship. Teachers are usually rated by a trained team including a principal from another school, a supervisor, and a peer teacher. The results indicate that meritorious teachers are nominated among their peers. TBE - Transitional Bilingual Education. This is an educational theory that states that children can most easily acquire fluency in a second language by first acquiring fluency in their native language. Fluency is defined as linguistic fluency (i.e., speaking) as well as literacy (i.e.., reading and writing). The goal of transitional bilingual education is to help transition a student into an English-only classroom as quickly as possible. A bilingual teacher instructs children in subjects such as math, science, and social studies in their native language, so that once the transition is made to an English-only classroom, the student has the knowledge necessary to compete with his peers in all other subject areas. The length of time a student is taught English while learning other subjects in their first language is typically three years. Research has shown that many of the skills learned in the native language can be transferred easily to the second language later. TBE-E - Enhanced Transitional Bilingual Education. See TBE. TBE-T - Typical Transitional Bilingual Education. See TBE. $\underline{\text { TBI }}$ - Task-Based Instruction. Also known as the related Task-Based Language Learning (TBLL) or Task-Based Language Teaching (TBLT). A methodology focused on the use of authentic language and on asking students to do meaningful tasks using the target language. Such tasks can include visiting a doctor, conducting an interview, or calling customer service for help. Assessment is primarily based on task outcome (in other 
words, the appropriate completion of tasks) rather than on accuracy of language forms. This makes TBI especially popular for developing target language fluency and student confidence.

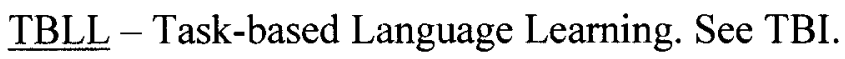

$\underline{\text { TBLT }}$ - Task-based Language Teaching. See TBI.

$\underline{\text { TBOP }}$ - Transitional Bilingual Observation Protocol. This observation protocol is used to empirically describe teaching behaviors in two types of programs, bilingual and structured English immersion. The two program models include an experimental version and a typical practice (control) of each type. Variations across the models are identified related to the teachers' pedagogical approaches.

Teacher preparation program/teacher education program - University programs designed with a state approved course of study and with legal authorization to prepare teachers.

TER - Teacher Evaluation Research. Teacher assessment serves to further dialogue about what is considered good teaching practice (Rabinowitz \& Ananda, 2001). As a rule, teachers are given verbal feedback, individually or during a faculty conference, on their job performance; but usually there is no documented evidence that the feedback was given. Teacher evaluation is a powerful tool for improving teacher effectiveness; given the importance of teacher quality for improving student achievement, teacher assessment has emerged as an important tool in improving education. Research on this field has become a key factor due the relevance of educators' development. TESOL - Teachers of English to Speakers of Other Languages. This is a global education association for English language teachers to speakers of others languages with individual 
and institutional members and extensive affiliations worldwide. TESOL's mission as a profit-making organization involves research and improvement of education and training, promoting professional standards in language education, networking and cooperation internationally, and advocacy of language rights and access to quality language education.

Test-Retest - The test-retest method is one way of ensuring that any instrument is stable over time by testing twice a survey in order to confirm stability on participants' replies. A method used to assess how constant scores remain from one occasion to another (DeVellis, 2003).

TOEFL - Test of English as a Foreign Language. This is an examination tool that evaluates the ability of an individual to use and understand English in an academic setting. It sometimes is an admission requirement for non-native English speakers at many English-speaking colleges and universities. Additionally, institutions such as government agencies, licensing bodies, businesses, or scholarship programs may require this test.

$\underline{\text { TPAI }}$ - Teacher Performance Assessment Instruments. A high inference assessment system developed by the North Carolina Department of Public Instruction and implemented in 1985. It is to be administered by school principals and other personnel who received extensive training in its proper use. TPR - Total Physical Response. A method developed by Dr. James J. Asher, a professor emeritus of psychology at San José State University, to aid learning second languages. The method relies on the assumption that when learning a second or additional language, language is internalized through a process of code breaking similar to first language 
development and that the process allows for a long period of listening and developing comprehension prior to production. Students respond to commands that require physical movement. TPR is primarily intended for ESL/EAL teachers, although the method is used in teaching other languages as well. The method became popular in the 1970s and attracted the attention or allegiance of some teachers, but it has not received generalized support from mainstream educators.

$\underline{\mathrm{UB}}$ - University of Barcelona. A public university located in the city of Barcelona, Catalonia, in Spain. It is a member of the Coimbra Group, LERU, European University Association, Mediterranean Universities Union, International Research Universities Network, and Joan Lluís Vives Institute. With 75 undergraduate programs, 353 graduate programs, 96 doctorate programs, and over 63,700 students, UB is considered to be the best University in Spain. Internationally, the 2010 QS World University Rankings ranked the university 148th overall in the world. Its subject rankings were: 72nd in Arts \& Humanities, 139th in Engineering \& IT, 68th in Life Sciences \& Biomedicine, 54th in Natural Sciences, and 118th in Social Sciences.

Validation - The process of determining the appropriateness, meaningfulness, and usefulness of a measure, an instrument, or an assessment process, and the inferences made from the results of it (Wheeler, Haertel, \& Scriven, 1993).

\section{Summary}

This chapter provides an introduction to the problem, purpose, relevance, and research questions posed for the research study. The problem posed by the study is: Can an observation instrument be developed to identify the significant characteristics of effective practice of EFL instruction in Spain? The purpose of this study is to answer this 
question by developing the items for a simple, easy to use tool, based on research in effective practice, for observing EFL instruction in Spain as part of a formative evaluation process. The research questions used to develop valid items for the instrument include: Do the items have content validity as demonstrated by the judgment of experts in the field of ESL/EFL instruction? Do the items demonstrate construct validity? Do the items demonstrate internal consistency? Do the items demonstrate stability as a measure of effective ESL/EFL teaching practices?

As this chapter demonstrates, direct observation is an important component of a teacher-evaluation process, and the use of classroom observation instruments in evaluating teacher performance is a widely accepted practice in teacher education for evaluating instructional effectiveness. However, to truly improve instruction, a deeper, more objective and systematic assessment of the individual teacher must also take place. The use of classroom observation is one of the premier data collection methods available to those interested in teaching behavior; but, because they lack validity, they might not be as effective as they could be in improving instruction, specifically in the area of languages.

Through classroom observation by experienced professionals who use a valid observation instrument, teachers can get reliable feedback on their performance and receive guidance on improving their instruction. For this reason classroom observation and the use of valid observation instruments are an essential part of the formative evaluation process.

Because of imperatives set forth by the European community, EFL instruction has become a very important part of the curriculum in many Spanish public and private 
schools. The development of items for a classroom observation instrument to provide formative feedback for teachers of EFL in Spain would enable teachers to move from where they are in their current teaching performance to an improved level of performance. Therefore, the goal of this study is to develop items for such an instrument. 


\section{CHAPTER II}

\section{LITERATURE REVIEW}

\section{Introduction}

As developing and validating items related to effective practice in English as a foreign language instruction in Spain involves theories and concepts from different content areas, it is not surprising that the theoretical constructs used in framing this study come from several different areas of research. This section will present the range of theories and concepts underlying the study, including the areas of language acquisition theory as it relates to language instruction, evaluation of teacher performance, classroom observation of teacher performance, effective practice, and the use of observation instruments in teacher professional development.

The purpose of this study is to develop items for a classroom observation instrument for EFL instruction and establish the validity of items related to effective ESL/EFL teaching practices in Spain. This instrument intends to be an easy-to-use instrument for assessing and improving teacher performance in EFL instruction. Because the instrument will be used in settings where a number of different methods of teaching English are employed, this literature review will provide background on theories and research pertaining to English language acquisition, teaching methods used in ESL and EFL, effective teaching practices, classroom observation for improving instruction, and classroom observation instruments used in improving English instruction. 


\section{Language Acquisition Theory}

The process of acquiring a new language, regardless of which native language is spoken, or whether it is a second or third language, is similar to native language acquisition but involves a lengthier process (Tomasello, 2005). There may be differences in the rate at which learners acquire a new language, depending on a number of factors including native language, age, the language learning environment, and affective issues; but, in general, the language acquisition process is the same (Brown, 2001; Krashen, 2003). Discussions over which method of language instruction is the most effective have been greatly influenced by theories of language acquisition, as there is a strong connection between theories of language acquisition and the practice of language instruction. According to Krashen (2003), language acquisition is concerned with what governs, affects, or constrains a learner's acquisition of a linguistic system, such as an individual's cognitive functioning or whether they are living where the new language is regularly spoken. Krashen states that language instruction, in contrast, addresses the impact that a formal learning environment, such as classroom discussion, student and teacher interaction, and grammatical instruction, has on the development of the new language. Therefore, while language acquisition research focuses on internal cognitive variables associated with learning a new language, language instruction focuses on variables external to the learner in order to study the effect of instruction on an individual's language acquisition (Brown, 2007).

Over the past 50 years, several theories have been put forth to explain the process by which children learn to understand and speak a language. According to Hawkins (2004), acquiring a new language "is defined as the mental processes by which learners 
come to organize and use features of the new language" (p. 15). Hawkins asserts that the process used for acquiring a new language is called Second Language Acquisition (SLA) and is concerned with how people learn a language other than their first and whether it is a second, third, or fourth language.

Language acquisition research typically concerns an infant's acquisition of their native language, rather than studying the acquisition of a second language in both children and adults. This field of study is typically referred to as SLA, which studies the psychology and sociology of the learning process (Brown, 2007).

Presently, the following three approaches dominate theory and research related to language acquisition: the Behavioral Approach, the Social Nativist Approach, and the Functional Approach.

1. Behavioral Approaches - B. F. Skinner, the individual most often associated with this theory, proposes that children imitate adults following a stimulusresponse pattern. According to this theory, children learn a language when their correct utterances are reinforced (Brown, 2007; Skinner, 1957).

2. Nativist Approach - Noam Chomsky published a criticism of the Behavioral Approach in 1957. Chomsky argued that the child's brain has a metaphorical "little black box" or Language Acquisition Device (LAD), which is responsible for language learning. In this approach children learn language not as a series of separate discrete items but as an integrated system (Brown, 2007; O'Grady, 1999; Schwartz, 1999).

3. Functional Approach - With the increase of constructivist theories, researchers such as Piaget, Chomsky, Bruner, and Vygotsky began studying human 
cognitive and affective abilities, as well as social interaction. The functional approach emphasizes cognition and language development, particularly in children. From a Piagetian perspective, language is just one aspect of a child's overall intellectual development (Brown, 2007). From a constructivist or social interactionist perspective, on the other hand, Jerome Bruner stressed the importance of the language input children receive from their care-givers. Language exists for the purpose of communication and can only be learned in the context of interaction with others (Brown, 2007).

The above mentioned approaches represent the major streams of thought related to the acquisition of language as a developmental process, typically occurring in infancy. These approaches have all contributed to the development of methods for teaching language, but have not taken into account the fact that people typically learn a second language later in life, either because of a change from one language community to another or through formal academic learning. To expand theories of language acquisition to the acquisition of a second language, Krashen (2003) developed several hypotheses of second language acquisition, all of which have direct applications to and have had a great influence on language instruction. According to Krashen, SLA or Second Language Learning (SLL) is the process by which people learn a second language in addition to their native language. Krashen asserts that while language acquisition is a subconscious and natural process, language learning is a conscious process, typically done in a school setting, and concerns primarily what the learner does, not what the teacher does. When learning a language as a natural process, children and adults are generally engaged in naturally occurring communicative situations. In contrast, a language learning 
environment is not a natural communicative environment, as there is much error correction and the study of grammatical rules isolated from the natural language.

Research in second language acquisition has typically focused on developing knowledge and use of a language by children and adults who already know at least one other language. Second language acquisition theory seeks to quantify how and by which processes individuals acquire a second language (Krashen, 2003).

According to Krashen (2003), language acquisition is a process that "while (it) is happening, we are not aware that it is happening" (p. 1). Based on his research in language acquisition, Krashen has developed the following five hypotheses of language acquisition which he asserts are applicable to the acquisition of a new language:

1. The Acquisition-Learning Hypothesis - Language acquisition is a subconscious and intuitive process, while language learning is a more conscious process of learning a language's form and function and is what usually occurs in school (Brown, 2007; Krashen, 2003).

2. The Monitor Hypothesis - The learner can edit, make alterations or correct his or her use of language during language acquisition to become a more accurate and more fluent language user (Brown, 2007; Krashen, 2003).

3. The Natural Order Hypothesis- Individuals will learn a new language in a predictable or "natural" order, based on the grammatical rules and structure of the new language and compatibility with the native language. The order for learning different elements of the new language may be the same or different from that of the native language (Brown, 2007; Krashen, 2003). 
4. The Input Hypothesis - Language acquisition occurs effectively when the new language or "input" is made understandable to the individual on a level that is not overwhelming (Brown, 2007; Krashen, 2003).

5. The Affective Filter Hypothesis-The language acquisition occurs when the environment does not cause a language learner to be anxious or defensive. Thus, an effective language learning environment must have a low affective filter (Brown, 2007; Krashen, 2003). According to Krashen, the affective filter influences how effectively the parts of the brain responsible for language acquisition can function (Krashen, 2003).

Krashen's theories have had a great impact on both English as a foreign language and English as a second language instruction (Tragant \& Muñoz, 2009). His research, although wide-ranging, has focused on validating his different hypotheses in the English as a Second Language classroom. Specific studies have included research on instructional approaches based on the Input Hypothesis, such as Language Immersion, the Total Physical Response Method, the Natural Approach, Sheltered Instruction, and the use of stories and free voluntary reading in the target language classroom (Gibbons, 2003; Krashen, 1981; Krashen, 1984; Krashen \& Terrell, 1983; Nikolov \& Krashen, 1997). In all cases, Krashen's hypotheses emphasize the importance of student engagement in the target language during instruction through the use of motivating activities such as reading, dialogue and storytelling, and a de-emphasis on instruction in formal principles of grammar (Krashen, 2003). 


\section{Language Instruction}

As illustrated in the previous section, there are a number of different approaches to understanding language acquisition that have given rise to a large body of research and theory that can be applied to language instruction. Oftentimes, methods in language instruction do not rely solely on one theory of language acquisition, but draw from any useful idea or area of research which has been put forward and has utility in the language classroom (Sanchez, 1997). The aim of this section is to discuss research based on different theory-based approaches to teaching English as a foreign or second language. Although the main concern of this study is developing an observation instrument for English teachers in Spain, research articles addressing a wide variety of issues in ESL/EFL instruction will be included here. Furthermore, the goal of this section is not to determine which method of instruction is best, but to provide examples of the different methods of teaching English as a foreign or second language that research has shown to contribute to student achievement.

According to Brown (2007), language instruction takes place in a variety of school settings and uses many different methods and approaches. In the field of language instruction, the terms "method" and "approach" are sometimes used interchangeably, while at other times they are used in a hierarchy where "approach" is a more broadly defined term encompassing many "methods" of language instruction. Brown defines an approach as "a unified but broadly based theoretical position about the nature of language and of language learning and teaching that forms a basis of methodology in the language classroom" (p. 376). In contrast, "a 'method' is a coherent, prescribed group of activities and techniques for language and teaching, unified by a homogeneous set of principles and 
foundations" (p. 386). Using Brown's distinctions, the following approaches to teaching foreign language appear to dominate the research literature:

1. The Structural Approach - This approach treats language as a system of structurally related elements to code meaning, typically in the classroom. The structural approach is equated with grammar instruction.

2. The Functional - Notional Approach - This approach sees language as a vehicle to express or accomplish a certain function, such as requesting something (Finocchiaro \& Brunfit, 1983).

3. The Interactive Approach - This approach sees language as a vehicle for the creation and maintenance of social relations, focusing on patterns of moves, acts, negotiation, and interaction found in conversational exchanges.

Based on these approaches, there is a wide variety of methods of teaching English as a foreign and second language currently in use in classrooms across the globe. Typically, language teachers do not rely on one sole method or approach. According to Celce-Murcia, "there were two types of approaches for Second Language Teaching (SLT) prior to the twentieth century: getting the learner to use a language versus getting the learner to analyze a language" $(2001$, p. 3). These two approaches for teaching language have been shifting back and forth for many centuries. For example, the classical Greek and the Medieval Latin periods emphasized language learning for its use, while during the Renaissance period learning language through linguistic analysis was the predominant approach. During the seventeenth century, the approach to learning a language shifted again to its use, and that remains the approach used today (CelceMurcia, 2001). 
Anthony's study (as cited in Celce-Murcia, 2001) makes the following distinction in approach and method: an approach is something that reflects the use of a certain instructional model, while a method is a set of procedures. In the 1970s the methods used in foreign language instruction proliferated, mixing Anthony's concepts of methods, materials, and procedures. These events resulted in instructional methods that included a varied assortment of methods, procedures, and activities (Celce-Murcia, 2001). According to Brown (2007) and Celce-Murcia (2001), the dominant methods in use today include the following:

- The Grammar Translation Method - The Grammar Translation Method involves providing direct instruction to students in the formal structure of the target language grammar and consists of vocabulary lists and memorization of direct translations. This approach extended methods of teaching classical languages into modern languages (Celce-Murcia, 2001). This was the predominant language teaching method in Europe in the 19th century and returned to popularity in the 1970s (Brown, 2007; Fotos, 2005).

- The Direct Instruction Method - This approach was a reaction from the failure of the Grammar Translation Method to get learners to be able to communicate in the target language (Celce-Murcia, 2001; Brown 2007). Direct Instruction involves specific ways of teaching, designing curriculum, conducting inservice education, and monitoring the performance of teachers and students (Gersten, 1984). With this method, the teacher uses the target language for communication, and grammar is learned indirectly. This approach stresses the importance of having native speaking teachers (Celce-Murcia, 2001). 
- The Reading Approach Method - With only a few teachers with native speaking skills to conduct a Direct Approach effectively, the Reading Approach is considered a reaction to the problems of the Direct Method. The Reading Approach employs reading as a means for learning and comprehending a foreign language for students who do not have the opportunity to travel to target language countries and who are taught by teachers who do not have a strong command of the target language. In this method, reading comprehension is the most important skill emphasized (CelceMurcia, 2001).

- The Audio-Lingual Method - The Audio-Lingual method was developed during World War II when the United States government recognized a need for more fluent speakers in many languages in military and intelligence operations. Using this method, students listen to or view recordings of native speakers. Students practice a variety of language drills, while the instructor emphasizes the use of the target language at all times. From a Behaviorist perspective, by reinforcing "correct" language behaviors, students would form correct language habits (Brown, 2007).

- The Oral-Situational Method - This method developed as a reaction to the Reading method and focused on practicing oral spoken language before the target language is presented in written form (Celce-Murcia, 2001). The target language is the language spoken in the classroom. Grammar principles are taught from simple forms to more complex. Reading and writing are 
introduced once a sufficient lexical and grammatical basis is established (Richards \& Rogers, 1986).

- The Cognitive Method - This method is a reaction to the Audio-Lingual method and views language learning as a process of acquiring rules rather than forming habits. In this approach, learners become responsible for their own learning, grammar is learned deductively or inductively, pronunciation is not relevant, reading and writing are learned simultaneously, errors are viewed as part of the learning process, and teachers are expected to be fluent in the target language (Celce-Murcia, 2001).

- The Affective-Humanistic Method - This method is a reaction to the lack of affective considerations in both Audio-Lingual and the Cognitive methods (Curran, 1976; Moskowitz, 1978). This method emphasizes the social aspect of language learning. Students regularly work in pairs and groups, while instruction focuses on communication that is meaningful to the learners. With this method, the classroom atmosphere is more important than the materials and methods used in class. The teacher acts as counselor or facilitator for learning and should be proficient in both the target and native languages, as both languages are used in the beginning phase of language learning (CelceMurcia, 2001).

- Comprehension-Based Method - Listening comprehension is a very important aspect of this method, as it focuses on reading, speaking, and writing in the target language. Using this method, learners start by listening to the target language and speak when they feel they are ready to do so. If the teacher does 
not have a high level of fluency in the target language, the use of audiovisual materials provides the appropriate input for the learners (Celce-Murcia, 2001).

- Communicative Language Teaching Method - The Communicative Language Teaching method (CLT), also known as the Communicative Approach, emphasizes social interaction as both the means and the ultimate goal of learning a language. The goal of instruction in the communicative approach is communicative competence. Despite a number of criticisms, it continues to be a recommended approach, particularly in Europe, where Constructivist views on language learning dominate academic discourse (Brown, 2007). In Spain, the government established the Communicative Method as the official method of foreign language instruction in 2002 (Criado \& Sanchez, 2009). A variant of the Communicative Method, called Task-based Language Learning (TBLL), Task-based Language Teaching (TBLT), or Task-Based Instruction (TBI), has grown steadily in popularity. This method employs the Communicative Approach but uses authentic task activities as both the organizing feature and the basis for assessment of language instruction. According to Tragant and Muñoz (2009), although the Communicative Approach is widely known and holds a dominant place in the academic literature, research indicates that the purely communicative methodology has had only marginal impact on foreign language teaching settings where the dominant pedagogy continues to involve a Structural or Grammar Translation methodology.

- The Total Physical Response Method - The Total Physical Response, or TPR method, was developed by James Asher in 1977 (Asher, 1997c). This method 
advocates the idea that learners should learn a foreign language in the ways they learned their first language - by first listening and then speaking. Asher believes that students should enjoy the language learning experience (Asher, 1997a). The role of the teacher is to be the director of children's imitations (Asher, 1997b).

- The Natural Method - This method, developed by Stephen Krashen, advocates for the development of interpersonal communication skills in the target language in order to cope with everyday activities such as conversations, shopping, or listening to the radio (Krashen \& Terrel, 1983). Krashen and Terrell identify this method as the "traditional" approach where there is an emphasis on exposure, or input, rather than practice (Richards \& Rodgers, 1986).

- The Post-Methods Era or "The Eclectic Approach" - With the growing realization that people learn languages in different ways and benefit from different methods of language instruction, various mixtures of the different methods described above are being used in classrooms. This approach to instruction is referred to as the "Eclectic Approach" or the "Post-methods era" (Liu, 2004; Richards \& Rodgers, 1986). In the Post-methods era, teachers use a wide array of approaches, methods, and techniques available for language instruction that best fit students' language learning needs.

According to Celce-Murcia (2001), the nine most common approaches to second language instruction in the $21^{\text {st }}$ century are: (1) the Grammar-Translation Method, (2) the Direct Instruction Method, (3) the Reading Approach Method, (4) the Audio-Lingual 
Method (United States), (5) the Oral-Situational Method (Britain), (6) the Cognitive Method, (7) the Affective-Humanistic Method, (8) the Comprehension-Based Method, and (9) the Communicative Language Teaching Method.

\section{Research on Effective Teaching Practices}

The success of a particular approach or method used in ESL/EFL instruction will depend upon how effective the teacher is in using the method to engage students in learning. Generally, this is referred to as effective practice. The effective teaching practices in ESL/EFL have been documented and have been incorporated into training manuals developed by the Center for Immigration Studies (CIS) (http://www.cis.org/), the International Association of Teachers of EFL (IATEFL) (http://www.iatefl.org/), International Association of Language Teaching Technology (IALLT) (http://www.iallt.org/), Teachers of English to Speakers of Other Languages (TESOL) (http://www.tesol.org/s tesol/index.asp), among others (Language Consultants International, 2009) .

Effective teachers typically use a multifaceted approach to teaching and learning, integrating specific skills instruction with numerous opportunities for acquiring a new language (Richards \& Farrell, 2005). The research on effective teaching practices indicates that there are marked similarities among teachers whose students have better achievement. Some of the effective teaching practices suggested by the research include the following:

- Creating an environment that fosters learning

- Integrating the teaching of different content-related skills

- Engaging students in different modes of interaction 
- Emphasizing specific content-related skills

- Spelling and vocabulary instruction

- Instructional grouping

- Engaging in motivating instructional practices (Danielson \& McGreal, 2000; Pennington \& Young, 1989)

Many researchers believe that effective teaching practices can be identified and taught to beginning or practicing teachers as part of their professional development. Medley, Coker, and Soar defined teacher competency as "a specific knowledge, skill, or attitude that a teacher either possesses or does not possess, which is believed to be important to succeed as a teacher" (as cited in Pennington \& Young, 1989, p.620). Some researchers have found that effective teachers in an ineffective school produce amazing results in student learning (Marzano, 2000; Olson, 2000). Improving student learning is a dynamic process requiring continual growth in teacher practice (Danielson \& McGreal, 2000). According to Darling-Hammond et al. (1996), the report from The National Commission on Teaching and America's Future, What Matters Most: Teaching for America's Future, identifies the quality of teachers in the classroom as having a critical impact on student learning. Their findings were based on three assumptions: (a) what teachers know and can do are the most important influences on what a student learns; (b) recruiting, preparing, and retaining good teachers are the central strategies for improving our schools; and (c) school reform cannot succeed unless it focuses on articulation of evaluation criteria for measuring the attainment of those skills and competencies necessary to be an effective teacher. 
Issues and methods associated with evaluating effective practice depend upon the stage of professional development attained by the teachers to be observed, assessed, or evaluated. Pre-service teachers would need to be considered separately from experienced teachers seeking career awards, promotion, or merit pay. Knowledge of the developmental characteristics that teachers exhibit during their careers can provide educators with an understanding of the abilities and inadequacies of teachers during different stages (Clickman \& Gordon, 1987). Information about these stages can serve as a foundation for improving pre-service teacher education, improving staff-development, and improving the assessment of teacher performance. In their study on the stages of teacher professional development, Stiggins and Duke (1990) suggest that the following parallel evaluation systems be used:

- An induction system for novice teachers with a focus on meeting performance standards in order to achieve tenure

- A remediation system for experienced teachers in need of remediation to correct deficiencies in performance so that they might avoid dismissal

- A professional development system for competent, experienced teachers pursuing excellence in particular areas of teaching These would be teachers pursuing continuing professional excellence.

Glickman's (1990) model of supervision expands the direct-assistance format found in the original clinical supervision model by adding a dimension concerned with human development and differences. Glickman suggests that the more reflective and self-directed teachers are better able to solve students' educational needs and that reflection should be an important part of any professional 
development model. Using different methods of supervision based on a teacher's developmental level allows the greatest growth potential for each teacher. This model of supervision is based on three general propositions:

1. Teachers operate at different levels of professional development.

2. Teachers need to be supervised in different ways because they operate at differing levels of conceptual understanding, ability, and effectiveness.

3. The long-range goals of supervision should be to increase every teacher's ability to grow toward higher stages of thought (Glickman \& Bey, 1990). In recent years, tracking teachers' growth and development and creating an effective monitoring system have become an important part of evaluation and supervision (Glickman \& Bey, 1990; Reiman \& Thies-Spirnthall, 1998). This approach calls for an evaluation instrument grounded in the developmental perspective that allows the supervisor to diagnose the individual teachers' strengths and weaknesses, and to match their professional needs with different professional development resources (Ellis, 2003; Clickman, 1981; Glickman \& Bey, 1990).

A number of research studies have been conducted over the years to determine which classroom teaching behaviors have positive effects on student learning. These teaching behaviors are referred to as Effective Teaching Practices (ETP). Effective teaching practices is the idea that asserts that there is an activity, technique, method, approach, procedure, or process which helps teachers to effectively achieve particular outcomes that benefit students (Tell, 2001). The behaviors identified as effective practices have been organized into domains. For this study, a domain will be a field of action and influence of instructional practice. The domains included will be: Classroom 
Dynamics (CD), Student Dynamics (SD), Teaching Approaches (TA), Language Arts Instruction (LAS), and Classroom Management (CM). The effective practice behaviors and domains provide the framework for the classroom observation instrument developed in this study.

\section{Classroom Dynamies (CD)}

This effective practice domain pertains to the strategies and activities that a teacher develops within a classroom that contribute to the effectiveness of the lesson. Morris and Tarone (2003) consider Classroom Dynamics to play a key role in furthering learning. Activities such as the opening, pacing, and closing of a lesson are all crucial moments which, if correctly implemented by the teacher, result in the students following the lesson and assimilating the knowledge in a far more efficient manner. Characteristics of an effective opening include an organized class, beginning the lesson on time, and a clear agenda for all activities (Smith et al., 2004). Additionally, effective openings also include repetition and the incorporation of daily concepts (including morning message, weather, days of the week, etc.) to help students learn and master the basic vocabulary in the classroom (House, 1996). Effective pacing and developmental levels of lessons also constitute an important element of Classroom Dynamics, as they ensure that the activities are suited to a students' learning level, keep the students engaged in the work, and monitor that transition times are implemented effectively and kept to a minimum (Baumann, Kame'enui, \& Ash, 2003; Echevarria \& Graves, 2011; Francis, Rivera, Lesaux, Kieffer, \& Rivera, 2006; Gibbons, 2003). The closing of a class constitutes a highly relevant part of Classroom Dynamics, for it is when students have the opportunity to connect past knowledge with present lessons as well as those to come. In an effective 
closing, students can reflect on the learned material and evaluate the understood elements, providing the teacher with the opportunity to create a summary of the lesson (Freeman \& Freeman, 2009; Smith, Polloway, Patton, \& Dowdy, 2004; Stronge, 1997).

\section{Student Dynamics (SD)}

Morris and Tarone (2003) consider that student participation, collaboration, motivation and interaction are fundamental elements for a lesson to flow and be effectively absorbed. Teachers creating participation activities which provide "wait and think time" result in students being able to elaborate better answers (Baumann, Kame'enui, \& Ash, 2003; Echevarria \& Graves, 2011; Gersten \& Baker, 2003). Another important element in the Student Dynamics domain is the interaction between the students, encouraged by the professor, with the aim of providing them with the motivation and opportunity to communicate. (Cary, 1997; Freeman \& Freeman, 2004; Fountas \& Pinnell, 2001). Student Dynamics in terms of student motivation are important in activities involving reading, writing, and speaking, which require them to interact with the teacher and each other throughout the entire lesson (Baumann, Kame'enui \& Ash, 2003; Gibbons, 2002; Gibbons, 2003; McCarrier, Pinnell, \& Fountas, 2000).

\section{Teaching Approaches (TA)}

Kember and Kwan (2000) assert that all approaches have different strengths and help students develop different abilities. For example, the Direct Instruction approach in a target language helps students in the first stages of the decoding process (Gersten \& Baker, 2003). Direct Instruction also helps students expand their vocabulary and critical thinking through the use of questions and making students discuss specific concepts in order to make the contents easier to understand (Cary, 1997; Celce-Murcia, 2001; 
Freeman \& Freeman, 2004; Gibbons, 2003). The Natural or Whole Language approach is another method used in language instruction that provides a more natural context for the language learner (Rigg, 1991; Rivers, 1987). This is achieved by providing the students with a connection between their personal experiences and the target language. Through the use of this approach, the professor manages to connect each student's previous knowledge with the teaching elements (Echevarria \& Graves, 2011; Freeman \& Freeman, 2004; Gibbons, 2003; McCarrier, Pinnell, \& Fountas, 2000; Shanahan \& Beck, 2006). Another approach widely used in language instruction is Cooperative Learning. Since the1980s, Cooperative Learning has been considered an essential methodology in order to develop collaboration skills among students in order for them to learn to help each other and to improve learning (Freeman \& Freeman, 2004; Slavin, 1987). When implementing Cooperative Learning, the professor encourages the students to become responsible for their own learning as well as raising awareness of the relevant role that they each play in their teams. This allows the students to become an independent member of the group, with the aim of creating a successful learning community (Cooper, 1993; Freeman \& Freeman, 2004; Gibbons, 2003; Slavin, 1987). Other general teaching approaches connected to effective practices in language instruction include: Scaffolding where the teacher provides meaningful support and guidance needed for students through questioning techniques that link their knowledge with their personal experience; Sheltered instruction, where the teacher introduces new content by using visual aids, music, and other media; Reciprocal teaching, where the teacher presents an interactive lesson, assesses the students' responses for comprehension, and then restructures the lesson to correct the student's response; Critical thinking, where the teacher encourages 
the students to ask and answer questions that start with the words "why" and "how"; and Multicultural approaches, where the teacher connects the instruction to students' native culture; and graphic organizers to allow access of information (Armtrong, 1994; Smith et al., 2004; Stronge, 1997)

\section{Language Art Strategies (LAS)}

Instructional methods specific to teaching in this domain play a crucial role in the language learning process, as students use language for creative expression in print, spoken word, and media formats (Flood, 2003; Watts-Taffes \& Truscott, 2000). The art of teaching a language relies on a selection of strategies and activities which range from structuring opportunities to use the target language, motivating the students to provide words in the target language, using spelling and phonics strategies systematically in the target language, developing new vocabulary, and relating spoken to written language (Routman, 1996). Language Arts instruction also uses story reading in order to create a context which allows the student to connect concepts in the target language and then express them in oral and written language (Baumann, Kame'enui, \& Ash, 2003; Beck \& Juel, 1995; Gersten \& Baker, 2003; McCandiss, Beck, Sandank, \& Perfetti, 2003; Morrow, 2001; Pikulski \& Chard, 2005). Language Arts instruction fortifies reading through various strategies such as Read Aloud, Read Along, and Read Alone. These strategies encourage the student to express and reflect their learning of the target language (Flood, 2003; Fountas \& Pinnell, 2001; Pikulski \& Chard, 2005). Developing written skills is a focus area in Language Arts and methods used include initiating learning through sound games based on phonological awareness which helps students make a connection between phonemes and graphemes. Other methods include the use of 
phonics graphs for students to construct letters, phrases and sentences, and guiding them through a writing process in which the students learn to structure the language and express themselves in written form (Fountas \& Pinnell, 2001; Flood, 2003; Freeman \& Freeman, 2001; Morrow, 2001).

\section{Classroom Management (CM)}

This domain refers to teaching behaviors that contribute to an overall positive classroom atmosphere that is supportive of student learning. The success of a good lesson greatly depends on an atmosphere based on respect and responsibility between the teacher and student. Ideally, the classroom should be structured to allow students to learn both academic content as well as classroom behaviors which result in positive group interaction (Weinstein, Tomlinson-Clarke, \& Curran, 2004). In order to obtain an effective classroom, the teacher needs to clarify what is permitted and what is not inside the classroom. It is also very important to make clear there are consequences to their behavior, both positive and negative (Canter \& Canter, 1976; Canter \& Canter, 2001; Canter, Canter, Thompson, \& Associates, 1993; Gallagher, 2002; Whelen \& Simpson, 1996). The important strategy for classroom management is an assertive discipline plan through which the students have a clear idea of the consequences of their behavior in the context of the group and when there is a lack of respect toward the teacher or the other students. An assertive discipline plan must consist of clear and concise directions which the students can follow and clear and positive feedback for students on their actions in the classroom (Canter \& Canter 2001; Canter, Canter, Thompson, \& Associates, 1993). 


\section{Research in ESL/EFL Instruction}

In a "post methods" era of language instruction such as the one we are experiencing today, researchers would not expect to see one instructional method employed exclusively in a language classroom. Teachers employ a variety of instruction methods best suited to meet student needs and intended learning outcomes. For the purposes of this study, a distinction must be made here between ESL versus EFL instruction. ESL instruction takes place in formal settings where the target language (English) is the predominant language spoken, and the student must learn it in order to function in that particular culture and society. EFL instruction occurs in settings where the target language (English) is not the predominant spoken language, and the student does not need to learn the language to function in that particular culture and society (Brown, 2001). According to Brown, the terms ESL and EFL are often used interchangeably in discussions related to language instruction, but the contexts of instruction and the language learners are quite different. While ESL classrooms may consist of speakers of multiple languages, all of whom are learning English in an Englishspeaking country, EFL classrooms generally consist of speakers of the same language or languages who are learning English to improve their employment prospects or because of academic requirements. Although this study draws from theories and research related to language acquisition and language learning and is informed by research on both ESL and EFL instruction, the study itself concerns primarily the context of learning English as a Foreign Language, particularly in Spain.

Research on instruction in ESL/EFL reflects the current state of affairs in the post-methods era. In this era, it is difficult to find ESL or EFL classrooms in which one 
instructional method is used exclusively. In Liu's 2004 international survey of ESL/EFL teachers' awareness and use of teaching methods, 70 to $84 \%$ of the respondents reported they were familiar with and use the Communicative Approach and the Eclectic Approach to English language instruction.

The Common European Framework for foreign language learning specifies the competencies for the European Community at two levels: (a) general competencies and (b) communicative language competencies (Council of Europe, 2001). The framework specifies that assessment in language competencies focus on communicative language teaching rather than basic areas of declarative knowledge (Hughes, 2007). In Spain, EFL instruction has mirrored the historical development of language instruction in Europe and the United States. According to Hughes (2007), in the 1950s the Oral method, which focused on pronunciation, reading, vocabulary, sentence production, oral recitations, and grammar, was predominant. The official method for teaching English as a foreign language during the early 1970 s was the Audio-lingual method and then changed to the Communicative method, which has been dominant during the last half of the $20^{\text {th }}$ century (Criado \& Sanchez, 2009). Current research has studied foreign language instruction that uses one method exclusively or a combination of teaching methods. Research included in this review will focus on current methods used in teaching ESL/EFL in different settings that have shown to positively impact student learning and, when available, discuss research findings from Spain.

Al-Shammari, Al-Sharoufi, and Yawkey (2009) conducted a study on the effectiveness of the Direct Instruction method in improving student achievement in English language learning. Two fifth-grade English classes in two public schools in 
Kuwait participated in the study. Class one (experimental group) received direct instruction, and class two (control group) did not receive the direct instruction methodology. The main data collection method was the use of a similar test given to both classes involved in this study. The test was designed and based on a Direct Instruction method. Results from the study indicated that children in the experimental class generally benefited from receiving direct instruction, demonstrating that direct instruction is an effective approach in teaching English. The mean of the experimental group $(M=3.52$, $S D=1.4)$ was greater than the mean of the control group $(M=1.09, S D=1.19)$. The mean rank of the experimental group was 30.52 , while the control group was 13.86 . The test statistics $(z)$ was 4.42 with a $p$-value $(.000)$. The mean rank of the experimental group was also greater than that of the control group. More specifically, these tests indicated that using a Direct Instruction method with the experimental group had better results as compared to the control group (traditional method) in terms of student achievement.

Vaughn et al., (2006) studied the effectiveness of Direct Instruction in reading on at-risk first-grade students in the United States whose home language was Spanish. The researchers analyzed systematic reading intervention in phonemic awareness, word attack, word reading, reading comprehension, and fluency. The research was based on studies suggesting that English-speaking students at risk for reading difficulties make significant progress when they are provided with systematic and explicit interventions in reading. The study's primary focus was on how an intervention in Spanish influences student outcomes in reading and oral language skills in Spanish and English. The study was conducted at seven schools in Texas with 69 participants randomly assigned to 20 different classrooms and treatment groups. Treatment groups of three to five students met 
daily for 50 minutes and were provided systematic and explicit instruction in oral language and reading by trained bilingual intervention teachers. Comparison students received the school's standard intervention for struggling readers. Instructional activities consisted of 50 minutes of read aloud, silent reading, writing and spelling activities, and isolated word pronunciation activities in English and Spanish. Pre- and post-test analyses indicated there were no differences between the treatment and comparison groups in either Spanish or English on any measures on the pre-test, but had significant post-test differences in favor of the treatment group for the following outcomes in Spanish: lettersound identification $(d=0.72)$, phonological awareness composite $(d=0.73)$, Woodcock Language Proficiency Battery-Revised oral language composite $(d=0.35)$, word attack $(d=0.85)$, passage comprehension $(d=0.55)$, and two measures of reading fluency $(d=$ $0.58-0.75)$. The results of this study indicated that the treatment group students performed significantly higher than comparison students on critical outcomes measured in Spanish, including phonemic awareness, word attack, word reading, reading comprehension, fluency, and overall language ability in Spanish. It is noteworthy in this study that students in the treatment group did not merely significantly outperform the comparison sample of students but made substantial gains in nearly all areas measured.

A study by Nakatani (2010) investigated the effectiveness of strategies used by the Communicative method of teaching EFL on Japanese students' oral fluency. In this study, 62 female Japanese students participated in one 90-minute English lesson per week for 12 weeks. Baseline scores in the participants' ability in English were established by the administration of the Secondary Level English Proficiency (SLEP) exam, which is similar to the Test of English as a Foreign Language (TOEFL). In each lesson, students 
were provided with a simulation of an authentic communication task in which they were required to engage in dialogue with the instructor. In each lesson, students reviewed the previous week's tasks and were then presented with a new communication task. Students were given five minutes to prepare for the new dialogue by rehearsing with peers and then engaged in a seven-minute dialogue with the instructor. Student dialogues were assessed using an instrument according to their fluency, interactivity, and flexibility with the dialogue. The videotaped student dialogues were then scored by two native speakers who did not take part in the instructional activities, using a previously developed instrument called the Oral Communication Assessment Scale for Japanese EFL Students. The study assessed students' ability to produce language, the errors they made, and the use of strategies to clarify and smooth the communication and/or reduce communication errors. A stepwise multiple regression analysis was used to analyze the student assessments. The result of the analysis showed that four variables were positively related to the conversation post-test scores $(p<.05)$, including response for maintenance strategies, production rate, signals for negotiation, and the result of the oral pre-test scores. These results indicated that the Communicative method can improve learners' English proficiency in communicative tasks.

Bernaus and Gardner (2008) conducted a study investigating the impact of English teaching strategies on students' motivation and their English achievement. Teachers and students were asked to indicate the extent to which 26 teaching strategies were used. There were 14 traditional strategies (teacher-centered activities focusing on the structural aspects of language such as grammar) and 12 innovative strategies (studentcentered strategies focusing on the communicative aspects of language such as letter 
writing or conversation). The purpose of the study was to determine if students and teachers have the same perception of classroom instructional strategies and if these strategies are related to student motivation or achievement in learning English. The population of this study was comprised of 31 English teachers and their students ( $N=$ 694) from public and private schools in the Catalan Autonomous Community of Spain. Both teachers and students completed a questionnaire designed to identify different strategies used by EFL teachers. The teacher questionnaire listed 26 teaching strategies and asked the participants to rate the frequency with which they used each strategy on a seven-point scale ranging from 1 (never) to 7 (always). The student questionnaire asked participants to rate the extent to which their teachers used each of the same 26 strategies that had been rated by their teachers. The students' language attitudes, motivation, and language anxiety were assessed by the Attitude Motivation Test Battery (AMTB), a standardized instrument used to assess anxiety in language learning. Mean scores on the student and teacher questionnaires were paired and correlated. Of the 26 strategies listed, 16 items were significantly correlated, meaning that students and teachers agreed that 10 of the traditional strategies and 6 of the innovative strategies were employed at a particular frequency. A paired t-test of these scores revealed that the teachers perceived that they made use of the traditional strategies more frequently than the innovative strategies, $M=5.06$ and $M=4.05 ; t(30)=6.60, p<.001$. Findings from this study indicated that teachers differ in the reported frequency with which they use various strategies to teach English, but they favored traditional methods over innovative methods. No correlations were found between instructional strategies and particular teaching methods. Correlations were found, however, with variables listed on the AMTB and 
student achievement in English, indicating that positive attitudes toward the learning situation have a positive effect on student achievement.

In a study conducted by White, Muñoz, and Collins (2007), a specific method associated with Direct Instruction called contrastive analysis was employed among adolescent second language learners in Spain and Canada. Two instructional treatments were used to determine if the approach aided student understanding and use of English language possessive determiners (his and hers). The study was conducted in Catalonia, Spain, and Quebec, Canada. The population comprised 50 students between the ages of 13 and 14. The method included direct instruction on rules governing English possessive determiners, presentation of contrastive information about possessives in the students' native language, repeated practice of the rules using the "cloze" or fill in the blank activities, and discussion and feedback on student performance. In comparison groups from both schools, the students did not receive any instruction in possessive determiners until after the study was completed. A pre-test, post-test research design was used to determine if the instructional method had positive effects. The treatment and comparison groups did not differ significantly on their pre-test scores $(t(53)=-0.44, p=0.66, \eta 2$ $=0.00)$. The post-test consisted of a passage correction and oral production task in which students had to correct possessives in a given passage and orally describe a series of cartoons involving family situations. Analysis of data indicated that, on the written passage correction task and on the oral production task, students in the treatment group performed significantly better from pre-test to post-test over the comparison group $t$ (27) $=5.31, p<0.01, \eta 2=0.50$. Results of this study indicated that Direct Instruction focusing on specific problem areas in the English language can significantly increase student 
learning in writing and speaking and can be implemented in different language communities.

A study conducted by Szpotowicz, Djigunovic, and Enever (2008) examined what can be achieved in second/foreign language learning in public schools across Europe, where limited amounts of time are dedicated to language learning. The study specifically explored the role of the teacher and impact of digital media on English language learning. A total of 1,050 children between the ages of six and eight from seven European countries (Croatia, England, Italy, Poland, Spain, the Netherlands, and Sweden) participated in the study. The research design was both qualitative and quantitative and included data collected from students, teachers, principals, and parents through interviews, classroom observations, and questionnaires. Student progress was tracked throughout the primary grades. Based on an analysis of the interviews with EFL teachers and data from classroom observations, the authors came to the conclusion that, although there were differences in classroom arrangements, class size, time spent in speaking in the target language, and the amount of correction provided, there was no significant variance in the teaching methods, the choice of activities, and classroom management techniques across schools in the seven participating countries. In contrast to the learning environment, there were differences in levels of motivation toward learning English among the students participating in the study. Although the overall level of motivation of the whole sample was found to be high: $M=2.56(\max =3), S D=.48$, girls were found to be significantly more motivated than boys $(t=5.447 ; p<.000)$. The study results suggested that young learners are positive about foreign language learning; and 
contextual factors related to the quality of teaching, the learning environment, and instructional activities are important in affecting positive learning.

In their research on the relationship between methods observed in EFL classrooms and methods embedded in nine secondary level EFL textbooks used in Spain, Criado and Sanchez (2009) found that, although the Communicative Approach which is the approved EFL instructional method in Spain was apparent in 50\% of the textbook curricula, the use of non-communicative methods, such as the grammar-translation method and vocabulary drills, was very prevalent in both the textbook curricula and in the classroom activities prescribed by the textbook. In an analysis of the classroom activities listed in the textbook, the potential for use of the communicative approach ranged between 4.4 and 7.9 on a ten-point scale, while the communicative nature of the strategies applied in the activities themselves ranged between 44 and $82 \%$. Results of this study indicate that, although the Spanish government's position on EFL instruction favors the Communicative Approach, "the authors of teaching materials, as well as publishers and institutional evaluators, turn to eclectic or integrative materials because their experience and the real situation of learners with their learning styles and different backgrounds advise them to proceed in that way" (Criado \& Sanchez, 2009, p. 13).

\section{Classroom Observation for Teacher Improvement}

Among all the factors contributing to student achievement, teacher performance has been found to be the most important (Darling-Hammond, 2000). Teacher development training is one of the most common ways for helping teachers to improve their teaching performance (Guskey, 2000). Often, teachers will not improve due to the lack of follow up with the knowledge they have acquired during different professional 
development workshops or training programs. Through classroom observation by experienced professionals, teachers can get feedback on their performance and receive guidance on implementing effective practices for improving their instruction (RoldánTapia, 1999; Wajnryb, 1992). The most important aspect of observing a class is to help teachers improve their teaching areas, whether their teaching at that moment is the result of implementing something learned in a professional development workshop or only the result of their typical routine of teaching (Villegas-Reimers, 2003).

At the beginning of the $20^{\text {th }}$ century, teacher evaluation was essentially based on a moralistic and ethical perspective in which teachers were mostly evaluated on their personal characteristics rather than evaluation procedures informed by a knowledge based on effective teaching and learning (Ellett \& Teddlie, 2003). Between the 1920s and the 1940 s, the study of teacher evaluation in the United States was influenced by emerging theories of personality mainly focused on personal characteristics of good teachers; and by the end of the 1940s, the knowledge base pertaining to teacher evaluation was beginning to appear in popular textbooks. According to Ellett and Teddlie (2003), at the beginning of the 1950s, the concept of Teacher Evaluation Research (TER) emerged. With the educational reforms of the 1980s, one of the most popular buzzwords used in professional literature was evaluation. From the 1990s to the present, teacher evaluation has focused on accountability, professional development, and school improvement. In this context, TER remains highly relevant. They stated that over the past decades, several systems for evaluation have been designed to evaluate teaching, such as the Louisiana System for Teaching and Learning Assessment and Review (STAR) and the Professional Assessment and Comprehensive Evaluation System (PACES). In 1987, the National 
Board of Professional Teaching Standards (2003) developed and implemented a variety of content-specific, standards-based tasks for identifying a set of beliefs and values about exemplary teaching.

Even though different evaluation systems have been put in place during the last decade, traditional approaches to teacher evaluation have done little to improve schools (Darling-Hammond, 1993). Critics argue that a new generation of learner-centered assessments and evaluation procedures are needed to connect the teaching and learning process with school effectiveness and school improvement (Ellett \& Teddlie, 2003). A new generation of teaching evaluation systems is also needed to respond to the formative and the summative needs of teachers and supervisors. During formative evaluation, a teacher's strengths and weaknesses are taken into consideration for the purpose of determining professional development needs. Formative evaluation allows focusing on specific areas of growth (Egelson \& McCoskey, 1998) and the improvement of instructional practice (Haefele, 1993). On the other hand, summative evaluation is designed to facilitate decision making by a supervisor and may be viewed as quality control for the protection of incompetent teaching (Sergiovanni, 1995a). Summative evaluation is used for making personnel decisions such as promotion, dismissal, and tenure (McKeachie, 1997).

Effective formative evaluation depends on objective and reliable assessment of teachers' abilities. Classroom observation is an essential part of the formative evaluation process (Darling-Hammond, Wise, \& Pease, 1983; Sergiovanni, 1995b). Classroom observation which is not part of a valid system of assessment and evaluation is not valid for research because observers see events as they happen from their own biased 
perspectives. Valid classroom observation must cover a specific area or interest in a systematic way (Griffe, 2005; Hitchcock \& Hughes, 1995). Therefore, observational tools specifically designed to record and analyze teaching skills and behaviors must be developed and tested (Cashin, 1996; Roberson, 1998). According to Hunter and Russell (1995), a high degree of professional feedback is required in order to identify these skills and behaviors and to implement them effectively in the professional development process. Classroom observation has the capacity to disclose the climate, compatibility, interactions, and operations of the classroom which is available from no other source (Peterson, 2000; Stronge \& Helm, 1991; Valentine, 1992). This makes it possible to gather valuable information to ensure a minimum quality of instruction for students and to improve the instructional lessons (Ambach, 1996; Darling-Hammond, 1998).

According to Roberson (1998), classroom observation is one of the premier data collection methods available to those interested in teaching observation. This method is particularly important to student teaching programs, but professional teachers also can receive benefits from instructional improvement activities. Systematic classroom observation is an important part of education reform because it provides the database of effective practices from which teachers can draw to improve their instruction (Guskey, 2000; Kennedy, 1999; Reed \& Berhemann, 1992). Classroom observation, according to VanTassell-Baska, Quek, and Feng (2007):

Classroom observation affords an opportunity to access the actual instructional experience that is at the heart of teaching and learning. It provides a nexus between the input variables of the teacher and his or her 
students and the process of instruction itself - a process that combines instructional intent (goals and objectives), curriculum resources and materials, instructional strategies, and classroom management skills within a delimited unit of time. It is the one part of professional development that allows the critical pieces of teacher knowledge and skills to come together in an authentic opportunity to gain insight about the quality of the learning experiences that are delivered. (p. 85)

One way of thinking about classroom observation is to see it as a performancebased assessment of the teacher within the context of the learning environment. Classroom observation affords many of the features of performance-based assessment with the teacher, rather than the student, as the unit of focus (Sanchez, 2009a). For instance, it is a relatively open-ended experience, with teachers exercising much control over the selection of the lesson to be taught. It allows for the demonstration of complex and higher-order behaviors, recognizing that good teaching derives from a sophisticated set of skills that unfold in an integrated way. It also allows for self-assessment, providing a metacognitive dimension to the experience. Most importantly, by using a structured form, it provides a benchmark against which the teaching process can be assessed based on expectations derived from effective practice in a given field (Billet, 2001; Duke \& Pearson, 2002).

The demands of teaching more challenging content to more diverse learners suggest a need for teacher education programs to provide a means to enable teachers to become more sophisticated in their understanding of the effects of context and learner variability on teaching and learning (Darling-Hammond \& McLaughlin, 1995). 
According to Darling-Hammond and Snyder (2000), "instead of implementing set routines, teachers need to become ever more skillful in their ability to evaluate teaching situations and develop teaching responses that can be effective under different circumstances" (p. 523).

Educators face ongoing pressure to improve student outcomes, especially with regard to academic achievement and social behavior. One viable strategy for supporting and improving instructional practices is to conduct classroom observations and provide formative feedback so that teachers can reflect upon and improve their practice. Research has shown formative feedback to be effective in the workplace, in institutional settings, and in educational settings. The emphasis of reflection in teacher education is on "teachers' ability to inquire into teaching and think critically about their work using their craft and personal knowledge as well as the knowledge derived from studies of learning, development, and society" (Carter \& Anders, 1996, p. 562).

Observation of teaching has been a common practice since the early $60 \mathrm{~s}$. There are a number of classroom teaching performance observation instruments developed to assess proficiency of beginning teachers such as the Teacher Performance Assessment Instruments (TPAI) (Ellet \& Capie, 1985); Teacher Assessment and Development System (TADS); Florida Performance Measurement System (FPMS) (Peterson, Micceri \& Smith, 1985; Peterson, Kromrey, Micceri, \& Smith, 1987); and the Observation Instrument for Assessing Pre-service Teachers (Tseng, 1998). Among them, the TPAI has been one of the most influential. This instrument is a high inference rating system of 14 generic teaching competencies, each articulate in two to five performance indicators (45 total). Several studies have established the instrument's reliability using factor analysis 
and have found the significant factors consistently appearing to be planning, motivation, classroom management, and instruction (Ellett \& Capie, 1985).

Although it is widely accepted that it is important for pre-service teachers to engage in reflective activities, not only to better learn new ideas but also to sustain professional growth after leaving the program, the use of classroom observation to improve the performance of practicing teachers in all fields is not widely conducted. Observation of teaching practices by an experienced teacher can be part of an effective reflective-practice teacher education paradigm that is geared to develop teachers' reasoning about why they employ certain instructional strategies and how they can improve their teaching to have a positive effect on students (Westberg, 1993).

Classroom observation of student teachers typically involves some kind of observation instrument. As previously mentioned, a wide variety of instruments are available for classroom observation of student teachers. However, research indicates that observation instruments for student teaching typically have not undergone the rigors of validity and reliability studies and are, therefore, not as effective as they could be for providing beginning teachers with effective feedback on their teaching performance (Chism, 1999).

Research shows that classroom observation for research on teacher performance as well as teacher preparation has been conducted for a long time in the United States and English speaking countries (Lagasabaster, 2001; Long, 1980; Roldán-Tapia, 2005). Observation of a student's early field experiences is a basic tool for future teacher education (Anderson, Barksdale, \& Hite, 2005) and so the classroom becomes a key aspect for teacher preparation in all subject areas. Even though in the United States 
observation in training teachers is common, the quality of teachers' learning experiences in the field remains a major concern, as educators face ongoing pressure to improve student outcomes, especially with regard to academic achievement and social behavior (Zeichener \& Wray, 2001). One viable strategy for supporting and improving instructional practices is to conduct classroom observations and provide performance feedback (Colvin, Flannery, Sugai, \& Monegan, 2008).

The study by Guyton and McIntyre (1990) investigated the use of student teacher observations of both peers and cooperating teachers in elementary classrooms where they had daily instructional duties. The purpose of the study was to better understand how student teachers valued and reflected upon peer observations. As part of this study, elementary education student teachers ( 30 female and 4 male) were trained in peercoaching and guided observation and were then paired with one another for peer observation and feedback on instruction. Peers participated in guided observations of one another during weekly sessions. Data sources also included dialogue journals each student teacher wrote with the university supervisor and a packet of data forms completed by teachers paired for observation for each peer observation session. These data were triangulated with the university supervisor's observations. The findings revealed that participants in this study perceived the experience of observing both cooperating teachers and peers to be both beneficial and enjoyable. In some cases, student teachers learned that, while developing advice for a peer on specific problems, they could begin to solve their own teaching problems or think of ways to overcome their bad habits.

In a study conducted by Colvin et al. (2008), a high school science teacher provides preliminary promising information of the relevance and effectiveness of the 
combination of a classroom observation and a performance feedback process focused on the relations among three key variables: classroom instructional settings, instructional practice, and classroom student behavior. The authors of the study used a process based on the observational data that identified when students were off task and pinpointed the corresponding setting categories and the teacher's instructional actions. The authors provided performance feedback using an observation instrument specifically designed to the research subject, a male science teacher in his second year of teaching at a suburban high school. As part of the study, three observations of classroom teaching were made using the observation instrument that coded teacher and student behaviors when students were primarily on task and off task. The authors then provided the teacher with information that directly related teaching context, instructional practices with class engagement, and social behaviors in one of his classes. The observers reviewed with the teacher information from three observations, which resulted in action plans focused on modifying instructional practices. Based on this feedback, the teacher made changes in the identified setting categories and teacher actions, resulting in substantial gains in classroom engagement and a reduction in problem behaviors. The specific changes in teacher behavior were based on standard effective instructional practices such as improvement of transitions, whole-class question-asking strategies, checks for understanding, and movement around the classroom to check for student engagement in class activities. Improvements in these targets were associated with corresponding improvements in class engagement and social behavior.

Everhart and Vaugh (2005) conducted a study to determine the difference between the teaching patterns of student teachers placed in suburban settings and the 
patterns of experienced teachers in rural, suburban, and urban settings. The participants were 26 student teachers who were asked to teach a similar type of lesson to $4^{\text {th }}$ graders in their respective suburban student teaching placement sites. Each of the lessons was videotaped from the beginning until the 20 -minute mark to make sure the duration of the lesson was controlled. After the lessons were videotaped, the tapes were analyzed by a trained observer with the Behavioral Evaluation Strategy and Taxonomy (BEST). Once the individual lessons were coded with BEST, the data were analyzed to show the following: (a) duration of occurrence of the behaviors, (b) frequencies of occurrence, (c) rates per minute of the behaviors, and (d) a sequential behavior analysis that showed conditional probabilities of chains and triads of behaviors. Results indicate that the group of student teachers tended to teach with the same balance of higher-order behaviors as did the suburban experienced teachers. The rural teacher had a better balance of higher-order and managerial behaviors but with no neutral behaviors. The urban teacher simply was not very active and did not have many higher-order behaviors documented for the lesson observed.

In some European countries, classroom observation has also been in place for many years for the purpose of teacher preparation and professional development. As an example of how classroom observation is used in the Netherlands, Krol, Veenman, and Voeten (2002) conducted research on the first year implementation effects of a staff development program on Cooperative Learning for Dutch elementary school teachers. A pre-test/post-test control group design was used to investigate the effects of the program on the instructional behaviors of 70 teachers ( 47 females and 23 males) in seven schools. During the workshops, the teachers worked together in heterogeneous cooperative 
groups. Each workshop lasted three hours. Following each workshop, the teachers were asked to put what they had learned into actual practice. For the study, an observational checklist was developed which included a number of variables related to cooperative learning including positive interdependence, individual accountability, face-to-face interaction, and social skills. Results showed a statistically significant treatment effect for the following instructional behaviors: structuring positive interdependence $(F(1,62)=$ $11.02, p=.000, M S E=0.77)$; individual accountability $(t(63)=4.46, p=.000)$; social skills $(t(63)=2.09, p=.04)$; and evaluation of the group process $(t(63)=5.26, p=.00)$. Positive effects were also found for the use of cooperative activities in the direct instruction model and for activation of prior knowledge of social skills on the part of students.

\section{ESL/EFL Classroom Observation Instruments}

Observation instruments have been used for different purposes: to measure teacher competencies, to document differentiation activities, to examine curricular and instructional practices, and for program evaluation. According to Van Tassel-Baska, Quek, and Feng (2007), the structure of the observation scales has been used to document the activities rather than examining the effectiveness of teachers' instructional practices.

Since the 1930s and 1940s, observation forms created to document classroom behavior have been in place. Since the 1960s, systematic observation instruments with an emphasis on the observation of the teaching process criteria have been in used. According to Gage (1963), the following criteria have been included in the classroom observations: teacher behaviors, classroom behavior, and student behaviors. These instruments included evaluation of instructional behaviors and student responses, 
descriptions of class materials and students, as well as the interactions taking place in the classroom at the time of the observation (Freiberg \& Waxman, 1988). Included in the list of systematic observation instruments are anecdotal recordings, rating scales, and checklists. However, according to Byra (1992) and Stodoloskt (1990), many of the traditional instruments used in classroom observation lack objectivity, reliability, and specificity.

Although classroom observation is part of teacher training in foreign language instruction in both the United States and in Spain, it appears that classroom observation for teacher improvement is not a regular part of teacher improvement programs in the United States and is rarely practiced in Spain. There are a number of observation instruments which have been developed for observing teachers in classrooms in Spain and for observing teachers in ESL classrooms in the United States (Lara-Alecio, Tong, Irby, \& Mathes, 2007; Graves, Gestern, \& Heager, 2004). These instruments have typically undergone validity and reliability studies but are predominantly used for the purposes of research rather than teacher improvement. This section will provide background research on the use of classroom observation for teacher improvement in beginning and experienced teachers and the use of observation instruments in classroom observation studies. Research reported will focus on how classroom observation and observation instruments can identify effective teaching practices and contribute to teacher improvement. When available, research on classroom observation and observation instruments for EFL instruction in Spain will be discussed.

In a study conducted by Leshem and Bar-Hama (2008), a questionnaire was designed to explore the preferences that EFL pre-service student teachers had toward how 
they might be assessed. Data in the study were retrieved from questionnaires, interviews, personal diaries, and documents that included minutes from meetings and assessment forms. The assessment process was drawn up to draft a 'simple survey' with two closed questions and one open-ended question. According to the researchers, the assessment of teaching quality through observation entails an internal paradox that encapsulates the initial urge to re-examine one's own practice. The research questions in their study related to the extent to which quality of teaching is assessed through criteria-based observation. Findings revealed that the students felt it was a valid method of assessment. Cirino, Pollard-Durodola, Foorman, Carlson, and Francis (2007) conducted a study that investigated the relation between teacher characteristics, including ratings of teacher quality, to classroom instructional variables and to bilingual students' literacy and oral language outcomes at the end of the kindergarten year. Teacher characteristics included classroom observational measures of oral language proficiency, quality, and classroom activity structure, as well as surveys of knowledge of reading-related skills. The study was conducted as part of a large, multistate, multisite, longitudinal project focusing on language and literacy development in young bilingual (Spanish/English) English Language Learners (ELL) from kindergarten through second grade. Data were collected in 35 kindergarten and first-grade classrooms in California and Texas with a majority of Spanish-speaking ELLs during the 2002-2003 academic years. A total of 141 teachers were observed three times using different classroom observation instruments. Among teachers observed in this study, overall teacher quality was positively related to overall student engagement $(p<.01)$. Teacher quality was not, however, related to time spent on content instruction in a small-group format $(p>.05)$. Time spent in non- 
instructional activities was significantly, though modestly, negatively related to teacher quality $(p<.05)$, with higher-quality teachers spending more time in content-based instruction. Although quality was related to these observational data, in general, teacher knowledge of reading-related information in either language was unrelated to observational data. Based on this study, it appears that teacher quality and literacy knowledge area related to instructional variables and teacher characteristics such as teacher quality, knowledge, oral language proficiency were related to students' language and literacy learning outcomes. The most notable findings regarding classroom observations were the positive relations of teacher quality ratings to student engagement and the negative relations of teacher quality to non-instructional time.

According to Hughes (2007), EFL teachers in Spain have generally worked independently and without external accountability. This is because external quality indicators for effective practice in EFL instruction have not been fully defined, developed, or implemented by the Spanish educational system. Hughes stated that there are different means to assess teacher performance in EFL instruction in the different autonomous regions of Spain, all of which he asserted to be lacking in "scope (i.e., it is applied to teachers in their first year of service) and focus (i.e., it may not fully target language specific concerns)" (p. 198). For example, in Andalucía, "EFL teachers are reviewed only in their first year of teaching with a review of lesson plans and onsite inspection, and primarily evaluated on general educational methods rather than foreign language specific methods" (p. 197). According to Hughes, a more enhanced evaluation of EFL teachers is conducted in Granada using an observation instrument containing items related to general education but not related to communicative competence. 
In efforts to establish criteria for quality EFL instruction in Spain, Hughes (2007) conducted a survey of EFL teachers in Andalucía, Spain, to discover different criteria EFL teachers deemed important in English language instruction. His qualitative study involving 43 public school teachers and administrators in Granada, Spain, indicated that, in response to open-ended questions on which aspects of teaching English were the most important to quality instruction, 15 indicators ranging from the availability of classroom materials and human resources, to classroom management, student engagement, and learning tasks, were reported as the key indicators of quality EFL teaching. Hughes research represents initial steps to develop an external measure of quality in EFL instruction.

Observation instruments have been developed by researchers to identify effective practice in ESL and EFL classrooms. The majority of research on learning English has been conducted in ESL in the United States and therefore is greater in number than EFL studies in other countries. According to Lasagabaster (2001), instruments for classroom observation in ESL and EFL classrooms were first developed in the 70s and 80s. The instruments widely range in their contents and measurement scales. To address the need for valid and reliable instruments in observing ESL instruction, Gersten and Baker (2003) conducted a validity and reliability study to develop an observation instrument for identifying effective teaching practices in teaching oral reading fluency in ESL classrooms. The English Language Learners Classroom Observation Instrument (ELCOI) is a 30-item moderate influence Likert-type scale. It has six empirically derived subscales (explicit teaching, instruction geared toward low performing students, shelter English techniques, interactive teaching, vocabulary development, phonemic awareness, and 
decoding). Validity and reliability studies indicate that the internal consistency reliability was high, with a median subscale alpha of 0.89 and a range from 0.80 to 0.95 on the six ELCOI subscales. The median inter-observer agreement on an item-by-item basis was $74 \%$. Criterion-related validity was established by correlating scores from each subscale with residualized growth scores in actual reading performance in 20 classrooms. The dependent measure for this analysis was a composite of post-test reading comprehension and oral-reading fluency, adjusted for pretest scores in letter-naming fluency. Criterionrelated validity coefficients between classroom ratings and residualized growth scores for each of the six subscales on the ELCOI were consistently in the high-moderate range: median coefficient was 0.60 , with a range from 0.49 to 0.65 . These findings were replicated in a study by Baker, Gersten, Haager, Dingle, and Goldenberg (2004), providing evidence of good internal consistency, reliability, reasonable inter-rater reliability (for a rating scale requiring a good degree of inference), and a good criterionrelated validity. The authors believed that, although the instrument is very useful for research purposes, it is not designed to be used in a teacher improvement system.

Graves, Gestern, and Heager (2004) used the ELCOI in a study committed to investigate the literacy practices in multiple-language first-grade classrooms and to explore the relationship between observed teaching practice and students' growth in reading. To accomplish this, the researchers developed quantified appraisals of the quality of instruction and linked those appraisals with oral-reading fluency outcomes. The research goals were: (a) to examine the relationship between the quality of literacy practices in first-grade classrooms and growth in oral reading fluency for the students taught, (b) to explore the percentage of students subsequently labeled with learning 
disabilities and examine their oral-reading fluency growth in first grade, and (c) to describe practices in classrooms rated as high quality in order to suggest methods that might be useful in teaching English learners to read in a second language. The two-year study was conducted in nine first-grade multiple language classrooms in three schools in a large urban district in southern California. The classrooms were observed during 2.5hour reading-language arts instruction between five and seven times using the ELCOI. At the conclusion of the second year of this study the range of mean scores on the ELCOI measure varied from 1.0 to 3.75 , where 1 was considered "not effective" and 4 "very effective." In year two, the range was not quite as extreme, ranging from 2.0 to 3.75 . The oral reading fluency pre-test mean for the classrooms (collapsed across the two years) was 16.45. Oral reading fluency post-test classroom means ranged 19.36 to 81.92 . The average gain in oral reading fluency in the classrooms was 29.62 words per minute. The range of gains in year one was 8.90 to $34.81 \mathrm{wpm}$, while in year two the range of gains was 31.44 to $59.25 \mathrm{wpm}$. The descriptive statistics reveal extraordinary variability in growth in Oral Reading Fluency. The field notes on the two teachers with the highest growth in both years included many examples of the practices tapped in ELCOI: high student engagement; ample opportunities to use newly learned skills; time spent reading: appropriate length for the various literacy activities; clear, explicit models of proficient performance; and daily attention to struggling readers through specialized small-group instruction. They also demonstrated use of the techniques commonly advocated for teaching academic content to English learners.

The project called English Language and Literacy Acquisition (ELLA) was a five-year study comparing different programs' models for English Language Learners in 
the United States. Eight hundred Spanish-speaking ELL received services in four program models: (a) typical transitional bilingual education (TBE-T), the control group which represents the typical practice in the school district; (b) enhanced TBE (TBE-E), the experimental group which represents the intervention of the project; (c) typical Structured English Immersion program (SEI-T), another control group; and (d) enhanced Structured English Immersion program (SEI-E), another experimental group. Based on this research, Lara-Alecio, Tong, Irby, and Mathes (2007) conducted a study using a Transitional Bilingual Observation Protocol (TBOP) to observe and identify teaching behaviors in two types of programs, bilingual and structured English immersion, for kindergarten Spanish-speaking English Language Learners in a large urban school district. There were identified variations across the models related to the teachers' pedagogical approaches. The two program models included an experimental version and a typical practice (control) version for each type of program. Two research questions guided the study: (a) What is the time allocation of pedagogical approaches implemented in transitional bilingual education (TBE) and structured English immersion (SEI) language classrooms, as observed by TBOP? and (b) Do teachers' pedagogical approaches vary among program models?

To describe and compare the characteristics of instruction provided in each condition in the study using the TBOP and a hand-held PDA for collecting data, teachers were observed providing English language instruction four times across the academic year. A total of 12,898 observations were collected. The findings indicated that within the same program label of SEI, significant differences were found between the typical and enhanced classrooms. The experimental teachers were observed less frequently speaking 
in Spanish during the ESL teaching time (SEI-E: 0.26\%; TBE-E: 0.14\%) than the control classrooms teachers (SEI-T: 8.5\%; TBE-T: 14.40\%). To the contrary, the SEI-E (97.3\%) and the TBE-E (98.3\%) teachers were observed speaking in English at a higher rate during their ESL instructional time than the SEI-T (86.1\%) and the TBE-T (75.4\%) teachers. All differences are statistically significant at $p=.05\left(\Delta \chi^{2}(1)>3.84\right)$ except for the use of Spanish between teachers in SEI-E and TBE-E classrooms. Interesting findings resulted from the examination of the language used by students. Chi-square test was significant at $\alpha=.05$, with a Cramer's $V$ of .14, indicating that the association between the variables is at the edge of weak to moderate in strength. A Chi-square test of homogeneity of proportion was employed to determine the differences of crossclassification among the four instructional settings. Overall, teachers in enhanced classrooms were significantly more involved in a higher percentage of instruction in (a) intensive English; (b) light and dense cognitive areas; (c) expressive language-related communication; (d) teacher-ask/student-answer type of activity, academic scaffolding, and leveled questions; (e) use of English in cognitive area; (f) use of English in expressive language-related communication mode; and (g) academic task rather than social participation task. There were also significant differences between the typical and enhanced TBE classrooms.

\section{Summary}

This literature review provides the scholarly context for this study in the area of language acquisition theory, effective teaching practices, language instruction, classroom observation as a method of teacher improvements, and classroom observation instruments used in evaluating teaching in ESL/EFL classrooms. Over the past 50 years, several 
theories have been put forth to explain the process by which children learn to understand and speak a language. Three approaches dominate theory and research related to language acquisition: the Behavioral approach, the Social Nativist approach, and the Functional approach. These approaches have all contributed to the development of methods for teaching language. In the late $20^{\text {th }}$ century, Krashen developed five hypotheses of language acquisition: the Acquisition-Learning hypothesis, the Monitor hypothesis, the Natural Order hypothesis, the Input hypothesis, and the Affective Filter hypothesis. Krashen's theories have had a great impact on both English as a Second Language (ESL) and English as a Foreign Language (EFL) (Tragant \& Muñoz, 2009).

As described in this chapter, language instruction takes place in a variety of school settings and uses different methods and approaches (i.e., the Structural approach, the Notational Functional approach, and the Interactive approach). Based on these approaches, there is a wide variety of methods of teaching ESL/EFL currently in use in classrooms worldwide. The dominant methods in use today include the Grammar Translation method, the Direct Instruction method, the Reading approach, the AudioLingual method, the Oral-Situational method, the Cognitive method, the AffectiveHumanistic method, the Comprehension-Based method, the Communicative Language Teaching method, the Total Physical Response method, the Natural method, and the PostMethods method.

A number of research studies have been conducted over the years to determine which classroom teaching behaviors have positive effects on student learning. These teaching behaviors are referred to as "Effective Teaching Practices." Effective Teaching Practices is the idea that asserts there is an activity, technique, method, approach, 
procedure, or process which helps teachers to effectively achieve particular outcomes that benefit students. The behaviors identified as Effective Practices have been organized into domains of behaviors which include Classroom Dynamics, Student Dynamics, Teaching Approaches, Language Arts Instruction, and Classroom Management. The Effective Practice behaviors and domains provide the framework for the classroom observation instrument developed in this study.

Research on instruction in ESL/EFL reflects the current state of affairs in the post-methods era; it is difficult to find ESL/EFL classrooms in which one instructional method is used exclusively. Although the Spanish government's position on EFL instruction favors the Communicative approach, publishers and authors of teaching materials turn to eclectic or integrative materials because their experience and the real situation of learners with their learning styles and different backgrounds advise them to proceed in that way (Criado \& Sanchez, 2009). The purpose of the review was not to assert that one method was more effective than another in teaching language, but that a variety of methods have been used and found to be effective in teaching English either as a foreign or second language.

Observation of teaching in general areas has been a common practice since the early 60 s. According to Lasagabaster (2001), instruments for classroom observation in ESL/EFL were first developed in the 70s and 80s. Although classroom observation has been part of teacher training in foreign language instruction in both the United States and in Spain, it appears that classroom observation for teacher improvement is not a regular part of teacher improvement programs in the United States and is rarely practiced in Spain (Graves, Gersten, \& Haager, 2004). Observation instruments for research in 
teaching EFL have been developed and used in Spain but have not been commonly used for teacher improvement, which leads credence to the need for this study, intended to create an easy-to-use classroom observation instrument for evaluating teacher performance in English language instruction. 


\section{CHAPTER III}

\section{METHODOLOGY}

\section{Introduction}

The purpose of this study was to develop items for an observation instrument in order to observe EFL instruction as part of formative evaluation of English teachers in Spain. This instrument was intended to be an easy-to-use tool for assessing teacher performance. In addressing the purpose of this study, the following objectives were applied: (a) identify the underlying domains for effective EFL teaching practices in Spain, and (b) design and validate items for an instrument that will assist in the observation of EFL practices for formative evaluation. This chapter describes the study's research design, research questions, methods, and procedures.

\section{Research Questions}

To design and determine the construct validity and reliability of items for an observation instrument for formative evaluation of EFL instruction, the following questions were proposed:

RQ1. Do the items have content validity as demonstrated by the judgment of experts in the field of ESL/EFL instruction?

RQ2. Do the items demonstrate construct validity?

RQ3. Do the items demonstrate internal consistency? 
RQ4. Do the items demonstrate stability as a measure of effective ESL/EFL teaching practices?

\section{Research Design}

This exploratory study relied mainly on quantitative research methods. This study utilized a non-experimental design in which data was collected via a survey instrument composed of Likert-type scaled responses. The survey and data collection methods used in this study took the form of a computerized self-administered questionnaire accessible via Internet. According to Dillman (2007), there are several methods of collecting survey data ranging from interviews conducted face-to-face or by phone to self-administered questionnaires. However, there is a societal trend toward self-administration of surveys because of the lower cost involved and the fact that organizations are able to conduct such surveys themselves without the need of a contracted professional organization. According to Couper and Nichols (1998), self-administered questionnaires have benefited from developments in information technologies, as computer-based survey collection methods eliminate laborious procedures and reduce the loss of data quality.

The survey was implemented according to procedures recommended by Dillman (2007). The items included in this study were from research on effective teaching practices for ESL/EFL instruction and referred to as "items." The aim of this study was to determine which items to include on an observation instrument designed to provide formative evaluation to EFL teachers for Pre-k to second grade in Spain. The survey developed for this study also included a section on demographic information to determine if age, gender or other demographic factors played a role in respondents' selection of particular items. 
The methodology used is described in the following steps:

Step 1: Determine domains and items relevant to effective instruction in ESL/EFL

Step 2: Determine the measurement format for validating the item

Step 3: Review the initial item pool for establishing content validity

3a: Select the panel of experts to review items for content validity

Group 1. ESL experts in United States.

Group 2. EFL experts in University of Barcelona, Spain.

$3 \mathrm{~b}$ : Distribute the initial pool of items to the panel of experts

3c: Select the final items for the observation instrument based on expert feedback

Step 4: Administer the survey of items to a small sample of EFL teachers in Spain to pilot the survey

Step 5: Administer the survey of items to a pre-selected population of faculty members from the foreign language departments in Spanish universities

Step 6: Analyze items for validity and reliability using Factor Analysis and Cronbach's alpha

Step 7: Assess stability of the items using Test-retest correlation

Step 8: Determine final items which will comprise the observation instrument.

Description of the steps will portray in detail the procedures to be conducted.

\section{Step 1: Determine domains and items relevant to effective instruction in EFL}

To develop a valid and reliable observation instrument, the first step in the process was to identify items which best describe the research construct being observed, in this case effective instruction in ESL/EFL. According to Linn and Gronlund (1995), a 
construct is an individual characteristic that can explain some aspect of behavior. For example, a psychological construct is defined as "a product of informed scientific imagination, an idea developed to permit categorization and description of some directly observable behavior" (Crocker \& Algina, 1987, p. 230). The construct in this study was the measurement of ESL/EFL effective teaching practices as represented through specific teaching behaviors. Since effective teaching behaviors are inferred based on observation, the first step in collecting evidence for the development of items for the observation instrument was identifying specific teacher behaviors for ESL/EFL effective teaching practices. The selection of ESL/EFL effective teaching practices to be included in the instrument is based on a literature review of effective ESL/EFL teaching practices and also previously developed observation instruments used in research studies.

The 111 items chosen for the initial pool were selected based on a comprehensive review of the literature. The items focused as much as possible on those behaviors that can be observed with a low level of inference from the observer. To achieve mutually exclusive items, teacher behaviors were grouped together into the following five discernible domains: Classroom Dynamics (CD), Student Dynamics (SD), Teaching Approaches (TA), Language Arts Strategies (LAS), and Classroom Management (CM). A domain is defined for this study as the major category under which related items will be organized. Moreover, each domain and its subsequent items were clearly defined so as to minimize inference. Specific items for this study were selected from the identified effective ESL/EFL teaching behaviors found in the research literature. Additionally, items were also selected from the following classroom observation instruments: (a) Sheltered Instruction Observation Protocol (SIOP), (b) English Learners Classroom 
Observation Instrument (ELCOI), and (c) Student Teacher Assessment Instrument (STAI) (see Appendix A).

The domains and the initial pool of items are shown in Table 1. Each item has been coded with the initials of its corresponding Domain and number (i.e., for item No.1 in Classroom Dynamics, the code will be CD1; for item No. 5 in Student Dynamics, the code will be SD5, etc.).

\section{Step 2: Determine the measurement format for validating the items}

The survey was comprised of 111 items relevant to effective ESL/EFL instruction, which participants evaluated using a six-point Likert type scale. According to DeVellis (2003), a measurement scale needs to discriminate differences in the underlying attribute. The initial items comprising the item pool for this study were declarative sentences followed by response options indicating varying degrees of agreement. The most commonly used scale to measure opinions is the Likert typescale; a six-point Likerttype scale was used in this study, with 1 indicating strongly agree and 6 indicating strongly disagree.

\section{Table 1}

Experts' Survey

\section{Classroom Dynamics}

CD1 Teacher is organized and starts class promptly

CD2 Teacher displays consistent opening routine

CD3 Teacher posts and refers to agenda for student tasks

CD4 Teacher clearly explains to students what they will be learning and doing

CD5 Teacher introduces morning message for oral communication

CD6 Teacher incorporates days of the week into the lesson

CD7 Teacher incorporates daily weather into the lesson

CD8 Teacher paces the lesson appropriately to the students' ability level

CD9 Teacher incorporates learning activities into transition times

CD10 Teacher keeps transition times to a minimum 
CD11 Teacher changes center or group work frequently

CD12 Teacher paces activities to keep students focused and engaged

CD13 Teacher provides a summarizing activity

CD14 Teacher demonstrates connections between past, present, and future lessons

CD15 Teacher elicits reflective comments from students on activities

CD16 Teacher uses informal assessment to gauge student understanding

\section{Student Dynamics}

ST1 Teacher engages students to participate throughout the lesson

ST2 Teacher encourages students to give elaborated responses

ST3 Teacher consistently provides wait-and-think time for student response

ST4 Teacher encourages students to share responsibility for instruction by constructing and writing the text

ST5 Teacher encourages students to collaborate in instruction by writing the composition

ST6 Teacher accepts multiple responses that students can support

ST7 Teacher provides frequent opportunities for interaction in the target language among students

ST8 Teacher structures opportunities to speak target language

ST9 Teacher provides opportunities for communicating with others about who is reading the target language

ST10 Teacher engages students in discussions about, a response to, and specific elements or contents of the book in the target language

SD11 Students demonstrate desire to talk and interact in the target language

SD12 Students exhibit on-task behavior

SD13 Students engage in discussions about texts they read in the target language

SD14 Activities keep students actively engaged

SD15 Students actively engage in writing

Teaching Approaches

TA1 Teacher provides explicit instruction in Target language

TA2 Teacher introduces difficult vocabulary prior to and during lesson

TA3 Teacher gives a chalk-talk with drawings on the board

TA4 Teacher only uses the target language for communication as well as feature of the target language culture to talk about it

TA5 Teacher selects and incorporates students' responses, ideas, examples, and experiences into lesson

TA6 Teacher uses direct explicit instruction to teach unknown words and expand knowledge of known words

TA7 Teacher models critical thinking questions and answers in a variety of forms

TA8 Teacher introduces the book and discusses the title, author, and illustrator

TA9 Teacher stops at selected places to emphasize a point, ask a question, do a think-aloud, model a strategy, clarify information, or monitor students' comprehension

TA10 Teacher models the use of comprehension strategies to make content understandable 
TA11 Teacher builds instructional context for students

TA12 Teacher links concepts to student's background experiences, and makes explicit connections between past learning and new concepts

TA13 Teacher makes connections between their knowledge, experiences, the ideas, events, and information in the text

TA14 Teacher helps students make connections between the text and personal knowledge and experiences

TA15 Teacher utilizes small groups to encourage students to work together to reach a common goal

TA16 Teacher ensures students are not only responsible for learning the material that is presented, but also for ensuring everyone in the group knows the material as well

TA17 Teachers directs students participate in group work and know their role in the group

TA18 Teacher works with a small group of students at the same instructional level with the same text

TA19 Teacher develops routines for students moving to and from centers, stations, literature circles

TA20 Teacher establishes learning centers that provide opportunities for direct application of previously taught skills and strategies

TA21 Teacher groups students heterogeneously for learning center activity work

TA22 Teacher shares responsibility for classroom routines with job boards or assignment charts

TA23 Teacher reviews comprehension skills and strategies in small group or literature circles

TA24 Teacher calls attention to words, phrases, sentences, and/or punctuation

Language Arts Strategies

LAS1 Teacher structures opportunities to speak target language throughout lesson

LAS2 Teacher uses the Morning Message to encourage students in oral participation

LAS3 Teacher provides repeated exposures to new words

LAS4 Teacher encourages students to explain their thinking in their own words

LAS5 Teacher accepts multiple responses that students can support

LAS6 Teacher connects spelling to phonics and modeling spelling strategies

LAS7 Teacher encourages students to use strategies of phonemic awareness to say words slowly before spelling them in writing

LAS8 Teacher uses echo or choral reading to promote fluency

LAS9 Teacher provides direct explicit instruction in each of the aspects of phonemic awareness

LAS10 Teacher models and directs practice in rhyming

LAS11 Teacher provides systematic instruction in phonemic awareness

LAS12 Teacher provides systematic instruction in letter-sound correspondence

LAS13 Teacher provides systematic instruction in decoding

LAS14 Teacher provides systematic instruction to vocabulary development

LAS15 Teacher asks questions to ensure comprehension

LAS16 Teacher uses poetry, big books of rhyme, or songs to assist in phonemic 
awareness

LAS17 Teacher teaches the relationship between spoken and written letters

LAS18 Teacher enhances and enriches phonics by teaching strategies which help students have alternative methods of decoding words

LAS19 Teacher systematically teaches the most productive phonics rules

LSA20 Teacher solidifies knowledge of the alphabet through multiple tasks

LAS21 Teacher uses echo and choral reading on a regular basis to increase fluency

LAS22 Teacher teaches students how to gain meaning from text through proper phrasing of text which demonstrates understanding

LAS23 Teacher uses poetry, big books of rhyme, or songs to assist in phonemic awareness

LAS24 Teacher teaches, prior to reading, words that are key to selection comprehension

LAS25 Teacher employs a variety of strategies to teach the skills of comprehension such as rereading, context, Questioning the Author, Think Aloud, Think Along, Think Alone

LAS26 Teacher prompts during the reading of texts to ask questions and monitor students' use of reading strategies and selection comprehension

LAS27 Teacher provides students with opportunities to demonstrate text comprehension through writing short answer questions

LAS28 Teacher demonstrates the act of writing and the writing process

LAS29 Teacher helps students generate ideas for writing

LAS30 Teacher allows students to draw pictures before reading to assist in sequencing writing

LAS31 Teacher allows students to share writing

LAS32 Teacher uses phonemic awareness skills to assist in writing unknown words

LAS33 Teacher encourages students to participate in the writing center

LAS34 Teacher has individuals write known letters, words, or phrases

LAS35 Teacher asks students to participate in the writing at strategic points

LAS36 Teacher reviews the writing process

LAS37 Teacher reviews or models what to write and how to plan

LAS38 Teacher observes students and assists them in their writing efforts

LAS39 Teacher calls attention to words, phrases, sentences, and/or punctuation

Classroom Management

CM1 Teacher posts class rules and reviews them periodically

CM2 Teacher positively reinforces student behavior and work

CM3 Teacher provides positive feedback to students

CM4 Teacher is able to respond quickly and efficiently to changes during lesson

CM5 Teacher provides corrective actions to students every time students choose to disrupt

CM6 Teacher provides positive immediate feedback to students

CM7 Teacher positively disciplines, encourages, and motivates intervention students

CM8 Teacher communicates clearly that students have the power to make choices, yet they need to accept the responsibility that goes with it

CM9 Teacher establishes rules that are observable and continually in effect 
CM10 Teacher uses supportive approaches to keep students on task

CM11 Teacher provides corrective actions in a calm, matter-of-fact manner

CM12 Teacher is consistent

CM13 Teacher provides clear, concise directions that are easy for students to follow

CM14 Teacher uses behavioral narration to motivate students to get on task

CM15 Teacher implements class-wide reward system

CM16 Teacher recognizes positive behavior at the first opportunity after correcting a student's behavior

CM17 Teacher provides an "escape mechanism" for students who are upset and want to talk about what happened

\section{Step 3: Review the initial indicator pool for content validity}

Crocker and Algina (1987) described validation as "the process by which a test

developer collects evidence to support the types of inferences that are drawn from test scores" (p. 217). Issues relevant to the consideration of content validity included appropriateness of the items, inclusion of enough information to cover the domain of interest, and the level of mastery at which the behavior is being described (Bitner \& Kratzner, 1995). Content validity is typically carried on by a panel of independent experts who assesses whether the indicators adequately represent a construct of specific interest (Crocker \& Algina, 1987). Content validity commonly refers to the degree to which the sample of test indicators represents the construct that the test is designed to measure. In this study, content validity was defined as the degree to which the items represent the ESL/EFL effective teaching practices identified in the literature.

The following steps were taken to examine the content validity of the proposed observation instrument for this study: (a) selection of panel of experts, (b) distribution of the observation instrument prototype to the panel of experts, and (c) selection of the final items and domains for the observation instrument. According to Bitner and Kratzner 
(1995), once these steps are complete, the content validity of the observation instrument will be established.

Step 3a: Selection of panel of experts. The members of this panel of experts were contacted via email to confirm their willingness to participate in the validation of the survey. The panel of experts was composed of two groups: Group 1 included experts from ESL instruction in United States, and Group 2 included experts from EFL researchers at the University of Barcelona, Spain. In Group 1, the ESL experts in the United States included Dr. Mary Ellen Vogt, Houghton Mifflin Harcourt Special Consultant; Dr. Mary Lou McCloskey, Director of Teacher Education and Curriculum Development, Educo in Atlanta, Georgia; Dr. Margo Gottlieb, Houghton Mifflin Harcourt Special Consultant; Dr. David Freeman, ESL Reading Specialist at University of Texas at Brownsville; Dr. Yvonne Freeman, ESL Literacy Specialist at University of Texas at Brownsville; Dr. Carl Falsgraf, Director of the Center for Applied Second Language Studies, University of Oregon, Eugene; Ms. Nancy Frampton, ESL Reading and Language specialist at Reedley College California; Dr. Mary Husain, California State University, Fresno; Mr. Samuel M. Shepherd, Advisor of The Society for Testing English Proficiency, Los Angeles, California; Dr. Berta Gonzalez, Associate Vice President at California State University, Fresno; Dr. Ye-Kyoung Kim, Houghton Mifflin Harcourt Special Consultant; Dr. Nancy Updegraff, Houghton Mifflin Harcourt Special Consultant; Dr. Gladys Cruz-García, Houghton Mifflin Harcourt Special Consultant; Ms. Sharon Reed, Director of Houghton Mifflin Harcourt International; and Dr. Janielle Lowsaw, Houghton Mifflin Harcourt Special Consultant. In Group 2, the EFL experts in Spain included Dr. Carmen Muñoz Lahoz, University of Barcelona; Dr. María Rosa 
Torras Cherta, University of Barcelona; Dr. Julià Font, University of Barcelona; and Dr. Elsa Tragant, University of Barcelona.

Step 3b: Distribute the initial pool to the panel of experts. The initial pool of items was distributed via email to the panel of experts to establish content validity and to narrow the items sent to the target population. The specific role of the panel of experts was to review the domains and the items, and to identify misinterpretations and omissions from the research, to provide comments on the clarity of the domains and indicators, and to suggest revisions. If the experts determined that some items required changes or deletions, the changes and deletions were completed. The panel was informed that these items are characteristics and behaviors related to effective teaching practices in ESL/EFL, which the investigator intended to measure using a classroom observation instrument. The panel of experts was asked to rate the indicators using a six-point Likert-type response scale. These ratings designate the panel members' opinions concerning the relevance of the indicators as they pertain to effective ESL/EFL teaching practices.

Step 3c: Selection of the final indicators for the observation instrument. After receiving the revised feedback on the initial item pool from the panel of experts the suggested changes for the indicators and domains were included in the final survey. Step 4: Administer the survey of items to a small sample of EFL teachers In order to obtain feedback about the structure of individual items within the survey, the researcher identified a sample of 15 Spanish EFL teachers knowledgeable in the field to participate in a pilot study. These teachers were not included as part of the sampling for the main study. The purpose of a pilot study is to improve the questions, format, and scales of the survey (Creswell, 2003). Participants for pilot testing were 
purposefully selected to represent a variety of teaching experience and a wide range of teaching skills. Each pilot participant was sent an email by the researcher and asked to complete the instrument and comment about the pertinence of questions, clarity of directions, and length of the survey. The pilot study helped ensure clarity regarding the procedure, instructions, and wording of statements, and to determine a reasonable procedural time estimate for inclusion in the invitation for the main data collection. Teachers who participated in the pilot testing received an email message explaining the pilot study procedure and providing them with the Web link to access the survey. After completing and submitting the instrument, participants were taken to a screen that allowed them to submit anonymous feedback along with their estimated completion time. The observation instrument was adjusted according to suggestions from the pilot study.

\section{Step 5: Administer the survey of items to a pre-selected population of faculty members from the foreign language departments in Spanish universities}

The items selected as a result of the content validity and pilot testing stages of the study were sent, along with demographic questions, to a pre-selected population of faculty members from the foreign language departments in Spanish universities. The demographic section of the survey consisted of five areas. These areas were designed to collect basic demographic information from participants. In order to further analyze data from the study, information from the selected demographic section were used to classify participants into categories. Information in this section of the survey included the following for each participant: age, gender, academic degree level, years of teaching experience, and professional development activities. 
Sample size for this analysis was determined following considerations made by Stevens (2002), who suggests that components with low loadings (0.40) are reliable as long as sample size is greater than 150 . Following considerations made by Dillman, Smyth, and Christian (2009), in order to achieve the required sample size of 150, the survey was sent to 740 faculty members from the foreign language departments actively teaching in 74 accredited universities in Spain by the National Agency for Quality Assessment and Accreditation (ANECA). Following the initial deployment of the survey, follow-up emails were sent to all participants in weekly intervals to remind them to respond. Participants were provided four weeks to respond to the survey.

\section{Step 6: Analyze the items for construct validity}

According to Linn and Gronlund (1995), after content validity of the items was established by peer review, construct validity using statistical analysis provided evidence that the construct existed, that it was little influenced by unrelated factors, and that it differed from other constructs. A commonly used approach to construct validity is factor analysis, an analytic tool that "helps us determine empirically how many constructs, or latent variables, or factors underlie a set of items" (DeVellis, 2003, p. 103). Factor analysis involves computing a correlation matrix to identify a reduced number of underlying variables which account for variation in an original set of factors (Crocker \& Algina, 1987). Construct validity of the items used in this study were analyzed through exploratory factor analysis, specifically using Principal Components Analysis. Principal Components Analysis generated a set of uncorrelated variables (the components) smaller than the number of original variables which accounted for most of the variance. The component procedure clustered variables empirically, and the job of the researcher was to 
name the underlying domains and identify the components (Stevens, 2002). Interpretation of components resulting from the factor analysis procedure was carried out by the researcher. Data gathered from participants were analyzed using the statistical package SPSS. According to Huck (2004), reliability is defined as the consistency across parts of a measurement instrument. "One of the most important indicators of a scale's quality is the reliability coefficient, alpha" (DeVellis, 2003, p. 94). Alpha can take values ranging from 0.0 to 1.0; DeVellis (2003) suggests that alpha below .60 are unacceptable; between .60 and .65 undesirable; between .65 and .70 minimally acceptable; between .70 and .80 respectable; and between .80 and .90 very good. Reliability for items used in this study was calculated using the Cronbach's alpha coefficient of internal consistency. This statistic were obtained using the statistical package SPSS.

\section{Step 7: Assess stability using test-retest correlation}

Test-retest reliability is a method used to assess how constant scores remain from one occasion to another (DeVellis, 2003). To assess stability for the items in this study, a test-retest procedure was used to establish the stability of results from respondents who were asked via email to re-take the survey. A two-week window from the initial email to the second request was provided to respondents. To quantify the degree of consistency among measurements, the Pearson's product-moment correlation was computed using SPSS.

\section{Step 8: Determine final items which will comprise the observation instrument}

Based on results from statistical analysis, the items which respondents most strongly agreed characterized effective practices in the five teaching domains were selected for the final observation instrument. 


\section{CHAPTER IV}

\section{RESULTS AND ANALYSIS}

\section{Introduction}

The purpose of this study was to develop, design, and evaluate items that will comprise an observational instrument to be used to provide EFL teachers in Spain with formative evaluation for improving their teaching. As part of this study, a survey of items related to effective classroom teaching practice in ESL/EFL instruction was developed, evaluated for content validity, piloted with a small group of EFL teachers, and then deployed to a target population of EFL faculty members in Spanish universities.

This chapter describes the statistical analysis of information and the results of the survey related to each of the research questions. This chapter presents each of the research questions followed by a summary of the data related to each and a table depicting the data.

\section{Research Question Data}

RQ1. Do the items have content validity as demonstrated by the judgment of experts in the field of ESL/EFL instruction?

Content validity refers to the extent to which a given measure describes all the features of a given construct (Carmines \& Zeller, 1991). To establish content validity in this study, first the underlying domains for effective teaching practices were identified as: Classroom Dynamics (CD), Student Dynamics (SD), Teaching Approaches (TA), Language Arts Strategies (LAS), and Classroom Management (CM). Then, 111 items 
associated with effective practices for ESL/EFL instructions were identified based on a comprehensive review of the literature. The domains and items are summarized in a list in Table 1. The five domains with 111 items comprised the initial survey sent via email to 18 experts in ESL/EFL instruction in the United States and Spain. The experts had the opportunity to rate, using a Likert-type scale, their level of agreement that the items characterized effective ESL/EFL teaching behavior from strongly agree to strongly disagree (survey is shown in Appendix B). The experts also had the opportunity to suggest items be deleted from the list because they duplicated other items in the domains or that items be revised to clarify the behavior being described (see Appendix C).

A total of 13 experts responded to the email. Based on their suggestions, some items were eliminated. Table 2 shows the initial items and the final items for each domain. Tables 3 portrays the items which were eliminated from the final survey at the suggestion of the panel of experts because of the following reasons: they were unclear, overlapped with other items, were included in other items, were difficult to observe at the Prek-2 levels, were difficult to observe in one lesson, were more appropriate for a "check list" instrument, was instruction on too low a level, or were too specific.

\section{Table 2}

Initial and Final Items after Experts' Suggestions

\begin{tabular}{lcc}
\hline \multicolumn{1}{c}{ Domain } & Initial items & Final Items \\
\hline Classroom Dynamics & 16 & 8 \\
Student Dynamics & 15 & 7 \\
Teaching Approaches & 24 & 13 \\
Language Arts Strategies & 39 & 12 \\
Classroom Management & 17 & 6 \\
\hline
\end{tabular}




\section{Table 3}

Items that were Eliminated by the Panel of Experts

Items that were eliminated since the panel of experts found them to be unclear

CD9 Teacher incorporates learning activities into transition times

TA5 Teacher selects and incorporates students' responses, ideas, examples, and experiences into lesson

TA10 Teacher models the use of comprehension strategies to make content understandable

TA11 Teacher builds instructional context for students

LAS34 Teacher has individuals write known letters, words, or phrases

LAS 39 Teacher calls attention to words, phrases, sentences, and/or punctuation

CM5 Teacher provides corrective actions to students every time students choose to "disrupt"

CM7 Teacher positively disciplines encourages and motivates intervention students

Items that were eliminated since the panel of experts found that they overlapped other items

CD4 Teacher clearly explains to students what they will be learning and doing

SD8 Teacher structures opportunities to speak target language

TA6 Teacher uses direct explicit instruction to teach unknown words and expand knowledge of known words

TA20 Teacher establishes learning center that provides opportunities for direct application of previously taught skills and strategies

TA21 Teacher groups students heterogeneously for learning center acridity work

LAS1 Teacher structures opportunities to speak target language throughout lesson

LAS2 Teacher uses the Morning Message to encourage students in oral participation

LAS7 Teacher encourages students to use strategies of phonemic awareness to say words slowly before spelling them in writing

LAS8 Teacher uses echo or choral reading to promote fluency

LAS9 Teacher provides direct explicit instruction in each of the aspects of phonemic awareness

LAS10 Teacher models and directs practice in rhyming

LAS11 Teacher provides systematic instruction in phonemic awareness

LAS12 Teacher provides systematic instruction in letter-sound correspondence

LAS 16 Teacher uses poetry, big books of rhymes, or songs to assist in phonemic awareness

LAS17 Teacher teaches the relationship between spoken and written letters

LAS32 Teacher uses phonemic awareness skills to assist n writing unknown words 
CM9 Teacher establishes rules that are observable and continually in effect

CM11 Teacher provides correctives actions in a calm, matter-of-fact manner

Items that were eliminated since the panel of experts found these items to be included in other items

CD5 Teacher introduces Morning Message for oral communication

CD6 Teacher incorporates days of the week into the lesson

CD7 Teacher incorporates weather into the lesson

SD12 Students exhibit on-task behavior

SD13 Students engage in discussions about texts they read in the target language

SD14 Activities keep students actively engaged

TA17 Teacher directs students participate in group work and know their role in the group

TA18 Teacher works with a small group of students at the same instructional level with the same text

TA19 Teacher develops routines for students moving to and from centers, stations, and literature circles

TA20 Teacher establishes learning centers that provide opportunities for direct application of previously taught skills and strategies

CM3 Teacher provides positive feedback to students

CM4 Teacher is able to respond quickly and efficiently to changes during lesson

CM6 Teacher provides positive immediate feedback to students

Items that were eliminated since the panel of experts found them to be difficult to be observed in students from lower grades

CD14 Teacher demonstrates connections between past, present, and future lessons

CD15 Teacher elicits reflective comments from students' activities

SD4 Teacher encourages students to share responsibility for instruction by construction and writing the text

SD5 Teacher encourage the students to collaborate in instruction by writing the composition

SD9 Teacher provides opportunities for communicating with other about what is read in the target language

SD10 Teacher engages students in discussions about, a response to, and specific elements or contents of the book in the target language

TA13 Teacher makes connections between their knowledge experiences, ideas, events, and information in the text

TA24 Teacher calls attention to words, phrases, sentences, and/or punctuation

LAS18 Teacher enhances and enriches phonics by teaching strategies which help students have alternative methods of decoding words

LAS 21 Teacher uses echo and choral reading on a regular basis to increase fluency 
LAS22 Teacher teaches students how to gain meaning from text through proper phrasing of text which demonstrates understanding

LAS27 Teacher provides students with opportunities to demonstrate text comprehension through writing short answer questions

LAS28 Teacher demonstrates the act of writing and the writing process

LAS33 Teacher encourages students to participate in the writing center

LAS35 Teacher asks students to participate in the writing at strategic points

LAS36 Teacher reviews the writing process

Items that were eliminated by the panel of experts since they found them to be difficult to be observed during one lesson

CD11 Teacher changes center of group work frequently

Items that were eliminated by the panel of experts since they were found to be better included in a checklist

TA3 Teacher gives a chalk

Items that were eliminated by the panel of experts because they reflected instruction on a very low level

LAS20 Teacher solidifies knowledge of the alphabet through multiple tasks

Items found by the panel of experts to be too specific for a particular behavior

LAS13 Teacher provides systematic instruction in decoding

LAS14 Teacher provides systematic instruction to vocabulary development

Based on feedback from the participating panel of experts, a new survey was designed using the same five Domains but with fewer items. The new survey was comprised of the following Domains and items listed in Table 11: Classroom Dynamics (CD), 8 items; Student Dynamics (SD), 7 items; Teaching Approaches (TA), 13 items; Language Arts Strategies (LAS), 12 items; Classroom Management (CM), 6 items. As with the previous survey, the new survey uses a six-point Likert-type scale asking participants to rate their level of agreement that the items describe effective ESL/EFL teaching practice from 1 , strongly agree, to 6 , strongly disagree. The final survey 
included the five Domains and associated items which, based on the experts' comments,

establishes the content validity of the survey (see Appendix D).

\section{Table 4}

Domains and Items for the Survey after Experts' Suggestions for Modification

\section{Classroom Dynamics}

CD1 Teacher is organized and starts class promptly

CD2 Teacher displays opening routine

CD3 Teacher posts and refers to list of student tasks

CD4 Teacher paces the lesson appropriately to the students' ability level

CD5 Teacher keeps transition times between activities to a minimum

CD6 Teacher paces activities to keep students focused and engaged

CD7 Teacher provides a summarizing activity

CD8 Teacher uses informal assessment to gauge student understanding

\section{Student Dynamics}

ST1 Teacher engages students to participate throughout the lesson

ST2 Teacher prompts students to give elaborated responses in the target language

ST3 Teacher consistently facilitates wait-and-think time for student responses

ST4 Teacher accepts multiple responses that students can support in the target language

ST5 Teacher provides frequent opportunities for interaction in the target language among students

ST6 Teacher aims to encourage the students' desire to use and interact in the target language

ST7 Teacher provides activities in which students are engaged in writing in the target language

Teaching Approaches

TA1 Teacher provides explicit instructions with the minimal use of L1

TA2 Teacher introduces difficult vocabulary prior to and during lesson

TA3 Teacher mostly uses the target language for communication and talk about culture

TA4 Teacher selects and incorporates students' spontaneous unplanned contributions into lesson

TA5 Teacher models critical thinking questions and answers in a variety of forms

TA6 Teacher stops at selected places to emphasize a point, ask a question, do a thinkaloud, model a strategy, clarify information, or monitor students' comprehension

TA7 Teacher links concepts to student's background experiences and makes explicit connections between past learning and new concepts

TA8 Teacher helps students make connections between the text and personal 


\section{knowledge and experiences}

TA9 Teacher utilizes small groups to encourage students to work together to reach a common goal

TA10 Group work incorporates individual and group accountability

TA11 Teacher has developed routines for students moving to and from centers, stations, and literature circles

TA12 Teacher shares responsibility for classroom routines with job boards or assignment charts

TA13 Teacher reviews comprehension skills and strategies in small group or literature circles

Language Arts Strategies

LAS1 Teacher provides repeated exposure to new words

LAS2 Teacher facilitates students' use of their own words in target language

LAS3 Teacher connects spelling to phonics and models spelling strategies

LAS4 Teacher asks questions to ensure comprehension

LAS5 Teacher enhances and enriches phonics by teaching strategies which help students have alternative methods of decoding words and develop new vocabulary

LAS6 Teacher systematically teaches the most prevalent phonics rules

LAS7 Teacher uses poetry, big books of rhyme, or songs to assist in phonemic awareness

LAS8 Teacher prompts during the reading of texts to ask questions and monitor students' use of reading strategies

LAS9 Teacher helps students generate ideas for writing and allows students to draw pictures through reading to assist in sequencing writing

LAS10 Teacher facilitates the sharing of student writing

LAS11 Teacher reviews or models how to plan and what to write

LAS12 Teacher observes students and assists them in their writing efforts

Classroom Management

CM1 Teacher implements a class-wide reward system with rules that are observable and reviews them periodically

CM2 Teacher positively reinforces student behavior and work

CM3 Teacher provides corrective actions to students every time students choose to disrupt

CM4 Teacher communicates clearly that students have the power to make choices, yet they need to accept the responsibility that goes with it

CM5 Teacher is consistent and provides clear, concise directions that are easy for students to follow

CM6 Teacher recognizes positive behavior at the first opportunity after correcting a student's behavior and provides an "escape mechanism" for students who are upset and want to talk about what happened 


\section{RQ2. Do the items demonstrate construct validity?}

Construct validity defines how well the items in a given measure fully describe a particular construct. In this case, construct validity concerns the degree to which participants agree that the items on the survey measure effective practice in ESL/EFL (Carmines \& Zeller, 1991). To establish construct validity, the survey was sent via email first to a pilot group of $15 \mathrm{EFL}$ teachers in Spain, and then to a larger population of 740 EFL faculty members of Spanish universities in Spain, whose responses were then analyzed using Factor Analysis, Cronbach's alpha, and Co-relational statistics.

\section{Sample Demographics}

Three samples were used for this study: the first sample for the pilot survey was composed of 15 EFL teachers in Spain (100\% female) who lived in the area of Barcelona, Spain. The mean age was 31.93 years, with standard deviation of 5.95 years. This group of EFL teachers was composed of teachers from different countries: Scotland, United States, Spain, Peru, Guatemala, Chile, and Mexico. The mean for their K-12 teaching experiences in EFL instruction was 7.07 years $(S D=4.36)$, and the mean for their professional development training in the past two years was $3.80(S D=1.568)$. The second sample for the final survey was composed of 740 faculty members from EFL departments in 74 Spanish universities accredited by ANECA. Out of the 740 faculty members contacted, a total of 192 responded to the survey, comprising $25 \%$ of the total population. The mean age of the respondents was 38.93 years $(S D=9.523)$, with $49.47 \%$ male and $50.52 \%$ female. The teaching experience of the respondents was a mean of 4.77 years $(S D=5.624)$ in $\mathrm{K}-12$ and 8.58 years $(S D=7.887)$ in higher education. The mean number of years engaged in professional development activities in EFL was 2.26 years 
$(S D=1.186)$. In order to collect data about the stability of the survey, participants were asked to re-take the survey. The original 740 faculty members of the EFL departments in the 74 Spanish universities accredited by ANECA were contacted again and asked to retake the survey. In total, 31 participants participated in the test-retest study. The mean age for the test-retest participants was 39.95 years $(S D=8.666)$, with approximately $12.90 \%$ male and $87.09 \%$ female. This sample had 3.81 years $(S D=3.674)$ of teaching experience in $\mathrm{K}-12$ and 8.06 years $(S D=6.501)$ of teaching experience in higher education. The mean years for engagement in professional development activities in EFL was 2.00 years $(S D=1.033)$.

\section{Instruments and Procedure}

The final version of the survey described in Table 11 included 46-items in five Domains. The final version of the survey was administered as a pilot first to a small sample of EFL teachers to ensure instructions on how to answer the survey were clear, to determine the amount of time needed to answer the survey, and to check that the on-line survey instrumentation was understood and functioning. Participants were contacted by email to complete demographic information and the final version of the survey. The second deployment of the survey was sent to 740 faculty members. These participants were contacted by email in four different instances. The first email was sent to invite them to participate in a study; the second email was sent a week later as a remainder of the invitation to participate in the study. A third email was sent 12 days after the first as a reminder of the invitation to participate in the study. For the purposes of establishing the stability of the instrument, all 740 faculty members of the EFL departments in the 74 Spanish universities accredited by ANECA were contacted by email two weeks later after 
the first email was sent, both as a reminder to participate in the study and also to invite them to participate in a test-retest study (see Appendix E).

\section{Descriptive Statistics}

Descriptive statistics for the survey items, including mean scores and standard deviations are described in Table 12. For a better understanding on reading the tables from the statistical results, each item from the final survey has been coded with its corresponding domain initials and its corresponding number in the underling domain (i.e., for item No.1 in Classroom Dynamics, the code will be CD1, for item No. 5 in Student Dynamics, the code will be SD5, etc.), as it was done for the initial survey.

\section{Table 5}

Descriptive Statistics for all 46 Items of the Final Survey $(N=192)$

\begin{tabular}{|c|c|c|c|}
\hline & & $M$ & $S D$ \\
\hline CD1 & Teacher is organized and starts class promptly & 1.21 & .54 \\
\hline $\mathrm{CD} 2$ & Teacher displays opening routine & 1.50 & .79 \\
\hline CD3 & Teacher posts and refers to list of student tasks & 1.55 & .94 \\
\hline CD4 & $\begin{array}{l}\text { Teacher paces the lesson appropriately to the students' } \\
\text { ability level }\end{array}$ & 1.35 & .68 \\
\hline CD5 & $\begin{array}{l}\text { Teacher keeps transition times between activities to a } \\
\text { minimum }\end{array}$ & 1.77 & 1.01 \\
\hline CD6 & $\begin{array}{l}\text { Teacher paces activities to keep students focused and } \\
\text { engaged }\end{array}$ & 1.26 & .63 \\
\hline CD7 & Teacher provides a summarizing activity & 1.57 & .96 \\
\hline CD8 & $\begin{array}{l}\text { Teacher uses informal assessment to gauge student } \\
\text { understanding }\end{array}$ & 1.42 & .71 \\
\hline SD1 & Teacher engages students to participate throughout the lesson & 1.30 & .54 \\
\hline SD2 & $\begin{array}{l}\text { Teacher prompts students to give elaborated responses in the } \\
\text { target language }\end{array}$ & 1.42 & .75 \\
\hline SD3 & $\begin{array}{l}\text { Teacher consistently facilitates wait-and-think time for } \\
\text { student responses }\end{array}$ & 1.50 & .68 \\
\hline SD4 & $\begin{array}{l}\text { Teacher accepts multiple responses that students can support } \\
\text { in the target language }\end{array}$ & 1.40 & .60 \\
\hline SD5 & $\begin{array}{l}\text { Teacher provides frequent opportunities for interaction in the } \\
\text { target language among students }\end{array}$ & 1.40 & .70 \\
\hline SD6 & Teacher aims to encourage the students' desire to use and & 1.64 & 1.06 \\
\hline
\end{tabular}


interact in the target language

SD7 Teacher provides activities in which students are engaged in writing in the target language

TA1 Teacher provides explicit instructions with the minimal use of L1

TA2 Teacher introduces difficult vocabulary prior to and during lesson

$1.55 \quad .86$

TA3 Teacher mostly uses the target language for communication and talk about culture unplanned contributions into lesson

$\begin{array}{lllll}\text { TA5 Teacher models critical thinking questions and answers in a } & 1.39 & .75\end{array}$ variety of forms

TA6 Teacher stops at selected places to emphasize a point, ask a $\quad 1.26 \quad 61$ question, do a think-aloud, model a strategy, clarify information, or monitor students' comprehension

TA7 Teacher links concepts to student's background experiences and makes explicit connections between past learning and new concepts

TA8 Teacher helps students make connections between the text and personal knowledge and experiences

$\begin{array}{llll}\text { TA9 Teacher utilizes small groups to encourage students to work } & 1.36 & .80\end{array}$ together to reach a common goal

TA10 Group work incorporates individual and group accountability $\quad 1.61 \quad 1.00$

TA11 Teacher has developed routines for students moving to and $\quad \begin{array}{ll}1.97 & 1.39\end{array}$ from centers, stations, and literature circles

TA12 Teacher shares responsibility for classroom routines with job boards or assignment charts

TA13 Teacher reviews comprehension skills and strategies in small group or literature circles

LAS1 Teacher provides repeated exposures to new words

LAS2 Teacher facilitates students' use of their own words in target language

LAS3 Teacher connects spelling to phonics and models spelling strategies

LAS4 Teacher asks questions to ensure comprehension

LAS5 Teacher enhances and enriches phonics by teaching strategies

$1.71 \quad .96$
which help students have alternative methods of decoding words and developing new vocabulary

LAS6 Teacher systematically teaches the most prevalent phonics rules

LAS7 Teacher uses poetry, big books of rhyme, or songs to assist in phonemic awareness

LAS8 Teacher prompts during the reading of texts to ask questions and monitor students' use of reading strategies

LAS9 Teacher helps students generate ideas for writing and allows 
students to draw pictures through reading to assist in sequencing writing

LAS10 Teacher facilitates the sharing of student writing

LAS11 Teacher reviews or models how to plan and what to write $\quad \begin{array}{ll}1.64 & 1.13\end{array}$

LAS12 Teacher observes students and assists them in their writing $\begin{array}{rr}1.58 & .90\end{array}$ efforts

CM1 Teacher implements a class-wide reward system with rules $\quad 1.68 \quad 1.21$ that are observable and reviews them periodically

CM2 Teacher positively reinforces student behavior and work $\quad 1.21 \quad .50$

$\begin{array}{lllll}\text { CM3 Teacher provides corrective actions to students every time } & 1.57 & .91\end{array}$ students choose to disrupt

CM4 Teacher communicates clearly that students have the power $\quad \begin{array}{lll}1.37 & .83\end{array}$ to make choices, yet they need to accept the responsibility that goes with it

CM5 Teacher is consistent and provides clear, concise directions $\quad 1.25 \quad .56$ that are easy for students to follow

$\begin{array}{lllll}\text { CM6 Teacher recognizes positive behavior at the first opportunity } & 1.40 & .74\end{array}$ after correcting a student's behavior and provides an "escape mechanism" for students who are upset and want to talk about what happened

Note: For each variable, missing values are replaced with the variable mean.

Descriptive statistics indicate that the mean responses to all of the items in the survey were generally between one and two on the Likert-type scale, indicating that respondents strongly agreed or agreed that the items on the survey corresponded with effective ESL/EFL teaching behaviors.

\section{Factor Analysis}

A factor analysis was performed to determine the construct validity of the scores by analyzing the strength of the relationship between the items and the construct of effective ESL/EFL instructional practices. Prior to the statistical procedures, a KaiserMeyer-Olkin measure of sampling adequacy and Bartlett's test of sphericity were conducted. Results of the correlation analysis demonstrated that the items possess factorability, as all the 46 items were correlated at a level of at least .30. Results of the Kaiser-Meyer-Olkin measure indicated that the sample size is adequate for factor 
analysis, as the sampling adequacy was .88 , which is above the recommended value of .6 , according to Stevens (2002). Analysis, Bartlett's test of sphericity was applied and resulted in significant results of $\chi^{2}(1035)=7043.522, p<.001$. The diagonals of the antiimage correlation matrix were all over .50 , indicating that each item was acceptable for inclusion in the factor analysis.

Finally, according to Stevens (2002), commonalities above .6 confirm that each item shared some common variance with other items. The results of this analysis indicated that most of the scores of the survey are a valid measure of the construct of ESL/EFL effective teaching practices. A factor analysis solution was tested resulting in nine factors. The items that loaded significantly are presented in Appendix F.

The use of Principle Component analysis identified that nine factors explained over $70 \%$ of the variance. Initially, there were nine factors that had eigenvalues greater than 1 . The first factor explained $41.988 \%$ of the variance, the second factor $6.676 \%$ of the variance, the third factor $4.187 \%$, the fourth factor $4.138 \%$, and the fifth factor $3.013 \%$. The rest of the factors explained less than $3.00 \%$ of the variance. Taking into consideration the percentage of variance explained as well as the number of items that fall into each factor, both a four-factor and five-factor solution were examined. The theoretical meaningfulness of the five factor solution led to the decision to use the fivefactor solution. Forty-four of the 46 items had structure coefficients of .40 or greater. The five-factor solution which explained $60.00 \%$ of the variance is shown in the scree plot in Figure 1. 


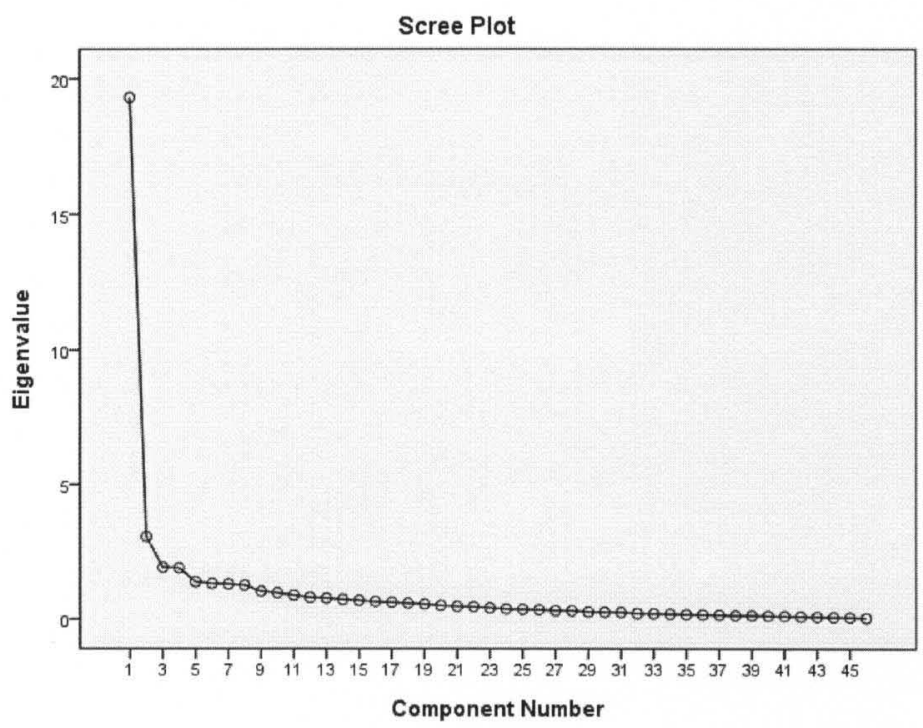

Figure 1

Factor Scree Plot based on a principle components analysis for the five-factor analysis ( $N$ $=192)$

The structure coefficients and communalities resulting from this analysis are reported in Table 13. Items from this table were coded and their description was synthesized (see Appendix G). 


\section{Table 6}

Factor Loadings and Communalities Based on a Principle Components Analysis with Varimax Rotation of the Final Survey $(N=192)$

\begin{tabular}{|c|c|c|c|c|c|c|}
\hline \multicolumn{7}{|c|}{ Rotated Component Matrix } \\
\hline \multirow{2}{*}{ Final 46 items } & $\begin{array}{c}\text { Factor } \\
1 \\
\end{array}$ & $\begin{array}{c}\text { Factor } \\
2 \\
\end{array}$ & $\begin{array}{c}\text { Factor } \\
3 \\
\end{array}$ & $\begin{array}{c}\text { Factor } \\
4 \\
\end{array}$ & $\begin{array}{c}\text { Factor } \\
5 \\
\end{array}$ & \\
\hline & $P$ & $P$ & $P$ & $P$ & $P$ & $h^{2}$ \\
\hline CM1 Class-wide reward system & .83 & -.05 & .15 & .11 & .20 & .77 \\
\hline TA12 Classroom routines & .76 & .11 & .21 & .27 & .19 & .75 \\
\hline CM6 Recognizes positive behavior & .73 & .21 & .05 & .13 & .18 & .64 \\
\hline CM2 Positively reinforcement & .67 & .24 & .21 & -.04 & -.08 & .57 \\
\hline LAS7 Assist in phonemic awareness & .64 & .24 & .10 & .34 & .06 & .60 \\
\hline LAS10 Facilitates sharing of writing & .64 & .25 & .35 & .06 & .17 & .63 \\
\hline TA11 Group routines & .60 & .29 & .07 & .49 & .19 & .73 \\
\hline CM3 Provides corrective actions & .59 & .13 & .08 & .21 & .24 & .48 \\
\hline TA13 Reviews comprehension skills & .59 & .33 & .16 & .33 & .05 & .60 \\
\hline CM4 Students make choices & .57 & .21 & .23 & .18 & .06 & .47 \\
\hline TA10 Group work for accountability & .57 & .20 & .16 & .18 & .20 & .47 \\
\hline LAS8 Use of reading strategies & .52 & .28 & .37 & .09 & .09 & .51 \\
\hline CM5 Provides clear directions & .50 & .37 & .10 & .32 & .12 & .52 \\
\hline $\mathrm{CD} 2$ Opening routine & .33 & .17 & .21 & .28 & .32 & .36 \\
\hline TA8 Students make connections & .17 & .75 & .24 & .17 & .09 & .70 \\
\hline TA7 Student's background & .12 & .75 & .13 & .13 & .19 & .60 \\
\hline TA6 Monitor comprehension & .10 & .75 & .11 & .01 & .25 & .65 \\
\hline CD4 Lesson pacing & .30 & .59 & .05 & .34 & .14 & .58 \\
\hline TA9 Utilizes small groups & .39 & .58 & .22 & .05 & .03 & .55 \\
\hline CD1 Class starts promptly & .06 & .57 & .28 & .38 & .11 & .57 \\
\hline CD7 Summarizing & .38 & .57 & .10 & .26 & .17 & .58 \\
\hline LAS1 Exposures to new words & .253 & .551 & .269 & .105 & .31 & .55 \\
\hline LAS4 Questions for comprehension & .17 & .55 & .25 & .27 & .017 & .473 \\
\hline SD4 Multiple responses & .20 & .54 & .15 & .18 & -.20 & .43 \\
\hline CD8 Assessment & .38 & .53 & .20 & .15 & -.08 & .50 \\
\hline LAS11 Models plan and write & .29 & .13 & .72 & .06 & .08 & .64 \\
\hline
\end{tabular}




$\begin{array}{lllllll}\text { LAS9 Generate ideas for writing } & .39 & .12 & .71 & .12 & .11 & .71 \\ \text { SD5 Opportunities for interaction } & .11 & .39 & .63 & .14 & .04 & .60 \\ \text { LAS12 Assists in writing efforts } & .57 & .26 & .58 & .03 & -.09 & .75 \\ \text { LAS2 Use own words in L2 } & -.17 & .35 & .54 & .43 & .09 & .65 \\ \text { TA4 Spontaneous contributions } & .35 & .36 & .52 & .18 & .07 & .57 \\ \text { CD3 List of tasks } & .22 & .16 & .50 & .32 & .27 & .51 \\ \text { SD3 Wait-and-think time } & .12 & .32 & .46 & .46 & .11 & .56 \\ \text { SD7 Activities for writing in L2 } & .37 & .34 & .12 & .65 & .01 & .69 \\ \text { SD6 Interact in L2 } & .38 & .24 & .05 & .64 & .20 & .66 \\ \text { TA1 Explicit instructions } & .14 & .10 & .38 & .56 & .41 & .66 \\ \text { CD6 Activities pacing } & .22 & .49 & .23 & .55 & -.09 & .66 \\ \text { TA5 Questions and answers } & .29 & .48 & .38 & .48 & .13 & .71 \\ \text { SD2 Responses in L2 } & .31 & .37 & .14 & .45 & .15 & .36 \\ \text { CD5 Transition times } & .26 & .37 & . .03 & .29 & .55 & .60 \\ \text { TA2 Introduce difficult vocabulary } & .19 & .43 & .24 & .23 & .55 & .64 \\ \text { TA3 L2 for communication } & .34 & -.11 & .09 & .37 & .54 & .57 \\ \text { LAS5 Strategies to help decoding } & .35 & .18 & .49 & .10 & .54 & .71 \\ \text { LAS6 Teach phonics' rules } & .48 & .22 & .31 & .04 & .53 & .68 \\ \text { LAS3 Connects spelling to phonics } & .41 & .28 & .37 & -.00 & .45 & .60 \\ \text { SD1 Participation } & .13 & .37 & .21 & .22 & -.41 & .57\end{array}$

Note: $P=$ pattern coefficients: $h^{2}=$ communalistes. Patterns coefficients greater than .40 are bold; they are used for interpretation of the factors.

Based on the analysis, a total of two items were eliminated because they did not contribute to a simple factor structure and failed to meet the minimum criteria of having a structure coefficient of .40 or greater (Stevens, 2002). Items "CD2 Opening routine" had a factor loading of .33 and "SDI Teacher engages students to participate throughout the lesson" had a factor loading of -.41. The results of this analysis indicate most of the items on the survey are a valid measure of the construct of ESL/EFL effective teaching practices.

Overall, the analysis indicated that the first five factors explain $60 \%$ of the variance. It also showed that the factors were often comprised of items from the same 
Domains. Factor 1 has all the "Classroom Management" items; and Factor 2 has a majority of "Classroom Dynamics" and "Teaching Approaches" items indicating a merging of these two domains. Factor 3 has a majority of items related to "Language Arts Strategies"; Factor 4 has the majority of items from the Domain "Student Dynamics"; and Factor 5 has a mix of items from the Domains "Classroom Dynamics" "Teaching Approaches"; and "Language Arts Strategies". Based on the literature review, it becomes apparent that the list of ESL/EFL effective practices could potentially consist of an endless number of teacher behaviors reflecting effective practice. For this reason, Factor 5 was given the name of "Check List," since it was composed of teacher behaviors from different Domains but which analysis indicated were associated with each other. In order to give a better explanation of how the factors related to the underlying construct, the factors have been provided with meaningful names related to the first five proposed Domains. Table 14 describes the five resultant factors with their respective items.

Table 7

Survey with the 5 Factors and their Items

Final Factors and their correspondence items

\section{Factor 1: Classroom Management}

1. Teacher implements a class-wide reward system with rules that are observable and reviews them periodically

2. Teacher shares responsibility for classroom routines with job boards or assignment charts

3. Teacher recognizes positive behavior at the first opportunity after correcting a student's behavior and provides an "escape mechanism" for students who are upset and want to talk about what happened

4. Teacher positively reinforces student behavior and work

5. Teacher uses poetry, big books of rhyme, or songs to assist in phonemic awareness

6. Teacher facilitates the sharing of student writing

7. Teacher has developed routines for students moving to and from centers, 
stations, and literature circles

8. Teacher provides corrective actions to students every time students choose to disrupt

9. Teacher reviews comprehension skills and strategies in small group or literature circles

10. Teacher communicates clearly that students have the power to make choices, yet they need to accept the responsibility that goes with it

11. Group work incorporates individual and group accountability

12. Teacher prompts during the reading of texts to ask questions and monitor students' use of reading strategies

13. Teacher is consistent and provides clear, concise directions that are easy for students to follow

Factor 2: Classroom Dynamics

1. Teacher helps students make connections between the text and personal knowledge and experiences

2. Teacher links concepts to student's background experiences, and makes explicit connections between past learning and new concepts

3. Teacher stops at selected places to emphasize a point, ask a question, do a think-aloud, model a strategy, clarify information, or monitor students' comprehension

4. Teacher paces the lesson appropriately to the students' ability level

5. Teacher utilizes small groups to encourage students to work together to reach a common goal

6. Teacher is organized and starts class promptly

7. Teacher provides a summarizing activity

8. Teacher provides repeated exposures to new words

9. Teacher asks questions to ensure comprehension

10. Teacher accepts multiple responses that students can support in the target language

11. Teacher uses informal assessment to gauge student understanding

Factor 3: Language Arts Strategies

1. Teacher reviews or models how to plan and what to write

2. Teacher helps students generate ideas for writing and allows students to draw pictures through reading to assist in sequencing writing

3. Teacher provides frequent opportunities for interaction in the target language among students

4. Teacher observes students and assists them in their writing efforts

5. Teacher facilitates students' use of their own words in target language

6. Teacher selects and incorporates students' spontaneous unplanned contributions into lesson

7. Teacher posts and refers to list of student tasks

8. Teacher consistently facilitates wait-and-think time for student responses 
Factor 4: Student Dynamics

1. Teacher provides activities in which students are engaged in writing in the target language

2. Teacher aims to encourage the students' desire to use and interact in the target language

3. Teacher provides explicit instructions with the minimal use of L1

4. Teacher paces activities to keep students focused and engaged

5. Teacher models critical thinking questions and answers in a variety of forms

6. Teacher prompts students to give elaborated responses in the target language

Factor 5: Check List

1. Teacher keeps transition times between activities to a minimum

2. Teacher introduces difficult vocabulary prior to and during lesson

3. Teacher mostly uses the target language for communication and talk about culture

4. Teacher connects spelling to phonics and models spelling strategies

5. Teacher enhances and enriches phonics by teaching strategies which help students have alternative methods of decoding words and develop new vocabulary

6. Teacher systematically teaches the most prevalent phonics' rules

\section{RQ 3. Do the items demonstrate internal consistency?}

Internal consistency measures the degree to which a set of items measures a single one-dimensional latent variable (Carmines \& Zeller, 1991). For this study the internal consistency measures were high for 44 of the 46 items of the final survey. Since items cannot be directly linked to the latent variable, conducting a reliability analysis will measure the inter-correlations among them. The higher they are related with each other the stronger the indication that they measure the same latent variable (Choi, Fuqua, \& Newman, 2009). Internal consistency for each of the factors was examined using Cronbach's alpha. The Cronbach's alpha scores are presented in Table 15. 


\section{Table 8}

Reliability Statistics for the 5 Factors with all the Items $(N=192)$

\begin{tabular}{lcccc}
\hline \multicolumn{5}{c}{ Reliability Statistics } \\
& $\begin{array}{c}\text { Cronbach's Alpha } \\
\text { Based on } \\
\text { Standardized Items }\end{array}$ & Mean & Variance & $\begin{array}{c}\text { N of } \\
\text { Items }\end{array}$ \\
Factor 1: Classroom Management & .93 & 1.59 & .06 & 13 \\
Factor 2: Classroom Dynamics & .90 & 1.33 & .01 & 11 \\
Factor 3: Language Arts Strategies & .88 & 1.44 & .01 & 8 \\
Factor 4: Student Dynamics & .87 & 1.40 & .01 & 6 \\
Factor 5: Check List & .82 & 1.64 & .01 & 7 \\
\hline
\end{tabular}

DeVellis (2003) suggests that items with a Cronbach's alpha below .60 do not demonstrate internal consistency; therefore, for this study all five factors showed internal consistency, in that the Cronbach's alpha scores ranged from the lowest $\alpha=.82$ to the highest $\alpha=.93$ (see Appendix H).

\section{RQ 4. Do the items demonstrate stability as a measure of effective ESL//EFL teaching practices?}

Two-week test-retest reliability analyses demonstrated that the scores had a high positive correlation (see Appendix I). Out of the 740 participants contacted to take the survey a second time, 31 responded to the survey again. A test re-test statistical analysis based on Pearson product-moment correlation analysis $(N=31)$ was performed. Results from the test-restest analysis showed that there was a significant positive correlation between scores on the first survey measure and those on the second survey measure ( $r=$ $.98, p=0.01$ ), thereby indicating that the items demonstrated stability as a measure of effective EFL teaching practice over time. 


\section{Summary}

Based on the procedures for establishing content and construct validity, the researcher designed and developed a survey for evaluating items in effective practice for ESL/ EFL teaching. The items from the final survey will be used to develop an observation instrument for providing formative feedback to EFL teachers in Spain. The research first identified the underlying domains and items for the instrument through a review of the literature. Based on the research literature, a survey was developed comprised of items associated with effective practice in ESL/EFL instruction. These items were evaluated for content validity using a panel of experts from the field. The items were also analyzed for construct validity using factor analysis. As part of this process, a final survey instrument was developed and piloted based on experts' feedback. The final instrument was deployed to 740 faculty members in EFL instruction in Spain, of whom 192, or $25 \%$, responded. According to the literature related to factor analysis, the number of responses to the survey was of sufficient size and character for factor analysis. Results of the factor analysis indicated that all of the items were significantly related to effective teaching practices in ESL/EFL instruction and fell into nine factors which differ in some ways from the original five Domains. The theoretical meaningfulness of a five-factor analysis led the conclusion that five Domains explained $60 \%$ of the variance in five factors. Tests for reliability and stability were also run; and, save for a few items on the survey, all have shown to be valid, reliable, and stable measures of effective teaching practices in ESL/EFL. Results of this study indicate that the items can be included on an observation instrument designed for providing formative 
feedback to teachers on their instruction in English as Foreign Language classrooms in Spain. 


\section{CHAPTER V}

\section{CONCLUSIONS AND RECOMMENDATIONS}

\section{Introduction}

According to Ashton and Webb (1986), teachers have the greatest impact on students' achievement. According to Goldhaber (2002), improving teaching is a much better investment than other policy interventions. Furthermore, even though it is widely known that good teaching is important for students' learning, researchers agree that it is difficult to identify and measure (Darling-Hammond, 1999; Goldhaber, 2002; Wenglinsky, 2000). As trained teachers are one of the most important aspects of students' academic success, it has become evident that helping teachers grow professionally is a crucial issue in teacher education (Egelson \& McCoskey, 1998). One of the effective ways for helping teachers to improve their teaching practice is through classroom observation. Through classroom observations, teachers are given the opportunity for improvement by reflecting on their own teaching (Loghram, 2002; Ludy, 1995). Improvement takes place when teachers develop and improve their teaching skills based on their teaching styles and stages. The use of classroom observation instruments in evaluating teacher performance is a widely accepted practice for evaluating instructional effectiveness (Chism, 1999). Observation instruments with good properties provide a framework for educational professionals to assess the effectiveness of teachers' classroom performance and enable them to make the necessary changes to meet accountability standards. 
The evaluation of teaching English as a Foreign Language (EFL) is an emerging field of study in Spain. In recent years, EFL instruction has become a very important part of the curriculum in many Spanish public and private schools. The Spanish government has been encouraging the growth and development of EFL instruction throughout the country, particularly in the early and primary grades (Reichelt, 2006). The overarching purpose of this study was to design and validate a classroom observation instrument that would provide formative feedback for teachers of EFL in Spain. The study proposed that a valid and reliable classroom observation instrument, based on effective practice in teaching ESL/EFL, could be developed and used in Spain to enable teachers to move from where they are in their current teaching performance to an improved level of performance. This study makes a significant contribution toward assisting English teachers in Spain with their professional growth through the development and validation of items for a classroom observation instrument for English as a foreign language instruction. Results of the study indicate that it is possible to create a valid and reliable 44 item observation instrument with four teaching domains and a check list representing effective teaching practice in English as a Foreign Language in Spain which can be used to provide EFL teachers with formative feedback on their instruction and ultimately improve their teaching practice.

In order to demonstrate the significance of the findings resulting from this study to the body of literature on ESL/EFL instruction, this final chapter will briefly review the research literature and discuss findings in relation to the literature review. This chapter will also discuss the limitations inherent to the study and make recommendations for extending and furthering knowledge in this field with future studies. 


\section{Summary of the Research}

The ultimate goal of this study was to develop the observation instrument which will allow administrators, cooperating teachers, and university supervisors to efficiently and effectively guide the development of skill levels and competencies of EFL teachers in Spain. To this end, the purpose of this study was to design, develop, and validate items for an effective, easy-to-use tool based on research in effective practice in ESL/EFL instruction for observation of English teachers in Spain as part of a formative evaluation process. Therefore, this study focused on the development and validation of items related to effective practices for ESL/EFL instruction.

To provide a theoretical context and conceptual framework for the study, the literature review covered the areas of language acquisition theory, language instruction, effective practices for ESL/EFL instruction, classroom observation as a method of teacher improvement, and classroom observation instruments used in evaluating teaching in ESL/EFL classrooms. The literature review discussed some of the observation instruments developed for observing ESL instruction in the United States such as the ELCOI, SIOP, and TBOP. All of these instruments have shown to be valid tools for researchers in studying effective classroom practice in ESL instruction. However, these instruments were limited in their usefulness for schools in providing support for teachers because they were very long and complicated observation instruments designed for

research rather than practical purposes (Gersten \& Baker, 2003; Graves, Gestern, \& Heager, 2004; Lara-Alecio, Tong, Irby, \& Mathes, 2007; Short \& Echevarria, 1999).

The development of a practical and easy-to-use classroom observation instrument comprised of items that have been validated for effective EFL practice in Spain, such as 
the one which will be developed based on results of this study, makes a clear contribution to the field of ESL/EFL instruction. The field of education in Spain is currently in a very developmental phase in their use of classroom observations to improve instruction, particularly in the field of EFL. According to personal communication with Dr. Muñoz (July 7, 2010), it will be extremely valuable to have a tool that administrators, supervisors, and even cooperating teachers can utilize to support teacher improvement and effective teaching strategies in EFL instruction.

\section{Discussion of Findings}

\section{Research Question One (RQ1)}

The first research question (RQ1) addressed the content validity of items in the initial survey as demonstrated by the judgment of experts in the field of ESL/EFL instruction.

A panel of experts was invited to review the initial survey comprised of behavior statements representing 111 effective ESL/EFL teaching practices. Thirteen experts participated in the study and made several suggestions to eliminate or to modify items for different reasons. From the 111 items proposed, it was apparent that some items were unclear, overlapped, or were not applicable for students from lower grades. Based on the experts' suggestions, the survey was narrowed to 46 instructional and behavior management teacher behaviors which described all the features of the construct of this study (Carmines \& Zeller, 1991).

As part of the content validation process, the researcher met with experts in Spain who informed her of the importance of her research to national initiatives in English language instruction. According to this group of experts, Spain is in a very important 
phase with regard to EFL instruction since English has become the predominant language for the European Community. Currently, Spain is considered the last on the list of European countries with an acceptable proficiency level on the English language (Criado \& Sanchez, 2009). Every single Autonomous Community in Spain has developed different initiatives and programs where schools can find support and help for getting their students to accomplish an acceptable proficiency level on the English language. Universities in Spain have become more involved in several projects for classroom observations as part of educational proposals from the European community.

When meeting with the experts from Spain, the researcher found that there was a special interest in performing studies using classroom observation methods and observational tools. They indicated that having an objective, easy-to-use observation instrument, such as one that will be developed as a result of this study, will allow users to gather important research information on EFL instruction, as well as providing teachers with valuable formative feedback. Showing evidence of content validity was a very important part of this process.

\section{Research Question Two (RQ2)}

The second research question (RQ2) sought to determine whether the items demonstrated construct validity. Construct validity defines how well the items in a given measure fully describe a particular construct. In this case, construct validity concerns the degree to which participants agreed that the items on the survey measure effective ESL/EFL teaching practices (Carmines \& Zeller, 1991). For this study a survey was sent to 740 EFL faculty members of Spanish universities, to which 192 EFL faculty members responded. Results showed that scores from nearly all items aligned with theoretically 
and empirically derived domains of effective practice in EFL instruction. Some differences in empirically derived domains occurred as a result of extraction procedures, although the differences observed still provided theoretically interpretable constructs. Results of the factor analysis indicated that all of the items were strongly related to the construct of effective practice in ESL/EFL; and, also, the majority of them were related to the different underlying original domains identified in the literature of Classroom Dynamics (CD), Student Dynamics (SD), Teaching Approaches (TA), Language Arts Strategies (LAS), and Classroom Management (CM) (Flood, 2003; Kember \& Kwan, 2000; Morris \& Tarone, 2003; Watts-Taffes \& Truscott, 2000; Weinstein, TomlinsonClarke, \& Curran, 2004).

Based on the analysis of results, initially a total of nine factors were identified as being responsible for a majority of the variance, indicating that there were additional or different underlying domains in ESL/EFL instruction other than the five original domains (Flood, 2003; Kember \& Kwan, 2000; Morris \& Tarone, 2003; Watts-Taffes \& Truscott, 2000; Weinstein, Tomlinson-Clarke, \& Curran, 2004). A second five-factor analysis was conducted, and results from this second analysis were consistent with the existing literature in four of the five proposed domains. The Domains "Classroom Dynamics" and "Teaching Approaches" merged into one and was labeled "Classroom Dynamics" (Morris \& Tarone, 2003). Based on the literature review and the experts' suggestions during the content validation process, the domain "Check List" was designated for factor 5 and contains a variety of teacher behaviors which the analysis indicates are interrelated. Lists of teacher behaviors are many and varied, so the panel of experts suggested that, when conducting classroom observations, it would be important for the observers 
not only to have the observation instrument, but also a check list containing a variety of teacher behaviors to support the items in the observation instrument. This Check List factor included the following items:

1. Teacher keeps transition times between activities to a minimum

2. Teacher introduces difficult vocabulary prior to and during lesson

3. Teacher mostly uses the target language for communication and talk about culture

4. Teacher connects spelling to phonics and models spelling strategies

5. Teacher enhances and enriches phonics by teaching strategies which help students have alternative methods of decoding words and develop new vocabulary

6. Teacher systematically teaches the most prevalent phonics

The resulting 44 items and 5 domains which emerged from the study will comprise the formal classroom observation instrument. Based on results of the study, these items are aligned with items found on observation instruments used to observe ESL instruction in the United States such as the SIOP, TBOP, and the ELCOI as well as theoretically and empirically derived domains of effective teaching practice. The items, therefore, have demonstrated construct validity and furthers the overarching goal of the study to create a practical and easy-to-use observation instrument for improving teacher practice in EFL instruction in Spain.

\section{Research Question Three (RQ3)}

The third question (RQ3) examined the internal consistency among all items in the survey. Results of the analysis indicated the items do possess internal consistency 
based on the Cronbach's alpha analysis for all the five factors. In this analysis none of the factors had Cronbach's alpha scores of below .60 and ranged from the lowest $\alpha=.82$ to the highest $\alpha=.93$. According to DeVellis (2003), items with these characteristics all demonstrated internal consistency, and the five factors emerging from result of factor analysis were valid.

Because internal consistency was verified by the Cronbach alpha, the items possessed strong inter-relationships, meaning that the items are also correlated to the main construct of effective ESL/EFL teaching practices. This finding contributes to the research literature, in that although the items have been validated as representative of effective ESL practice in the United States, until now they had not been validated as representative of effective ESL/EFL practice in Spain. Because the items included in this study were drawn from instruments used in observing ESL teaching practice in the United States, the results of the current study will now allow researchers in ESL/EFL instruction in Spain to incorporate the use of observation instruments such as the SIOP, TBOP, and ELCOI developed in the United States and the instrument developed as a result of this study in research studies on ESL/EFL instruction in Spain.

\section{Research Question Four (RQ4)}

The last research question of this study (RQ4) looked to find whether the items of the survey demonstrated stability as a measure of effective ESL/EFL teaching practices. As a result of this, all items showed stability, meaning that the participants' ratings agreed in both the initial survey and the second one and that the 46 items were validated in both occasions. Based on the test-retest procedure using Pearson's product-moment correlation statistics, it appears that the items are a stable measure of effective ESL/EFL 
teaching practices. Over a two-week test and retest on reliability, the scores demonstrated a significant positive correlation $(r=.98, p=0.01)$.

These results provide evidence that the final instrument designed to measure effective ESL/EFL teaching practices will be one that can be used different times but assured that the meaning of the items will be stable from one observation event to another.

\section{Limitations}

As with most survey research, there are limitations to the conclusions that can be drawn based on the real-life conditions that are part of every research study. As noted by Couper and Nichols (1998), many of the principles of survey research are not fully met under real-life conditions:

Precise population definitions, exhaustive sampling frames, full probability sampling methods, thoroughly pretested questionnaires, and fully-successful field operations are not always attainable. A variety of survey errors result from applying these principles in practice. These include coverage errors, sampling errors, non-response errors, and measurement errors, some reflecting errors associated with the mode of administration. (p. 3)

In particular, a factor affecting computerized survey response is the dependence on the reliability of automatic mailing lists available to reach the population of interest, in other words, the making of contacts by email only. Even if an email is sent to the entire population comprising the mailing list, several issues ranging from users' accounts that have been removed from the list to users' emails being over quota, the number of recipients can be dramatically reduced after the server's first attempt to deliver the message.

In this study, 192 members of the target population responded to the survey for a response rate of $25 \%$. The response rate could be the result of the time difference between Spain and the United States, user error, or technological problems. 
In the construct validation process, the sample size was obtained from the database of foreign language departments in Spanish universities belonging to the ANECA. This excluded the population of teachers in the school year Pre-K, K, first grade, and second grade, which may bias the results of the study.

The study's participant sample was selected from the accessible population representing the EFL faculty members from universities in Spain. Although, according to Stevens (2002), the size of the sample was sufficient for a factor analysis, it may not be representative of the target population. Therefore, results may be biased toward a particular subgroup of the population.

\section{Conclusions}

Given the educational environment in Spain, in which a multiplicity of instructional strategies are used for teaching English as a foreign language, the results of this study will provide an important tool for improving English language instruction in the country. The literature review conducted for this study has documented the need for supporting EFL teachers in their professional growth, not only by the private and public schools in Spain but also by the Spanish Government. The observational instrument which will be developed as a result of this study will be an important means for supporting EFL instruction initiatives in Spain. In considering the conclusions that can be reached as a result of this study, it is clear that the findings have potential value in several areas. These areas for consideration include the following:

1. The information can be used to further research in EFL instruction - Research on instruction in ESL/EFL in the United States which has been an important part of this study will be useful in studying EFL in Spain. This finding will 
widen the universe of research that can be conducted and shared among researchers in Spain and the United States and has the potential to expand the conclusions that can be drawn to a wider population of language learners. The observation tools that will be created as part of this study can be used in both Spain and the United States to provide ESL/EFL teachers with formative feedback on their instructional practice.

2. The study provided evidence that classroom observations are an important strategy for teacher professional growth and additional professional development - Although there are limits to the use of classroom observation methodologies based on the subjective nature of the enterprise, this study has captured the interest of EFL researchers and scholars in Spain who see the importance of having valid and reliable items which can be used in tools to observe EFL teaching in Spain and improve their teachers' professional practice.

3. This study also provided evidence supporting the need for developing an observational instrument to be used in Spain - Again, although there are limits to the use of classroom observation methodologies and tools, the study established the methods and procedures which can be used to validate observation instruments which can be used in Spain to improve teachers' professional growth.

By far, the most significant conclusion that can be reached as part of this study is that, although multiple teaching methods are used in EFL instruction in Spain and currently no objective and reliable instrument has been developed to observe, assess, or 
evaluate the extent to which effective classroom instructional practices are being used, a valid and reliable tool for observing classroom ESL/EFL instruction can be developed. This study provided the evidence that the items related to effective practice in ESL/EFL instruction have content and construct validity and reliability based on expert review, factor and co-relational analyses, and test-retest procedures and can be incorporated into an observation instrument that can be a valid and reliable measure of ESL/EFL instruction in Spain.

\section{Recommendations for Future Research}

Based on the results of the study, the researcher may have confidence that items to be included in an observation instrument will be valid and reliable measures of effective EFL instruction. The observation instrument to be designed will be intended for use by cooperating teachers, professional observers, evaluators, or supervisors when student teachers or professional teachers are engaged in EFL instruction.

It is recommended that the next step for realizing and achieving this goal should be to field-test the instrument in real-life classroom settings in order to establish interrater reliability. Inter-rater reliability or inter-observer reliability is defined as the extent to which two or more individuals agree on a specific observed behavior (Fink, 1995). This step is an important one due to the fact that when observing the same event such as EFL instruction, observers may not agree on what they are observing, and errors of human perception are likely. The process of establishing inter-rater reliability helps to mitigate these types of errors.

As an outgrowth of the previous recommendations to improve the validity and reliability of the observation instrument by establishing inter-rater reliability, it is also 
recommended that users of this instrument participate in a course for training observers on the use of the instrument. Training of the observers will consist of providing a clear explanation of the items contained in each domain and concrete examples of those teacher behaviors in the classroom. As part of developing a training course, it will be important to conduct a pilot training or in-service workshop for the observers or supervisors of ESL/EFL teachers. This type of in-service workshop would also lend itself to an additional research study, such as in the design of the workshop itself to establish the most effective length of time for the workshop, the types of observer participants (i.e., cooperating teachers, supervisors, administrators, faculties, etc.) to be trained and most effective format for delivering information to the participants. The collection and analysis of the results from a pilot workshop would provide important data for developing future training courses for using the instrument.

A final recommendation for further research is to conduct a longitudinal study of EFL teachers in Spain who have been evaluated and provided formative feedback using the classroom observation instrument developed as part of this study. This type of study would observe the same teachers over a period of time and acquire data effectiveness of the observation instrument and formative evaluation in impacting teacher improvement over time. As formative evaluation is an effective method for nourishing the professional growth and development of teachers at all levels by helping them to clarify performance targets, develop skills and abilities, evaluate progress, and build on their strengths, an important recommendation would be to conduct at least two types of longitudinal studies: one for pre-service teachers in Spain who are in student teaching programs in Spanish universities, and another for practicing EFL teachers in Spain as part of their professional 
development. Regression analysis should be a part of these studies because it cannot be assumed that other factors such as a teacher's years of experience with children, advanced education, or collegial relationships are directly related to the teacher's developmental stage (Stronge, 1997). Data from longitudinal studies and regression analysis will allow researchers to identify factors that may influence a teacher's ability to acquire effective classroom instructional and behavior management skills and may lead to valuable insights related to improving the quality of instruction provided by EFL teachers in Spain.

As use of classroom observation and observation instruments to improve teacher performance in Spain are in their early stages of development, recommendations for future areas of research and activities related to improving EFL instruction in Spain are essential. Observation in training teachers at the pre-service level is as common in Spain as it is in the United States, but the quality of teachers' learning experiences in the field after they leave their university training remains a major concern. This is particularly true as educators face ongoing pressure to improve student outcomes, especially with regard to academic achievement and social behavior (Zeichener \& Wray, 2001). One viable strategy for supporting and improving instructional practices is to conduct classroom observations and provide formative feedback on teachers' performance (Colvin, Flannery, Sugai, \& Monegan, 2008). This study furthers the goal of improving EFL instruction in Spain by developing and validating items for a practical, easy-to-use classroom observation instrument for providing teachers with formative evaluative feedback on the effectiveness of their instruction. 


\section{REFERENCES}

Aherm, A. K., García Bermejo, L. M., \& Fleta, T. (2008). Holistic learning through stories: children's literature in the EFL classroom. Paper presented at the International Conference - ELT in Primary Education. Retrieved from http://www.fedu.uniba.sk/fileadmin/user_upload/editors/KAJLHromnikova/publikacie/Zbornik_Conference_ELT_in_Primary_Education.pdf\#p age $=98$.

Almarza, G. G. (2000). Modelos de formación para los profesores de lenguas extranjeras en enseñanza primaria: Las experiencias española y británica. Aula, 12, 35-42.

Alonso, A. (2006). La competencia intercultural en la enseñanza del inglés dentro del contexto turístico. Encuentro, 16, 17-26.

Al-Shammari, Z., Al-Sharoufi, H., \& Yawkey, T. (2009). The effectiveness of direct instruction in teaching English in elementary public education schools in Kuwait: A research case study. Education, 129(1), 80-90.

Ambach, G. (1996). Standards for teachers' potential for improving practice. Phi Delta Kappan, 78(3), 207-210.

Anderson, N. A., Barksdale, M.A., \& Hite, C. (2005). Pre-service teachers' observations of cooperating teachers and peers while participating in an early field experience. Teacher Education Quarterly, 32(4), 97-117.

Anthony, E. M. (1963). Approach, method, and technique. ELT Journal, 17(2), 63-67.

Aragonés, J. (2002). La utilización de Internet en idiomas. Educar en red: Internet como recurso para la educación, Capitulo XV, 289-306.

Armstrong, T. (1994). "Multiple intelligences in the classroom," Educational Leadership, $52(3), 26-28$.

Asher, J. (1977a). Children learning another language: A developmental hypothesis. Child Development, 48, 1040-1048.

Asher, J. (1977b). Total physical response. New York, NY: John Wiley \& Sons.

Asher, J. (2003). Learning another language through actions: The complete teacher's guidebook. Los Gatos, CA: Sky Oak. 
Ashton, P. T., \& Webb, R.B. (1986). Making a difference: Teachers' sense of efficacy and student achievement. Westport, CT: Longman.

Bacin, L. P., \& Pla, L. (1989). Enseñar y aprender inglés: Bases psicopedagógicas. Barcelona, Spain: Horsori.

Baker, K. (1998). Structured English Immersion: Breakthrough in teaching limitedEnglish-proficient students. Phi Delta Kappan, 80(3), 199-200.

Baker, S., Gersten, R., Haager, D., Dingle, M., \& Goldenberg, C. (2004). The relationship between observed teaching practice and growth in reading in 1 st graders who are English learners. (Technical Report 2004-1). Eugene, OR: Pacific Institutes for Research.

Baumann, J. F., Kame'enui, E.J., \& Ash, G.E. (2003). Research on vocabulary instruction: Voltaire redux. Handbook of research on teaching the English language arts, (2), $752-785$.

Beck, I. L., Perfetti, C. A., \& McKeown, M.G. (1982). Effects of long-term vocabulary instruction on lexical access and reading comprehension. Journal of Educational Psychology, 74(4), 506-521.

Beck, I. L. \& Juel, C. (1995). The role of decoding in learning to read. American Educator, 19(2), 8.

Beck, I.L. \& McKeown, M.G. (2001). Text talk: Capturing the benefits of read-aloud experiences for young children. The Reading Teacher, 55(1), 10-20.

Berg, E. C., Hult, F. M., \& King, K.A. (2001). Shaping the climate for language shift? English in Sweden's elite domains. World English, 20(3), 305-319.

Bernaus, M., \& Gardner, R. C. (2008). Teacher motivation strategies, student perceptions, student motivation, and English achievement. The Modern Language Journal, 9(2), 387-401.

Biggs, J. (1987). Student Approaches to Learning and Studying. Research Monograph. Hawthorn, Australia: Australian Council for Educational Research.

Billett, S. (2001). Learning in the workplace: Strategies for effective practice. New York, NY: Allen \& Bacon.

Bitner, T., \& Kratzner, R. (1995). A primer on building teacher evaluation instruments. Paper presented at the Annual Meeting of the Midwest Educational Research Association. Retrieved from http://eric.ed.gov/PDFS/ED394953.pdf. 
Bluford, V. \& Dillon Jr., C. H. (1995). Working with foreign languages, with older people, or outdoors. Occupational Outlook Quarterly, 38(4), 24-35.

Broca-Fernández, A., \& Escobar-Montero, M. (2001). Fundamentos para la elaboración del programa de inglés en turismo. Servicio de publicaciones Dialnet. Lenguas para fines específicos, 7, 207-216.

Brown, H. D. (2001). Principles of language learning and teaching (3rd ed.) Englewood Cliffs, NJ: Prentice-Hall.

Brown, H. D. (2007). Principles of language learning and teaching (5th ed.) White Plains, NY: Pearson Longman.

Burke, M. D., Hagan-Burke, Kwok, O., \& Parker, R. J. (2009). Predictive validity of early literacy indicators from the middle of kindergarten to second grade. Special Education, 42(4), 209-226.

Byra, M. (1992). Measuring qualitative aspects of teaching in physical education. Journal of Physical Education, Recreation, and Dance, 63, 83-89.

Canter, L., \& Canter, M., (1976). Assertive discipline: A take charge approach for today's educator. Seal Beach, CA: Canter and Associates.

Canter, L. \& Canter, M. (2001). Assertive discipline: Positive behavior management for today's classroom. Seal Beach, CA: Canter and Associates.

Canter, L., Canter, M., Thompson, J., \& Canter and Associates. (1993) Assertive discipline. Santa Monica, CA: Canter and Associates.

Carmines, E. G., \& Zeller, R. A. (1991). Reliability and viability assessment. Thousand Oaks, CA: Sage.

Carter \& Anders (1996). Program pedagogy. The teacher educator's handbook: Building a knowledge base for the preparation of teachers. 557-592.

Cary, S. (1997). Second language learners. Portland, ME: Stenhouse.

Cashin, W. E. (1996). Developing an effective faculty evaluation system. IDEA Paper No. 33, Kansas State University. Center for Faculty Evaluation and Development. Retrieved from http://eric.ed.gov/PDFS/ED395536.pdf.

Celce-Murcia, M. (2001) Teaching English as a second or foreign language (3rd ed.). Boston, MA: Heinle \& Heinle.

Cerezo, L. (2007). Investigación sobre las directrices curriculares relativas a la enseñanza de la lengua inglesa y su aplicación en el aula $\left(1^{\circ}\right.$ de bachillerato). (Doctoral dissertation). Retrieved form http://digitum.um.es/jspui/handle/10201/3043. 
Chamot, A. U., \& O'Malley, J. M. (1987). The cognitive academic language learning approach: A bridge to the mainstream. TESOL quarterly, 21(2), 227-249.

Chism, N. V. N. (1999). Peer review of teaching: A sourcebook. Boston, MA: Anker.

Choi, N., Fuqua, D. R., \& Newman, J. L. (2009). Exploratory and confirmatory studies of the structure of the Bem Sex Role Inventory short form with tow divergent samples. Educational and Psychological Measurement, 69(4), 696-705.

Cirino, P., Pollard-Durodola, S., Foorman, B., Carlson, C., \& Francis, D. (2007). Teacher characteristics, classroom instruction, and student literacy and language outcomes in bilingual kindergartners. The Elementary School Journal, 107(4), 341-364.

Colvin, G., Flannery, B., Sugai, G., \& Monegan, J. (2008). Using observational data to provide performance feedback to teachers: A high school case study. Preventing School Failure, 53(2), 95-104.

Cooper, J. D. (1993). Literacy: Helping children construct meaning. Burlington, MA: Houghton Mifflin.

Council of Europe. (2001). Common European Framework of Reference for Language: Learning, teaching, assessment. Cambridge, MA: Cambridge University Press.

Couper, M. P., \& Nichols, W. L. (1998). The history and development of computer assisted survey information collection methods. In M. P. Couper, R. P. Baker, J. Bethlehem, C. Z. E. Clark, J. Martin, W. L. Nichols, \& J. M. O'Reilly (Eds.), Computer Assisted Survey Information Collection (pp. 1-22). New York, NY: John Wiley \& Sons.

Crandall, J. A. (2008). Content-centered learning in the US. Annual Review of Applied Linguistics, 13, 110-126.

Creswell, J. W. (2003). Research design: Qualitative, quantitative, and mixed methods approach (2nd ed.). Thousand Oaks, CA: Sage

Criado, R., \& Sanchez, A. (2009). English language teaching in Spain: Do textbooks comply with the official methodological regulations? A sample analysis. International Journal of English Studies, 9(1), 1-28.

Crocker, L., \& Algina, J. (1987). Introduction to classical and modern test theory. New York, NY: Holt, Rinehart and Winston.

Curran, C. A. (1976). Counseling-learning in second language learning. East Dubuque, IL: Counseling Learning Education. 
Dalton, S. (1998). Pedagogy matters: Standards for effective teaching practice. Santa Cruz, CA: Center for Research on Education, Diversity and Excellence (CREDE).

Danielson, C., \& McGreal, T. L (2000). Teacher evaluation to enhance professional practice. Alexandria, VA: ASCD.

Darling-Hammond, L., Wise, A. E., \& Pease, S.R. (1983). Teacher evaluation in the organizational context: A review of the literature. Review of educational research, 53(3), 285-328.

Darling-Hammond, L. (1993). Reframing the school reform agenda: Developing capacity for school transformation. Phi Delta Kappan, 74(10), 753-761.

Darling-Hammond, L., \& McLaughlin, M. W. (1995). Policies that support professional development in an era of reform. Phi Delta Kappan, 76(8), 597-604.

Darling-Hammond, L. et al. (1996). What matters most: Teaching for America's future. New York, NY: National Commission on Teaching and America's Future.

Darling-Hammond, L. (1998). Standards for assessing teacher effectiveness are key: A response to Schalock, Schalock, \& Myton. Phi Delta Kappan, 79, 417-472.

Darling-Hammond, L. (1999). Teacher quality and student achievement: A review of state policy evidence. Seattle, WA: Center for the Study of Teaching and Policy.

Darling-Hammond, L. (2000). How teacher education matters. Journal of Teacher Education, 51(3), 166-173.

Darling-Hammond, L., \& Snyder, J. (2000). Authentic assessment of teaching in context. Teaching and Teacher Education, 16(5-6), 523-545.

de las Comunidades Europeas, D. O. (1990) Reglamento CEE No. 2676/90 de la Comisión 17 de Septiembre de 1990. Brusselles, Belgium: Comunidad Económica Europea.

DeVellis, R. F. (2003). Scale development: Theory and applications (2nd ed.). Thousand Oaks, CA: Sage.

Díaz, C. G. (2004). Lengua y cultura para la comunicación en lengua extranjera. Habilidades comunicativas en las lenguas extranjeras, Instituto Superior de Promoción del Profesorado, Gobierno de España, 89-114.

Dillman, D. A. (2007). Mail and internet surveys: The tailored designed method. Hoboken, NJ: John Wiley \& Sons.

Dillman, D. A., Smyth, J. D., \& Christian, L. M. (2009). Internet, mail, and mixed-mode surveys: The tailored design method (3rd ed.). Hoboken, NJ: John Wiley \& Sons. 
Dörnyei, Z. (2001). New themes and approaches in second language motivation research. Annual Review of Applied Linguistics, 21, 43-59.

Duke, N. K., \& Pearson, P. D. (2002). Effective practices for developing reading comprehension. What research has to say about reading instruction, 3, 205-242.

Echevarria, J., Short, D., \& Powers, K. (2006). School reform and standards-based education: A model for English-language learners. The Journal of Educational, 99(4), 195-211.

Echevarria, J. \& Graves, A. (2003). Sheltered content instruction: Teaching Englishlanguage learners with diverse abilities. Boston, MA: Allyn and Bacon.

Echevarria, J. \& Graves, A. (2011). Sheltered content instruction: Teaching Englishlanguage learners with diverse abilities (4th ed.). Boston, MA: Pearson.

Egelson, P., \& McColskey, W. (1998). Teacher evaluation: The road to excellence. Tallahassee, FL: SERVE.

Ellett, C. D. (2000). Professional assessment and comprehensive evaluation system (PACES): Teaching and learning professional growth manual. Watkinsville, GA: CDE Research Associates.

Ellett, C. D., Annunziata, J., \& Schiavone, S. (2002). Web-based support for teacher evaluation and professional growth: The professional assessment and comprehensive evaluation system (PACES). Journal of Personnel Evaluation in Education, 16(1), 63-74.

Ellett, C. D., Loup, K.S., \& Chauvin, S. W. (1989). System for Teaching and Learning Assessment and Review (STAR): Annotated Guide to Teaching and Learning. Baton Rouge, LA: Louisiana Teaching Internship and Teacher Evaluation Projects.

Ellett, C. D., \& Capie, W. (1985). Assessing meritorious teacher performance: A differential validity study. Paper presented at the Annual Meeting of the American Educational Research Association, Chicago, IL, March 31-April 4, 1985.

Ellett, C. D, \& Teddlie, C. (2003). Teacher evaluation, teacher effectiveness and school effectiveness: perspectives from USA. Journal of Personnel Evaluation in Education, 17(1), 101-128.

Ellis, N. (2003). Constructions, chunking, and connectionism. The emergence of second language structure. In C. Doughty \& M. Long (Eds). The handbook of second language acquisition, 63-103. 
Ellis, R. (2005). Instructed language learning and task-based teaching. In E. Hinkel, Handbook of research in second language teaching and learning. (pp. 713-728). Mahwah, NJ: Lawrence Erlbaum Associates.

Eurobarómetro, E. S. (2007). European social reality report, $N^{\circ} 273$, Luxembourg, Lux: TNS Opinion \& Social

Everhart, B., \& Vaugh, M. (2005). A comparison of teaching patterns of student teachers and experienced teachers in three distinct settings: Implications for preparing teachers for all settings. Education, 126(2), 221-239.

Fink, A. (1995). How to measure survey reliability and validity (7th ed.). Thousand Oaks, CA: Sage.

Finocchiaro, M., \& Brumfit, C. (1983). The Functional-Notional Approach. New York, NY: Oxford University Press.

Flood, J. (2003). Handbook of research on teaching the English language arts. International Reading Association, National Council of Teachers of English. Mahwah, NJ: Lawrence Erlbaum.

Fotos, S. (2005). Traditional and grammar translation methods for second language teaching. In E. Hinkel, Handbook of research in second language teaching and learning. (pp. 653-670). Mahwah, NJ: Lawrence Erlbaum Associates.

Fountas, I. C., \& Pinnell, G. S. (2001). Guiding readers and writers, grades 3-6: Teaching comprehension, genre, and content literacy. Westport, CT: Heinemann.

Fraser, B., \& Walberg, H. (1995). Improving Science Education. Chicago, IL: National Society for the Study of Education.

Francis, D. J., Rivera, M., Lesaux, N., Kieffer, M., \& Rivera, H. (2006). Practical guidelines for the education of English language learners: Research-based recommendations for instruction and academic interventions. Portsmouth, $\mathrm{NH}$ : RMC Research Corporation, Center on Instruction.

Freeman, D. E., \& Freeman, Y. S. (2004). Essential linguistics: What you need to know to teach reading, ESL, spelling, phonics, and grammar. New York, NY: Heinemann.

Freeman, Y.S., Mercuri, S., \& Freeman, D.E. (2001). Keys to success for bilingual students with limited formal schooling. Bilingual Research Journal, 25(1/2), 203 214.

Freeman, Y. S., \& Freeman, D. E. (1998). ESL/EFL teaching: Principles for success. Portsmouth, NH: Heinemann. 
Freeman, Y. S., \& Freeman, D. E. (2009). ESL/EFL teaching: Principles for success. TESL-EJ, 14(2).

Freeman, Y. S., \& Freeman, D. E. (2010). ESL/EFL teaching: Principles for success. TESL-EJ, 4(1).

Freiberg, H. J., \& Waxman, H. C (1988). Alternative feedback approaches for improving student teachers' classroom instruction. Journal of Teacher Education, 39(4), 8.

Gage, N. L. (1963). Paradigms for research on teaching. In N.L. Gage (Ed), Handbook of research on teaching, 65(1), 97-97.

Gallagher, P. A. (2002). Teaching students with behavior disorders: Techniques and activities for classroom instruction (3rd ed.). Denver, CO: Love Publishing.

Gardner, R. C. (1985). Social psychology and second language learning: The role of attitudes and motivation. Baltimore, MD: E. Arnold.

Gattegno, C. (1976). The common sense of teaching foreign languages. New York, NY: Educational Solutions.

George, J. W., \& Cowan, J. (2004). A handbook of techniques for formative evaluation: Mapping the student's learning experience. London, UK: Routledge Falmer.

Gersten, R. (1984). Follow through revisited: Reflections on the site variability issue. Educational Evaluation and Policy Analysis, 6(4), 411-423.

Gersten, R., \& Baker, S. (2003). English-language learners with learning disabilities. In H. L. Swamson, K. R. Harris, \& S. Graham (Eds.), Handbook of learning disabilities (pp. 94-109). New York, NY: Guilford.

Gibbons, P. (2002). Scaffolding language, scaffolding learning: Teaching second language learners in the mainstream classroom. Westport, CT: Heinemann.

Gibbons, P. (2003). Mediating language learning: Teacher interactions with ESL students in a content-based classroom. TESOL Quarterly, 37 (2), 247-273.

Glickman, C. D. (1981). Developmental supervision: Alternative practices for helping teachers improve instruction. Alexandria, VA: ASCD.

Glickman, C. D. (1990). Supervision of instruction: A developmental approach (2nd ed.). Boston, MA: Allyn and Bacon.

Glickman, C. D., \& Bey, T. (1990). Supervision. In W.R. Houston (Ed.), Handbook of research on teacher education. New York, NY: Macmillan, 549-566.

Glickman, C. D., \& Gordon, S. P. (1987). Clarifying developmental supervision. Educational Leadership, 44(8), 64-68. 
Goldhaber, D. (2002). The mystery of good teaching. Education Next, 2(1), 50-55.

Graddol, D. (1997). The future of English? A guide to forecasting the popularity of the English language in the 21st century. London, United Kingdom: British Council.

Graves, A. W., Gersten, R., \& Haager, D. (2004). Literacy instruction in multiplelanguage first-grade classrooms: Linking student outcomes to observed instructional practice. Learning Disabilities Research \& Practice, 19(4), 262-272.

Griffee, D. T. (2005). Research tips: Classroom observation data collection, Part II. J Dev Education, 29(2), 36-39.

Guskey, T. R. (2000). Evaluating professional development. Thousand Oaks, CA: Corwin Press.

Guyton, E., \& McIntyre, D. J. (1990). Student teaching and school experiences. Handbook of research on teacher education, 1, 514-534.

Haefele, D. L. (1993). Evaluating teachers: A call for change. Journal of Personnel Evaluation in Education, 7(1), 21-31.

Hansen-Thomas, H. (2008). Sheltered instruction: Best practices for ELLs in the mainstream. Kappa Delta Pi Record, 44(4), 165 -169.

Hawkins, M. (2004). Researching English language and literacy development in schools. Educational Researcher, 33(3), 14-25.

Haycock, K., \& Jerald, C. (2001). Closing the achievement gap. Educational Leadership, $58(6), 6-11$.

Hinrichsen, J., \& Thaler, E. (2003). The Process in developing a model for field placement experiences for preservice teacher education students integrating technology in their instruction. In C. Crawford et al. (Eds.), Proceedings of Society for Information Technology \& Teacher Education International Conference 2003 (2229-2230). Chesapeake, VA: AACE

Hitchcock, G., \& Hughes, D. (1995).Research and the teacher: A qualitative introduction to school-based research (2nd ed.). New York, NY: Routledge.

House, J. (1996). Developing pragmatic fluency in English as a foreign language:

Routines and metapragmatic awareness. Studies in Second Language Acquisition, I8(2), 225 - 252.

Huck, S. W. (2004). Reading statistics and research (4th ed.). Boston, MA: Pearson. 
Hughes, S. P. (2007). The identification of quality indicators in English language teaching: A study in compulsory secondary level a non-compulsory secondary level language education in the province of Granada. (Doctoral Dissertation). Retrieved from http:/digibug.ugr.es/bitstream/10481/1701/1/1711701x.pdf.

Hunter, M., \& Russell, D. (1995). Mastering coaching and supervision. Thousand Oaks, CA: Corwin.

Hyrkstedt, I., \& Kalaja, P. (1998). Attitudes toward English and its functions in Finland: A discourse-analytic study. World English, 17(3), 345-357.

Jones, V. F., \& Jones, L. S. (1986). Comprehensive classroom management: Creating positive learning environments (2nd Ed.). Newton, MA: Allyn and Bacon.

Kagan, S. (1995). We can talk: Cooperative learning in the elementary ESL classroom. Washington, DC: ERIC Digest.

Kember, D., \& Kwan, K. P. (2000). Lecturers' approaches to teaching and their relationship to conceptions of good teaching. Instructional Science, 28(5), 469 490 .

Kennedy, M. M. (1999). Approximations to indicators of student outcomes. Educational Evaluation and Policy Analysis, 21(4), 345.

Kindelán-Echevarría, M. P., (2007). The learning of genre. Estudios Ingleses de la Universidad Complutense, 15, 61-77.

Krashen, S. D. (1981). Second language acquisition and second language learning. Oxford, MA: Oxford University Press.

Krashen, S. D. (1984). Principles and practice in second language acquisition. New York, NY: Pergamon.

Krashen, S. D. (2003). Explorations in language acquisition and use. Portsmouth, NH: Heinemann.

Krashen, S. D., \& Terrell, T.D. (1983). The natural approach: Language acquisition in the classroom. Oxford, MA: Pergamon.

Krol, K., Veenman, S., \& Voeten, M., (2002). Toward a more cooperative classroom: Observations of teachers' instructional behaviors. Journal of Classroom Interaction, 37(2), 37-46.

Labrie, N., \& Quell, C. (1997). Your language, my language or English? The potential language choice in communication among nationals of the European Union. World English, 16(1), 3-26. 
Language Consultants International. (2009). Best practices in ESL teaching. Retrieved from http://www.englishlci.com/blog/best-practices-in-esl-teaching.

Lara-Alecio, R., Tong, F., Irby, B., \& Mathes, P. (2007). Using an observation protocol in bilingual and ESL classrooms in institute for education. Paper presented at the Annual Meeting of the American Educational Research Association.

Lasagabaster, D. (2001). Bilingualism, immersion programmes and language learning in the Basque Country. Journal of Multilingual and Multicultural Development, 22(5), 401-425.

Leinhardt, G., Weidman, C., \& Hammond, K. M. (1987). Introduction and integration of classroom routines by expert teachers. Curriculum Inquiry, 17(2), 135-176.

Leshem S., \& Bar-Hama, R. (2008). Evaluating teaching practice. ELT Journal, 62 (3). $257-65$.

Linn, R. L., \& Gronlund, N. E. (1995). Measurement and assessment in teaching (7th ed.). New Jersey, NJ: Prentice-Hall.

Liu, J. (2004). Methods in the post-methods era: Report on an international survey on language teaching methods. International Journal of English Studies, 4(1), 137152.

Long, M. H. (1980). Inside the "black box": Methodological issues in classroom research on language learning. Language Learning, 30(1), 1-42.

Loughran, J. J. (2002). Effective reflective practice: In search of meaning in learning about teaching. Journal of Teacher Education, 53(1), 33.

Ludy, R. (1995). A survey of evaluation procedures for student teaching in special education: Based on institutional size and funding status, 9705639. Needs a more complete citation

Macmillan, C., \& Pendlebury, S. (1985). The Florida performance measurement system: A consideration. The Teachers College Record, 87(1), 67-78.

Marzano, R. J. (2000). A new era of school reform: Going where the research takes us. Aurora, CO: Mid-continent Research for Education and Learning.

McCandliss, B., Beck, I. L., Sandak, R., \& Perfetti, C. (2003). Focusing attention on decoding for children with poor reading skills: Design and preliminary tests of the word building intervention. Scientific Studies of Reading, 7(1), 75-104.

McCarrier, A., Pinnell, G. S., \& Fountas, I. C. (2000). Interactive writing: How language \& literacy come together, $K-2$. Portsmouth, NH: Heinemann. 
McKeachie, W. J. (1997). Student ratings: The validity of use. American Psychologist, $52(11), 1218-1225$.

Miret, F. S. (2003) Actas del XXIII Congreso Internacional de Lingüística y Filología Románica. Salamanca, Spain: Miret.

Morris, F. A., \& Tarone, E. E. (2003). Impact of classroom dynamics on the effectiveness of recasts in second language acquisition. Language Learning, 53(2), 325 - 368.

Morrow, L. M. (2001). Literacy development in the early years: Helping children read and write (4th ed.). Boston, MA: Allyn \& Bacon.

Moskowitz, G. (1978). Caring and sharing in the foreign language class: A sourcebook on humanistic techniques. Rowley, MA: Newberry House.

Nakatani, Y. (2010), Identifying strategies that facilitate EFL learners' oral communication: A classroom study using multiple data collection procedures. Modern Language Journal, 94 (1), 116-136.

National Board of Professional Teaching Standards. (2010). Better teaching, better learning, better schools. Retrieved from http://www.nbpts.org/.

Nikolov, M., \& Krashen, S. (1997). Need we sacrifice accuracy for fluency? System, $25(2), 197-201$.

O'Grady, W. (1999).Toward a new nativism. Studies in second language acquisition, 21(4), 621-633.

Omatsu, G. (2006). Mobilizing students to respond to community needs: Organizing a class around a community project. In Teaching about Asian Pacific Americans. Effective activities, strategies and assignments for classrooms and communities (205-214) Oxford, UK: Rowman \& Littlefield.

Olson, L. (2000). Finding and keeping competent teachers. Quality counts: Who should teach? Education Week, 19(18), 12-18.

Pennington, M. C., \& Young, A. L. (1989). Approaches to faculty evaluation for ESL. TESOL Quarterly, 23(4), 619-646.

Peterson, K. D. (2000). Teacher evaluation: A comprehensive guide to new directions and practices ( 2 nd ed.). Thousand Oaks, CA: Corwin.

Peterson, K. D., Kromrey, J., Micceri, T., \& Smith, B. O. (1987). Florida Performance Measurement System: An example of its application. The Journal of Educational Research, 80(3), 141-148. 
Peterson, K. D., Micceri, T., \& Smith, B. O. (1985). Measurement of teacher performance: A study in instrument development. Teaching and Teacher Education, 1(1), 63-77.

Petzold, R., \& Berns, M. (2000). Catching up with Europe: Speakers and functions of English in Hungary. World Englishes, 19(1), 113-124.

Phillipson, R. (2001). English for globalization or for the world's people? International Review of Education, 47(3), 185-200.

Pikulski, J. J., \& Chard, D. J. (2005). Fluency: Bridge between decoding and reading comprehension. The Reading Teacher, 58(6), 510-519.

Puyal, M. et al. (2005). Oralidad y enseñanza-aprendizaje del francés a hispanohablantes. Revista Interuniversitaria de Formación del Profesorado, 53, 47-74.

Rabinowitz, S., \& Ananda, S. (2001). Balancing local assessment with statewide testing: Building a program that meets student needs. Knowledge Brief. San Francisco, CA: WestEd.

Reed, A. \& Bergemann, V. E. (1992). A guide to observation and participation in the classroom. Guilford, CT: Dushkin.

Reichelt, M. (2006). English in a multilingual Spain. English Today, 22, 3-9.

Reiman, A. J., \& Thies-Sprinthall, L. (1998). Mentoring and supervision for teacher development. Reading, MA: Addison Wesley Longman.

Richards, J. C., \& Farrell, T. S. C. (2005). Professional development for language teachers: Strategies for teacher learning. Cambridge, MA: Cambridge University Press.

Richards, J. C., \& Rodgers, T. S. (1986). Approaches and methods in language teaching: A description and analysis. Cambridge, MA: Cambridge University Press.

Rigg, P. (1991). Whole language in TESOL. TESOL Quarterly, 25(3), 521-542.

Rivers, W. M. (1987). Interactive language teaching. Cambridge, UK: Cambridge University Press.

Roberson, T. J. (1998). Classroom observation: Issues regarding validity and reliability. Paper presented at the annual meeting of the Mid-South Educational Research Association, New Orleans, LA, November 4-6, 1998. (ERIC Document Reproduction Service No. ED427070).

Roldán-Tapia, A. R. (1999). La observación sistemática del aula de inglés como instrumento de formación del profesorado. Aula Abierta, 73, 159-172. 
Roldán-Tapia, A. R. (2005). Propuestas educativas plurilingües y multiculturales para desarrollar la competencia intercultural. Aula Abierta, 86, 155-168.

Routman, R. (1996). Literacy at the crossroads: Crucial talk about reading, writing, and other teaching dilemmas. Portsmouth, NH: Heinemann.

Rowan, B., Correnti, R., \& Miller, R. (2002). What large-scale survey research tells us about teacher effects on student achievement: Insights from the prospects study of elementary schools. The Teachers College Record, 104(8), 1525-1567.

Sanchez, A. (1997). Los métodos en la enseñanza de idiomas. Madrid, Spain: SGEL.

Sanchez, A. (2009a). La observación en el aula. Didáctica@21. Retrieved from http://www.didacta21.com/documentos/revista/Abril09_Sanchez_Nunez_Antonia .pdf.

Sanchez, A. (2009b). La enseñanza de idiomas en los últimos cien años. Madrid, Spain: SGEL.

Sanchez, A. (2009c). Language teaching before and after digitalized corpora: Three main issues. Cuadernos de Filologia Inglesa, 9(1), 5-37.

Schwartz, B. (1999). Let's make up your mind: "Special nativist" perspectives on language, modularity of mind, and nonnative language acquisition. Studies in Second Language Acquisition, 21(4), 635-655.

Sergiovanni, T. J. (1995a). The principalship: A reflective practice perspective (3rd ed.) Boston, MA: Allyn \& Bacon.

Sergiovanni, T.J. (1995b). Small schools, great expectations. Educational Leadership, $53(3), 48-52$.

Shanahan, T., \& Beck, I. L. (2006). Effective literacy teaching for English-language learners. Developing literacy in second-language learners: Report of the National Literacy Panel on Language-Minority Children and Youth. New Jersey: Lawrence Erlbaum Assoc., Inc.

Short, D. J., \& Echevarria, J. (1999). The sheltered instruction observation protocol: $A$ tool for teacher-researcher collaboration and professional development. Center for research on education, diversity and excellence. University of California, Santa Cruz. Retrieved September 18, 2006, from http://www.cal.org/crede/pubs/edpractice/epr3.pdf. 
Silveira, J. C. P. (2000). Do you really speak English? Learning a language to get a job. Paper presented at the III Congrés Internacional sobre Llengües para Finalitats Especifiques. Retreived from http://books.google.es/books?hl=es\&lr=\&id=im_U0Hul4WIC\&oi=fnd\&pg=PA23 $9 \& \mathrm{dq}=$ Silveira, + J.C.P. $+(2000) .+$ Do + you + really + speak + English $\% 3 F+$ Learning $+\mathrm{a}$ +language + to + get $+\mathrm{a}+$ job\&ots $=q q E Q Q B E Z F q \&$ sig $=3 i i$ cldpizvCy_TSwnj6r1Bx $7 \mathrm{Qg \# v}=$ onepage $\& \mathrm{q} \& \mathrm{f}=$ false.

Silveira, P., \& Carlos, J. (1998). La utilización de la publicidad en Internet dentro del aula de inglés. Comunicar, 11, 137-141.

Simmons, P. E., Emory, A., Carter, T., Coker, T. et al. (1999). Beginning teachers: Beliefs and classroom actions. Journal of Research in Science Teaching, 36(8), 930-954.

Skinner, B. F. (1957). Verbal Behavior. New York, NY: Appleton-Century-Crofts.

Slavin, R. E. (1987). Cooperative learning. Review of Educational Research, 50(2), 315.

Smith, T., Polloway, E., Patton, J. R., \& Dowdy, C. A. (2004). Teaching students with special needs in inclusive settings. New York, NY: Allyn \& Bacon.

Simmons, P. E., Emory, A., Carter, T., Coker, T., Finnegan, B., Crockett, D., \& Labuda, K. (1999). Beginning teachers: Beliefs and classroom actions. Journal of Research in Science Teaching, 36(8), 930-954.

Stevens, J. (2002). Applied multivariate statistics for the social sciences (4th ed.). Mahwah, NJ: Lawrence Erlbaum.

Stiggins, R. J., \& Duke, D. L. (1990). The case for commitment to teacher growth: Research on teacher evaluation. New York, NY: State University of New York Press.

Stodolosky, S. S. (1990). Classroom observation. In Millman, J., \& Darling-Hammond, L. (Eds). The new handbook of teacher evaluation: Assessing elementary and secondary school teachers. Newbury, CA: SAGE.

Stronge, J. H. (1997). Evaluating teaching: A guide to current thinking and best practice. Thousand Oaks, CA: Corwin.

Stronge, J. H., \& Helm, V. M. (1991). Evaluating professional support personnel in education. Newbury Park, CA: Sage.

Szpotowicz, M., Djigunovic, J.M., \& Enever, J. (2008) Language Learning in Europe: a multinational, longitudinal study. The Way Forward: Learning from international experience of TEYL, 147-154. 
Tell, C. (2001). Appreciating good teaching: A conversation with Lee Shulman. Educational Leadership, 58(5), 6-11.

Tomasello, M. (2005). Constructing a language: A usage-based theory of language acquisition. Cambridge, MA: Harvard University Press.

Tragant, E., \& Muñoz, C. (2009). Second language acquisition and language teaching. International Journal of English Studies, 4(1), 197-219.

Tseng, K. K. (1998). Observation instrument for assessing pre-service technology teachers. Paper presented at the Annual Meeting of the International Technology Education Association. Retrieved from http://eric.ed.gov/PDFS/ED419103.pdf.

Valentine, J. W. (1992). Principles and practices for effective teacher evaluation. Boston, MA: Allyn \& Bacon.

Van Tassel-Baska, J., Quek, C., \& Feng, A. X. (2007). The development and use of a structured teacher observation scale to assess differentiated best practice. Report Review, 29(2), 84-92.

Vaughn, S., Linan-Thompson, S., Mathes, P., Cirino, P., Carlson, C., Pollard-Durodola, \& Francis, D. (2006). Effectiveness of Spanish intervention for first-grade English language learners at risk for reading difficulties. Journal of Learning Disabilities, 39(1), 56-73.

Villegas-Reimers, E. (2003). Teacher professional development: An international review of the literature. Paris, France: UNESCO, International Institute for Educational Planning.

Wajnryb, R. (1992). Classroom observation tasks: A resource book for language teachers and trainers. Cambridge, MA: Cambridge University Press.

Watts-Taffe, S., \& Truscott, D. M. (2000). Using what we know about language and literacy development for ESL students in the mainstream classroom. Language Arts, 77(3), 258- 265.

Weinstein, C. S., Tomlinson-Clarke, S., \& Curran, M. (2004). Toward a conception of culturally responsive classroom management. Journal of Teacher Education, 55(1), 25.

Wenglinsky, H. (2000). How teaching matters: Bringing the classroom back into discussions of teacher quality. A Policy Center Information Report prepared for Education Teaching Services. Retrieved from www.ets.orgfresearch/pic/teamat.pdf.

Westberg, K. L. (1993). The classroom practices observation study. Journal for the Education of the Gifted, 16(29), 120-146. 
Whelen, R. J., \& Simpson, R. L. (1996). Preparation of personnel for students with emotional and behavioral disorders: Perspectives on a research foundation for future practice. Behavioral Disorders. 22(1), 49-54.

White, J., Muñoz, C., \& Collins, L. (2007). The his/her challenge: Making progress in a 'regular' L2 programme. Language Awareness, 16(4), 278-299.

Wilson, S. M., Floden, R. E., \& Ferrini-Mundy, J. (2001). Teacher preparation research: Current knowledge, gaps, and recommendations. Seattle, WA: University of Washington, Center for the Study of Teaching and Policy.

Wilson, S. M., Floden, R. E., \& Ferrini-Mundy, J. (2002). Teacher preparation research: An insider's view from the outside. Journal of Teacher Education, 53(3), 190.

Wragg, E. C. (1999). An introduction to classroom observation ( $2^{\text {nd }}$ ed.). London, UK: Routledge. 


\section{APPENDIX A}

\section{RESEARCH BASED ITEMS}

Research Based Selection of Items for Domain: Classroom Dynamics (Morris \& Tarone, 2003; Omatsu, 2006).

\begin{tabular}{ll}
\hline Items & Supporting Research \\
\hline CD1 Teacher is organized and starts & Bacin \& Pla, 1989; Billett, \\
class promptly & 2001; Echevarria \& Graves, \\
& 2003; Gattegno, 1976; Smith \\
et al., 2004; Tapia \& Rafael, & 1999. \\
& Billett, 2001; Dalton, 1998; \\
CD2 Teacher displays consistent & Ellis, 2005; Hansen-Thomas, \\
opening routine & 2008; House, 1996; Leinhardt, \\
& Weidman, \& Hammond, 1987; \\
& Tapia \& Rafael, 1999. \\
& Bacin \& Pla, 1989; Gibbons, \\
CD3 Teacher posts and refers to & 2002; Hansen-Thomas, 2008; \\
agenda for student tasks & Leinhardt, Weidman, \& \\
& Hammond, 1987; Smith et al., \\
& 2004; Stronge, 1997. \\
& Bacin \& Pla, 1989; Cary, 1997; \\
CD4 Teacher clearly explains to & Cirino, Pollard-Durodola, \\
students what they will be learning & Foorman, Carlson, \& Francis, \\
and doing & 2007; Echevarria \& Graves, \\
& 2003; Gattegno, 1976; \\
& Gibbons, 2002; Tapia, \& \\
& Rafael, 1999. \\
& Baumann, Kame'enui, \& Ash, \\
& 2003; Dalton, 1998; Ellis, \\
CD5 Teacher introduces morning & 2005; Gattegno, 1976. \\
message for oral communication & Bacin \& Pla, 1989; Billett, \\
& 2001; Hansen-Thomas, 2008; \\
CD6 Teacher incorporates days of & House, 1996; Leinhardt, \\
the week into the lesson & Weidman \& Hammond, 1987. \\
&
\end{tabular}


CD7 Teacher incorporates daily weather into the lesson

CD8 Teacher paces the lesson appropriately to the students' ability level

CD9 Teacher incorporates learning activities into transition times

CD10 Teacher keeps transition times to a minimum

CD11 Teacher changes center or group work frequently

CD12 Teacher paces activities to keep students focused and engaged

CD13 Teacher provides a summarizing activity

CD14 Teacher demonstrates connections between past, present, and future lessons
Cirino, Pollard-Durodola, Foorman, Carlson, \& Francis, 2007; Echevarria, \& Graves, 2003; Gibbons, 2002; House, 1996.

Bacin \& Pla, 1989; Dalton, 1998; Echevarría \& Graves, 2011; Ellis, 2005; Tapia \& Rafael, 1999.

Baumann, Kame'enui, \& Ash, 2003; Cirino, Pollard-

Durodola, Foorman, Carlson, \& Francis, 2007; Gattegno, 1976; Gibbons, 2002; HansenThomas, 2008.

Bacin \& Pla, 1989; Billett, 2001; Cirino, PollardDurodola, Foorman, Carlson, \& Francis, 2007; Echevarria \& Graves, 2003; Ellis, 2005;

Gibbons, 2003.

Bacin \& Pla, 1989; Echevarria \& Graves, 2003; Gattegno, 1976; Francis, Rivera, Lesaux, Kieffer, \& Rivera, 2006; Leinhardt, Weidman \& Hammond, 1987; Tapia, \& Rafael, 1999.

Bacin \& Pla, 1989; Echevarria \& Graves, 2003; Francis, Rivera, Lesaux, Kieffer, \& Rivera, 2006 ; Gattegno, 1976; Gibbons, 2002.

Billett, 2001; Cirino, PollardDurodola, Foorman, Carlson, \& Francis, 2007; Dalton, 1998; Ellis, 2005; Hansen-Thomas, 2008; Leinhardt, Weidman, \& Hammond, 1987; Smith et al., 2004; Stronge, 1997; Tapia \& Rafael, 1999.

Armstrong, 1994; Bacin \& Pla, 1989; Billett, 2001; Cirino, Pollard-Durodola, Foorman, Carlson, \& Francis, 2007;

Hansen-Thomas, 2008; Smith 
CD15 Teacher elicits reflective comments from students on activities

CD16 Teacher uses informal assessment to gauge student understanding et al., 2004; Stronge, 1997. Echevarria \& Graves, 2003;

Ellis, 2005; Freeman \& Freeman, 2010; Gattegno, 1976; Gibbons, 2002; Tapia, \& Rafael, 1999.

Billett, 2001; Cirino, PollardDurodola, Foorman, Carlson, \& Francis, 2007; Dalton, 1998; Ellis, 2005; Freeman \& Freeman, 2010; HansenThomas, 2008.

Research Based Selection of Items for Domain: Student Dynamics (Biggs, 1987; Morris \& Tarone, 2003).

\begin{tabular}{ll}
\hline Items & Supporting Research \\
\hline SD1 Teacher engages students to & Asher, 1977; Bernaus \& \\
& \\
& Gardner, 2008; Cirino, Pollard- \\
& Durodola, Foorman, Carlson, \\
& \& Francis, 2007; Echevarría \& \\
& \& Haves, 2011; Graves, Gersten \\
& Tarone, 2004; Morris \& \\
SD2 Teacher encourages & Asher, 1977; Cirino, Pollard- \\
students to give elaborated & Durodola, Foorman, Carlson, \\
responses & \& Francis, 2007; Echevarria \& \\
& Graves, 2003; Gersten \& \\
& Baker, 2003; Leinhardt, \\
& Weidman, \& Hammond, 1987. \\
SD3 Teacher consistently & Bernaus \& Gardner, 2008; \\
provides wait-and-think time for & Cary, 1997; Echevarría \& \\
student response & Graves, 2011; Gersten \& \\
& Baker, 2003; Morris \& Tarone, \\
& 2003; Van Tassel-Baska, \\
& Quek, \& Feng, 2007. \\
DS4 Teacher encourages & Bernaus \& Gardner, 2008; \\
students to share responsibility & Freeman \& Freeman, 2004; \\
for instruction by constructing & Graves, Gersten, \& Haager, \\
and writing the text & 2004; Leinhardt, Weidman, \& \\
& Hammond, 1987; Morris \& \\
& Tarone, 2003; Van Tassel- \\
& Baska, Quek, \& Feng, 2007. \\
& Baumann, Kame'enui, \& Ash, \\
DS5 Teacher encourages & 2003; Cirino, Pollard- \\
students to collaborate in & Durodola, Foorman, Carlson, \\
instruction by writing the & \& Francis, 2007; Echevarria \& \\
composition &
\end{tabular}


DS6 Teacher accepts multiple responses that students can support

SD7 Teacher provides frequent opportunities for interaction in the target language among students

DS8 Teacher structures opportunities to speak target language

SD9 Teacher provides opportunities for communicating with others about what is read in the target language

SD10 Teacher engages students in discussions about, a response to, and specific elements or contents of the book in the target language

SD11 Students demonstrate desire to talk and interact in the target language

SD12 Students exhibit on-task behavior
Graves, 2003; Fountas \& Pinnell, 2000; Graves, Gersten, \& Haager, 2004.

Asher, 1977; Bernaus \& Gardner, 2008; Fountas \& Pinnell, 2000; Leinhardt, Weidman, \& Hammond, 1987; Van Tassel-Baska, Quek, \& Feng, 2007. Bernaus \& Gardner, 2008; Cirino, Pollard-Durodola, Foorman, Carlson, \& Francis, 2007; Echevarría \& Graves, 2011; Morris \& Tarone, 2003, Van Tassel-Baska, Quek, \& Feng, 2007.

Asher, 1977; Gersten \& Baker, 2003; Echevarria \& Graves, 2003; Graves, Gersten, \& Haager, 2004.

Baumann, Kame'enui, \& Ash, 2003; Leinhardt, Weidman, \& Hammond, 1987; Bernaus \& Gardner, 2008; Cirino, PollardDurodola, Foorman, Carlson, \& Francis, 2007; Fountas \& Pinnell, 2001; Morris \& Tarone, 2003.

Bernaus \& Gardner, 2008;

Echevarria \& Graves, 2003; Fountas \& Pinnell, 200; Graves, Gersten, \& Haager, 2004; Leinhardt, Weidman, \& Hammond, 1987; Van TasselBaska, Quek, \& Feng, 2007. Ash, 2003; Asher, 1977; Baumann, Kame'enui, \& Cary, 1997; Cirino, PollardDurodola, Foorman, Carlson, \& Francis, 2007; Morris \& Tarone, 2003.

Bernaus \& Gardner, 2008; Echevarria \& Graves, 2003; Gibbons, 2002, 2003; Graves, Gersten, \& Haager, 2004; Leinhardt, Weidman, \& 
SD13 Students engage in discussions about texts they read in the target language

SD14 Activities keep students actively engaged
Hammond, 1987; Morris \& Tarone, 2003.

Bernaus \& Gardner, 2008;

Cirino, Pollard-Durodola, Foorman, Carlson, \& Francis, 2007; McCarrier, Pinnell, \&

Fountas, 2000.

Asher, 1977; Cirino, PollardDurodola, Foorman, Carlson, \& Francis, 2007; Fountas \& Pinnell, 2001; Graves, Gersten, \& Haager, 2004; Morris \& Tarone, 2003.

SD15 Students actively engage in writing
Asher, 1977; Echevarria \& Graves, 2003; Leinhardt, Weidman, \& Hammond, 1987; McCarrier, Pinnell, \& Fountas, 2000.

Research Based Selection of Items for Domain: Teaching Approaches (Fraser \& Walberg, 1995; Kember \& Kwan, 2000).

\begin{tabular}{ll}
\hline Items & \\
\hline & TA1 Teacher provides explicit \\
instruction in Target language & \\
& TA2 Teacher introduces difficult \\
& vocabulary prior to and during lesson
\end{tabular}

Supporting Research

Al-Shammari, Al-Sharoufi, \& Yawkey, 2009; Anthony, 1963; Celce-Murcia, 2001;

Cerezo, 2007; Criado \&

Sanchez, 2009; Fotos, 2005;

Gersten \& Baker, 2003.

Anderson- Barksdale, \& Hite, 2005; Crandall, 2008; Criado \& Sanchez, 2009; Ellis, 2005; Fotos, 2005; Gersten \& Baker, 2003.

TA3 Teacher gives a chalk-talk with drawings on the board

Anderson- Barksdale, \& Hite, 2005; Cary, 1997; Crandall, 2008; Echevarria, \& Graves 2003.

TA4 Teacher only uses the target Al-Shammari, Al-Sharoufi, \& language for communication as well as feature of the target language culture to talk about it

TA5 Teacher selects and incorporates students' responses, Yawkey, 2009; Anthony, 1963; Celce-Murcia, 2001; Cerezo, 2007; Freeman \& Freeman, 2004; Fotos, 2005; Gibbons, 2002, 2003; Shanahan \& Beck, 2006.

Anderson- Barksdale, \& Hite, 2005; Anthony, 1963; Cerezo, 
ideas, examples, and experiences into lesson

TA6 Teacher uses direct explicit instruction to teach unknown words and expand knowledge of known words

TA7 Teacher models critical thinking questions and answers in a variety forms

TA8 Teacher introduces the book and discusses the title, author, and illustrator

TA9 Teacher stops at selected places to emphasize a point, ask a question, do a think-aloud, model a strategy, clarify information, or monitor students' comprehension TA10 Teacher models the use of comprehension strategies to make content understandable

TA11 Teacher builds instructional context for students

TA12 Teacher links concepts to student's background experiences, and makes explicit connections between past learning and new concepts

TA13 Teacher makes connections between their knowledge and experiences and the ideas, events, and information in the text AT14 Teacher helps students make connections between the text and
2007; Crandall, 2008;

Echevarria \& Graves 2003; Ellis, 2005; Gersten \& Baker, 2003.

Al-Shammari, Al-Sharoufi, \& Yawkey, 2009; Celce-Murcia, 2001; Cerezo, 2007; Ellis, 2005; Freeman \& Freeman, 2004; Fotos, 2005.

Anderson- Barksdale \& Hite, 2005; Anthony, 1963; CelceMurcia, 2001; Criado \& Sanchez, 2009; Gibbons, 2002, 2003.

Al-Shammari, Al-Sharoufi, \& Yawkey, 2009; Cerezo, 2007; Crandall, 2008; Echevarria \& Graves 2003; Freeman \& Freeman, 2004; Fotos, 2005; Shanahan \& Beck, 2006. Anderson- Barksdale, \& Hite, 2005; Anthony, 1963; Ellis, 2005; Fotos, 2005; Fountas \& Pinnell, 2001.

Celce-Murcia, 2001; Cerezo, 2007; Echevarria \& Graves 2003; McCarrier, Pinnell, \& Fountas, 2000; Shanahan \& Beck, 2006.

Al-Shammari, Al-Sharoufi, \& Yawkey, 2009; Baumann, Kame'enui, \& Ash, 2003;

Cary, 1997; Cerezo, 2007;

Ellis, 2005.

Cerezo, 2007; Criado \&

Sanchez, 2009; Echevarría \&

Graves, 2011; Fotos, 2005.

Echevarria \& Graves 2003; Ellis, 2005; McCarrier, Pinnell, \& Fountas, 2000.

Al-Shammari, Al-Sharoufi, \& Yawkey, 2009; Anderson- 
personal knowledge and experiences

TA15 Teacher utilizes small groups to encourage students to work together to reach a common goal

TA16 Teacher ensures students are not only responsible for learning the material that is presented, but also for ensuring everyone in the group knows the material as well

TA17 Teachers direct students participate in group work and know their role in the group

TA18 Teacher works with a small group of students, at the same instructional level with the same text

TA19 Teacher develops routines for students moving to and from centers, stations, literature circles

TA20 Teacher establishes learning centers that provide opportunities for direct application of previously taught skills and strategies

TA21 Teacher groups students heterogeneously for learning center activity work

TA22 Teacher shares responsibility for classroom routines with job boards or assignment charts
Barksdale \& Hite, 2005. Anthony, 1963; Criado \& Sanchez, 2009; Echevarria \& Graves 2003; Ellis, 2005; Gibbons, 2002, 2003.

Brandt, 1987; Celce-Murcia, 2001; Cerezo, 2007; Fotos, 2005; Kagan \& Kagan, 1994; Slavin, 1980.

Anderson- Barksdale \& Hite, 2005; Crandall, 2008; Criado \& Sanchez, 2009; Ellis, 2005; Kagan \& Kagan, 1994; Slavin, 1980.

Cerezo, 2007; Crandall, 2008;

Echevarria \& Graves 2003;

Gibbons, 2002, 2003; Kagan \& Kagan, 1994; Slavin, 1980.

Al-Shammari, Al-Sharoufi, \& Yawkey, 2009; AndersonBarksdale \& Hite, 2005; Crandall, 2008; Ellis, 2005; Kagan \& Kagan, 1994; Slavin, 1980.

Anthony, 1963; Cerezo, 2007;

Cooper, 1993; Crandall, 2008;

Criado \& Sanchez, 2009;

Freeman \& Freeman, 2004;

Kagan \& Kagan, 1994; Slavin, 1980.

Al-Shammari, Al-Sharoufi, \& Yawkey, 2009; AndersonBarksdale, \& Hite, 2005;

Anthony, 1963; Cerezo, 2007; Cooper, 1993; Echevarria \& Graves 2003; Kagan \& Kagan, 1994; Slavin, 1980.

Anthony, 1963; Celce-Murcia, 2001; Cooper, 1993; Criado \& Sanchez, 2009; Ellis, 2005; Kagan \& Kagan, 1994; Slavin, 1980.

Al-Shammari, Al-Sharoufi, \& Yawkey, 2009; Celce-Murcia, 2001; Cooper, 1993; Crandall, 2008; Echevarria \& Graves 
TA23 Teacher reviews

comprehension skills and strategies in small group or literature circles

TA24 Teacher calls attention to words, phrases, sentences, and/or punctuation
2003; Kagan \& Kagan, 1994; Slavin, 1980.

Anderson- Barksdale \& Hite, 2005; Cerezo, 2007; Cooper, 1993; Criado \& Sanchez, 2009; Echevarria \& Graves 2003;

Freeman \& Freeman, 2004;

Slavin, 1980.

Al-Shammari, Al-Sharoufi, \& Yawkey, 2009; Anthony, 1963;

Crandall, 2008; Ellis, 2005;

Freeman \& Freeman, 2004;

Fotos, 2005.

Research Based Selection of Items for Domain: Language Arts Strategies (Flood, 2003; Chamot \& O'Malley, 1987; Watts-Taffes \& Truscott, 2000).

\begin{tabular}{ll}
\hline Items & Supporting Research \\
\hline LAS1 Teacher structures & Baumann, Kame'enui, \& Ash, \\
opportunities to speak target & 2003; Beck \& Juel, 1995; \\
language throughout lesson & Beck \& McKeown, 2001; \\
& Burke, Hagan-Burke, Kwok, \& \\
& Parker, 2009; Cirino, Pollard- \\
& Durodola, Foorman, Carlson, \\
& \& Francis, 2007; Duke, \& \\
& Pearson, 2002; Echevarria \& \\
& Graves 2003; Gersten \& Baker, \\
& 2003; McCandliss, Beck, \\
& Sandak, \& Perfetti, 2003; \\
& Mack D. Burke, Shanna \\
& Hagan-Burke, Oiman Kwok, \& \\
& Richard Parker, 2009. \\
& Aherm, García Bermejo, \& \\
& Fleta, 2008; Baumann, \\
& Kame'enui, \& Ash, 2003; \\
LAS2 Teacher uses the Morning & Beck, Perfetti, \& McKeown, \\
Message to encourage students in & 1982; Graves, Gersten, \& \\
oral participation & Haager, 2004; Morrow, 2001; \\
& McCarrier, Pinnell, \& Fountas, \\
& 2000; Pikulski \& Chard, 2005. \\
& Armstrong, 1994; Baumann, \\
& Kame'enui, \& Ash, 2003; \\
& Duke \& Pearson, 2002; \\
& McCandliss, Beck, Sandak, \& \\
LAS3 Teacher provides repeated & Perfetti, 2003; Pikulski \& \\
exposures to new words & Chard, 2005. \\
& Beck \& Juel, 1995; Beck \& \\
&
\end{tabular}


to explain their thinking in their own words

LAS5 Teacher accepts multiple responses that students can support

LAS6 Teacher connects spelling to phonics and modeling spelling strategies

LAS7 Teacher encourages students to use strategies of phonemic awareness to say words slowly before spelling them in writing

LAS8 Teacher uses echo or choral reading to promote fluency

LAS9 Teacher provides direct explicit instruction in each of the aspects of phonemic awareness
McKeown, 2001; Cooper, 1993; Echevarria \& Graves 2003; Pikulski \& Chard, 2005;

Shanahan \& Beck, 2006. Beck \& Juel, 1995; Burke, Hagan-Burke, Kwok, \& Parker, 2009; Cirino, PollardDurodola, Foorman, Carlson, \& Francis, 2007; Graves, Gersten, \& Haager, 2004; Morrow, 2001.

Aherm, García Bermejo, \& Fleta, 2008; Beck, Perfetti, \& McKeown, 1982; Cooper, 1993; McCandliss, Beck, Sandak, \& Perfetti, 2003; Pikulski \& Chard, 2005. Armstrong, 1994; Beck \& Juel, 1995; Beck \& McKeown, 2001; Burke, Hagan-Burke, Kwok, \& Parker, 2009; Echevarria \& Graves 2003; House, 1996; McCandliss, Beck, Sandak, \& Perfetti, 2003; McCarrier, Pinnell, \& Fountas, 2000.

Beck \& Juel, 1995; Beck \& McKeown, 2001; Duke \& Pearson, 2002; Graves, Gersten, \& Haager, 2004; McCandliss, Beck, Sandak, \& Perfetti, 2003; Pikulski \& Chard, 2005; Shanahan \& Beck, 2006.

Aherm, García Bermejo, \& Fleta, 2008; Armstrong, 1994; Beck, Perfetti, \& McKeown, 1982; Beck \& McKeown, 2001; Cirino, PollardDurodola, Foorman, Carlson, \& Francis, 2007; Duke \& Pearson, 2002; Freeman \& Freeman, 2004; Graves, Gersten, \& Haager, 2004; McCandliss, Beck, Sandak, \& Perfetti, 2003. 
LAS10 Teacher models and directs practice in rhyming

LAS11 Teacher provides systematic instruction in phonemic awareness

LAS12 Teacher provides systematic instruction in letter-sound correspondence

LAS13 Teacher provides systematic instruction in decoding

LAS14 Teacher provides systematic instruction to vocabulary development

LAS15 Teacher asks questions to ensure comprehension
Beck, Perfetti, \& McKeown, 1982; Beck \& McKeown, 2001; Burke, Hagan-Burke, Kwok, \& Parker, 2009; Cooper, 1993; Freeman \& Freeman, 2004; McCandliss, Beck, Sandak, \& Perfetti, 2003; McCarrier, Pinnell, \& Fountas, 2000.

Armstrong, 1994; Beck \& Juel, 1995; Cirino, Pollard-

Durodola, Foorman, Carlson, \& Francis, 2007; Cooper, 1993; Echevarria \& Graves 2003; Gersten \& Baker, 2003; McCandliss, Beck, Sandak, \& Perfetti, 2003; Pikulski \& Chard, 2005.

Beck \& Juel, 1995; Beck \& McKeon, 2001; Echevarria \& Graves 2003; Graves, Gersten, \& Haager, 2004; Gersten \& Baker, 2003; McCandliss, Beck, Sandak, \& Perfetti, 2003; McCarrier, Pinnell, \& Fountas, 2000.

Aherm, García Bermejo, \& Fleta, 2008; Beck, Perfetti, \& McKeown, 1982; Cooper, 1993; Duke \& Pearson, 2002; Echevarria \& Graves 2003; Gersten \& Baker, 2003;

McCandliss, Beck, Sandak, \& Perfetti, 2003.

Armstrong, 1994; Beck \& Juel, 1995; Burke, Hagan-Burke, Kwok, \& Parker, 2009; Cirino, Pollard-Durodola, Foorman, Carlson, \& Francis, 2007; Graves, Gersten, \& Haager, 2004; Gersten \& Baker, 2003; McCandliss, Beck, Sandak, \& Perfetti, 2003.

Beck, Perfetti, \& McKeown, 1982; Gersten \& Baker, 2003; McCandliss, Beck, Sandak, \& 
LAS16 Teacher uses poetry, big books of rhyme or songs to assist in phonemic awareness

LAS17 Teacher teaches the relationship between spoken and written letters

LAS18 Teacher enhances and enriches phonics by teaching strategies which help students have alternative methods of decoding words

LAS19 Teacher systematically teaches the most productive phonics' rules

LAS20 Teacher solidifies knowledge of the alphabet through multiple tasks

1. LAS21 Teacher uses echo and choral reading on a regular basis to increase
Perfetti, 2003; McCarrier, Pinnell, \& Fountas, 2000; Pikulski \& Chard, 2005. Aherm, García Bermejo, \& Fleta, 2008; Beck \& Juel, 1995; Beck \& McKeown, 2001; Duke \& Pearson, 2002;

Echevarria \& Graves 2003; McCarrier, Pinnell, \& Fountas, 2000; Morrow, 2001;

Shanahan \& Beck, 2006. Beck \& Juel, 1995; Cirino, Pollard-Durodola, Foorman, Carlson, \& Francis, 2007; Cooper, 1993; Fountas \& Pinnell, 2001; Graves, Gersten, \& Haager, 2004; McCandliss, Beck, Sandak, \& Perfetti, 2003; Pikulski \& Chard, 2005. Armstrong, 1994; Beck, Perfetti, \& McKeown, 1982; Burke, Hagan-Burke, Kwok, \& Parker, 2009; Cooper, 1993; Freeman, Mercuri, \& Freeman, 2001; McCarrier, Pinnell, \& Fountas, 2000; Shanahan \& Beck, 2006.

Aherm, García Bermejo, \& Fleta, 2008; Beck \& Juel, 1995; Beck \& McKeown, 2001; Cirino, PollardDurodola, Foorman, Carlson, \& Francis, 2007; Fountas \& Pinnell, 2001; McCandliss, Beck, Sandak, \& Perfetti, 2003.

Armstrong, 1994; Cirino, Pollard-Durodola, Foorman, Carlson, \& Francis, 2007; Cooper, 1993; Duke \& Pearson, 2002; Graves, Gersten, \& Haager, 2004; Pikulski \& Chard, 2005; Beck \& Juel, 1995.

Aherm, García Bermejo, \& Fleta, 2008; Armstrong, 1994; 
fluency

LAS22 Teacher teaches students how to gain meaning from text through proper phrasing of text which demonstrates understanding

LAS23 Teacher uses poetry, big books of rhyme or songs to assist in phonemic awareness

LAS24 Teacher teaches, prior to reading, words that are key to selection comprehension

LAS25 Teacher employs a variety of strategies to teach the skills of comprehension such as rereading, context, Questioning the Author, Think Aloud, Think Along, Think Alone

LAS26 Teacher prompts during the reading of texts to ask questions and monitor students' use of reading strategies and selection comprehension
Beck, Perfetti, \& McKeown, 1982; Fountas \& Pinnell, 2001; McCandliss, Beck, Sandak, \& Perfetti, 2003; Pikulski \& Chard, 2005; Shanahan \& Beck, 2006.

Aherm, García Bermejo, \& Fleta, 2008; Beck \& Juel, 1995; Burke, Hagan-Burke, Kwok, \& Parker, 2009; Cirino, Pollard-Durodola, Foorman, Carlson, \& Francis, 2007;

Duke \& Pearson, 2002;

Echevarria, \& Graves 2003;

Pikulski \& Chard, 2005. Armstrong, 1994; Beck \& Juel, 1995; Cirino, PollardDurodola, Foorman, Carlson, \& Francis, 2007; Cooper, 1993; Duke \& Pearson, 2002; Flood, 2003; Graves, Gersten, \& Haager, 2004; Pikulski \& Chard, 2005; Shanahan \& Beck, 2006.

Aherm, García Bermejo, \& Fleta, 2008; Beck, Perfetti, \& McKeown, 1982; Burke, Hagan-Burke, Kwok, \& Parker, 2009; Fountas \& Pinnell, 2001; McCarrier, Pinnell, \& Fountas, 2000. Beck, 2006; Beck \& Juel, 1995; Cirino, PollardDurodola, Foorman, Carlson, \& Francis, 2007; McCandliss, Beck, Sandak, \& Perfetti, 2003; McCarrier, Pinnell, \& Fountas, 2000; Shanahan \& Armstrong, 1994; Pikulski \& Chard, 2005; Shanahan \& Beck, 2006.

Beck, Perfetti, \& McKeown, 1982; Beck \& McKeown, 2001; Cirino, PollardDurodola, Foorman, Carlson, \& Francis, 2007; Cooper, 
LAS27 Teacher provides students with opportunities to demonstrate text comprehension through writing short answer questions

LAS28 Teacher demonstrates the act of writing and the writing process

LAS29 Teacher helps students generate ideas for writing

LAS30 Teacher allows students to draw pictures before reading to assist in sequencing writing

LAS31 Teacher allows students to share writing

LAS32 Teacher use phonemic awareness skills to assist in writing
1993; Duke \& Pearson, 2002;

Echevarria \& Graves 2003; Flood, 2003; McCandliss, Beck, Sandak, \& Perfetti, 2003.

Aherm, García Bermejo, \& Fleta, 2008; Beck, Perfetti, \& McKeown, 1982; Beck \& Juel, 1995; Burke, Hagan-Burke, Kwok, \& Parker, 2009; Graves, Gersten, \& Haager, 2004; McCandliss, Beck, Sandak, \& Perfetti, 2003; Shanahan \& Beck, 2006. Armstrong, 1994; Beck \& Juel, 1995; Echevarria \& Graves 2003; Flood, 2003; Graves, Gersten, \& Haager, 2004; Beck \& Juel, 1995; Pikulski \& Chard, 2005.

Aherm, García Bermejo, \& Fleta, 2008; Beck, Perfetti, \& McKeown, 1982; Beck \& McKeown, 2001; Duke \& Pearson, 2002; Echevarria \& Graves 2003; Fountas \& Pinnell, 2001; McCarrier, Pinnell, \& Fountas, 2000. Beck, Perfetti, \& McKeown, 1982; Burke, Hagan-Burke, Kwok, \& Parker, 2009; Cirino, Pollard-Durodola, Foorman, Carlson, \& Francis, 2007;

Fountas \& Pinnell, 2001; McCandliss, Beck, Sandak, \& Perfetti, 2003.

Beck, 2006; Beck \& Juel, 1995; Cooper, 1993; Duke \& Pearson, 2002; Fountas \& Pinnell, 2001; McCarrier, Pinnell, \& Fountas, 2000; Beck \& Juel, 1995; Pikulski \& Chard, 2005; Shanahan \& Beck, 2006.

Aherm, García Bermejo, \& Fleta, 2008; Armstrong, 1994; 
unknown words

LAS33 Teacher encourages students to participate in the writing center

LAS35 Teacher asks students to participate in the writing at strategic points

LAS36 Teacher reviews the writing process

LAS37 Teacher reviews or models what to write and how to plan
Beck, Perfetti, \& McKeown, 1982; Beck \& McKeown, 2001; Burke, Hagan-Burke, Kwok, \& Parker, 2009; Fountas \& Pinnell, 2001; McCandliss, Beck, Sandak, \& Perfetti, 2003.

Beck, 2006; Cooper, 1993;

Echevarria \& Graves 2003; Fountas \& Pinnell, 2001; Beck \& Juel, 1995; Pikulski \& Chard, 2005; Shanahan \& Beck, 2006.

Armstrong, 1994; Morrow, 2001; Beck \& Juel, 1995;

Burke, Hagan-Burke, Kwok, \& Parker, 2009; Cirino, PollardDurodola, Foorman, Carlson, \& Francis, 2007; Duke, \& Pearson, 2002; Fountas \& Pinnell, 2001; Graves, Gersten, \& Haager, 2004; McCarrier, Pinnell, \& Fountas, 2000. Aherm, García Bermejo, \& Fleta, 2008; Beck, Perfetti, \& McKeown, 1982; Cooper, 1993; Echevarria \& Graves 2003; Fountas \& Pinnell, 2001; Morrow, 2001; Pikulski \& Chard, 2005; Shanahan \& Beck, 2006.

Burke, Hagan-Burke, Kwok, \& Parker, 2009; Fountas \& Pinnell, 2001; Beck \& Juel, 1995; Graves, Gersten, \& Haager, 2004; McCandliss, Beck, Sandak, \& Perfetti, 2003; McCarrier, Pinnell, \& Fountas, 2000; Morrow, 2001; Shanahan \& Beck, 2006. Beck, Perfetti, \& McKeown, 1982; Beck \& McKeown, 2001; Burke, Hagan-Burke, Kwok, \& Parker, 2009; Cirino, Pollard-Durodola, Foorman, Carlson, \& Francis, 2007; 
LAS38 Teacher observes students and assists them in their writing efforts

LAS39 Teacher calls attention to words, phrases, sentences, and/or punctuation
Duke \& Pearson, 2002;

Echevarria \& Graves 2003; Graves, Gersten, \& Haager, 2004; Morrow, 2001; Pikulski \& Chard, 2005.

Beck \& Juel, 1995; Burke, Hagan-Burke, Kwok, \& Parker, 2009; Cirino, PollardDurodola, Foorman, Carlson, \& Francis, 2007; Cooper, 1993; Freeman, Mercuri, \& Freeman, 2001; McCandliss, Beck, Sandak, \& Perfetti, 2003; Pikulski \& Chard, 2005; Shanahan \& Beck, 2006. Aherm, García Bermejo, \& Fleta, 2008; Armstrong, 1994; Beck \& Juel, 1995; Duke \& Pearson, 2002; Echevarria \& Graves 2003; Freeman, Mercuri, \& Freeman, 2001; Graves, Gersten, \& Haager, 2004; McCandliss, Beck, Sandak, \& Perfetti, 2003; McCarrier, Pinnell, \& Fountas, 2000; Pikulski \& Chard, 2005.

Research Based Selection of Items for Domain: Classroom Management (Jones, 1986; Weinstein, Tomlinson-Clarke, \& Curran, 2004).

\begin{tabular}{ll}
\hline Items & Supporting Research \\
\hline $\begin{array}{l}\text { CM1 Teacher posts class rules and } \\
\text { reviews them periodically }\end{array}$ & $\begin{array}{l}\text { Canter \& Canter, 1976; Canter, } \\
\text { Canter, Thompson, \& Canter } \\
\text { and Associates, 1993; Canter \& } \\
\text { Canter, 2001. }\end{array}$ \\
$\begin{array}{l}\text { CM2 Teacher positively reinforces } \\
\text { student behavior and work }\end{array}$ & $\begin{array}{l}\text { Canter \& Canter, 1976; Canter, } \\
\text { Canter, Thompson, \& Canter }\end{array}$ \\
& $\begin{array}{l}\text { and Associates, 1993; Canter \& } \\
\text { Canter, 2001. }\end{array}$ \\
CM3 Teacher provides positive & Canter \& Canter, 1976; Canter, \\
feedback to students & Canter, Thompson, \& Canter \\
& and Associates, 1993; Canter \& \\
& Canter, 2001; Gallagher, 2002. \\
CM4 Teacher is able to respond & Canter \& Canter, 1976; Canter, \\
quickly and efficiently to changes & Canter, Thompson, \& Canter \\
aring lesson & Canter, 2001; Whelen, 1998.
\end{tabular}


CM5 Teacher provides corrective actions to students every time students choose to disrupt

CM6 Teacher provides positive immediate feedback to students

CM7 Teacher positively disciplines, encourages and motivates intervention students

CM8 Teacher communicates clearly that students have the power to make choices, yet they need to accept the responsibility that goes with it CM9 Teacher establishes rules that are observable and continually in effect

CM10 Teacher uses supportive approaches to keep students on task

CM11 Teacher provides corrective actions in a calm, matter-of-fact manner

CM12 Teacher is consistent

CM13 Teacher provides clear, concise directions that are easy for students to follow

CM14 Teacher uses behavioral narration to motivate students to get on task

CM15 Teacher implements classwide reward system

CM16 Teacher recognizes positive behavior at the first opportunity after
Canter \& Canter, 1976; Canter, Canter, Thompson, \& Canter and Associates, 1993; Canter \& Canter, 2001; Gallagher, 2002. Canter \& Canter, 1976; Canter, Canter, Thompson, \& Canter and Associates, 1993; Canter \& Canter, 2001.

Canter \& Canter, 1976; Canter, Canter, Thompson, \& Canter and Associates, 1993; Canter \& Canter, 2001.

Canter \& Canter, 1976; Canter, Canter, Thompson, \& Canter and Associates, 1993; Canter \& Canter, 2001.

Canter \& Canter, 1976; Canter, Canter, Thompson, \& Canter and Associates, 1993; Canter \& Canter, 2001.

Canter \& Canter, 1976; Canter, Canter, Thompson, \& Canter and Associates, 1993; Canter \& Canter, 2001.

Canter \& Canter, 1976; Canter, Canter, Thompson, \& Canter and Associates, 1993; Canter \& Canter, 2001.

Canter \& Canter, 1976; Canter, Canter, Thompson, \& Canter and Associates, 1993; Canter \& Canter, 2001.

Canter \& Canter, 1976; Canter, Canter, Thompson, \& Canter and Associates, 1993; Canter \& Canter, 2001.

Canter, \& Canter, 1976;

Canter, Canter, Thompson, \& Canter and Associates, 1993;

Canter \& Canter, 2001. Canter \& Canter, 1976; Canter, Canter, Thompson, \& Canter and Associates, 1993; Canter \& Canter, 2001.

Canter \& Canter, 1976; Canter, Canter, Thompson, \& Canter 
correcting a student's behavior

CM17Teacher provides an "escape mechanism" for students who are upset and want to talk about what happened and Associates, 1993; Canter \& Canter, 2001.

Canter \& Canter, 1976; Canter, Canter, Thompson, \& Canter and Associates, 1993; Canter \& Canter, 2001. 


\section{APPENDIX B}

\section{B1. EXPERT SURVEY INSTRUCTIONS}

\section{Q LOUISVILLE}

\section{Validation of an Observation Instrument for ELF Instruction in Spain: iFFOD}

University of Louisvillewestern Kentucky University

Cooperative Doctoral Program Department of Educational Leadership

University of Louisville Department of Educational Administration,

Leadership and Research, College of Education and Behavioral Sciences. Western Kentucky University

Expert Survey Instructions

\section{Dear Expert:}

Thank you for your willingness to review the survey instrument that follows.

The intent of the instrument is to include Effective Practice for teaching English as a Foreign Language in Spain for students at grades Pre-K through Second Grade. Please write your comments relative to any item on the survey in the space provided next to Experts comments.

Specifically, are there effective practice items that should be omitted, additions needed, modifications in wording, or other revisions that would enhance the quality and value of the survey instrument.

When you finish please click submit on the bottom of the page and go to the next section.

Thank you for your assistance.

First Name $\square$ Last Name 


\section{B2. EXPERT SURVEY INFORMED CONCENT FORM}

\section{a \\ Louisvitit}

由WKU

Validation of an Observation Instrument for ELF Instruction in Spain: iFFOD

University of Louisville Western Kentucky University

Cooperative Doctoral Program Department of Educational Leadership.

University of Louisville Department of Educational Administration.

Leadership and Research, College of Education and Behavioral Sciences. Western Kentucky University

Informed Consent Form

Fall 2010

\section{Dear Colleague:}

Please accept this invitation to participate in a research study about effective practices for EFL/ESL instruction. This study is being conducted by Maria Gómez (doctoral candidate) and Dr. Christopher Wagner (Advisor) and sponsored by the Department of Leadership, Foundations, and Human Resource Education at the University of Louisville (UofL)

This study involves completing an online survey. Participation in this study is entirely voluntary and should take approximately 15 minutes of your time.

By completing the survey you are voluntarily agreeing to participate. There are no known risks for your participation in this research study. The information collected may not benefit you directly. The information learned in this study may be helpful to others. Your

complete survey will be compiled in aggregate format and maintained on a secure computer that is password protected. Presentations or publications of the study will be based on grouped data and will not reveal your identity. You may decline to answer any questions or stop taking part in this study at any time without penalty of losing any benefits to which you are otherwise entitled. Completion of this survey enters you into a random drawing to get a small token of appreciation for your participation.

If you have any questions or concerns please contact the principal investigator, Dr. Christopher Wagner, at (270) 745-4980. If you have any questions about your rights as a research subject, you may call the Human Subjects Protection Program office at (502)

852-5188. You will be given the opportunity to discuss any questions about your rights as a research subject, in private, with a member of the Institutional Review Board (IRB). The IRB is an independent committee composed of people from the University community, staff of the institutions, as well as people from the community not connected with these institutions. The IRB has reviewed and approved this research study. If you have concerns or complaints about the research or research staff and you do not wish to give your name, you may call 1-877-852-1167. This is a 24 hour hot line answered by people who do not work at the University of Louisville.

Sincerely

Christopher Wagner, Ph.D.

Maria Gómez, Doctoral candidate 


\section{B3. EXPERT SURVEY FOR CONTENT VALIDITY}

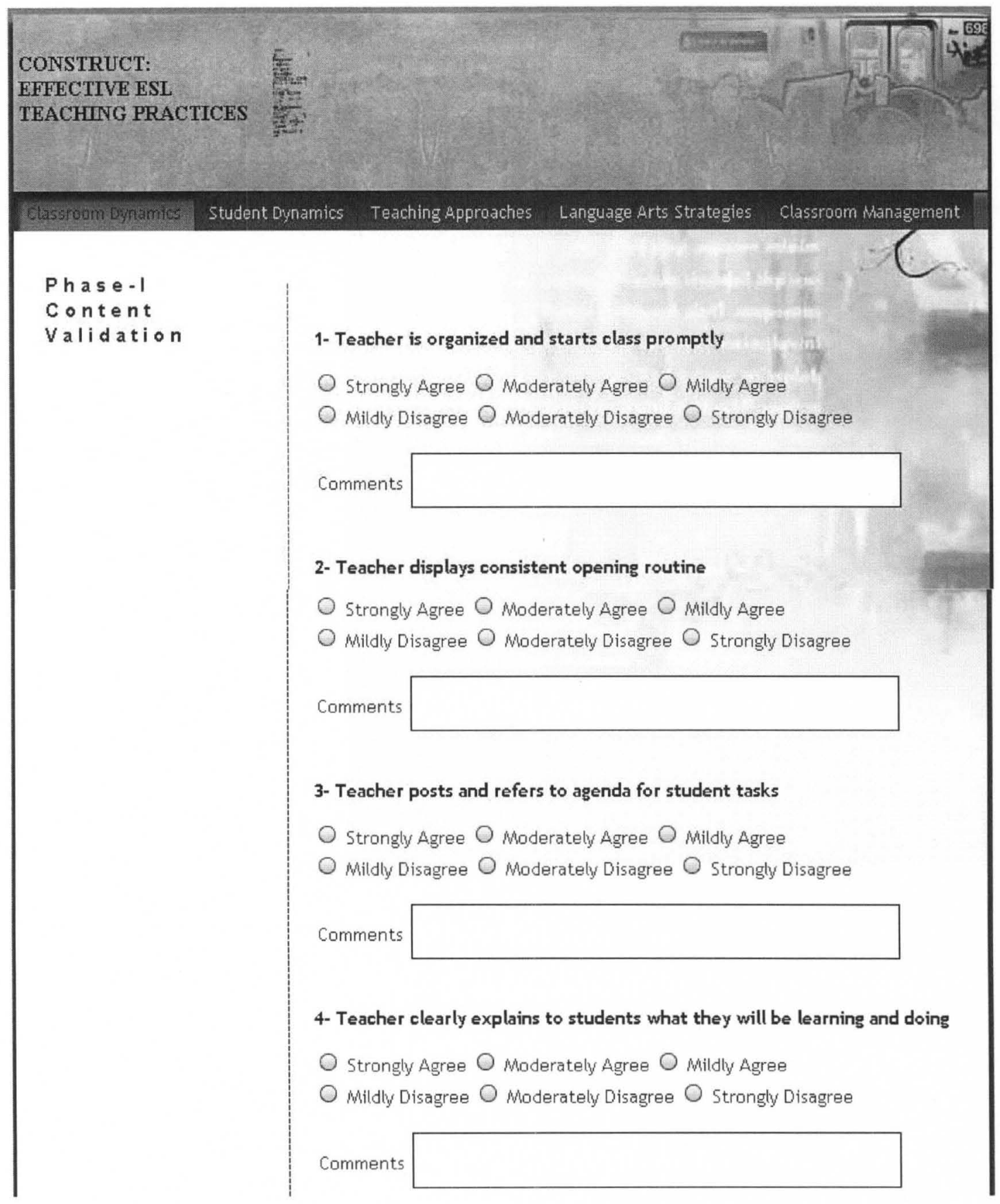


5- Teacher introduces morning message for oral communication

Strongly Agree $\bigcirc$ Moderately Agree $\bigcirc$ Mildly Agree

$\bigcirc$ Mildly Disagree $\bigcirc$ Moderately Disagree $\bigcirc$ strongly Disagree

Comments

6- Teacher incorporates days of the wreek into the lesson

$\bigcirc$ strangly Agree $\bigcirc$ Moderately Agree $\bigcirc$ Mildly Agree

$\bigcirc$ Mildly Disagree $\bigcirc$ Moderately Disagree $\bigcirc$ Strongly Disagree

Comments

7- Teacher incorporates daily weather into the lesson

$\bigcirc$ Strongly Agree $\bigcirc$ Moderately Agree $\bigcirc$ Mildly Agree

$\bigcirc$ Mildy Disagree $\bigcirc$ Moderately Disagree $\bigcirc$ Strongly Disagree

Comments

8- Teacher paces the lesson appropriately to the students' ability level

$\bigcirc$ 5trongly Agree $\bigcirc$ Moderately Agree $\bigcirc$ Mildly Agree

$\bigcirc$ Mildly Disagree $\bigcirc$ Moderately Disagree $\bigcirc$ strongly Disagree

Comments

9- Teacher incorporates learning activities into transition times

$\bigcirc$ Strongly Agree $\bigcirc$ Moderately Agree $\bigcirc$ Mildly Agree

$\bigcirc$ Mildy Disagree $\bigcirc$ Moderately Disagree $\bigcirc$ Strongly Disagree

Comments

10- Teacher keeps transition times to a minimum 
$\bigcirc$ Strongly Agree $\bigcirc$ Moderately Agree $\bigcirc$ Mildy Agree

$\bigcirc$ Mildly Disagree $\bigcirc$ Moderately Disagree $\bigcirc$ Strongly Disagree

Comments

11- Teacher changes center or group work frequently

$\bigcirc$ Strongly Agree $\bigcirc$ Moderately Agree $\bigcirc$ Mildly Agree

$\bigcirc$ Mildy Disagree $\bigcirc$ Moderately Disagree $\bigcirc$ strongly Disagree

Comments

12- Teacher paces activities to keep students focused and engaged

Strongly Agree $\bigcirc$ Moderately Agree $\bigcirc$ Mildy Agree

$\bigcirc$ Mildly Disagree $O$ Moderately Disagree $O$ strongly Disagree

Comments

\section{3- Teacher provides a summarizing activity}

$\bigcirc$ Strongly Agree $\bigcirc$ Moderately Agree $\bigcirc$ Mildly Agree

$\bigcirc$ Mildy Disagree $\bigcirc$ Moderately Disagree $O$ Strongly Disagree

Comments

14- Teacher demonstrates connections between past, present, and future lessons

$\bigcirc$ Strongly Agree $\bigcirc$ Moderately Agree $\bigcirc$ Mildly Agree

$\bigcirc$ Mildly Disagree $\bigcirc$ Moderately Disagree $\bigcirc$ strongly Disagree

Comments

\section{5- Teacher elicits reflective comments from students on activities}

$\bigcirc$ Strongly Agree $\mathrm{O}$ Moderately Agree $\mathrm{O}$ Mildly Agree

$\bigcirc$ Mildy Disagree $\bigcirc$ Moderately Disagree $\bigcirc$ strongly Disagree 


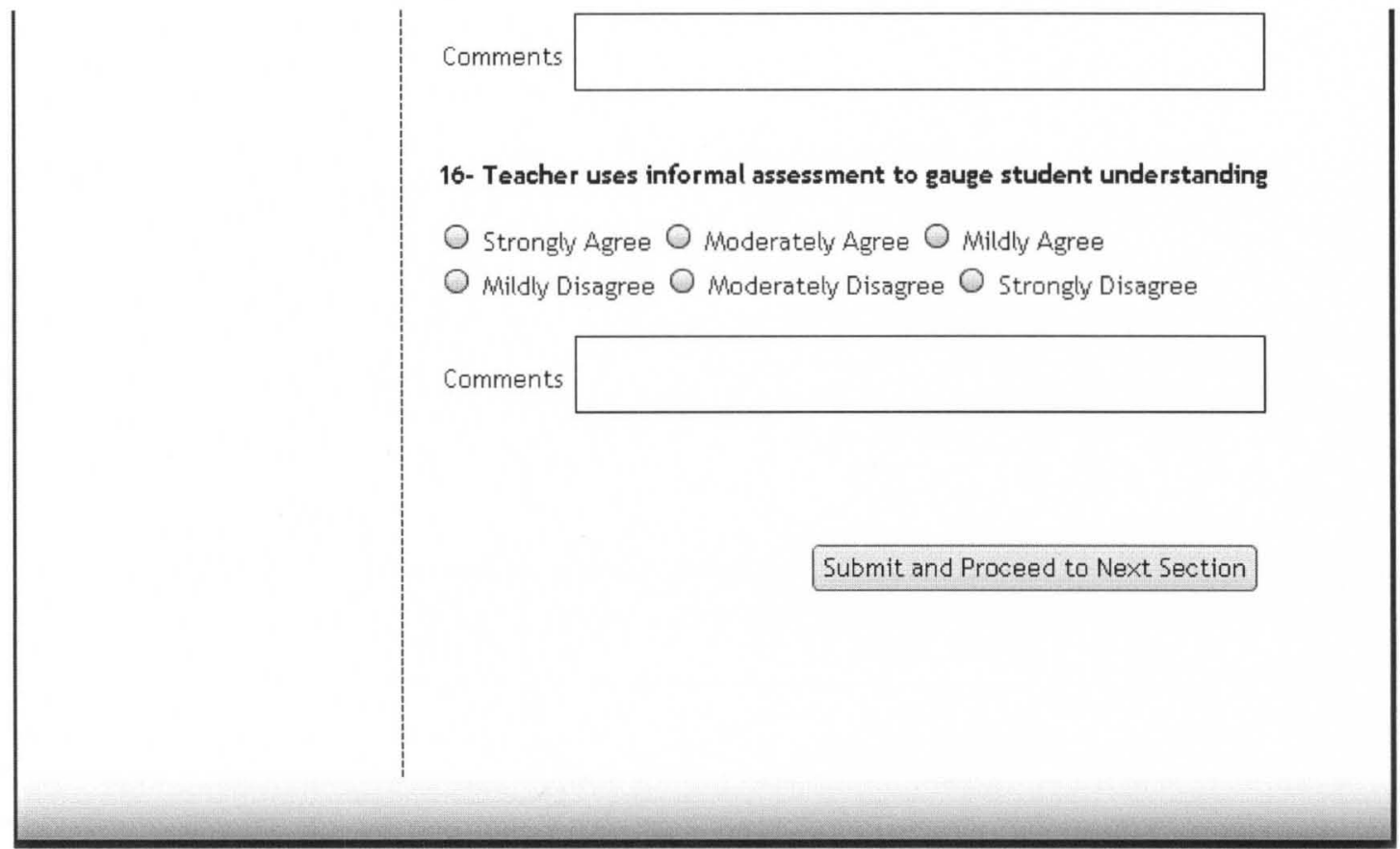




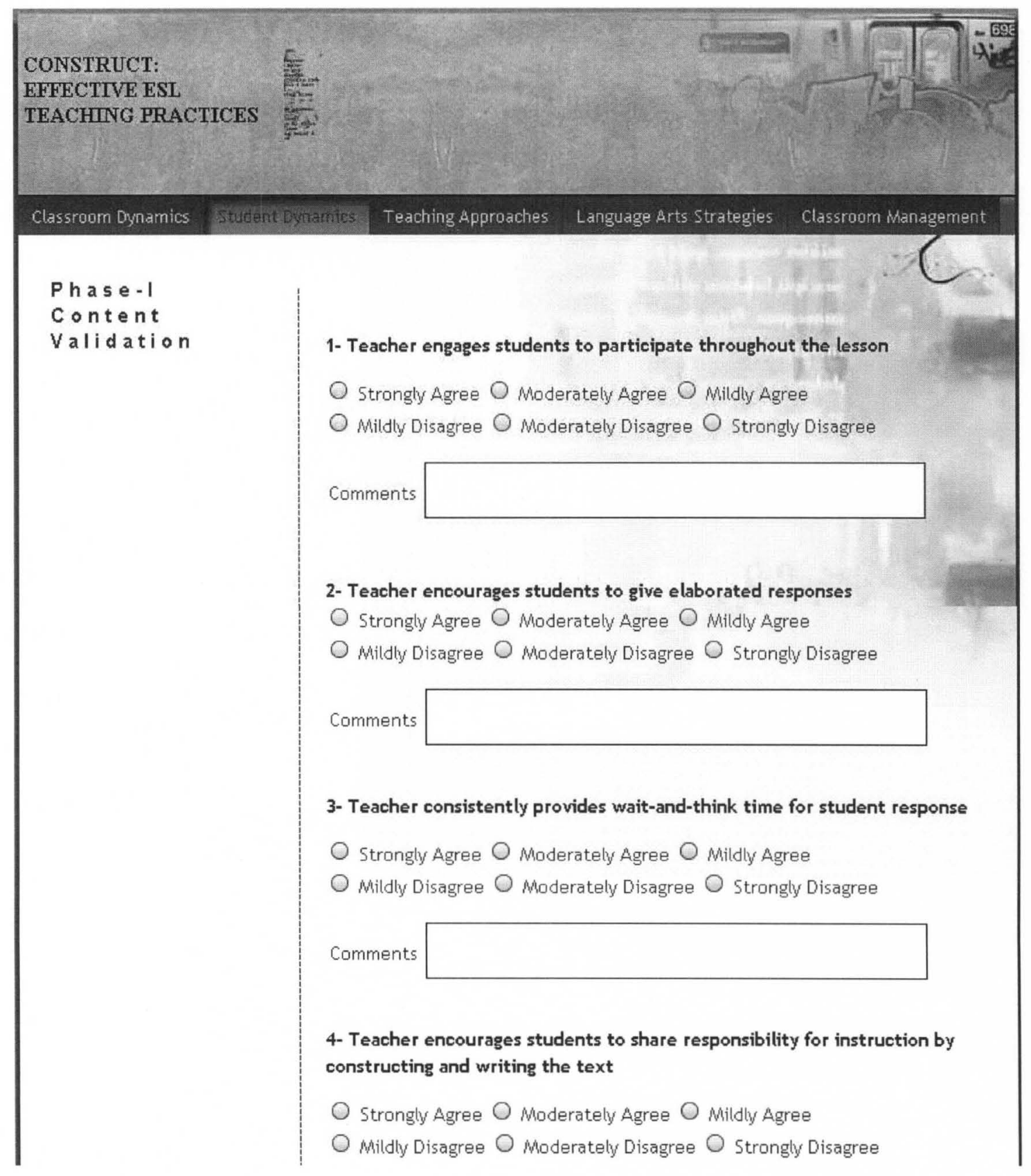


Comments

5- Teacher encourages students to collaborate in instruction by writing the composition

$\bigcirc$ Strongly Agree $\bigcirc$ Moderately Agree $\bigcirc$ Mildly Agree
$\bigcirc$ Mildly Disagree $\bigcirc$ Moderately Disagree $\bigcirc$ Strongly Disagree

Comments

6- Teacher accepts multiple responses that students can support

$\bigcirc$ Strongly Agree $\bigcirc$ Moderately Agree $\bigcirc$ Mildly Agree

$\bigcirc$ Mildly Disagree $\bigcirc$ Moderately Disagree $\bigcirc$ Strongly Disagree

Comments language among students

$\bigcirc$ Strongly Agree $\bigcirc$ Moderately Agree $\bigcirc$ Mildly Agree

$\bigcirc$ Mildly Disagree $\bigcirc$ Moderately Disagree $\bigcirc$ Strongly Disagree

Comments

8- Teacher structures opportunities to speak target language

$\bigcirc$ Strongly Agree $\bigcirc$ Moderately Agree $\bigcirc$ Mildly Agree

$\bigcirc$ Mildly Disagree $\bigcirc$ Moderately Disagree $\bigcirc$ Strongly Disagree

Comments

8- Teacher provides opportunities for communicating with others about what is read in the target language 
$\bigcirc$ Strongly Agree $\bigcirc$ Moderately Agree $\bigcirc$ Mildy Agree

$\bigcirc$ Mildy Disagree $\bigcirc$ Moderately Disagree $\bigcirc$ strongly Disagree

Comments

s

9- Teacher engages students in discussions about, a response to, and specific elements or contents of the book in the target language

Strongly Agree $\bigcirc$ Moderately Agree $\bigcirc$ Mildly Agree

$\bigcirc$ Mildly Disagree $\bigcirc$ Moderately Disagree $\bigcirc$ strongly Disagree

Comments

10- Teacher engages students in discussions about, a response to, and specific elements or contents of the book in the target language

$\bigcirc$ strongly Agree $\bigcirc$ Moderately Agree $\bigcirc$ Mildy Agree

$\bigcirc$ Mildly Disagree $\bigcirc$ Moderately Disagree $\bigcirc$ strongly Disagree

Comments

11- Students demonstrate desire to talk and interact in the target language

$\bigcirc \bigcirc$ strongly Agree $\bigcirc$ Moderately Agree $\bigcirc$ Mildly Agree

$\bigcirc$ Mildly Disagree $\bigcirc$ Moderately Disagree $\bigcirc$ Strongly Disagree

Comments

12- Students exhibit on-task behavior

$\bigcirc$ strongly Agree $\bigcirc$ Moderately Agree $\bigcirc$ Mildly Agree

$\bigcirc$ Mildy Disagree $\bigcirc$ Moderately Disagree $\bigcirc$ strongly Disagree

Comments

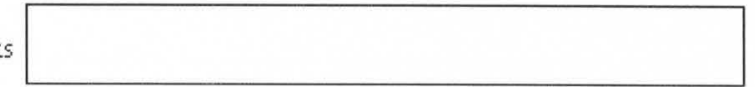


13- Students engage in discussions about texts they read in the target language

$\bigcirc$ Strongly Agree $\bigcirc$ Moderately Agree $\bigcirc$ Mildy Agree

$\bigcirc$ Mildy Disagree $\bigcirc$ Moderately Disagree $\bigcirc$ strongly Disagree

Comments

\section{4- Activities keep students actively engaged}

$\bigcirc$ Strongly Agree $\bigcirc$ Moderately Agree $\bigcirc$ Mildly Agree

$\bigcirc$ Mildy Disagree $\bigcirc$ Moderately Disagree $\bigcirc$ Strongly Disagree

Comments

\section{5- Students actively engage in writing}

$\bigcirc$ Strongly Agree $\bigcirc$ Moderately Agree $\bigcirc$ Mildly Agree

$\bigcirc$ Mildly Disagree $\bigcirc$ Moderately Disagree $\bigcirc$ strongly Disagree

15- Students actively engage in writing

$\bigcirc$ strongly Agree $\bigcirc$ Moderately Agree $\bigcirc$ Mildly Agree

$\bigcirc$ Mildly Disagree $\bigcirc$ Moderately Disagree $\bigcirc$ Strongly Disagree

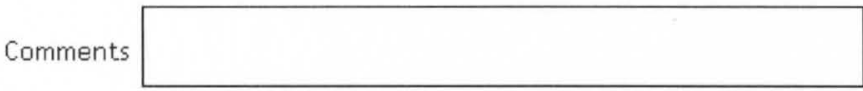

Submit and Proceed to Next Section 
CONSTRUCT:

EFFECTIVE ESL

TEACHING PRACTICES

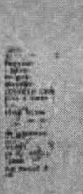

\section{Classroom Dynamies Student Dynamics Teaching Approaches Language Arts Strategies Classroom Management.}

Phase-I

Content

Validation
1- Teacher provides explicit instruction in target language

5trongly Agree $\bigcirc$ Moderately Agree $\bigcirc$ Mildy Agree

$\bigcirc$ Mildly Disagree $\bigcirc$ Moderately Disagree $\bigcirc$ Strongly Disagree

Comments

2- Teacher introduces difficult vocabulary prior to and during lesson

$\bigcirc$ strongly Agree $\bigcirc$ Moderately Agree $\bigcirc$ Mildy Agree

$\bigcirc$ Mildy Disagree $\bigcirc$ Moderately Disagree $O$ Strongly Disagree

Comments

3- Teacher gives a chalk-talk with drawings on the board

Strongly Agree $\mathrm{O}$ Moderately Agree $\mathrm{O}$ Mildly Agree

$\bigcirc$ Mildy Disagree $\bigcirc$ Moderately Disagree $\bigcirc$ strongly Disagree

Comments

4- Teacher only uses the target language for communication as well as feature of the target language culture to talk about it

$\bigcirc \bigcirc$ strongly Agree $\bigcirc$ Moderately Agree $\bigcirc$ Mildly Agree

$\bigcirc$ Mildy Disagree $\bigcirc$ Moderately Disagree $\bigcirc$ strongly Disagree 
Comments

5- Teacher selects and incorporates students' responses, ideas, examples, and experiences into lesson

$\bigcirc$ strongly Agree $\bigcirc$ Moderately Agree $\bigcirc$ Mildly Agree

$\bigcirc$ Mildly Disagree $\bigcirc$ Moderately Disagree $\bigcirc$ strongly Disagree

Comments

6- Teacher uses direct explicit instruction to teach unknown words and expand knowledge of known words

$\bigcirc$ Strongly Agree $\bigcirc$ Moderately Agree $\bigcirc$ Mildly Agree

$\bigcirc$ Mildly Disagree $\bigcirc$ Moderately Disagree $\bigcirc$ strongly Disagree

Comments

7- Teacher models critical thinking questions and answers in a variety forms

$\bigcirc$ strongly Agree $\bigcirc$ Moderately Agree $\bigcirc$ Mildly Agree

$\bigcirc$ Mildly Disagree $\bigcirc$ Moderately Disagree $\bigcirc$ strongly Disagree

Comments

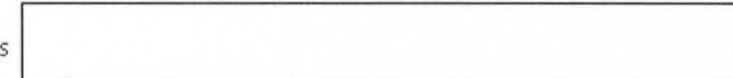

8- Teacher introduces the book and discusses the title, author, and illustrator
Strongly Agree
Moderately Agree $\bigcirc$ Mildy Agree
$\bigcirc$ Mildly Disagree
Moderately Disagree
Strongly Disagree

Comments

9- Teacher stops at selected places to emphasize a point, ask a question, do a think-aloud, model a strategy, clarify information, or monitor students' comprehension. 
$\bigcirc$ Strongly Agree $\bigcirc$ Moderately Agree $\bigcirc$ Mildly Agree

$\bigcirc$ Mildy Disagree $\bigcirc$ Moderately Disagree $\bigcirc$ strongly Disagree

Comments

10- Teacher models the use of comprehension strategies to make content understandable

$\bigcirc$ strongly Agree $\bigcirc$ Moderately Agree $\bigcirc$ Mildly Agree

$\bigcirc$ Mildy Disagree $\bigcirc$ Moderately Disagree $O$ Strongly Disagree

Comments

11- Teacher builds instructional context for students

$\bigcirc$ Strongly Agree $\bigcirc$ Moderately Agree $\bigcirc$ Mildly Agree

$\bigcirc$ Mildy Disagree $\bigcirc$ Moderately Disagree $\bigcirc$ Strongly Disagree

Comments

12- Teacher links concepts to student's background experiences, and makes explicit connections between past learning and new concepts

$\bigcirc$ strongly Agree $\bigcirc$ Moderately Agree $\bigcirc$ Mildy Agree

$\bigcirc$ Mildly Disagree $\bigcirc$ Moderately Disagree $\bigcirc$ Strongly Disagree

Comments

13- Teacher makes connections between their knowledge and experiences and the ideas, events, and information in the text

$\bigcirc$ Strongly Agree $\mathrm{O}$ Moderately Agree $\mathrm{O}$ Mildly Agree

$\bigcirc$ Mildy Disagree $\bigcirc$ Moderately Disagree $O$ Strongly Disagree

Comments 
14- Teacher helps students make connections between the text and personal knowledge and experiences

$\bigcirc$ Strongly Agree $\bigcirc$ Moderately Agree $\bigcirc$ Mildy Agree

$\bigcirc$ Mildly Disagree $\bigcirc$ Moderately Disagree $\bigcirc$ Strongly Disagree

Comments

15- Teacher utilizes small groups to encourage students to work together to reach a common goal

$\bigcirc$ Strongly Agree $\bigcirc$ Moderately Agree $\bigcirc$ Mildly Agree

$\bigcirc$ Mildy Disagree $\bigcirc$ Moderately Disagree $\bigcirc$ Strongly Disagree

Comments

16- Teacher ensures that not only are individual students responsible for learning the material but also for ensuring everyone in the group knows the material as well

$\bigcirc$ strongly Agree $\bigcirc$ Moderately Agree $\bigcirc$ Mildly Agree

$\bigcirc$ Mildy Disagree $\bigcirc$ Moderately Disagree $\bigcirc$ Strongly Disagree

Comments

17- Teachers directs students participation in group work and know their role in the group

Strongly Agree $\bigcirc$ Moderately Agree $\bigcirc$ Mildly Agree

$\bigcirc$ Mildy Disagree $\bigcirc$ Moderately Disagree $\bigcirc$ strongly Disagree

Comments

18- Teacher works with a small group of students, at the same instructional level utilizing the same text

$\bigcirc$ Strongly Agree $\bigcirc$ Moderately Agree $\bigcirc$ Mildy Agree

$\bigcirc$ Mildy Disagree $\bigcirc$ Moderately Disagree $\bigcirc$ Strongly Disagree 
Comments

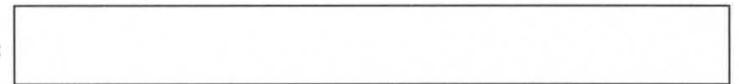

19- Teacher develops routines for students moving to and from centers, stations, literature circles

$\bigcirc$ Strongly Agree $\bigcirc$ Moderately Agree $\bigcirc$ Mildly Agree

$\bigcirc$ Mildy Disagree $\bigcirc$ Moderately Disagree $\bigcirc$ Strongly Disagree

Comments

20- Teacher establishes learning centers that provide opportunities for direct application of previously taught skills and strategies

Strongly Agree $\bigcirc$ Moderately Agree $O$ Mildly Agree

$\bigcirc$ Mildy Disagree $\bigcirc$ Moderately Disagree $\bigcirc$ strongly Disagree

Comments

21- Teacher groups students heterogeneously for learning center activity work

$\bigcirc$ Strongly Agree $\bigcirc$ Moderately Agree $\bigcirc$ Mildly Agree

$\bigcirc$ Mildly Disagree $\bigcirc$ Moderately Disagree $\bigcirc$ Strongly Disagree

Comments

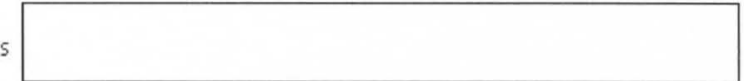

22- Teacher shares responsibility for classroom routines with job boards or assignment charts

$\bigcirc$ Strongly Agree $\bigcirc$ Moderately Agree $\bigcirc$ Mildly Agree

$\bigcirc$ Mildly Disagree $\bigcirc$ Moderately Disagree $\bigcirc$ Strongly Disagree

Comments

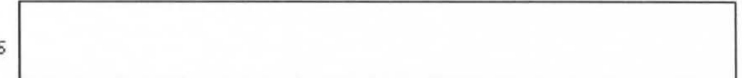

23- Teacher reviews comprehension skills and strategies in small group or literature circles 


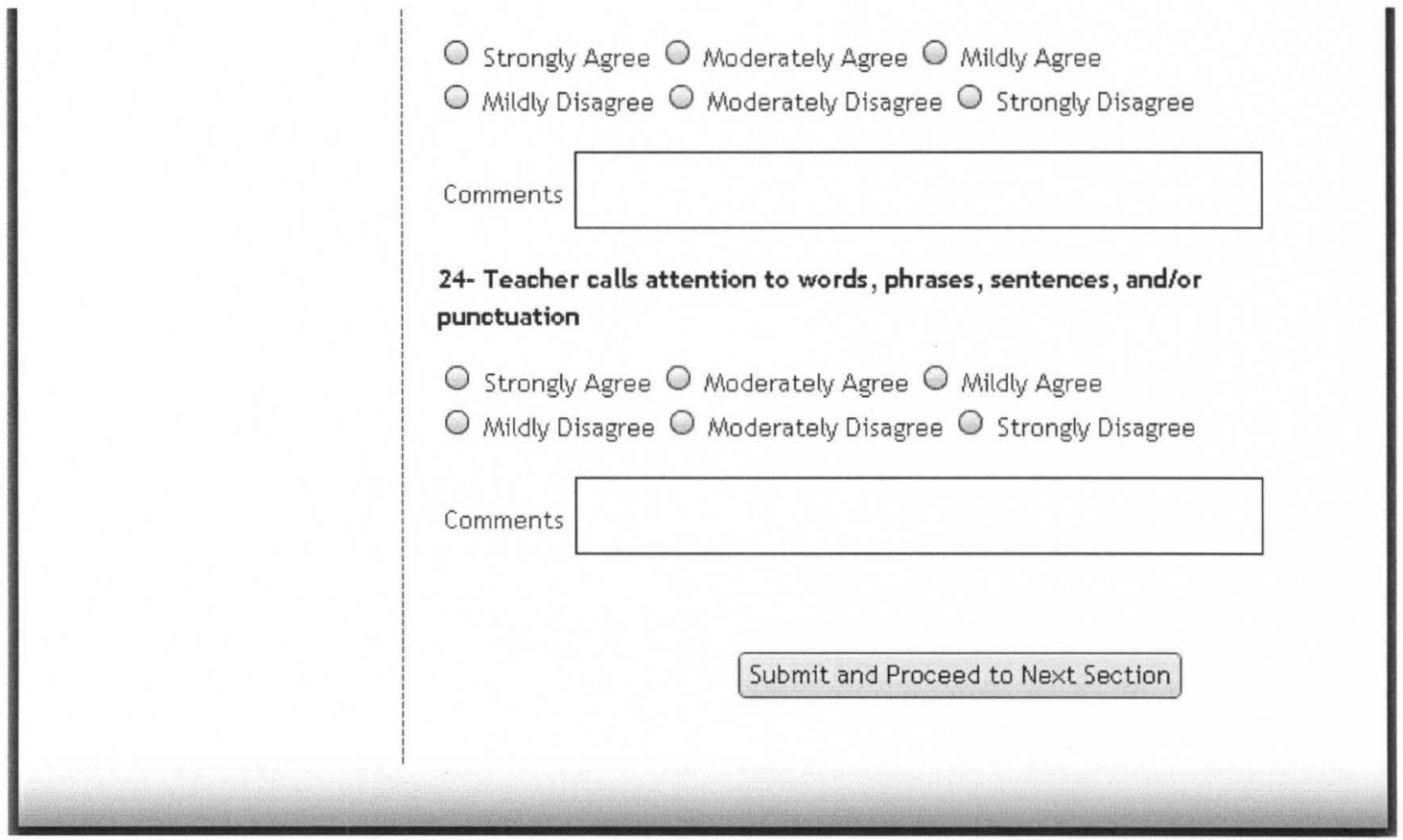


CONSTRUCT:

EFFECTTVE ESL

TEACHING PRACTICES

Classroom Dynamics Student Dynamics Teaching Approaches fanguage Arts Strategles Classroom Management

$P$ hase -1

Content

Validation
1- Teacher structures opportunities to speak target language throughout lesson

$\bigcirc$ Strongly Agree $\bigcirc$ Moderately Agree $\bigcirc$ Mildly Agree

$\bigcirc$ Mildly Disagree $\bigcirc$ Moderately Disagree $\bigcirc$ strongly Disagree

Comments

2- Teacher uses the Morning Message to encourage studentes in oral participation

$\bigcirc$ Strongly Agree $\bigcirc$ Moderately Agree $\bigcirc$ Mildly Agree

$\bigcirc$ Mildly Disagree $\bigcirc$ Moderately Disagree $\bigcirc$ strongly Disagree

Comments

3- Teacher provides repeated exposures to new words

$\bigcirc$ strongly Agree $\bigcirc$ Moderately Agree $\bigcirc$ Mildly Agree

$\bigcirc$ Mildly Disagree $\bigcirc$ Moderately Disagree $\bigcirc$ strongly Disagree

Comments

4- Teacher encourages students to explain their thinking in their own words

5trongly Agree $\bigcirc$ Moderately Agree $\bigcirc$ Mildly Agree

$\bigcirc$ Mildly Disagree $\bigcirc$ Moderately Disagree $\bigcirc$ Strongly Disagree

Comments 
5- Teacher accepts multiple respnses that students can support

$\bigcirc$ strongly Agree $\bigcirc$ Moderately Agree $\bigcirc$ Mildy Agree

$\bigcirc$ Mildly Disagree $\bigcirc$ Moderately Disagree $\bigcirc$ strongly Disagree

Comments

6. Teacher connects spelling to phonics and modeling spelling strategies

$\bigcirc$ Strongly Agree $\bigcirc$ Moderately Agree $\bigcirc$ Mildly Agree

$\bigcirc$ Mildy Disagree $\bigcirc$ Moderately Disagree $\bigcirc$ strongly Disagree

Comments

7. - Teacher encourages students to use strategies of phonemic awareness to say words slowly before spelling them in writing

$\bigcirc$ strongly Agree $\bigcirc$ Moderately Agree $\bigcirc$ Mildly Agree

$\bigcirc$ Mildly Disagree $\bigcirc$ Moderately Disagree $\bigcirc$ Strongly Disagree

Comments

8.- Teacher uses echo or choral reading to promote fluency

Strongly Agree $\bigcirc$ Moderately Agree $\bigcirc$ Mildy Agree

$\bigcirc$ Mildly Disagree $\bigcirc$ Moderately Disagree $\bigcirc$ Strongly Disagree

Comments

9.- Teacher provides direct explicit instruction in each of the aspects of phonemic awareness

Strongly Agree $\bigcirc$ Moderately Agree $\bigcirc$ Mildly Agree

$\bigcirc$ Mildy Disagree $\bigcirc$ Moderately Disagree $\bigcirc$ Strongly Disagree

Comments

10.- Teacher models and directs practice in rhyming 
$\bigcirc$ Strongly Agree $\bigcirc$ Moderately Agree $\bigcirc$ Mildy Agree

$\bigcirc$ Mildly Disagree $\bigcirc$ Moderately Disagree $\bigcirc$ strongly Disagree

Comments

11- Teacher provides systematic instruction in phonemic awareness

$\bigcirc$ strongly Agree $\bigcirc$ Moderately Agree $\bigcirc$ Mildly Agree

$\bigcirc$ Mildy Disagree $\bigcirc$ Moderately Disagree $\bigcirc$ strongly Disagree

Comments

12- Teacher provides systematic instruction in letter-sound correspondence

$\bigcirc$ strongly Agree $\bigcirc$ Moderately Agree $\bigcirc$ Mildly Agree

$\bigcirc$ Mildy Disagree $\bigcirc$ Moderately Disagree $\bigcirc$ strongly Disagree

Comments

13- Teacher provides systematic instruction in decoding

$\bigcirc$ strongly Agree $\bigcirc$ Moderately Agree $\bigcirc$ Mildy Agree

$\bigcirc$ Mildy Disagree $\bigcirc$ Moderately Disagree $\bigcirc$ Strongly Disagree

Comments

Coments

14- Teacher provides systematic instruction to vocabulary development

$\bigcirc$ strongly Agree $\bigcirc$ Moderately Agree $\bigcirc$ Mildly Agree

$\bigcirc$ Mildly Disagree $\bigcirc$ Moderately Disagree $\bigcirc$ strongly Disagree

Comments

15- Teacher asks questions to ensure comprehension

$\bigcirc$ strongly Agree $\bigcirc$ Moderately Agree $\bigcirc$ Mildly Agree

$\bigcirc$ Mildy Disagree $\bigcirc$ Moderately Disagree $\bigcirc$ strongly Disagree 
Comments

16- Teacher uses poetry, big books of rhyme or songs to assist in phonemic awareness

$\bigcirc$ Strongly Agree $\bigcirc$ Moderately Agree $\bigcirc$ Mildly Agree

$\bigcirc$ Mildy Disagree $\bigcirc$ Moderately Disagree $\bigcirc$ Strongly Disagree

Comments

17- Teacher teaches the relationship between spoken and written letters

$\bigcirc$ strongly Agree $\bigcirc$ Moderately Agree $\bigcirc$ Mildy Agree

$\bigcirc$ Mildy Disagree $\bigcirc$ Moderately Disagree $\bigcirc$ Strongly Disagree

Comments

18- Teacher enhances and enriches phonics by teaching strategies which help students have alternative methods of decoding words

$\bigcirc$ strongly Agree $\bigcirc$ Moderately Agree $\bigcirc$ Mildly Agree

$\bigcirc$ Mildly Disagree $\bigcirc$ Moderately Disagree $\bigcirc$ strongly Disagree

Comments

19- Teacher systematically teaches the most productive phonics' rules

Strongly Agree $\bigcirc$ Moderately Agree $\bigcirc$ Mildly Agree

$\bigcirc$ Mildly Disagree $\bigcirc$ Moderately Disagree $\bigcirc$ strongly Disagree

Comments

20- Teacher solidifies knowledge of the alphabet through multiple tasks

$\bigcirc$ strongly Agree $\bigcirc$ Moderately Agree $\bigcirc$ Mildy Agree

$\bigcirc$ Mildly Disagree $\bigcirc$ Moderately Disagree $\bigcirc$ strongly Disagree 
21- Teacher uses echo and choral reading on a regular basis to increase fluency

$\bigcirc$ strongly Agree $\bigcirc$ Moderately Agree $\bigcirc$ Mildly Agree

$\bigcirc$ Mildy Disagree $\bigcirc$ Moderately Disagree $\bigcirc$ Strongly Disagree

Comments

22- Teacher teaches students how to gain meaning from text through proper phrasing of text which demontrates understanding

$\bigcirc$ strongly Agree $\bigcirc$ Moderately Agree $O$ Mildly Agree

$\bigcirc$ Mildy Disagree $\bigcirc$ Moderately Disagree $\bigcirc$ Strongly Disagree

Comments

23- Teacher uses poetry, big books of rhyme or songs to assist in phonemic awareness

$\bigcirc$ Strongly Agree $\bigcirc$ Moderately Agree $\bigcirc$ Mildly Agree

$\bigcirc$ Mildly Disagree $\bigcirc$ Moderately Disagree $\bigcirc$ strongly Disagree

Comments

24- Teacher teaches, prior to reading, words that are key to selotion comprehension

$\bigcirc$ Strongly Agree $\bigcirc$ Moderately Agree $\bigcirc$ Mildly Agree

$\bigcirc$ Mildy Disagree $\bigcirc$ Moderately Disagree $\bigcirc$ Strongly Disagree

Comments

25- Teacher employs a variety of strategies to teach the skills of comprehension such as reading, context, Questioning the Author, Think Aloud, Think Along, Think Alone 
$\bigcirc$ Strongly Agree $\bigcirc$ Moderately Agree $\bigcirc$ Mildly Agree

$\bigcirc$ Mildly Disagree $\bigcirc$ Moderately Disagree $\bigcirc$ Strongly Disagree

Comments

26- Teacher prompts during the reading of texts to ask questions and monitor students' use of reading strategies and selection comprehension

strongly Agree $\bigcirc$ Moderately Agree $\bigcirc$ Mildly Agree

$\bigcirc$ Mildy Disagree $\bigcirc$ Moderately Disagree $\bigcirc$ strongly Disagree

Comments

27- Teacher provides students with opportunities to demonstrate text comprehension through writing short answer questions

$\bigcirc$ strongly Agree $\bigcirc$ Moderately Agree $\bigcirc$ Mildly Agree

$\bigcirc$ Mildly Disagree $\bigcirc$ Moderately Disagree $\bigcirc$ strongly Disagree

Comments

28- Teacher demonstrates the act of writing and the writing process

$\bigcirc$ strongly Agree $\bigcirc$ Moderately Agree $\bigcirc$ Mildy Agree

$\bigcirc$ Mildly Disagree $\bigcirc$ Moderately Disagree $\bigcirc$ Strongly Disagree

Comments

29- Teacher helps students generate ideas for writing

$\bigcirc$ strongly Agree $\bigcirc$ Moderately Agree $O$ Mildty Agree

$\bigcirc$ Mildy Disagree $\bigcirc$ Moderately Disagree $\bigcirc$ Strongly Disagree

Comments

Comments

30- Teacher allows students to draw pictures before reading to assist in sequencing writing 
$\bigcirc$ Strongly Agree $\bigcirc$ Moderately Agree $\bigcirc$ Mildly Agree

$\bigcirc$ Mildy Disagree $\bigcirc$ Moderately Disagree $\bigcirc$ Strongly Disagree

Comments

\section{1- Teacher allows students to share writing}

$\bigcirc$ 5trongly Agree $\bigcirc$ Moderately Agree $\bigcirc$ Mildly Agree

$\bigcirc$ Mildly Disagree $\bigcirc$ Moderately Disagree $O$ Strongly Disagree

Comments

32- Teacher use phonemic awareness skills to assist in writing unknown words

$\bigcirc$ strongly Agree $\bigcirc$ Moderately Agree $\bigcirc$ Mildly Agree

$\bigcirc$ Mildly Disagree $\bigcirc$ Moderately Disagree $\bigcirc$ strongly Disagree

Comments

33- Teacher encourages students to participate in the writing center

$\bigcirc$ Strongly Agree $\bigcirc$ Moderately Agree $\bigcirc$ Mildly Agree

$\bigcirc$ Mildy Disagree $\bigcirc$ Moderately Disagree $\bigcirc$ strongly Disagree

Comments

34- Teacher has individuals write known letters, words, or phrases

$\bigcirc$ Strongly Agree $\bigcirc$ Moderately Agree $\bigcirc$ Mildy Agree

$\bigcirc$ Mildy Disagree $\bigcirc$ Moderately Disagree $\bigcirc$ strongly Disagree

Comments

35- Teacher asks students to participate in the writing at strategic points 
5trongly Agree $\bigcirc$ Moderately Agree $\bigcirc$ Mildly Agree

$\bigcirc$ Mildly Disagree $\bigcirc$ Moderately Disagree $\bigcirc$ Strongly Disagree

Comments

\section{6- Teacher reviews the writing process}

$\bigcirc$ strongly Agree $\bigcirc$ Moderately Agree $\bigcirc$ Mildly Agree

$\bigcirc$ Mildy Disagree $\bigcirc$ Moderately Disagree $\bigcirc$ strongly Disagree

Comments

\section{7- Teacher reviews or models what to write and how to plan}

$\bigcirc$ strongly Agree $\bigcirc$ Moderately Agree $\bigcirc$ Mildy Agree

$\bigcirc$ Mildy Disagree $\bigcirc$ Moderately Disagree $O$ Strongly Disagree

Comments

38- Teacher observes students and assists them in their writing efforts

$\bigcirc$ Strongly Agree $\bigcirc$ Moderately Agree $\bigcirc$ Mildly Agree

$\bigcirc$ Mildy Disagree $\bigcirc$ Moderately Disagree $\bigcirc$ strongly Disagree

Comments

39- Teacher calls attention to words, phrases, sentences, and7or punctiation

$\bigcirc \bigcirc$ Strongly Agree $\bigcirc$ Moderately Agree $\bigcirc$ Mildly Agree

$\bigcirc$ Mildy Disagree $\bigcirc$ Moderately Disagree $\bigcirc$ strongly Disagree

Comments

Submit and Proceed to Next Section 


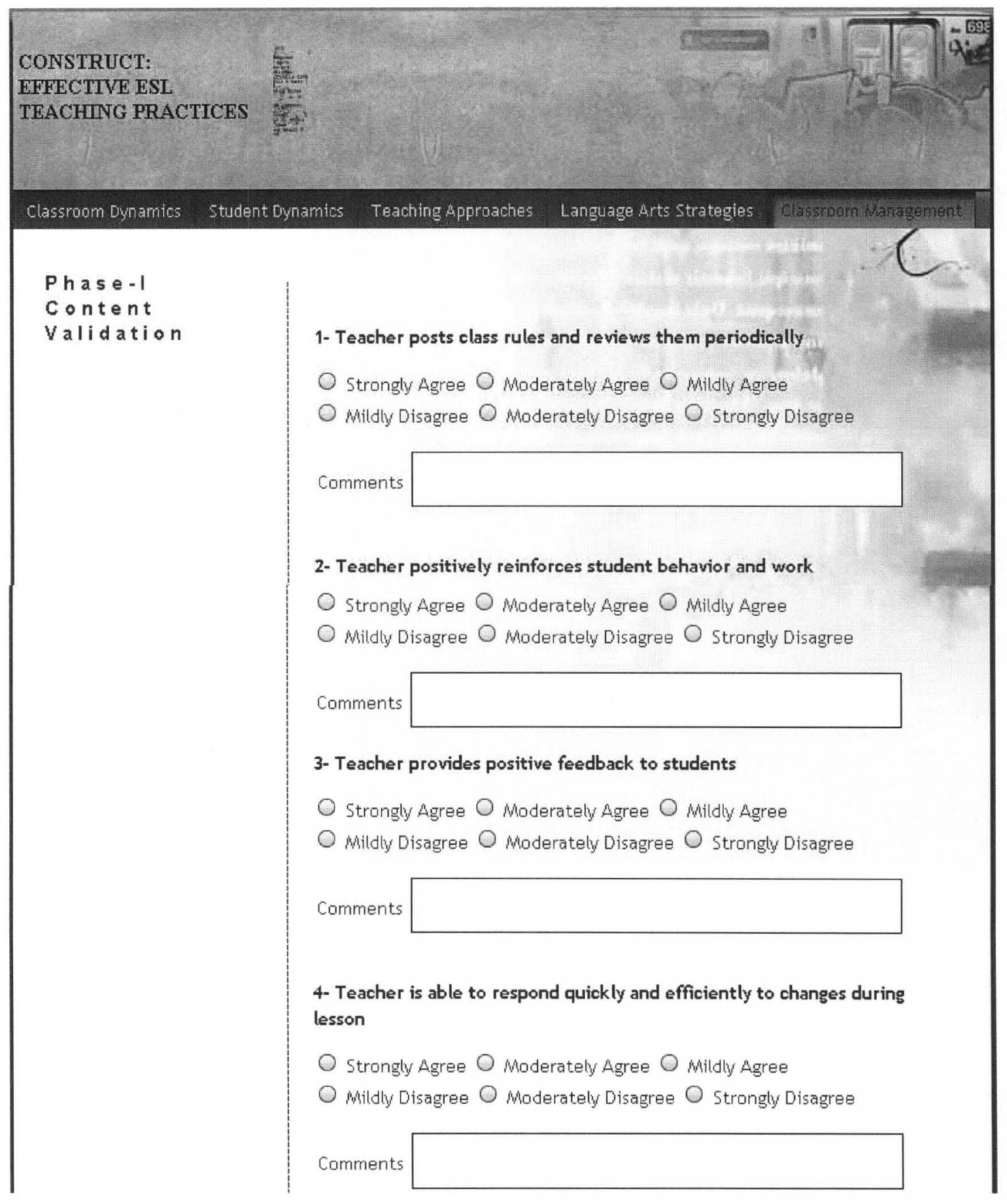


5- Teacher provides corrective actions to students every time students choose to disrupt

$\bigcirc$ Strongly Agree $\bigcirc$ Moderately Agree $\bigcirc$ Mildly Agree

$\bigcirc$ Mildy Disagree $\bigcirc$ Moderately Disagree $\bigcirc$ strongly Disagree

Comments

6- Teacher provides positive immediate feedback to students

$\bigcirc$ Strongly Agree $\bigcirc$ Moderately Agree $\bigcirc$ Mildly Agree

$\bigcirc$ Mildly Disagree $\bigcirc$ Moderately Disagree $\bigcirc$ strongly Disagree

Comments

7- Teacher positively disciplines, encourages and motivastes intervention students

Strongly Agree $\bigcirc$ Moderately Agree $\bigcirc$ Mildy Agree

$\bigcirc$ Mildly Disagree $\bigcirc$ Moderately Disagree $\bigcirc$ Strongly Disagree

Comments

8- Teacher communicates clearly that students have the power to make choices, yet they need to accept the responsibility that goes with it

$\bigcirc$ strongly Agree $\bigcirc$ Moderately Agree $\bigcirc$ Mildy Agree

$\bigcirc$ Mildly Disagree $\bigcirc$ Moderately Disagree $\bigcirc$ strongly Disagree

Comments

9- Teacher establishes rules that are observable and continually in effect

$\bigcirc$ strongly Agree $\bigcirc$ Moderately Agree $\bigcirc$ Mildly Agree

$\bigcirc$ Mildy Disagree $\bigcirc$ Moderately Disagree $\bigcirc$ Strongly Disagree

Comments

10- Teacher uses supportive approaches to keep students on task 
Strongly Agree $\bigcirc$ Moderately Agree $\bigcirc$ Mildly Agree

$\bigcirc$ Mildy Disagree $\bigcirc$ Moderately Disagree $\bigcirc$ strongly Disagree

Comments

11- Teacher provides corrective acions in a calm, matter-of-fact manner

$\bigcirc$ Strongly Agree $\bigcirc$ Moderately Agree $\bigcirc$ Mildly Agree

$\bigcirc$ Mildly Disagree $\bigcirc$ Moderately Disagree $\bigcirc$ strongly Disagree

Comments

12- Teacher is consistent, and provides clear, concise directions that are easy for students to follow

$\bigcirc$ strongly Agree $\bigcirc$ Moderately Agree $\bigcirc$ Mildly Agree

$\bigcirc$ Mildly Disagree $\bigcirc$ Moderately Disagree $\bigcirc$ Strongly Disagree

Comments

13- Teacher uses behavioral narration to motivate students to get on task

Strongly Agree $\bigcirc$ Moderately Agree $\bigcirc$ Mildy Agree

$\bigcirc$ Mildly Disagree $\bigcirc$ Moderately Disagree $\bigcirc$ Strongly Disagree

Comments

14- Teacher implements class-wide reward system

$\bigcirc$ strongly Agree $\bigcirc$ Moderately Agree $\bigcirc$ Mildy Agree

$\bigcirc$ Mildy Disagree $\bigcirc$ Moderately Disagree $\bigcirc$ strongly Disagree

Comments

16- Teacher recognizes positive behavior at the first opportunity after correcting a student's behavior 


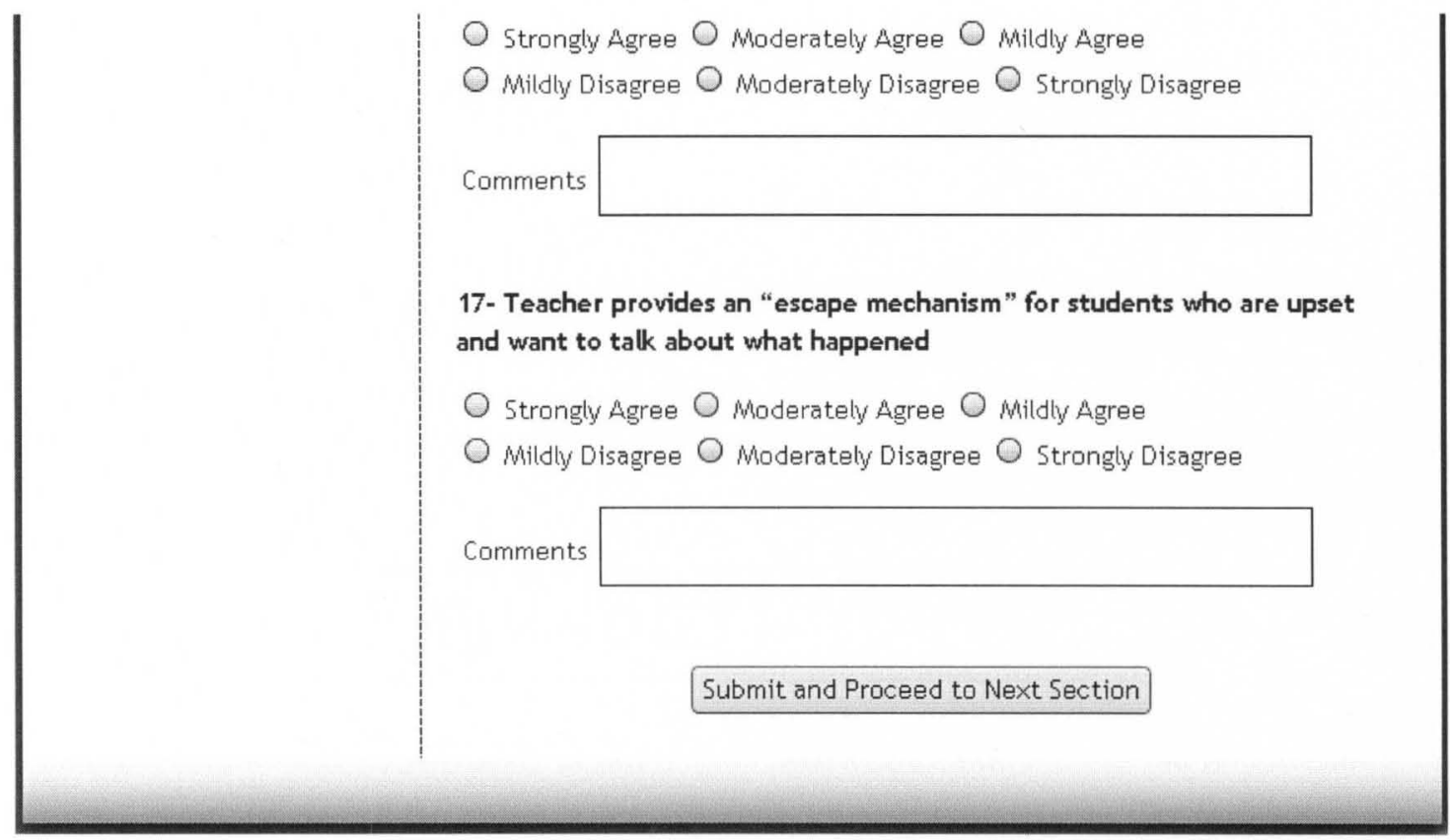

CONSTRUCT:

EFFECTIVE ESL

TEACHING PRACTICES

$P$ hase - I

Content

Validation

MARIA G,

Thanks for your Participation! 


\section{APPENDIX C}

\section{C1. EXPERTS SUGGESTIONS FOR ITEMS MODIFICATIONS}

Panel of experts' suggestions for modification: Classroom Dynamics

\begin{tabular}{|c|c|}
\hline Items & Suggestions \\
\hline \multicolumn{2}{|l|}{$\begin{array}{l}\text { CD1 Teacher is organized and starts } \\
\text { class promptly }\end{array}$} \\
\hline $\begin{array}{l}\text { CD2 Teacher displays consistent } \\
\text { opening routine }\end{array}$ & Eliminate the word consistent. \\
\hline $\begin{array}{l}\text { CD3 Teacher posts and refers to agenda } \\
\text { for student tasks }\end{array}$ & Substitute agenda for with list of \\
\hline $\begin{array}{l}\text { CD4 Teacher clearly explains to } \\
\text { students what they will be learning and } \\
\text { doing }\end{array}$ & Eliminate \\
\hline $\begin{array}{l}\text { CD5 Teacher introduces morning } \\
\text { message for oral communication }\end{array}$ & Eliminate \\
\hline $\begin{array}{l}\text { CD6 Teacher incorporates days of the } \\
\text { week into the lesson }\end{array}$ & Eliminate \\
\hline $\begin{array}{l}\text { CD7 Teacher incorporates daily weather } \\
\text { into the lesson }\end{array}$ & Eliminate \\
\hline $\begin{array}{l}\text { CD9 Teacher incorporates learning } \\
\text { activities into transition times }\end{array}$ & Eliminate \\
\hline $\begin{array}{l}\text { CD10 Teacher keeps transition times to } \\
\text { a minimum }\end{array}$ & $\begin{array}{l}\text { Meaning ambiguous, change to } \\
\text { transition time between activities }\end{array}$ \\
\hline $\begin{array}{l}\text { CD11 Teacher changes center or group } \\
\text { work frequently }\end{array}$ & Eliminate \\
\hline $\begin{array}{l}\text { CD14 Teacher demonstrates } \\
\text { connections between past, present, and } \\
\text { future lessons }\end{array}$ & Eliminate \\
\hline $\begin{array}{l}\text { CD15 Teacher elicits reflective } \\
\text { comments from students on activities }\end{array}$ & Eliminate \\
\hline
\end{tabular}


Panel of experts' suggestions for modification: Student Dynamics

\begin{tabular}{|c|c|}
\hline Items & Suggestions \\
\hline $\begin{array}{l}\text { SD2 Teacher encourages students to give } \\
\text { elaborated responses }\end{array}$ & $\begin{array}{l}\text { Change encourages to } \\
\text { prompts. } \\
\text { Add in the target language } \\
\text { after responses }\end{array}$ \\
\hline $\begin{array}{l}\text { CD3 Teacher consistently provides wait- } \\
\text { and-think time for student response } \\
\text { CD4 Teacher encourages students to share } \\
\text { responsibility for instruction by constructing } \\
\text { and writing the text }\end{array}$ & $\begin{array}{l}\text { Change provides to facilitates } \\
\text { and use the plural of response } \\
\text { Eliminate }\end{array}$ \\
\hline $\begin{array}{l}\text { CD6 Teacher accepts multiple responses that } \\
\text { students can support }\end{array}$ & $\begin{array}{l}\text { Add in the target language } \\
\text { after support }\end{array}$ \\
\hline $\begin{array}{l}\text { CD8 Teacher structures opportunities to } \\
\text { speak target language }\end{array}$ & Eliminate \\
\hline $\begin{array}{l}\text { CD9 Teacher provides opportunities for } \\
\text { communicating with others about what is } \\
\text { read in the target language }\end{array}$ & Eliminate \\
\hline $\begin{array}{l}\text { CD10 Teacher engages students in } \\
\text { discussions about, a response to, and } \\
\text { specific elements or contents of the book in } \\
\text { the target language }\end{array}$ & Eliminate \\
\hline $\begin{array}{l}\text { CD1 } 1 \text { Students demonstrate desire to talk } \\
\text { and interact in the target language }\end{array}$ & $\begin{array}{l}\text { Change to Teacher aims to } \\
\text { encourage the students' desire } \\
\text { to use and interact in the target } \\
\text { language. }\end{array}$ \\
\hline CD12 Students exhibit on-task behavior & Eliminate \\
\hline $\begin{array}{l}\text { CD13 Students engage in discussions about } \\
\text { texts they read in the target language }\end{array}$ & Eliminate \\
\hline CD15 Students actively engage in writing & $\begin{array}{l}\text { Change to Teacher provides } \\
\text { activities in which students are } \\
\text { engaged in writing in the } \\
\text { target language }\end{array}$ \\
\hline
\end{tabular}


Panel of experts' suggestions for modification: Teaching Approaches

Items
TA1 Teacher provides explicit
instruction in Target language
TA3 Teacher gives a chalk-talk with
drawings on the board
TA4 Teacher only uses the target
language for communication as well as
feature of the target language culture to
talk about it
TA5 Teacher selects and incorporates
students' responses, ideas, examples,
and experiences into lesson

TA6 Teacher uses direct explicit Suggestions

Change to Teacher provides

explicit instructions with the

minimal use of $L 1$

Eliminate

Change to Teacher mostly uses

the target language for

communication and talk about

culture

Change to Teacher selects and

incorporates students'

spontaneous unplanned

contributions into lesson.

Eliminate

instruction to teach unknown words and expand knowledge of known words TA7 Teacher models critical thinking questions and answers in a variety forms

TA8 Teacher introduces the book and discusses the title, author, and illustrator TA10 Teacher models the use of comprehension strategies to make content understandable

TA11 Teacher builds instructional context for students

TA13 Teacher makes connections between their knowledge and experiences and the ideas, events, and information in the text

TA16 Teacher ensures students are not only responsible for learning the material that is presented, but also for ensuring everyone in the group knows the material as well

TA17 Teachers direct students participate in group work and know their role in the group

TA18 Teacher works with a small group of students, at the same instructional level with the same text TA19 Teacher develops routines for students moving to and from centers, stations, literature circles

Add of before forms

Eliminate

Eliminate

Eliminate

Eliminate

Change to Group work incorporates individual and group accountability

Eliminate

Eliminate

Change develops to has developed and add and before literature circles 
TA20 Teacher establishes learning centers that provide opportunities for direct application of previously taught skills and strategies

TA24 Teacher calls attention to words, phrases, sentences, and/or punctuation
Eliminate

Eliminate

Panel of experts' suggestions for modification: Language Arts Strategies

\begin{tabular}{|c|c|}
\hline Items & Suggestions \\
\hline $\begin{array}{l}\text { LAS1 Teacher structures opportunities } \\
\text { to speak target language throughout } \\
\text { lesson }\end{array}$ & Eliminate \\
\hline $\begin{array}{l}\text { LAS2 Teacher uses the Morning } \\
\text { Message to encourage students in oral } \\
\text { participation }\end{array}$ & Eliminate \\
\hline $\begin{array}{l}\text { LAS4 Teacher encourages students to } \\
\text { explain their thinking in their own } \\
\text { words }\end{array}$ & $\begin{array}{l}\text { Change to Teachers facilitates } \\
\text { students' use of their own words } \\
\text { in target language }\end{array}$ \\
\hline $\begin{array}{l}\text { LAS5 Teacher accepts multiple } \\
\text { responses that students can support }\end{array}$ & Eliminate \\
\hline $\begin{array}{l}\text { LAS6 Teacher connects spelling to } \\
\text { phonics and modeling spelling } \\
\text { strategies }\end{array}$ & Change modeling to models \\
\hline $\begin{array}{l}\text { LAS7 Teacher encourages students to } \\
\text { use strategies of phonemic awareness to } \\
\text { say words slowly before spelling them } \\
\text { in writing }\end{array}$ & Eliminate \\
\hline $\begin{array}{l}\text { LAS8 Teacher uses echo or choral } \\
\text { reading to promote fluency }\end{array}$ & Eliminate \\
\hline $\begin{array}{l}\text { LAS9 Teacher provides direct explicit } \\
\text { instruction in each of the aspects of } \\
\text { phonemic awareness }\end{array}$ & Eliminate \\
\hline $\begin{array}{l}\text { LAS } 10 \text { Teacher models and directs } \\
\text { practice in rhyming }\end{array}$ & Eliminate \\
\hline $\begin{array}{l}\text { LAS11 Teacher provides systematic } \\
\text { instruction in phonemic awareness }\end{array}$ & Eliminate \\
\hline $\begin{array}{l}\text { LAS12 Teacher provides systematic } \\
\text { instruction in letter-sound } \\
\text { correspondence }\end{array}$ & Eliminate \\
\hline $\begin{array}{l}\text { LAS13 Teacher provides systematic } \\
\text { instruction in decoding }\end{array}$ & Eliminate \\
\hline $\begin{array}{l}\text { LAS14 Teacher provides systematic } \\
\text { instruction to vocabulary development }\end{array}$ & Eliminate \\
\hline $\begin{array}{l}\text { LAS16 Teacher uses poetry, big books } \\
\text { of rhyme or songs to assist in phonemic } \\
\text { awareness }\end{array}$ & Eliminate \\
\hline
\end{tabular}


LAS17 Teacher teaches the relationship Eliminate between spoken and written letters LAS1 8 Teacher enhances and enriches phonics by teaching strategies which help students have alternative methods of decoding words

LAS19 Teacher systematically teaches the most productive phonics' rules LAS20 Teacher solidifies knowledge of the alphabet through multiple tasks LAS21 Teacher uses echo and choral reading on a regular basis to increase fluency

LAS22 Teacher teaches students how to gain meaning from text through proper phrasing of text which demonstrates understanding LAS24 Teacher teaches, prior to reading, words that are key to selection comprehension

LAS25 Teacher employs a variety of strategies to teach the skills of comprehension such as rereading, context, Questioning the Author, Think Aloud, Think Along, Think Alone LAS26 Teacher prompts during the reading of texts to ask questions and monitor students' use of reading strategies and selection comprehension LAS27 Teacher provides students with opportunities to demonstrate text comprehension through writing short answer questions

LAS28 Teacher demonstrates the act of writing and the writing process LAS29 Teacher helps students generate ideas for writing LAS30 Teacher allows students to draw pictures before reading to assist in sequencing writing

LAS31 Teacher allows students to share writing

LAS32 Teacher use phonemic awareness skills to assist in writing

Change to Teacher enhances and enriches phonics by teaching strategies which help students have alternative methods of decoding words and develop new vocabulary

Change productive to prevalent

Eliminate

Eliminate

Change to Teacher encourages to gain meaning from text through proper phrasing that demonstrates understanding Eliminate

Eliminate

Delete and selection comprehension

Eliminate

Eliminate

Merge with 31 .

Change before to through

Change to Teacher facilitates the sharing of student writing Eliminate 
unknown words

LAS33 Teacher encourages students to Eliminate participate in the writing center

LAS34 Teacher has individuals write Eliminate

known letters, words, or phrases

LAS35 Teacher asks students to

participate in the writing at strategic

points

LAS36 Teacher reviews the writing process

LAS37 Teacher reviews or models what to write and how to plan

Eliminate

Eliminate

Change to Teacher reviews or

models how to plan and what to

write

LAS39 Teacher calls attention to words, Eliminate phrases, sentences, and/or punctuation

Panel of experts' suggestions for modification: Classroom Management

Items
reviews them periodically
resier posts class rules and
CM3 Teacher provides positive
feedback to students
CM4 Teacher is able to respond quickly
and efficiently to changes during lesson
CM6 Teacher provides positive

CM6 Teacher provides positive

Suggestions

Change to Teacher implements a

class - wide reward system with

rules that are observable and

reviews them periodically

Eliminate

immediate feedback to students

CM7 Teacher positively disciplines,

Eliminate

encourages and motivates intervention

student

CM9 Teacher establishes rules that are

observable and continually in effect

CM10 Teacher uses supportive

Eliminate

approaches to keep students on task

CM11 Teacher provides corrective

actions in a calm, matter-of-fact manner

CM12 Teacher is consistent

Eliminate

CM13 Teacher provides clear, concise directions that are easy for students to follow

CM14 Teacher uses behavioral

Eliminate

Eliminate

Eliminate

Change to Teacher is consistent and provides clear, concise directions that are easy for students to follow

Eliminate narration to motivate students to get on task 
CM15 Teacher implements class-wide reward system

CM16 Teacher recognizes positive behavior at the first opportunity after correcting a student's behavior
Eliminate

Merge with 17 to Teacher recognizes positive behavior at the first opportunity after correcting a student's behavior and provides an "escape mechanism" for students who are upset and want to talk about what happened.

Eliminate

CM17 Teacher provides an "escape mechanism" for students who are upset and want to talk about what happened 


\section{C2. EACH EXPERT SUGGESTIONS FOR ITEMS MODIFICATIONS}

Panel of experts' suggestions for modifications: Classroom Dynamics

\begin{tabular}{|c|c|}
\hline \multirow{2}{*}{$\begin{array}{l}\text { Expert } \\
\text { Expert } 1\end{array}$} & Suggestions \\
\hline & $\begin{array}{l}\text { CD2 This is confusing. Is the teacher being observed more than } \\
\text { once? Or does this mean that the opener is consistent with the } \\
\text { approved/required methodology of curriculum? } \\
\text { CD3 Instead of "agenda for" how about "list of" } \\
\text { CD4 Okay. Note that this is similar to item CD3, eliminate } \\
\text { CD5 What is "morning message"? Is this part of the } \\
\text { curriculum? If so, use quotations. This is a minor point. Is this } \\
\text { something that always takes place in the morning? } \\
\text { CD6 and CD7 are very similar. It seems like overkill to be } \\
\text { required to do both of these things every day. Do classes meet } \\
\text { daily? What about a checklist, where teachers would need to do } \\
\text { at least ONE specified things, like these two items? } \\
\text { CD9 This is awkward. Are "transition times" unstructured times } \\
\text { between parts of a lesson? Again, a checklist might be helpful } \\
\text { and "other: } \\
\text { an observation worksheet it transparent, it can be instructional } \\
\text { for teachers and teachers training, kind of like a rubric. } \\
\text { CD10 This potentially contradicts the item above. Do you mean } \\
\text { the amount of time for a transition or the number of transitions? } \\
\text { CD11 This is nice, especially for children. Is there a rule of } \\
\text { thumb for the number of activities in one lesson that would be } \\
\text { deemed too many or too few? } \\
\text { CD14 This is good, but the "future" might not always be } \\
\text { realistic. You might delete that part. }\end{array}$ \\
\hline Expert 2 & $\begin{array}{l}\text { CD1 Okay } \\
\text { CD8 This look good } \\
\text { CD12 Good }\end{array}$ \\
\hline \multicolumn{2}{|l|}{ Expert 3} \\
\hline Expert 5 & $\begin{array}{l}\mathrm{CD} 2 \text { Eliminate the word consistent } \\
\mathrm{CD} 7 \text { This is important for early elementary but not so } \\
\text { appropriate for the situation, I am not sure about it } \\
\text { CD14 May be difficult to early ECE students to "get" but very } \\
\text { important nonetheless. }\end{array}$ \\
\hline $\begin{array}{l}\text { Expert } 6 \\
\text { Expert } 7\end{array}$ & \\
\hline Expert 8 & $\begin{array}{l}\text { CD4 Similar to CD3 } \\
\text { CD5, CD6, and CD7 group them } \\
\text { CD11 Is this a specific way to work? Centers? }\end{array}$ \\
\hline Expert 9 & $\begin{array}{l}\text { Incorporate more the use of the target language } \\
\text { CD9 What exactly is a transition time? Is it unstructured time? } \\
\text { This is very unclear. }\end{array}$ \\
\hline
\end{tabular}


Expert

CD14 Past and present. Future seems more optional

10

Expert CD2 Can you see that in one observation?

11 CD5, CD6, CD7 can be one more general about classroom routines to open the lesson like $\mathrm{CD} 2$

CD8 Change Teacher paces the lesson appropriately for The lesson is appropriate

CD11 Often this does not happen frequently but one or two times a lesson

CD12 Change Teacher paces activities to keep for Students' keep CD15 May be difficult to see that in one lesson

CD16 Unclear and maybe difficult to observe

Expert CD15 Eliminate, difficult to observe

12

Expert

13

Panel of experts' suggestions for modifications: Student Dynamics

\begin{tabular}{ll}
\hline Expert & Suggestions \\
\hline Expert 1 & SD2 Instead of "encourages", how about "prompts"? \\
& SD3 Add "s" to "response". Instead of "provides", how \\
about "facilitates"? \\
SD4 Add "collaborating in" after by \\
SD8 Similar to SD7 \\
SD9 Also similar to SD7 SD8 \\
SD10 Is this evaluative? This might be outside of the \\
teacher's control \\
SD11 Same comment as SD10. ONE generic item about \\
teacher/student interaction seems sufficient \\
SD13 Similar to SD8 and SD9 \\
SD14 Similar to an item of the first section, Classroom \\
Dynamics
\end{tabular}

Expert 2

Expert 3

Expert 4

Expert 5

Expert 6

Expert 7

Expert 8

Expert 9

SD9 "Material" instead of book, especially in this age as we move more and more towards multimedia

SD2 Delete "to participate" You might want a separate item on participation

SD9 I find this observation activity language a bit confusing

SD10 This might be asking too much. Perhaps this item should be deleted

SD4 and SD5 Unclear how to observe in lower grades

SD2 Add "in the target language"

SD3 Add "in the target language" 
SD6 Add "in the target language"

Expert $10 \quad$ SD5 Eliminate

Expert $11 \quad$ SD4 and SD5 difference is unclear

SD10 This is an activity more for adults

SD12, SD13, and SD14 similar

SD14 and SD15 overlap

Expert 12 SD14, I think questions 12 and 13 and 14 the same issue

Expert 13

Panel of experts' suggestions for modifications: Teaching Approaches

\begin{tabular}{ll}
\hline Expert & Suggestions \\
\hline Expert 1 & TA1 It seems minimal use of Llmight be permissible, \\
& realistically speaking. How about "with minimal use of \\
L1."? Having taught a foreign language, I am aware of the \\
challenges \\
TA3 "Chalk talk" is a specialized methodology. Is this a \\
requirement? Again, this might part of a checklist \\
addressing use of multi-media, where at least ONE check \\
mark would be minimally adequate. The checklist itself \\
would be instructional for teachers informing them of the \\
array of options available to them. This questionnaire is too \\
encompassing sing, so I am looking for way o consolidate \\
like items. \\
TA4 I would definitely change "only" to "mostly" \\
TA6 "Direct, explicit instruction" is a bit obscure. What \\
about freeing up the teacher and evaluating the \\
"effectiveness of teacher in teaching unknown words and \\
expanding knowledge of known words."?? I always say it is \\
possible to learn something new from a creative teacher \\
TA7 Add "of" before forms
\end{tabular}

TA9 I am not sure what a compression strategy is. Could a checklist be created to make this more explicit?

TA10 This is especially vague. As such, it could be deleted, unless there is some special value attached to this item, in which case, it needs to be made much more concrete. As I see it, all teachers build an instructional context for students, for better of for worse. What is important in here? T16 What about something like this: "Group work incorporates individual and group accountability." In this case, the next item could be deleted T18 This seems like an unrealistic item. The teacher cannot guarantee that students are tat the same level and in any given class hour, it may be impossible for her to actually work with a group. I would delete this item or perhaps replace it with something that indicates the teacher 


\begin{tabular}{|c|c|}
\hline & "monitors" groups \\
\hline & T19 Has developed... (add "and" before literature circles) \\
\hline & T23 This might not be possible in any particular class hour \\
\hline & but wouldn't mean that a teacher does not engage in such \\
\hline Expert 2 & activity. \\
\hline Expert 2 & $\begin{array}{l}\text { TA2 Good } \\
\text { TA5 Fliminate }\end{array}$ \\
\hline & TA8 Good \\
\hline & TA12 Good \\
\hline & T17 Difficult to observe \\
\hline & $\begin{array}{l}\text { T21 Good, except that sometimes teachers intentionally } \\
\text { choose to groun bv level }\end{array}$ \\
\hline & TA22 Good \\
\hline Expert 3 & TA3 Unclear \\
\hline Expert 4 & \\
\hline Expert 5 & $\begin{array}{l}\text { TA4 To help students make the "known to the new" for } \\
\text { learning about culture, I think allowances need to }\end{array}$ \\
\hline & $\begin{array}{l}\text { TA6 As well as other good vocabulary instructional } \\
\text { strategies, I would eliminate it }\end{array}$ \\
\hline & $\begin{array}{l}\text { TA18 Should this be more about "flexible" grouping? Or are } \\
\text { you specifically looking for small group/partn., not clear }\end{array}$ \\
\hline & $\begin{array}{l}\text { TA18 A good goal- not sure of the strength of this for } K-2 \text {. } \\
\text { Upper grades ves }\end{array}$ \\
\hline & TA20 and TA21 Good goals. Sometimes classroom space \\
\hline & simply does not allow for this. \\
\hline Expert 6 & \\
\hline Expert 7 & TA16 Eliminate \\
\hline Expert 8 & \\
\hline Expert 9 & TA17, TA18, TA19, and TA20 Very similar, merge \\
\hline Expert 10 & TA4 Eliminate \\
\hline Expert 11 & TA3 How can this be done? Specific methodology? \\
\hline & TA5 Unclear, too similar \\
\hline & TA8 Too specific, not observable all the time \\
\hline & TA9 and TA10 Overlap \\
\hline & TA11 Unclear, teachers always builds context? \\
\hline & TA12 and TA13 Overlap \\
\hline & T20 and T21 Overlap \\
\hline Expert 12 & TA24 This is more applicable in upper grades \\
\hline Expert 13 & \\
\hline
\end{tabular}


Panel of experts' suggestions for modifications: Language Arts Strategies

\begin{tabular}{|c|c|}
\hline Expert & Suggestions \\
\hline Expert 1 & $\begin{array}{l}\text { LAS4 Very ambitious depending on the level of the students. } \\
\text { How about changing "encourages" to "facilitates" and } \\
\text { adjusting the syntax in the rest of the item? } \\
\text { LAS5 Change "modeling" to " models" } \\
\text { LAS8 This depend on the level. To free up a teacher, how } \\
\text { about "effective practices" to promote fluency? } \\
\text { LAS9 This relates to the spelling item above. Could a check } \\
\text { sheet used here? } \\
\text { LAS12 Don't the materials do this? How about something } \\
\text { like "calls attention to letter-sound correspondences? } \\
\text { LAS } 13 \text { And what would examples of this be? Of all words? } \\
\text { Of difficult words? This item needs attention } \\
\text { LAS } 14 \text { This item is also not very specific. What aspects of } \\
\text { vocabulary development and what methods are you looking } \\
\text { for? (checklist?) } \\
\text { LAS15 What kinds of questions do you want asked? (iteral } \\
\text { and interpretative, critical reading?) } \\
\text { LAS17 Overlap "productive" to "prevalent" } \\
\text { LAS } 19 \text { Change "prover } \\
\text { LAS20 This implies instruction at a very low level } \\
\text { LAS } 26 \text { Eliminate "and selection comprehension" } \\
\text { LAS30 Sounds great! But does every lesson have writing? } \\
\text { LAS } 31 \text { Change "allows" to "facilitates the sharing of } \\
\text { student writing } \\
\text { LAS32 Change "use" to "models" } \\
\text { LAS34 Where, in what context, this is rather vague } \\
\text { LAS35 In class writing? How? } \\
\text { LAS37 Change order of items }\end{array}$ \\
\hline Expert 2 & $\begin{array}{l}\text { LAS3 Good } \\
\text { LAS18 Unclear } \\
\text { LAS21 and LAS22 Not clear, you are talking about phrases } \\
\text { group here } \\
\text { LAS29 Good } \\
\text { LAS38 Good }\end{array}$ \\
\hline Expert 3 & $\begin{array}{l}\text { LAS36 Not observable in one lesson } \\
\text { LAS37 Unclear }\end{array}$ \\
\hline Expert 4 & $\begin{array}{l}\text { LAS18 Difficult to observe in students from lower grades } \\
\text { LAS21, LAS22 Difficult to observe in students from lower } \\
\text { grades }\end{array}$ \\
\hline
\end{tabular}

Expert 5 LAS3 Certainly research based through numerous studies LAS30 Allows students to draw pictures THROUGH reading.... 
Expert 6

Expert 7

LAS1 Overlapped with item in section 2

LAS 23 Good

LAS29 and LAS30 Merge

Expert 8

Expert 9

Expert 10

LAS30 and LAS31 Merge in one

Expert 11

LAS5 Eliminate

LAS2 Overlapped with items in section 1

LAS4 Add in target language

LAS5 Similar to item 6 in Student Dynamics, eliminate

LAS 7, LAS8, LAS9, LAS10, LAS11, LAS12 Overlap

LAS17 Similar to 6, eliminate

LAS32 Overlaps with 11

LAS35 Unclear

LAS36 Not observable in one lesson

LAS39 During writing? Unclear

Expert 12 LAS27, LAS28 Difficult to observed in lower grades, eliminate

Expert 13

Panel of experts' suggestions for modifications: Classroom Management

\begin{tabular}{ll}
\hline Expert & Suggestions \\
\hline Expert 1 & CM3 and CM6 Similar, also overlap with CM2 \\
& CM11 and CM16 Overlap \\
& As a general suggestion since items are very similar merge \\
& items \\
Expert 2 & CM1 Good \\
Expert 3 & CM9 and CM15 similar \\
Expert 4 & \\
Expert 5 & CM7 Unclear \\
Expert 6 & \\
Expert 7 & \\
Expert 8 & \\
Expert 9 & \\
Expert 10 & \\
Expert 11 & CM3, CM4, CM5 and CM6 Similar \\
Expert 12 & \\
Expert 13 & \\
\hline
\end{tabular}




\section{APPENDIX D}

\section{D1. PARTICIPANTS SURVEY INFORMED CONCENT FORM}

\section{UNIVERSITY OF \\ Q LOUISVILLE}

\section{这WKU}

Validation of an Observation Instrument for ELF Instruction in Spain: iFFOD

University of Louisville Nestern Kentucky University

Cooperative Doctoral Program Department of Educational Leadership.

Iniversity of Louisville Department of Educational Administration.

Leadership and Research, College of Education and Behavioral Sciences, Western Kentucky University

Informed Consent Form

Fall 2010

Dear Colleague:

Please accept this invitation to participate in a research study about effective practices for EFL/ESL instruction. This study is being conducted by Maria Gómez (doctoral candidate) and Dr. Christopher Wagner (Advisor) and sponsored by the Department of Leadership, Foundations, and Human Resource Education at the University of Loulsville (Uof)

This study involves completing an online survey. Participation in this study is entirely voluntary and should take approximately 15 minutes of your time.

By completing the survey you are voluntarily agreeing to participate. There are no known risks for your participation in this research study. The information collected may not benefit you directly. The information learned in this study may be helpful to others. Your complete survey will be compiled in aggregate format and maintained on a secure computer that is password protected. Presentations or publications of the study will be based on grouped data and will not reveal your identity. You may decline to answer any questions or stop taking part in this study at any time without penalty of losing any benefits to which you are otherwise entitled. Completion of this survey enters you into a random drawing to get a small token of appreciation for your participation.

If you have any questions or concerns please contact the principal investigator, Dr. Christopher Wagner, at (270) 745-4980. If you have any questions about your rights as a research subject, you may call the Human Subjects Protection Program office at (502) 852-5188. You will be given the opportunity to discuss any questions about your rights as a research subject, in private, with a member of the Institutional Review Board (IRB). The IRB is an independent committee composed of people from the University community, staff of the institutions, as well as people from the community not connected with these institutions. The IRB has reviewed and approved this research study. If you have concerns or complaints about the research or research staff and you do not wish to give your name, you may call 1-877-852-1167. This is a 24 hour hot line answered by people who do not work at the University of Louisville.

Sincerely,

Christopher wagner, Ph.D.

Maria Gómez, Doctoral candidate 


\section{D2. PARTICIPANTS DEMOGRAPHICS SURVEY}

\section{UNIVERSITY OF \\ Q LOUISVILLE}

\section{Validation of an Observation Instrument for ELF Instruction in Spain: iFFOD}

University of LouisvilleMvestern Kentucky University

Cooperative Doctoral Program Department of Educational Leadership.

University of Louisville Department of Educational Administration.

Leadership and Research, College of Education and Behavioral Sciences, Western Kentucky University

\section{DEMOGRAPHICS SURVEY}

\section{Dear Colleague:}

Thank you for your willingness to respond to this survey instrument that includes a number of teacher behaviors used in teaching English as a Foreign Language in Spain.

I am asking you to rate each item in terms of the extent to which you agree or disagree that it represents effective practices in teaching English as a foreign language in Spain for students at grades Pre-K through Second Grade.

There are five sections in the survey that include possible effective teaching practices.

These five sections are: Classroom Dynamics, Student Dynamics, Teaching Approaches, Language Arts Strategies, and Classroom Management.

When you finish each section please click submit at the bottom of the page and go to the next section.

Please do not use the back button on the top of the page when you are responding to the survey.

Thank you for your cooperation and assistance.

Instructions:

The purpose of this section is to gather demographic data and the extent of professional development activities associated with EFL Instruction. Please fill in, or check, the following items that apply to your best.

\begin{tabular}{|c|c|}
\hline 1. Age(in years) & \\
\hline 2. Gender & $\begin{array}{l}\text { Female } \\
\text { Male }\end{array}$ \\
\hline 3. Position & $\begin{array}{l}\text { Faculty } \\
\text { Administrator } \\
\text { Teacher }\end{array}$ \\
\hline 4. Teaching Experience in $\mathrm{K}-12$ Education & \\
\hline 5. Teaching Experience in Higer Education & \\
\hline $\begin{array}{l}\text { 6. During the last two years, have you participated in professional development activities regarding } \\
\text { EFL instruction: }\end{array}$ & $\begin{array}{l}\text { Yes } \\
\text { O No }\end{array}$ \\
\hline 7. Please select the level of training activities in which you more commonly participated in: & $\begin{array}{l}\text { Basic } \\
0 \text { Intermediate } \\
0 \text { Advanced } \\
0 \text { Teaching }\end{array}$ \\
\hline
\end{tabular}




\section{D3. PARTICIPANTS SURVEY}

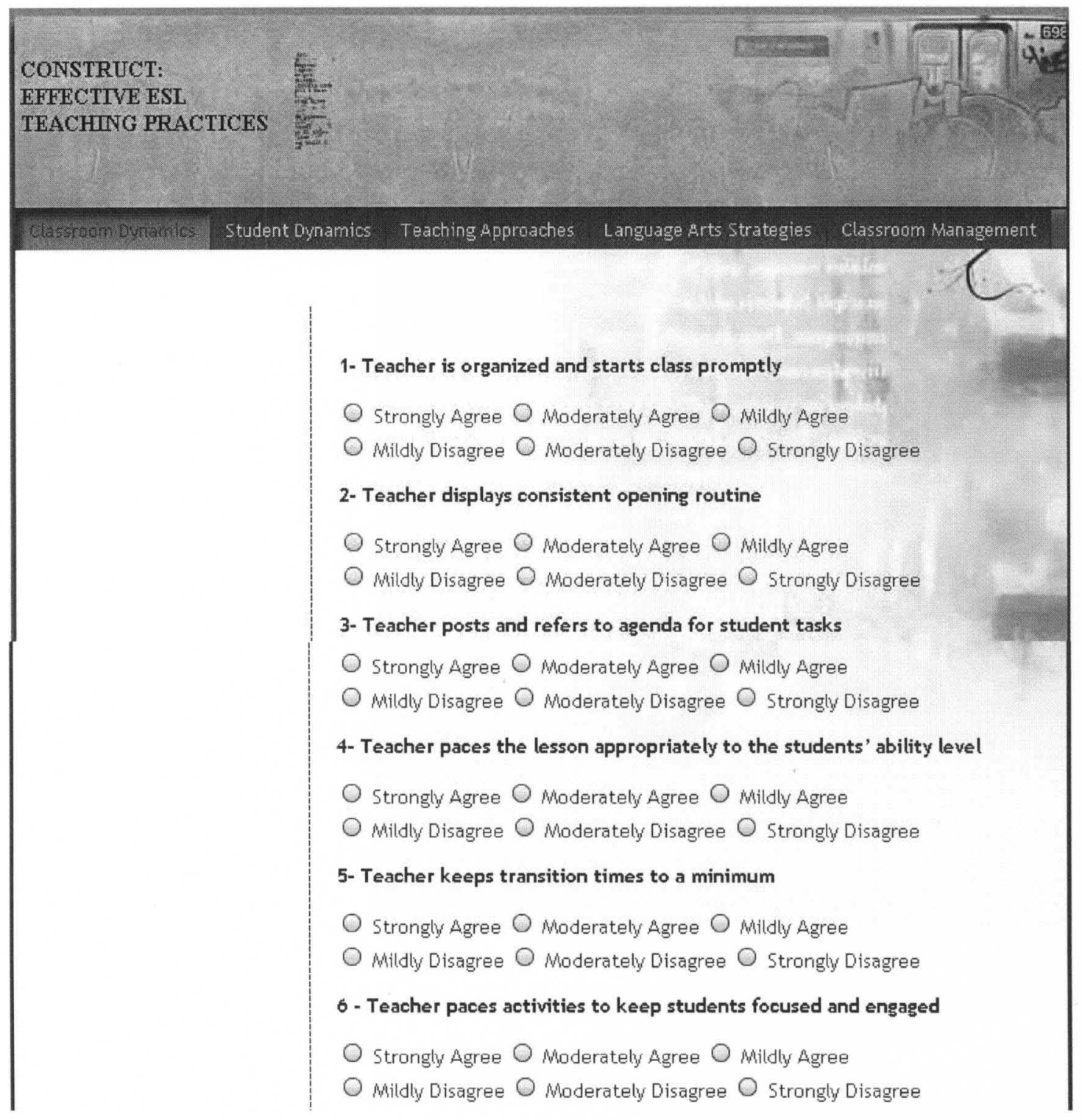




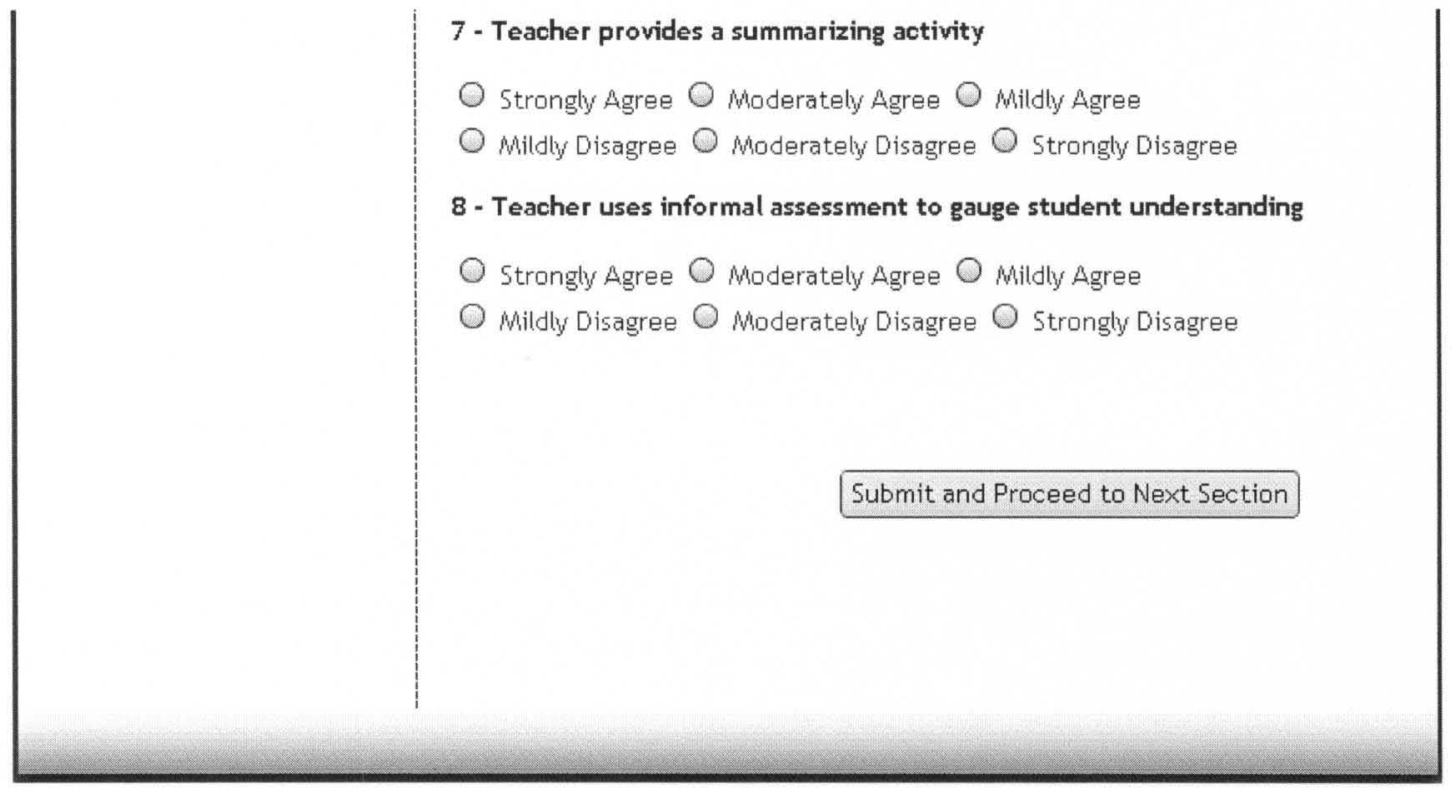


CONSTRUCT:

EFFECTIVE ESL

TEACHING PRACTICES

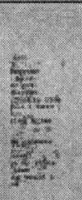

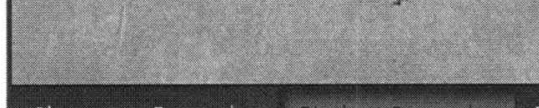

Classroom Dynamics

1- Teacher engages students to participate throughout the lesson

strongly Agree $\bigcirc$ Moderately Agree $\bigcirc$ Mildly Agree

$\bigcirc$ Mildy Disagree $\bigcirc$ Moderately Disagree $\bigcirc$ strongly Disagree

2- Teacher encourages students to give elaborated responses in target language

$\bigcirc$ strongly Agree $\bigcirc$ Moderately Agree $\bigcirc$ Mildly Agree

$\bigcirc$ Mildly Disagree $\bigcirc$ Moderately Disagree $\bigcirc$ strongly Disagree

3- Teacher consistently provides wait-and-think time for student response

$\bigcirc$ Strongly Agree $\bigcirc$ Moderately Agree $\bigcirc$ Mildly Agree

$\bigcirc$ Mildy Disagree $\bigcirc$ Moderately Disagree $\bigcirc$ strongly Disagree

4.- Teacher accepts multiple responses that students can support in the target language

Strongly Agree $\bigcirc$ Moderately Agree $\bigcirc$ Mildy Agree

$\bigcirc$ Mildy Disagree $\bigcirc$ Moderately Disagree $\bigcirc$ strongly Disagree

5.- Teacher provides frequent opportunities for interaction in the target language among students

$\bigcirc$ strongly Agree $\bigcirc$ Moderately Agree $\bigcirc$ Mildly Agree

$\bigcirc$ Mildy Disagree $\bigcirc$ Moderately Disagree $\bigcirc$ strongly Disagree

6.- Students demonstrate desire to talk and interact in the target language

$\bigcirc$ strongly Agree $\bigcirc$ Moderately Agree $\bigcirc$ Mildly Agree

$\bigcirc$ Mildly Disagree $\bigcirc$ Moderately Disagree $\bigcirc$ Strongly Disagree

7.- Students engage in discussions about texts they read in the target language 


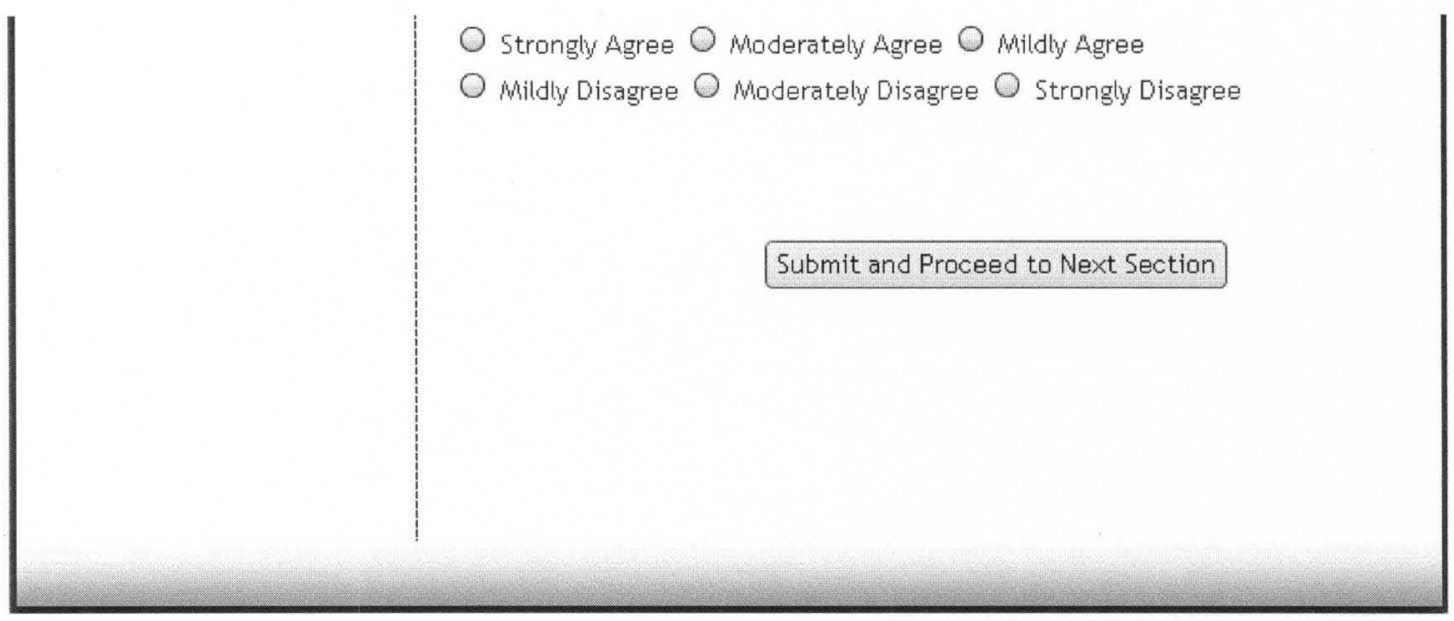


1- Teacher provides explicit instruction in target language

Strongly Agree $\bigcirc$ Moderately Agree $\bigcirc$ Mildly Agree

$\bigcirc$ Mildly Disagree $\bigcirc$ Moderately Disagree $\bigcirc$ strongly Disagree

2- Teacher introduces difficult vocabulary prior to and during lesson

$\bigcirc$ Strongly Agree $\bigcirc$ Moderately Agree $\bigcirc$ Mildly Agree

$\bigcirc$ Mildly Disagree $\bigcirc$ Moderately Disagree $\bigcirc$ strongly Disagree

3 - Teacher only uses the target language for communication and talk about culture

Strongly Agree $\bigcirc$ Moderately Agree $\bigcirc$ Mildly Agree

$\bigcirc$ Mildly Disagree $\bigcirc$ Moderately Disagree $\bigcirc$ Strongly Disagree

4- Teacher selects and incorporates students' responses, ideas, examples, and experiences into lesson

Strongly Agree $\bigcirc$ Moderately Agree $\bigcirc$ Mildly Agree

$\bigcirc$ Mildly Disagree $\bigcirc$ Moderately Disagree $\bigcirc$ strongly Disagree

5- Teacher models critical thinking questions and answers in a variety forms

$\bigcirc$ Strongly Agree $\bigcirc$ Moderately Agree $\bigcirc$ Mildly Agree

$\bigcirc$ Mildly Disagree $\bigcirc$ Moderately Disagree $\bigcirc$ strongly Disagree

6- Teacher stops at selected places to emphasize a point, ask a question, do a think-aloud, model a strategy, clarify information, or monitor students' comprehension.

$\bigcirc$ strongly Agree $\bigcirc$ Moderately Agree $\bigcirc$ Mildly Agree

$\bigcirc$ Mildly Disagree $\bigcirc$ Moderately Disagree $\bigcirc$ Strongly Disagree

7- Teacher links concepts to student's background experiences, and makes explicit connections between past learning and new concepts 
$\bigcirc$ Strongly Agree $\bigcirc$ Moderately Agree $\bigcirc$ Mildly Agree

$\bigcirc$ Mildy Disagree $\bigcirc$ Moderately Disagree $\bigcirc$ Strongly Disagree

8 - Teacher helps students make connections between the text and personal knowledge and experiences

$\bigcirc$ strongly Agree $\bigcirc$ Moderately Agree $\bigcirc$ Mildly Agree

$\bigcirc$ Mildly Disagree $\bigcirc$ Moderately Disagree $\bigcirc$ strongly Disagree

9 - Teacher utilizes small groups to encourage students to work together to reach a common goal

$\bigcirc$ Strongly Agree $\bigcirc$ Moderately Agree $\bigcirc$ Mildly Agree

$\bigcirc$ Mildly Disagree $\bigcirc$ Moderately Disagree $\bigcirc$ strongly Disagree

10 - Teacher ensures that not only are individual students responsible for learning the material but also for ensuring everyone in the group knows the material as well

$\bigcirc$ Strongly Agree $\mathrm{O}$ Moderately Agree $\mathrm{O}$ Mildly Agree

$\bigcirc$ Mildly Disagree $\bigcirc$ Moderately Disagree $\bigcirc$ strongly Disagree

11- Teacher develops routines for students moving to and from centers, stations, literature circles

Strongly Agree $\bigcirc$ Moderately Agree $\bigcirc$ Mildly Agree

$\bigcirc$ Mildly Disagree $\bigcirc$ Moderately Disagree $O$ strongly Disagree

12 - Teacher shares responsibility for classroom routines with job boards or assignment charts

$\bigcirc$ strongly Agree $\bigcirc$ Moderately Agree $\bigcirc$ Mildy Agree

$\bigcirc$ Mildy Disagree $\bigcirc$ Moderately Disagree $\bigcirc$ strongly Disagree

13 - Teacher reviews comprehension skills and strategies in small group or literature circles

$\bigcirc$ Strongly Agree $\bigcirc$ Moderately Agree $\bigcirc$ Mildly Agree

$\bigcirc$ Mildy Disagree $\bigcirc$ Moderately Disagree $\bigcirc$ Strongly Disagree

Submit and Proceed to Next Section 


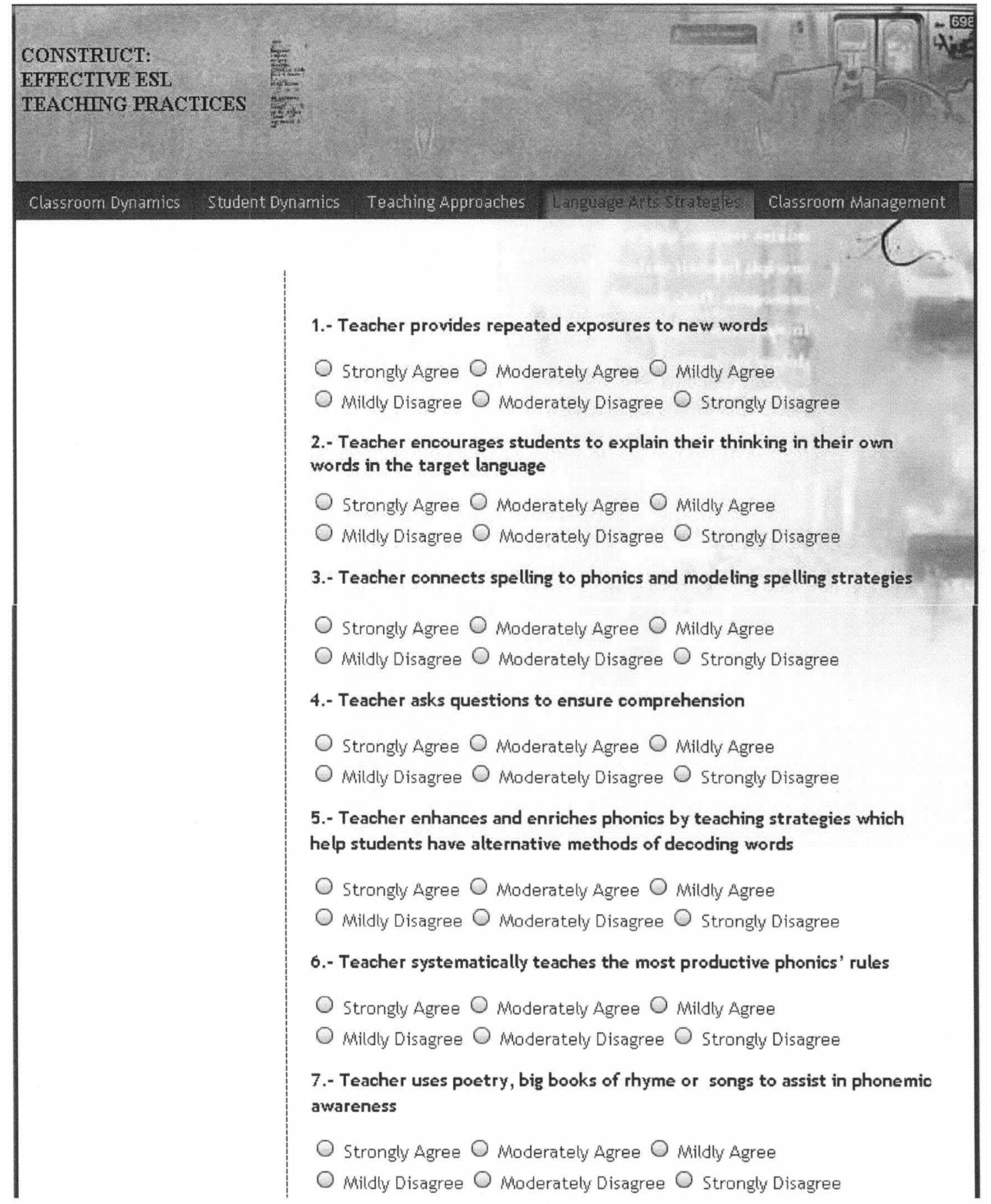


8.- Teacher prompts during the reading of texts to ask questions and monitor students' use of reading strategies and selection comprehension

$\bigcirc$ Strongly Agree $\bigcirc$ Moderately Agree $\bigcirc$ Mildy Agree

$\bigcirc$ Mildly Disagree $\bigcirc$ Moderately Disagree $\bigcirc$ Strongly Disagree

9.- Teacher helps students generate ideas for writing

$\bigcirc$ Strongly Agree $\bigcirc$ Moderately Agree $\bigcirc$ Mildy Agree

$\bigcirc$ Mildy Disagree $\bigcirc$ Moderately Disagree $\bigcirc$ strongly Disagree

10.- Teacher allows students to share writing

$\bigcirc$ strongly Agree $\bigcirc$ Moderately Agree $\bigcirc$ Mildly Agree

$\bigcirc$ Mildy Disagree $\bigcirc$ Moderately Disagree $\bigcirc$ strongly Disagree

11.- Teacher reviews or models what to write and how to plan

$\bigcirc \bigcirc$ strongly Agree $\bigcirc$ Moderately Agree $\bigcirc$ Mildly Agree

$\bigcirc$ Mildly Disagree $\bigcirc$ Moderately Disagree $\bigcirc$ strongly Disagree

12. -Teacher observes students and assists the $m$ in their writing efforts

$\bigcirc$ Strongly Agree $\bigcirc$ Moderately Agree $\bigcirc$ Mildly Agree

$\bigcirc$ Mildly Disagree $\bigcirc$ Moderately Disagree $\bigcirc$ strongly Disagree

Submit and Proceed to Next Section 
1- Teacher implements a class - wide reward system with rules that are observable and reviews them periodically

Strongly Agree $\bigcirc$ Moderately Agree $\bigcirc$ Mildly Agree

$\bigcirc$ Mildly Disagree $\bigcirc$ Maderately Disagree $\bigcirc$ Strongly Disagree

2- Teacher positively reinforces student behavior and work

$\bigcirc$ Strongly Agree $\bigcirc$ Moderately Agree $\bigcirc$ Mildy Agree

$\bigcirc$ Mildy Disagree $\bigcirc$ Moderately Disagree $\bigcirc$ strongly Disagree

3- Teacher provides corrective actions to students every time students choose to disrupt

$\bigcirc$ Strongly Agree $\bigcirc$ Moderately Agree $\bigcirc$ Mildly Agree

$\bigcirc$ Mildy Disagree $\bigcirc$ Moderately Disagree $\bigcirc$ Strongly Disagree

4- Teacher communicates clearly that students have the power to make choices, yet they need to accept the responsibility that goes with it

$\bigcirc$ Strongly Agree $\bigcirc$ Moderately Agree $\bigcirc$ Mildly Agree

$\bigcirc$ Mildy Disagree $\bigcirc$ Moderately Disagree $\bigcirc$ 5trongly Disagree

5.- Teacher is consistent, and provides clear, concise directions that are easy for students to follow

$\bigcirc$ Strongly Agree $\bigcirc$ Moderately Agree $\bigcirc$ Mildly Agree

$\bigcirc$ Mildy Disagree $\bigcirc$ Moderately Disagree $\bigcirc$ Strangly Disagree

6.- Teacher recognizes positive behavior at the first opportunity after correcting a student's behavior and provides an "escape mechanism" for students who are upset and want to talk about what happened

Strongly Agree $\bigcirc$ Moderately Agree $O$ Mildly Agree

$\bigcirc$ Mildly Disagree $\bigcirc$ Moderately Disagree $\bigcirc$ strongly Disagree

Submit and Proceed to Next Section 
CONSTRUCT:

EFFECTIVE ESL

TEACHING PRACTICES

\section{Thanks for your Participation in this study!}

This survey is anonymous.

This survey uses your email address as the identifying code to indicate that you have (or have not) completed the survey and to enter your email in a drawing to get a token of appreciation for your participation.

There is no way of matching your email address with your survey responses.

Survey responses and email address are managed in a seperate databases.

Please enter your email address to register.

\begin{tabular}{|l|l|}
\hline Email \\
Address:
\end{tabular}

Submit 


\section{APPENDIX E}

\section{E1. FACULTY INVITATION LETTER}

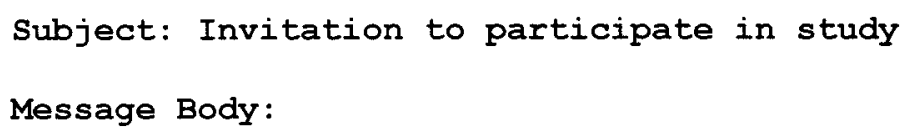

Please accept this invitation to participate in a study about effective practices for EFL/ESL instruction in Spain. The purpose of this survey is to learn about which of the survey practices are considered effective practices for EFL/ESL instruction. This survey is comprised of teaching practices divided in 5 sections as follows:

Section 1: Classroom Dynamics

Section 2: Student Dynamics

Section 3: Teaching Approaches

Section 4: Language Arts Strategies

Section 5: Classroom Management

Please be aware that this survey will take about 15 minutes of your time and that it is very important that you evaluate all teaching practices. At the end of the last section you will be given the opportunity to provide your name and e-mail address to enter in a drawing to get a $500 \mathrm{~GB}$ External $\mathrm{HD}$ or one of 10 webcams as a token of appreciation for your participation.

We value your opinion and are hopeful that you will agree to participate in the study.

Best regards,

Christopher Wagner, Ph.D. (Advisor); E-mail: Christopher.Wagner@wku.edu Ms. María Gómez (Doctoral Candidate); E-mail: marigome@itesm.mx

To access the survey, please click here:

http://www.wku.edu/tsonline/mariela_gomez/survey/

A note of privacy

This survey is anonymous. This survey uses your e-mail address as the identifying code to indicate that you have (or have not) completed the survey and to enter your email in a drawing to get a token of appreciation for your participation. There is no way of matching your e-mail address with your survey responses. Survey responses and email addresses are managed in a separate database. 


\section{E2. FACULTY INVITATION REMINDER LETTER}

Subject: Survey Reminder

Message Body:

\section{Dear Colleague:}

A week ago we invited you to participate in a survey regarding effective practices for ELF/ESL instruction in Spain.

If you already took the survey, please disregard this message. If you have not still completed the survey, we want to encourage you to do so.

To access the survey, please click here:

http://www.wku.edu/tsonline/mariela_gomez/survey

We value your opinion and are hopeful that you will agree to participate in the study.

Best regards,

Christopher Wagner, Ph.D. (Advisor)

Ms. María Gómez (Doctoral Candidate)

\section{A note of privacy}

This survey is anonymous. This survey uses your e-mail address as the identifying code to indicate that you have (or have not) completed the survey and to enter your email in a drawing to get a token of appreciation for your participation. There is no way of matching your e-mail address with your survey responses. Survey responses and email addresses are managed in a separate database. 


\section{E3. FACULTY INVITATION REMINDER LETTER}

Subject: Survey Reminder

Message Body:

\section{Dear Colleague:}

Twelve days ago we invited you to participate in a survey regarding effective practices for ELF/ESL instruction in Spain.

If you already took the survey, please disregard this message. If you have not still completed the survey, we want to encourage you to do so.

To access the survey, please click here:

http://www.wku.edu/tsonline/mariela_gomez/survey

We value your opinion and are hopeful that you will agree to participate in the study.

Best regards, Christopher Wagner, Ph.D. (Advisor)

Ms. María Gómez (Doctoral Candidate)

A note of privacy

This survey is anonymous. This survey uses your e-mail address as the identifying code to indicate that you have (or have not) completed the survey and to enter your email in a drawing to get a token of appreciation for your participation. There is no way of matching your e-mail address with your survey responses. Survey responses and e-mail addresses are managed in a separate database. 


\section{E4. FACULTY INVITATION LETTER TO PARTICIPATE IN A TEST RETEST STUDY}

Subject: Invitation or participation in a test-restest study

Message Body:

\section{Dear Colleague:}

Dear Colleague:

Two weeks ago we invited you to participate in a survey regarding effective practices for ELF/ESL instruction in Spain.

If you already took the survey, please take it again for a test-retest analysis. If you have not still completed the survey, we want to encourage you to do so.

To access the survey, please click here:

http://www.wku.edu/tsonline/mariela_gomez/survey/

We value your opinion and are hopeful that you will agree to participate in the study.

Best regards, Christopher Wagner, Ph.D. (Advisor)

Ms. María Gómez (Doctoral Candidate)

A note of privacy

This survey is anonymous. This survey uses your e-mail address in a drawing to get a token of appreciation for your participation. There is no way of matching your email address with your survey responses. Survey responses and e-mail addresses are managed in a separate database. 


\section{APPENDIX F}

FACTORIAL FACTOR ANALYSIS DATA ANALYSIS

GET

FILE='C: \Users $\backslash D L 1 \backslash$ Desktop\DATOS\FA data revised.sav'.

DATASET NAME DataSet1 WINDOW=FRONT.

FACTOR

/VARIABLES CD1 CD2 CD3 CD4 CD5 CD6 CD7 CD8 SD1 SD2 SD3 SD4 SD5 SD6 SD7 TA1 TA2 TA3 TA4 TA5 TA6 TA7 TA8 TA9 TA10 TA11 TA12 TA13 LAS1 LAS2 LAS3 LAS4 LAS5 LAS6 LAS7 LAS8 LAS9 LAS10 LAS1 1 LAS12 CM1 CM2 CM3 CM4 CM5 CM6 /MISSING MEANSUB /ANALYSIS CD1 CD2 CD3 CD4 CD5 CD6 CD7 CD8 SD1 SD2 SD3 SD4 SD5 SD6 SD7 TA1 TA2 TA3 TA4 TA5 TA6 TA7 TA8 TA9 TA10 TA11 TA12 TA13 LAS1 LAS2 LAS3 LAS4 LAS5 LAS6 LAS7 LAS8 LAS9 LAS10 LAS1 1 LAS12 CM1 CM2 CM3 CM4 CM5 CM6 /PRINT UNIVARIATE INITIAL CORRELATION SIG DET KMO INV REPR AIC EXTRACTION ROTATION FSCORE /FORMAT SORT /PLOT EIGEN /CRITERIA MINEIGEN (1) ITERATE (25) /EXTRACTION PC /CRITERIA ITERATE (25) /ROTATION VARIMAX /METHOD $=$ CORRELATION. 


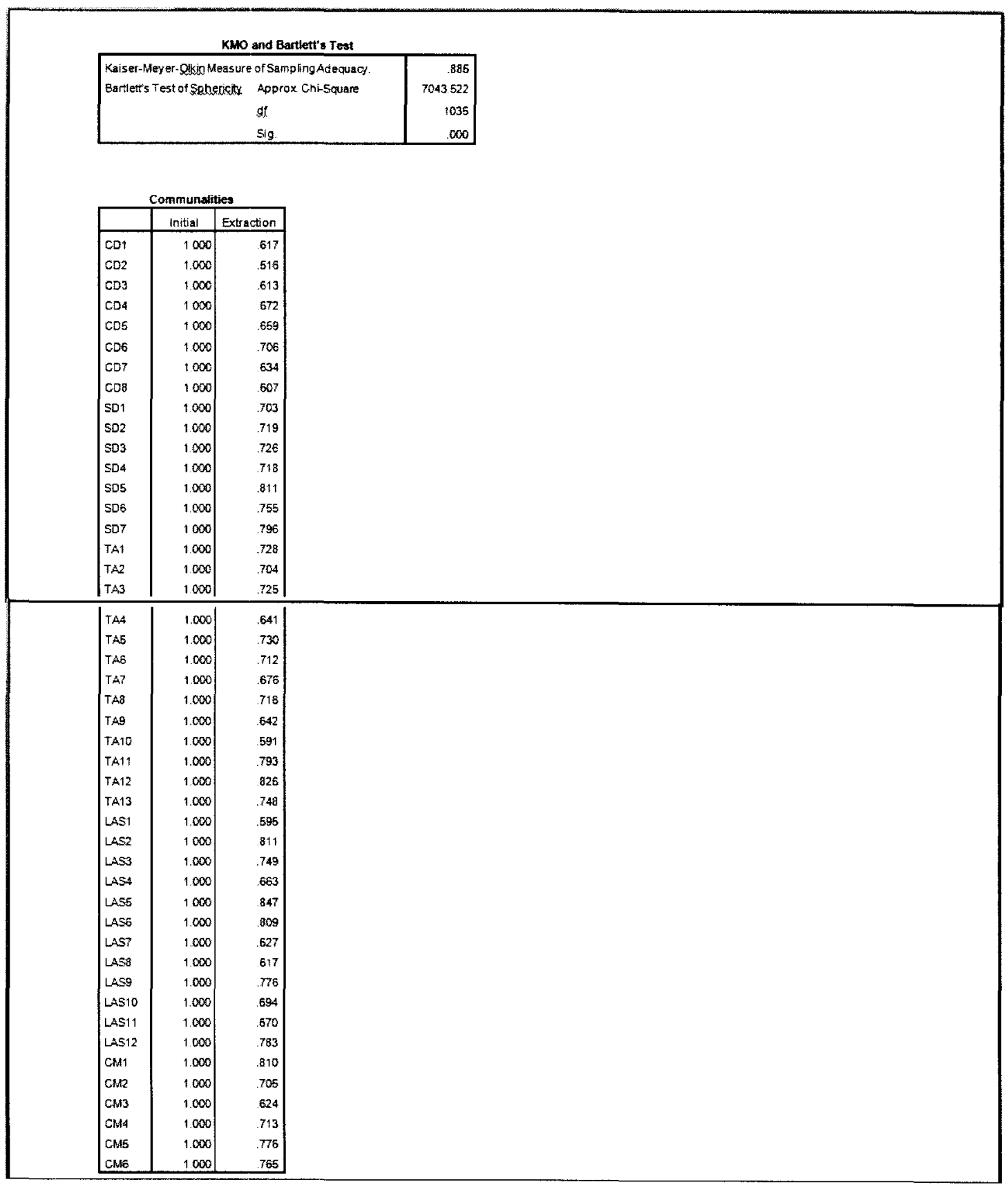




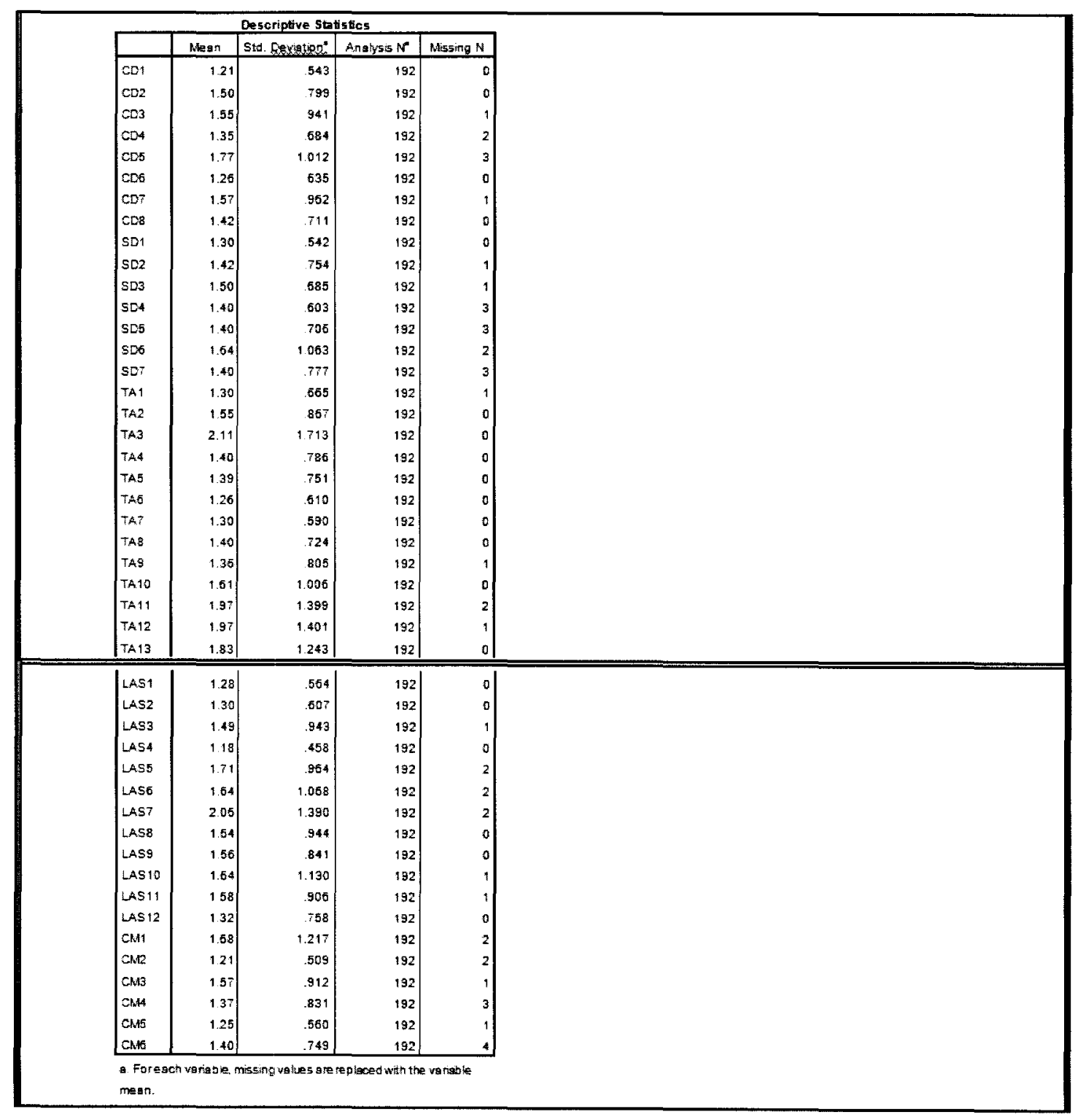




\begin{tabular}{|c|c|c|c|c|c|c|c|c|c|}
\hline \multicolumn{10}{|c|}{ Total Variance Explained } \\
\hline \multirow{2}{*}{ Componert } & \multicolumn{3}{|c|}{ Initial Ejgrengalues } & \multicolumn{3}{|c|}{ Extraction Sums of Squared Loadings } & \multicolumn{3}{|c|}{ Rotation Sums of Squared Loadings } \\
\hline & Total & $\%$ of Variance & Cumulative $\%$ & Total & $\%$ of variance & Cumulative \% & Total & $\%$ of Variance & Cumulative \% \\
\hline 1 & 19.314 & 41.968 & 41.988 & 19314 & 41.988 & 41.988 & 5.642 & 12.265 & 12.265 \\
\hline 2 & 3.071 & 6.676 & 48.654 & 3071 & 6.676 & 48.664 & 5.388 & 11.714 & 23.979 \\
\hline 3 & 1.926 & 4.187 & 52.851 & 1926 & 4.187 & 52.851 & 4.255 & 9.250 & 33.229 \\
\hline 4 & 1.903 & 4.138 & 56.988 & 1.903 & 4.138 & 56.983 & 3.958 & 8.605 & 41.834 \\
\hline 5 & 1.386 & 3.013 & 60.001 & 1.386 & 3.013 & s0.001 & 3.389 & 7.367 & 49.201 \\
\hline 6 & 1.325 & 2.861 & 62.862 & 1.325 & 2.881 & 62.882 & 2.829 & 6.149 & 55.350 \\
\hline 7 & 1.302 & 2.830 & 65.712 & 1302 & 2.630 & 65.712 & 2.806 & 6.101 & 61.450 \\
\hline 8 & 1.262 & 2.743 & 68.455 & 1262 & 2.743 & 68.455 & 2.162 & 4.700 & 66.151 \\
\hline 9 & 1.032 & 2.244 & 70.699 & 1032 & 2.244 & 70.699 & 2002 & 4.548 & 70.699 \\
\hline 10 & .974 & 2.118 & 72.817 & & & & & & \\
\hline 11 & .885 & 1.925 & 74.742 & & & & & & \\
\hline 12 & .803 & 1.745 & 76.487 & & & & & & \\
\hline 13 & .776 & 1.687 & 78.174 & & & & & & \\
\hline 14 & .728 & 1.583 & 79.757 & & & & & & \\
\hline 15 & 693 & 1.507 & 81.264 & & & & & & \\
\hline 16 & .647 & 1.407 & 82.671 & & & & & & \\
\hline 17 & 622 & 1.353 & 84.024 & & & & & & \\
\hline 18 & .585 & 1.272 & 85.296 & & & & & & \\
\hline 19 & .555 & 1.206 & 86.503 & & & & & & \\
\hline 20 & .505 & 1.097 & 87.600 & & & & & & \\
\hline 21 & 470 & 1.022 & 88.622 & & & & & & \\
\hline 22 & .459| & .998 & 89.621 & & & & & & \\
\hline 23 & .414 & .900 & 50.520 & & & & & & \\
\hline 24 & .374 & .813 & 91.334 & & & & & & \\
\hline 25 & .360 & .783 & $\$ 2.117$ & & & & & & \\
\hline 26 & .348 & .757 & 92.873 & & & & & & \\
\hline 27 & .314 & .682 & 93.555 & & & & & & \\
\hline $2 a$ & .308 & .670 & 94.225 & & & & & & \\
\hline 29 & .264 & .575 & 54.600 & & & & & & \\
\hline 30 & .255 & .553 & 95.353 & & & & & & \\
\hline 31 & .247 & .537 & 96.890 & & & & & & \\
\hline 32 & .211 & .458 & 96.348 & & & & & & \\
\hline 33 & .200 & .434 & 96.783 & & & & & & \\
\hline 34 & .184 & .400 & 97.182 & & & & & & \\
\hline 35 & .170 & 370 & 97.552 & & & & & & \\
\hline 36 & .156 & 340 & 97.892 & & & & & & \\
\hline 37 & .751 & 329 & 38.221 & & & & & & \\
\hline $3 a$ & .131 & .284 & 98.505 & & & & & & \\
\hline 39 & .128 & .278 & 98.783 & & & & & & \\
\hline 40 & .116 & 253 & 99.036 & & & & & & \\
\hline 41 & .107 & .232 & 99268 & & & & & & \\
\hline 42 & .093 & 203 & 99.470 & & & & & & \\
\hline 43 & .082 & .178 & 99.649 & & & & & & \\
\hline 44 & .065 & .141 & 99.790 & & & & & & \\
\hline 45 & .057 & 123 & 99.913 & & & & & & \\
\hline 46 & . & . 687 & 1000000 & & & & & & \\
\hline
\end{tabular}




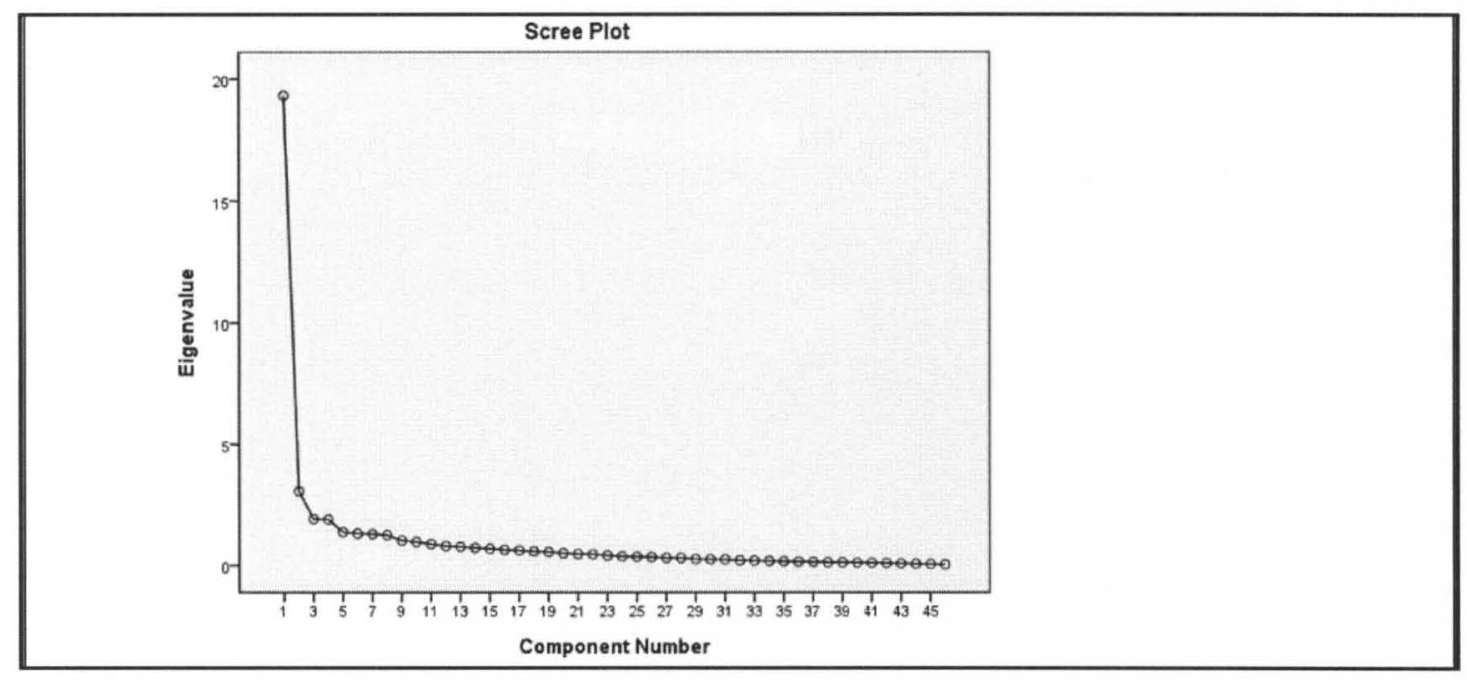




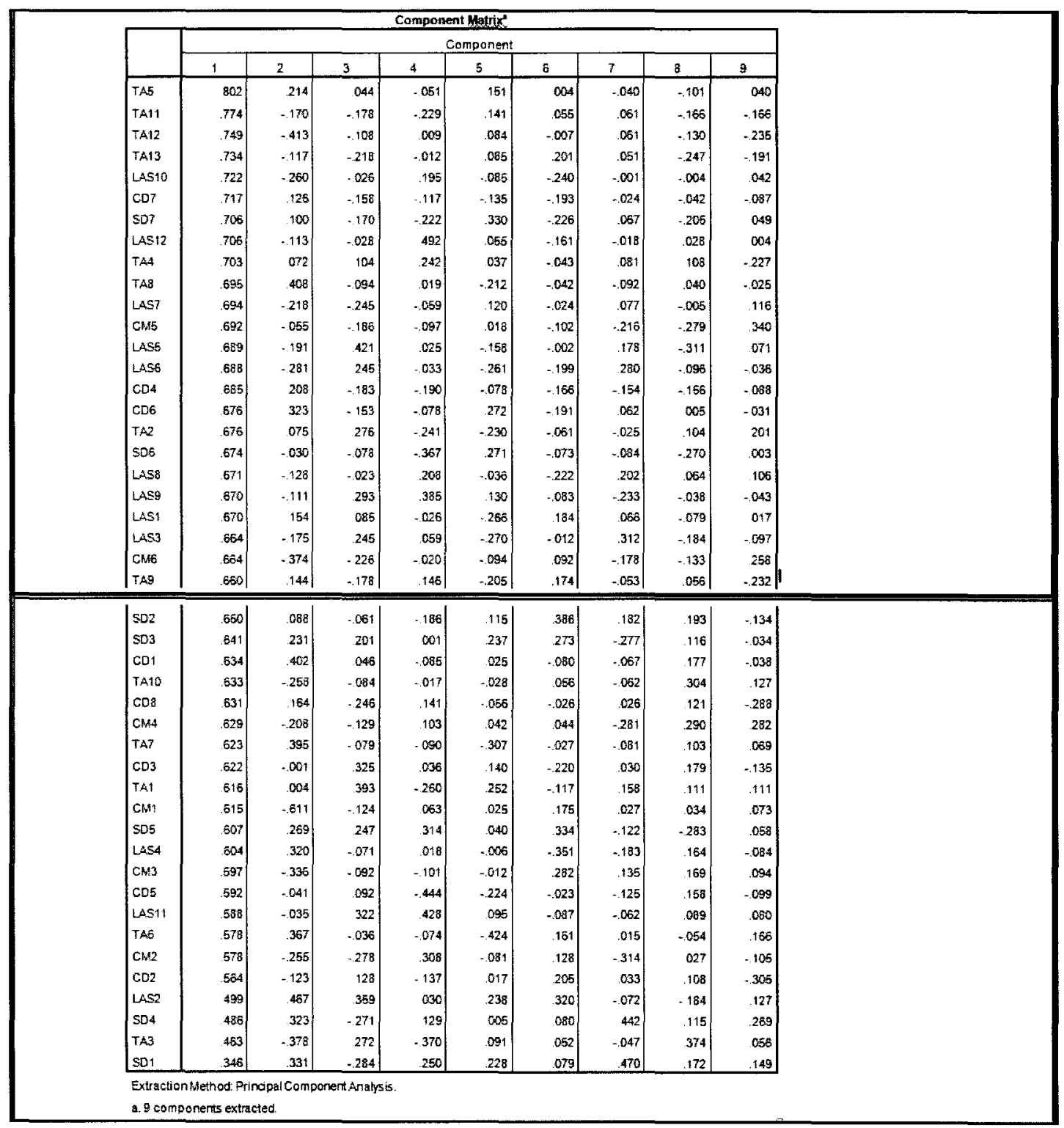




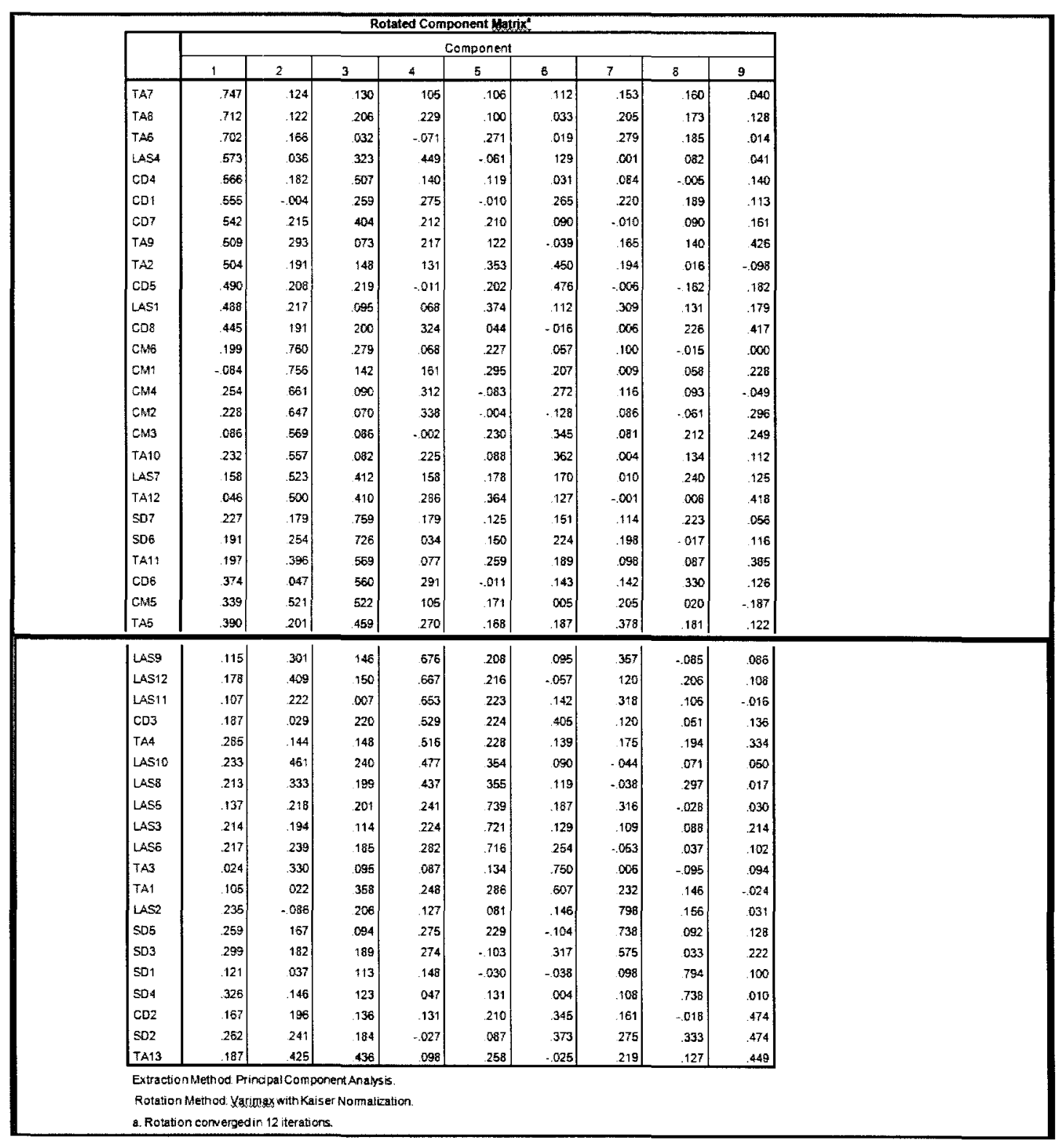




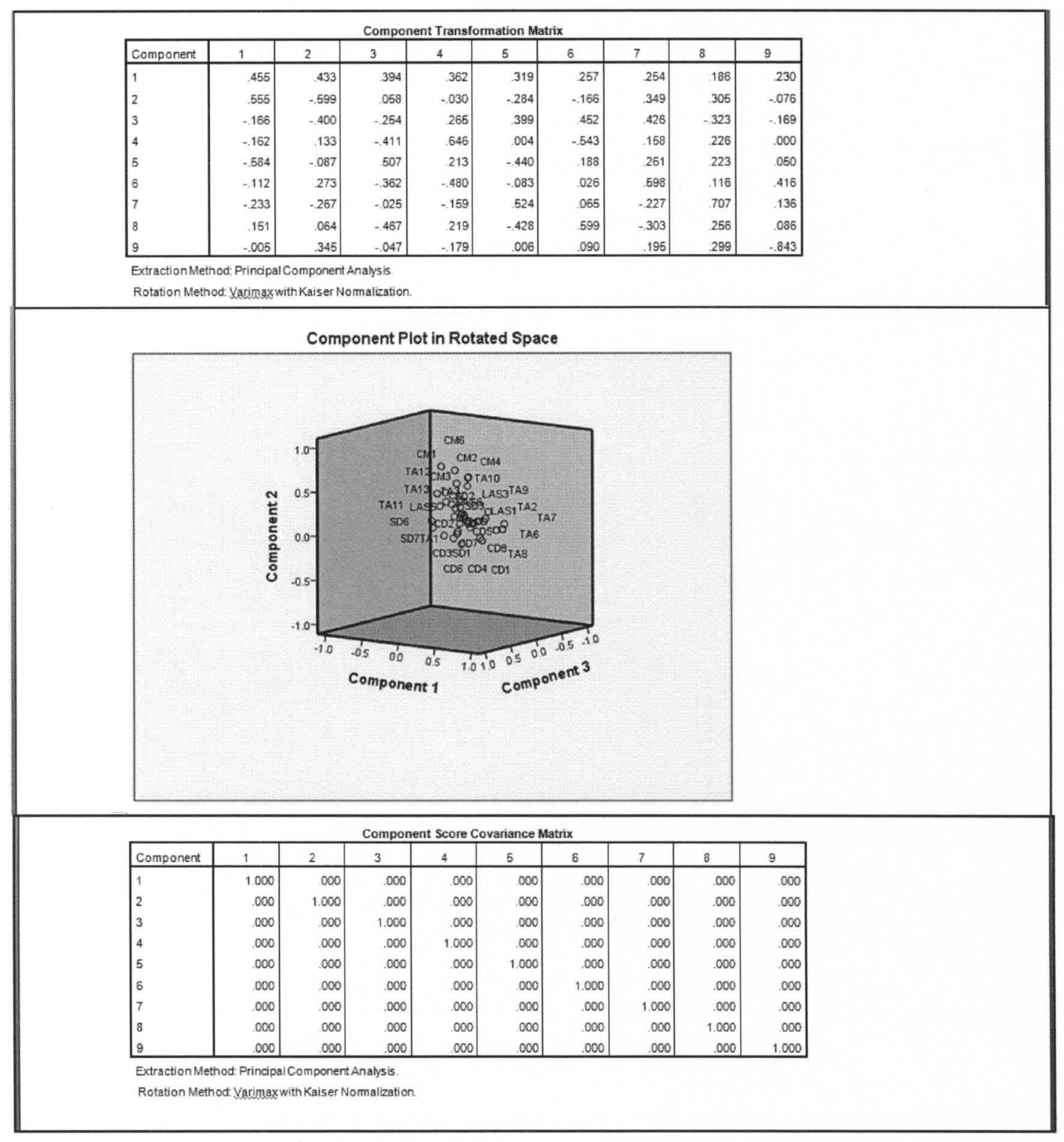




\section{APPENDIX G}

FACTORIAL FIVE-FACTOR ANALYSIS DATA ANALYSIS

/VARIABLES CD1 CD2 CD3 CD4 CD5 CD6 CD7 CD8 SD1 SD2 SD3 SD4 SD5 SD6 SD7 TA1 TA2 TA3 TA4 TA5 TA6 TA7 TA8 TA9 TA10 TA11 TA12 TA13 LAS1 LAS2 LAS3 LAS4 LAS5 LAS6 LAS7 LAS8 LAS9 LAS10 LAS11 LAS12 CM1 CM2 CM3 CM4 CM5 CM6 /MISSING MEANSUB /ANALYSIS CD1 CD2 CD3 CD4 CD5 CD6 CD7 CD8 SD1 SD2 SD3 SD4 SD5 SD6 SD7 TA1 TA2 TA3 TA4 TA5 TA6 TA7 TA8 TA9 TA10 TA11 TA12 TA13 LAS1 LAS2 LAS3 LAS4 LAS5 LAS6 LAS7 LAS8 LAS9 LAS10 LAS11 LAS12 CM1 CM2 CM3 CM4 CM5 CM6 /PRINT UNIVARIATE INITIAL CORRELATION SIG DET KMO INV REPR AIC EXTRACTION ROTATION FSCORE /FORMAT SORT /PLOT EIGEN /CRITERIA FACTORS (5) ITERATE (25) /EXTRACTION PC /CRITERIA ITERATE (25) /ROTATION VARIMAX /METHOD=CORRELATION. 


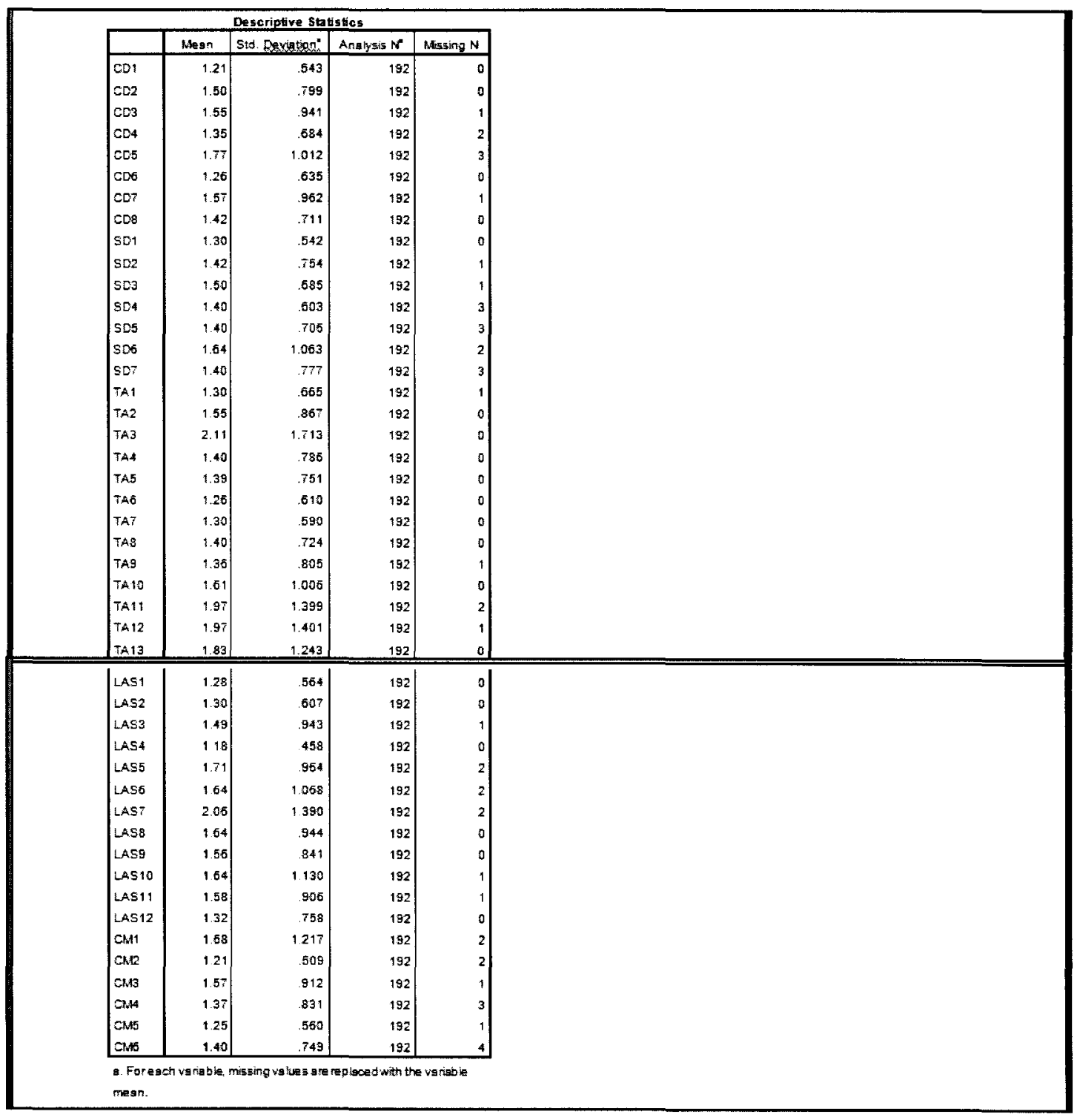




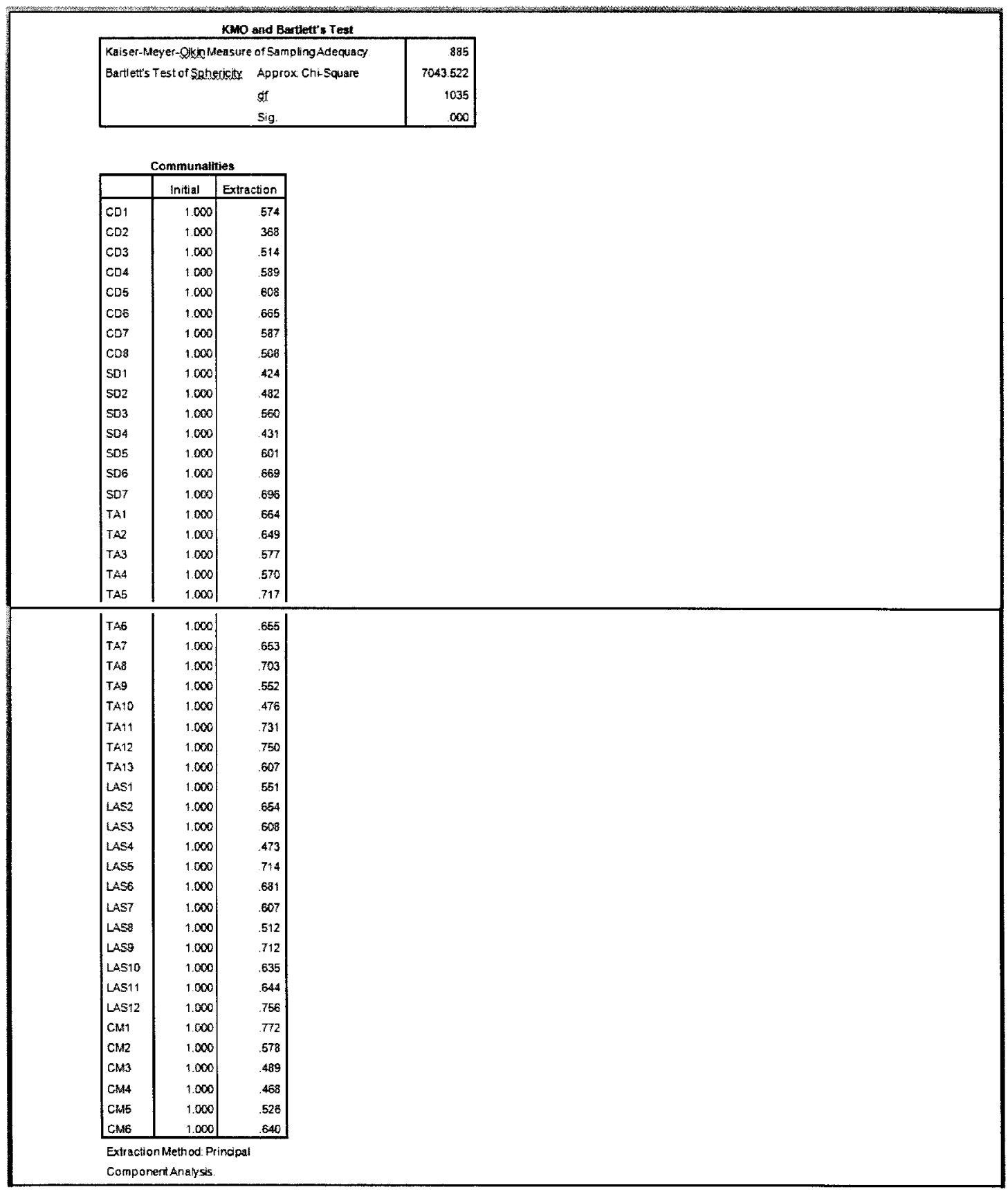




\begin{tabular}{|c|c|c|c|c|c|c|c|c|c|}
\hline \multicolumn{10}{|c|}{ Total Varisnce Expleained } \\
\hline Component & Totai & $\begin{array}{l}\text { Initial Ejgencell } \\
\% \text { of variance }\end{array}$ & Cumber & $\begin{array}{l}\text { Extractior } \\
\text { Total }\end{array}$ & $\begin{array}{l}\text { n Sums of Square } \\
\% \text { of variance }\end{array}$ & $\begin{array}{l}\text { ed Loadings } \\
\text { Curmulative \%s }\end{array}$ & Rotation Sums of Squared Losdings & $\begin{array}{l}n \text { Sums of Squar } \\
\% \text { of Variance }\end{array}$ & Cardosdings \\
\hline 1 & 19.314 & 41.988 & 41.988 & 19.314 & 41.988 & 41988 & 8.342 & 18.136 & 18.136 \\
\hline 2 & 3.071 & 6.676 & 48.664 & 3.071 & 6.676 & 48.564 & 7.145 & 15.534 & 33.609 \\
\hline 3 & 1.926 & 4187 & 52.851 & 1.926 & 4.187 & 52851 & 4.833 & 10.506 & 44.176 \\
\hline 4 & 1.903 & 4.138 & 56.988 & 1.903 & 4.138 & 56.988 & 4.254 & 9.247 & 53.423 \\
\hline 5 & 1.386 & 3.013 & 60.001 & 1.386 & 3.013 & 60.001 & 3.026 & 6.579 & 60.001 \\
\hline 6 & 1.325 & 2.881 & 62.882 & & & & & & \\
\hline 7 & 1.302 & 2.830 & 65.712 & & & & & & \\
\hline 8 & 1.262 & 2.743 & 68.465 & & & & & & \\
\hline 9 & 1.032 & 2.244 & 70.699 & & & & & & \\
\hline 10 & .974 & 2.118 & 72.817 & & & & & & \\
\hline 11 & 885 & 1.925 & 74.742 & & & & & & \\
\hline 12 & .803 & 1.745 & 76.487 & & & & & & \\
\hline 13 & .776 & 1.687 & 78.174 & & & & & & \\
\hline 14 & .728 & 1.583 & 79.757 & & & & & & \\
\hline 15 & 693 & 1.507 & B1.264 & & & & & & \\
\hline 16 & 647 & 1407 & 82.671 & & & & & & \\
\hline 17 & 622 & 1.353 & 84.024 & & & & & & \\
\hline 18 & .585 & 1.272 & 85.296 & & & & & & \\
\hline 19 & .555 & 1.206 & 86.503 & & & & & & \\
\hline 20 & 505 & 1.097 & 87500 & & & & & & \\
\hline 21 & .470 & 1.022 & 38.622 & & & & & & \\
\hline 22 & .459 & .998 & 89.621 & & & & & & \\
\hline$\left.\right|_{23}$ & .414 & .900 & 90.520 & & & & & & \\
\hline 24 & 374 & $.813]$ & 91.334 & & & & & & \\
\hline 25 & 360 & .783 & 92.117 & & & & & & \\
\hline 26 & 348 & .757 & 92.873 & & & & & & \\
\hline 27 & .314 & .682 & 93.556 & & & & & & \\
\hline 28 & 300 & .670 & 94.225 & & & & & & \\
\hline 29 & 264 & .575 & 94.800 & & & & & & \\
\hline 30 & .255 & .553 & 95.353 & & & & & & \\
\hline $3 t$ & 247 & .537 & 95.890 & & & & & & \\
\hline 32 & 211 & .458 & 96.348 & & & & & & \\
\hline 33 & 200 & .434 & 96.783 & & & & & & \\
\hline 34 & 184 & .400 & 97.182 & & & & & & \\
\hline 36 & 170 & 370 & 97.552 & & & & & & \\
\hline 36 & 156 & .340 & 97.892 & & & & & & \\
\hline 37 & 151 & .328 & $\$ 8.221$ & & & & & & \\
\hline 38 & 131 & .284 & 98.505 & & & & & & \\
\hline 39 & 128 & .278 & 38.783 & & & & & & \\
\hline 40 & .118 & .253 & 99036 & & & & & & \\
\hline 41 & 107 & .232 & 99.268 & & & & & & \\
\hline 42 & 293 & .203 & 99.470 & & & & & & \\
\hline 43 & 082 & .178 & 99.649 & & & & & & \\
\hline 44 & 065 & .141 & 99790 & & & & & & \\
\hline 45 & .057 & .123 & 99.913 & & & & & & \\
\hline 46 & .040 & ]. & 100.000 & & & & & & \\
\hline \multicolumn{10}{|c|}{ Extraction Method Prinepal Componert Anabssis. } \\
\hline
\end{tabular}




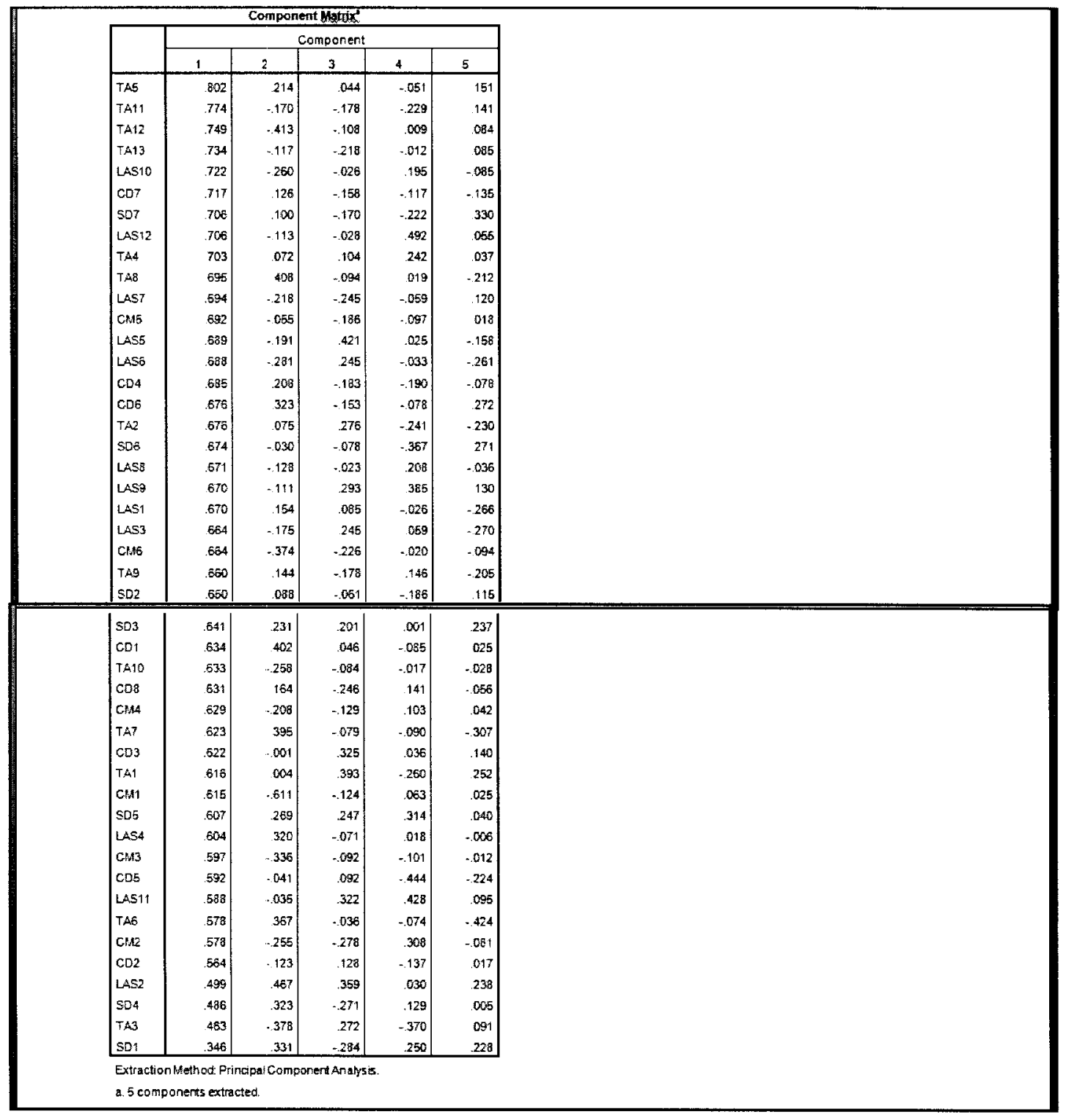

\begin{tabular}{|c|c|c|c|c|c|}
\hline \multicolumn{6}{|c|}{ ransformation Matry } \\
\hline Component & 1 & 2 & 3 & 4 & 5 \\
\hline 1 & 582 & .528 & 410 & .386 & 255 \\
\hline 2 & -.674 & .653 & .117 & .179 & .272 \\
\hline 3 & -.425 & -293 & .604 & .001 & 607 \\
\hline 4 & .161 & -.026 & 637 &. .531 & -.635 \\
\hline 5 & .026 & .457 & 218 & .733 & -.454 \\
\hline
\end{tabular}

Extraction Method: Principal Component Analysis.

Rotation Method Yarimg with Kaiser Nomalzation. 


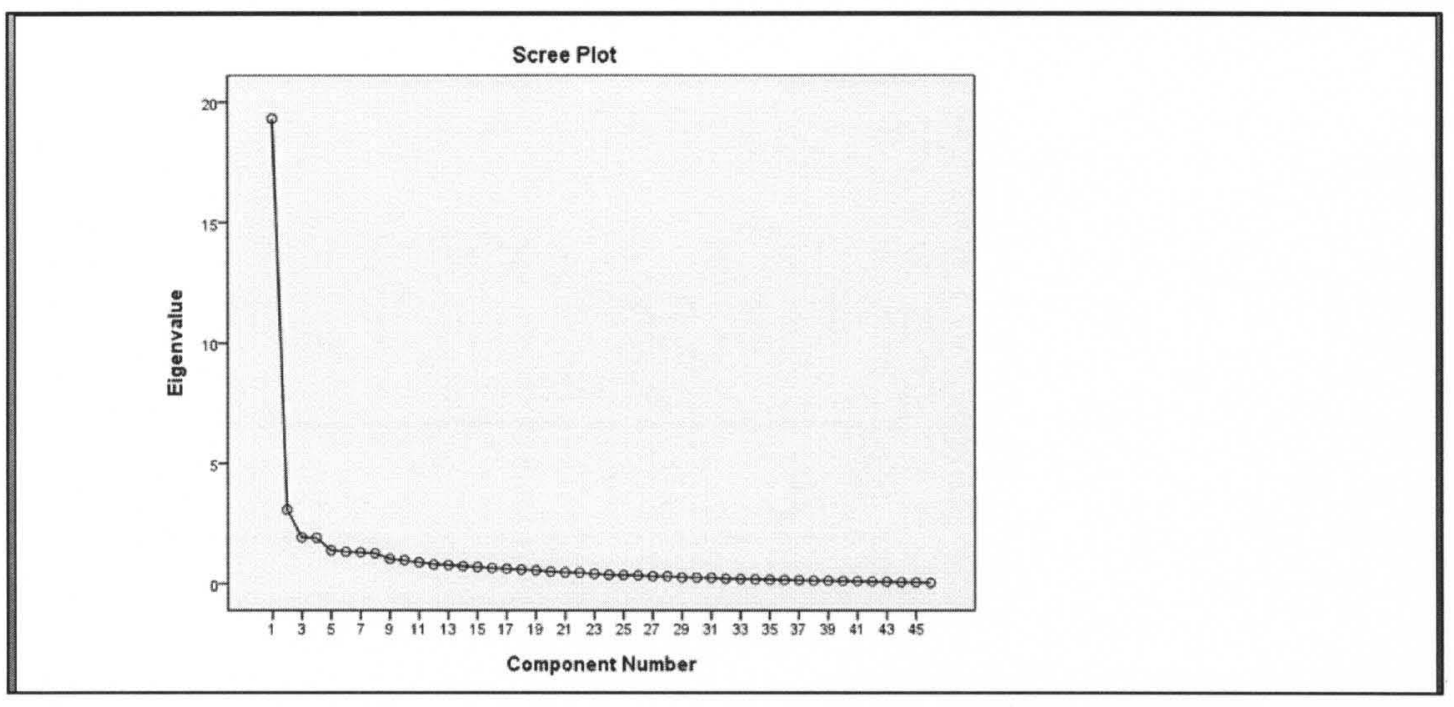

\begin{tabular}{|c|c|c|c|c|c|}
\hline \multicolumn{6}{|c|}{ Component Score Covariance Matrix } \\
\hline Component & 1 & 2 & 3 & 4 & 5 \\
\hline 1 & 1.000 & .000 & .000 & .000 & .000 \\
\hline 2 & .000 & 1.000 & .000 & .000 & .000 \\
\hline 3 & .000 & .000 & 1.000 & .000 & .000 \\
\hline 4 & .000 & .000 & $\infty 00$ & 1.000 & .000 \\
\hline 5 & .000 & .000 & .000 & .000 & 1.000 \\
\hline
\end{tabular}

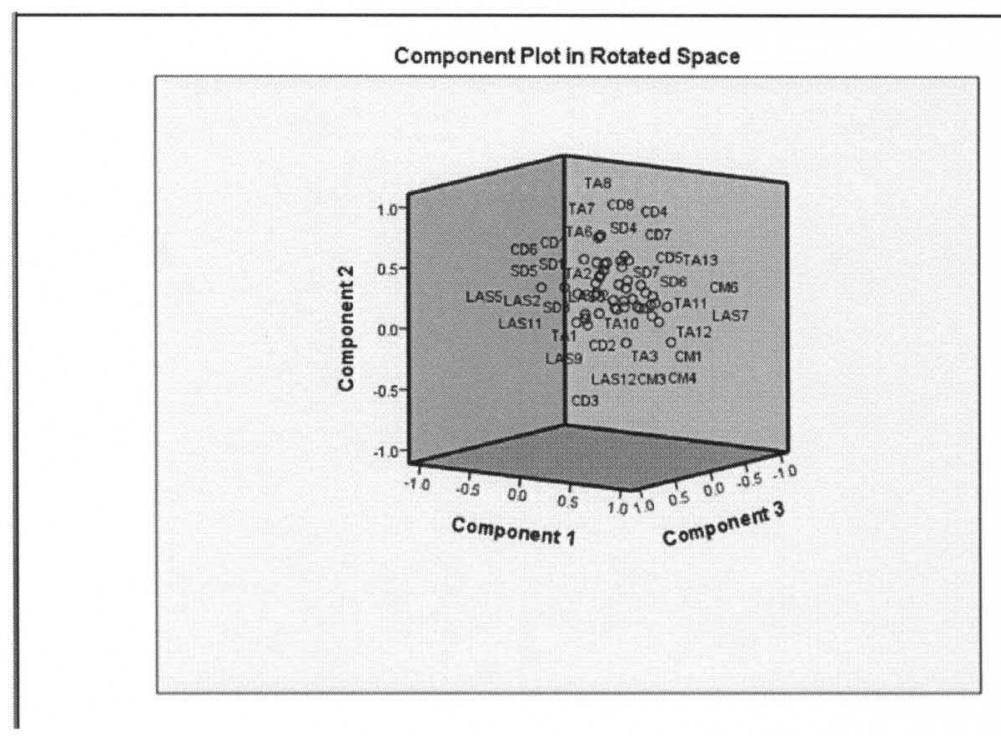




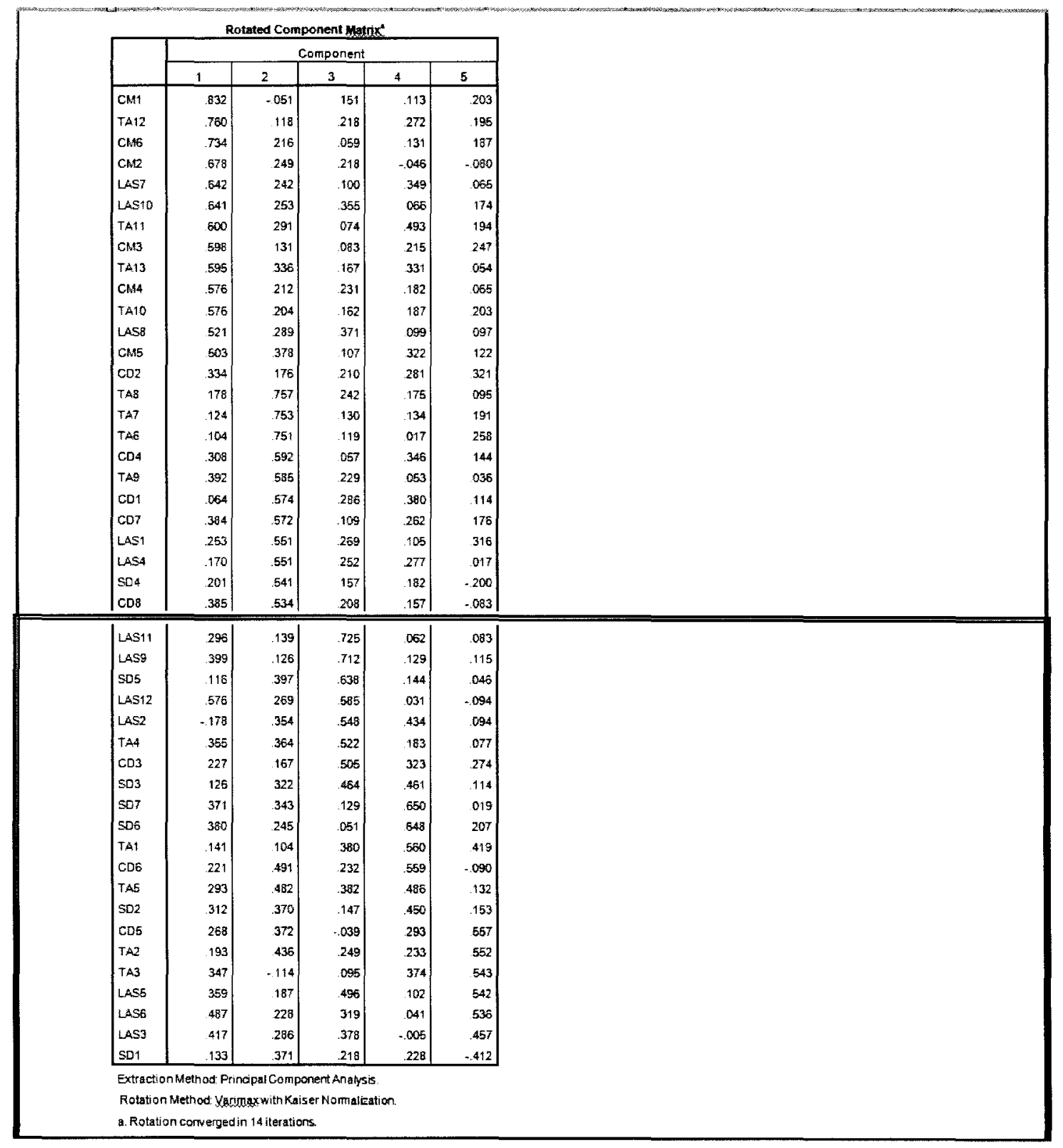




\section{APPENDIX H}

\section{RELIABILITY DATA ANALYSIS FOR THE FIVE FINAL FACTORS}

\section{RELIABILITY}

VARIABLES $=$ CM1 CM6 CM2 TA12 LAS7 LAS 10 TA11 CM3 TA13 CM4 TA10

LAS8 CM5

SCALE ('ALL VARIABLES') ALL

MODEL=ALPHA

/STATISTICS=DESCRIPTIVE CORR

/SUMMARY=MEANS VARIANCE.

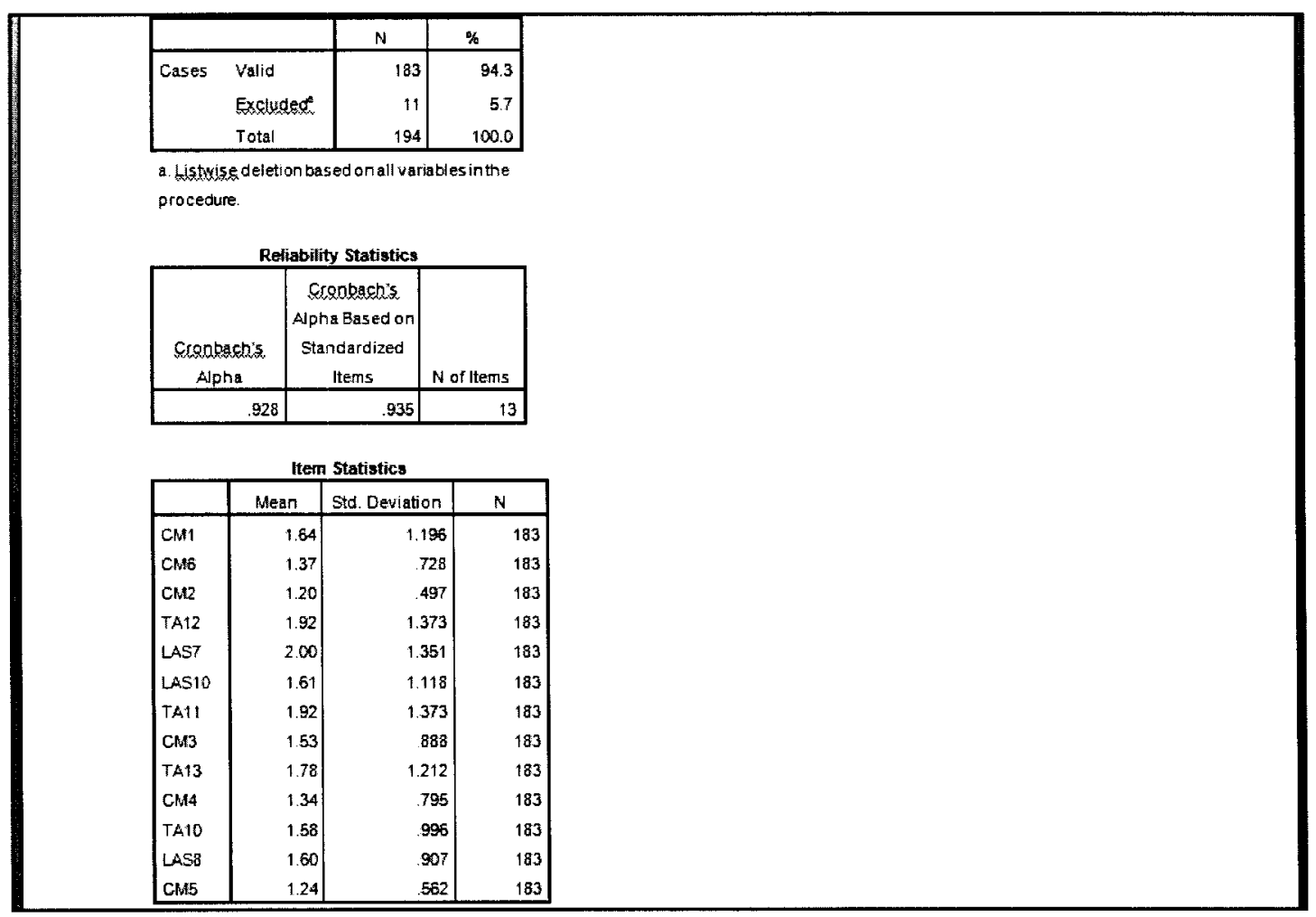




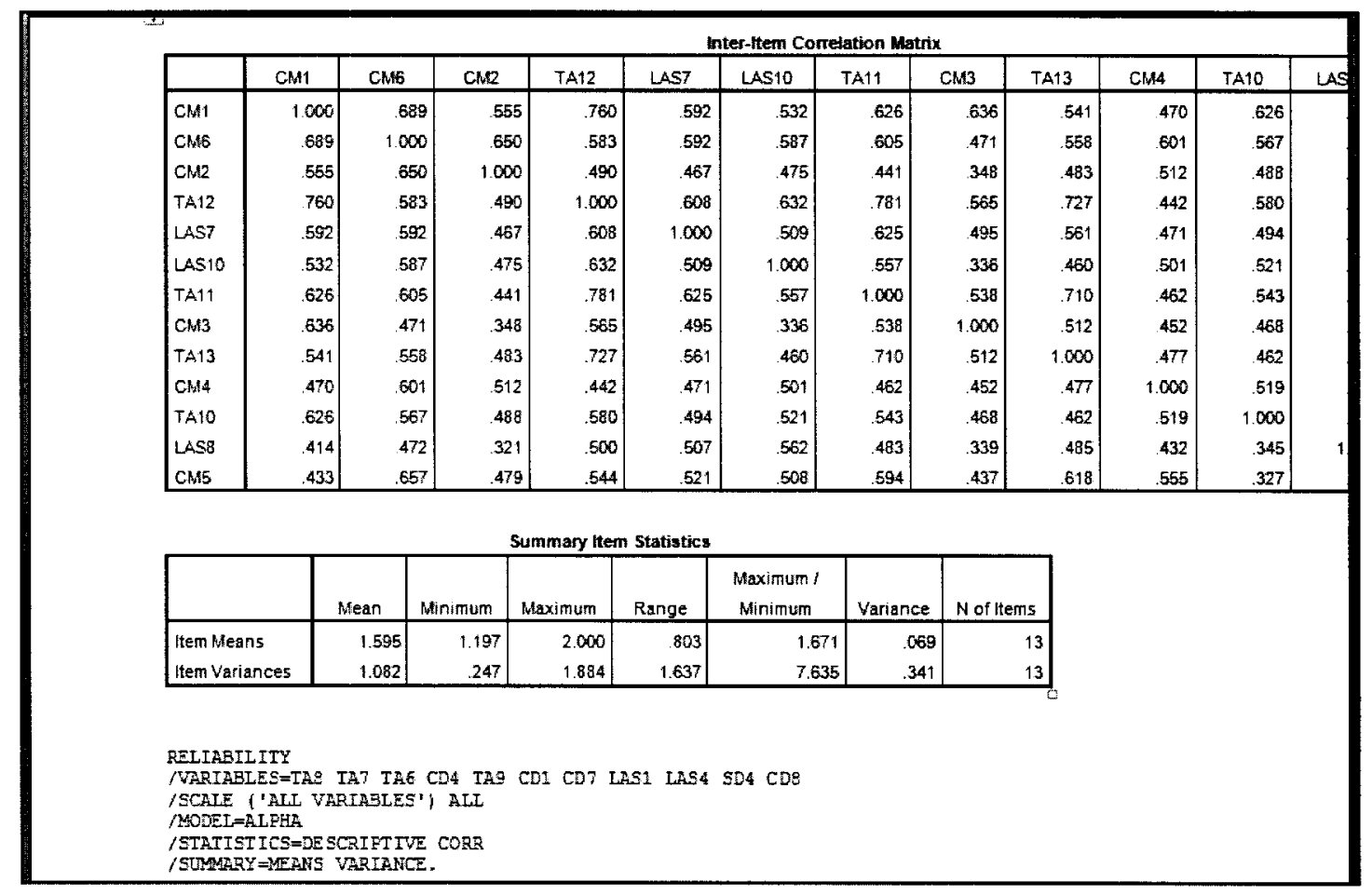

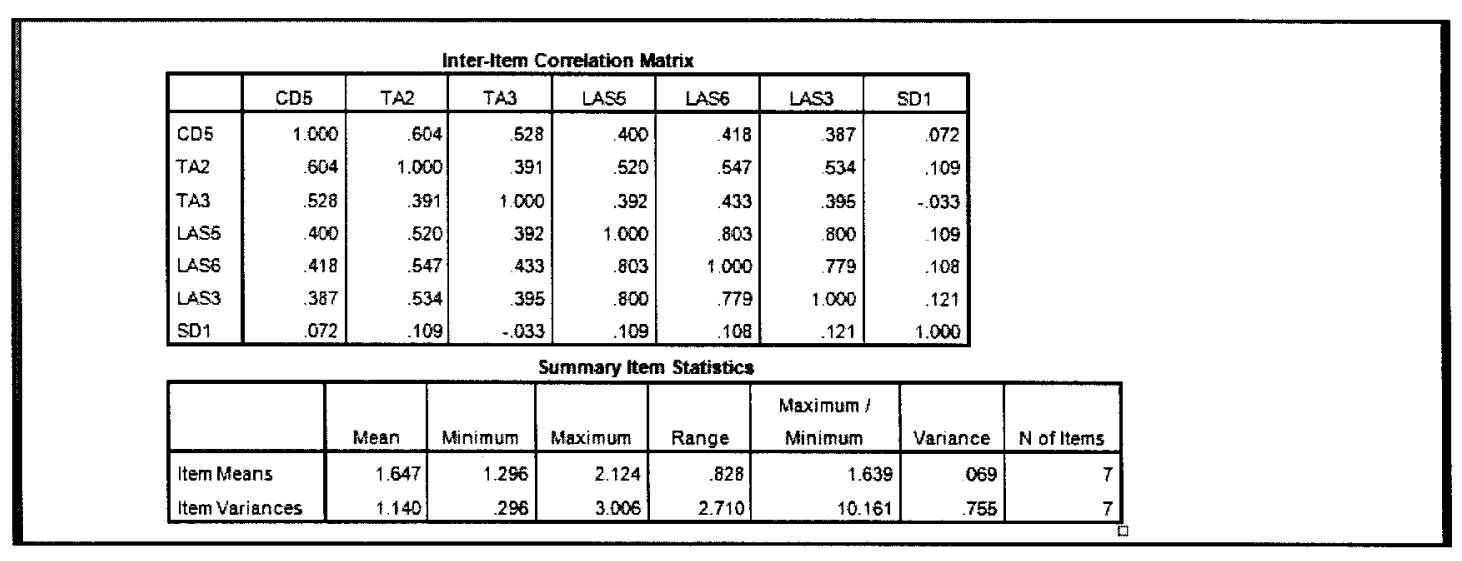




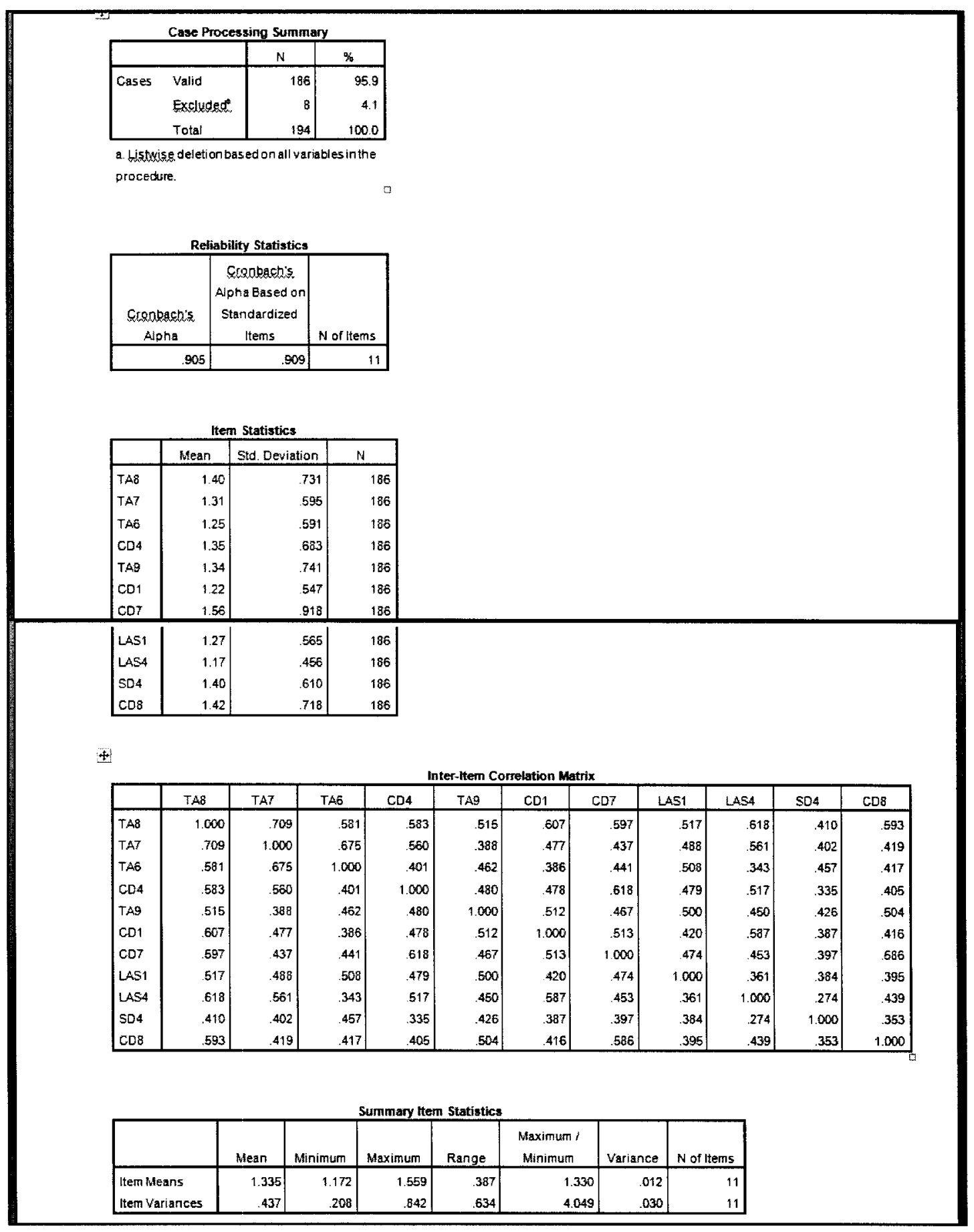




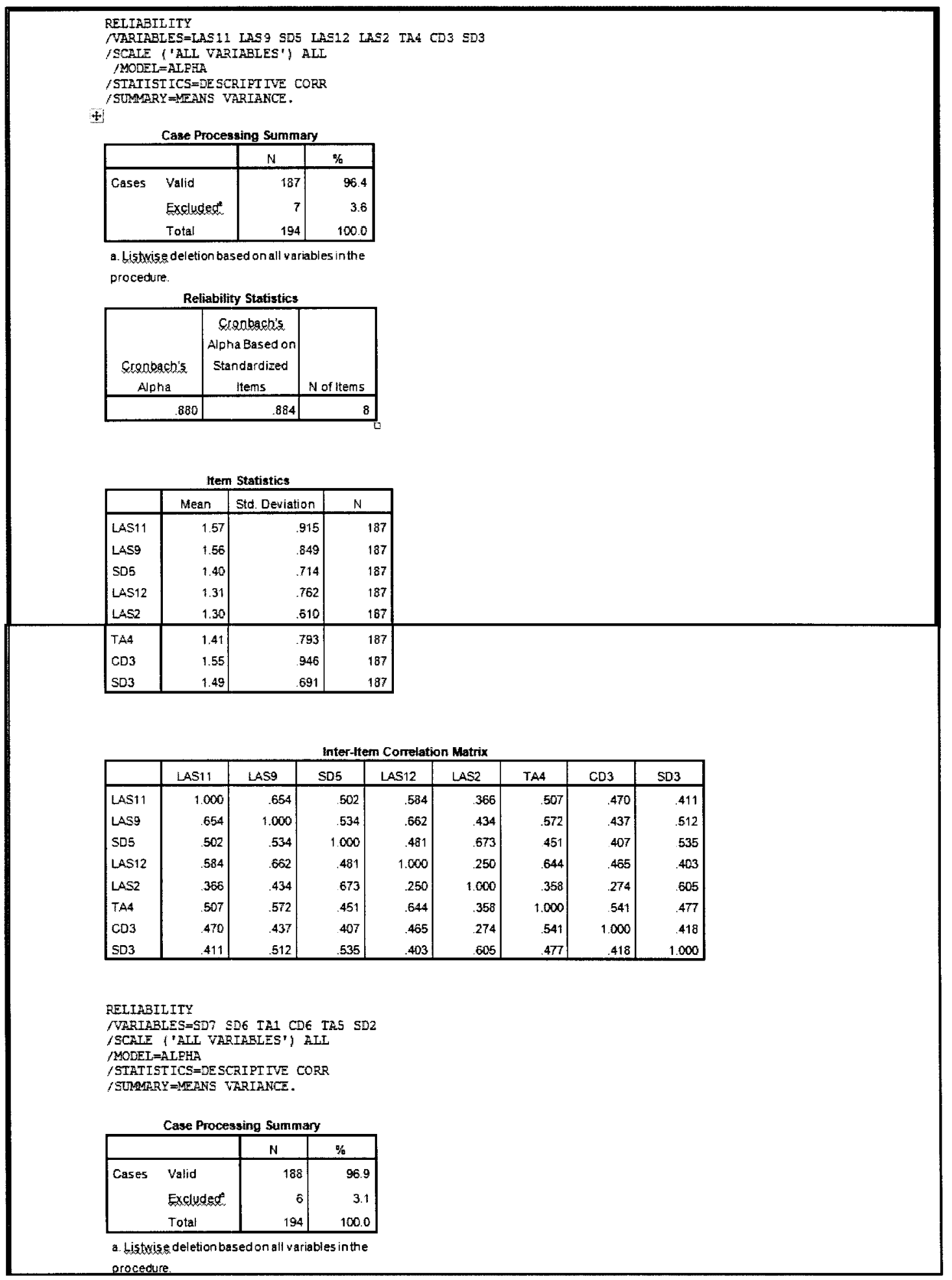




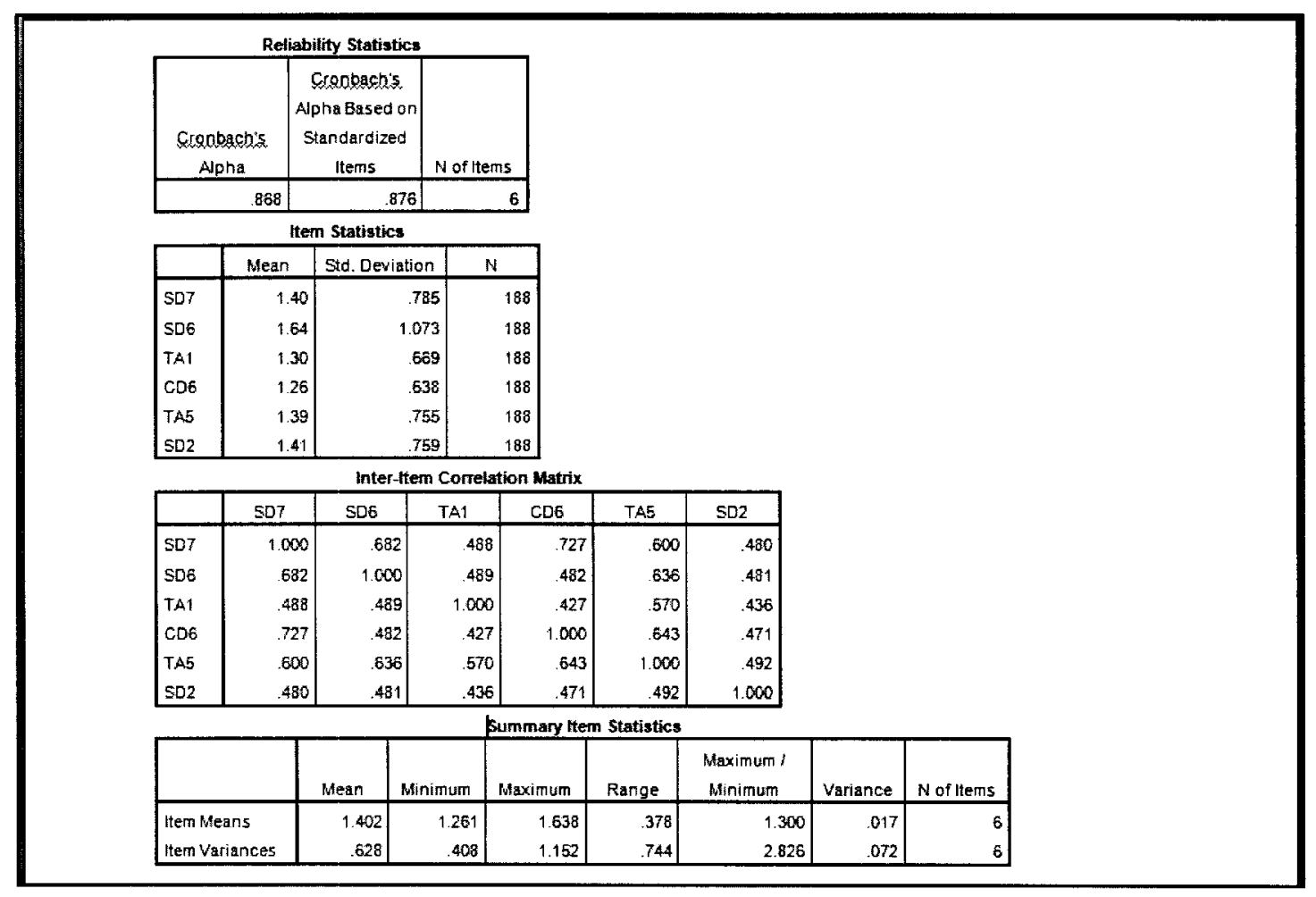

RELIABILITY

TVRIARLES=CD5 TH2 TA3 LASS LAS6 LAS3 SD1

ISCALE ('ALL VARIABLEE') ALI

/MOUEL=ALFHA

/STATIST ICS=OE SCRIPT TUE CORR

+ /SOMARY=MEANS DRIANCE.

\begin{tabular}{|c|c|c|c|}
\hline \multicolumn{4}{|c|}{ Case Processing Summary } \\
\hline & & $M$ & $x$ \\
\hline \multirow[t]{3}{*}{ Cases } & Valid & 186 & 95.9 \\
\hline & Excludect & 8 & 4.1 \\
\hline & Total & 194 & 100.0 \\
\hline
\end{tabular}

a. Listwise deletion based on all yariables in the procedure.

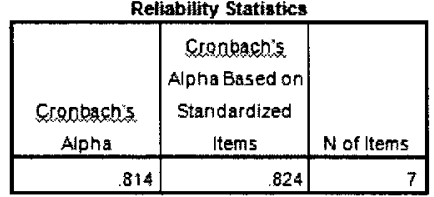

Item Statistics

\begin{tabular}{|l|r|r|r|}
\hline & Mean & Std. Deviation & N \\
\hline CD5 & 1.76 & 1.014 & 186 \\
TA2 & 1.54 & .858 & 186 \\
TA3 & 2.12 & 7.734 & $\mathbf{1 8 6}$ \\
LAS5 & 1.72 & .975 & 186 \\
LAS6 & 1.64 & 1.083 & 186 \\
LAS3 & 1.46 & .889 & 186 \\
SD1 & 1.30 & .544 & 186 \\
\hline
\end{tabular}




\section{APPENDIX I}

\section{TEST-RETEST DATA ANALYSIS}

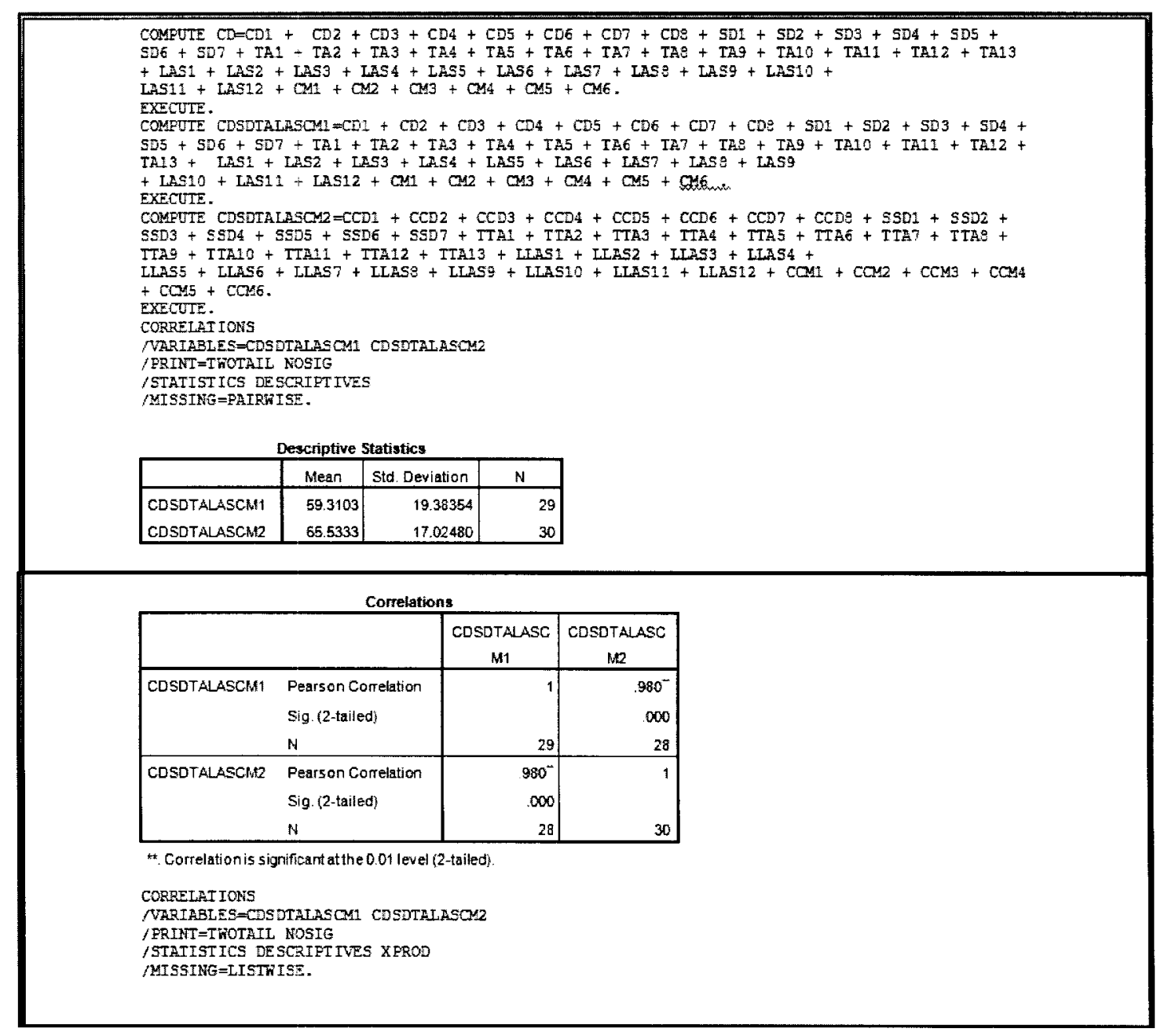




\title{
CURRICULUM VITAE
}

\author{
Maria Gómez-García
}

Cardedeu 1, 4B

La Garriga Barcelona 08530 SPAIN

00 (34) 9311.38729

00 (34) 6790.00984

E-mail: marigome@itesm.mx
Instituto Tecnológico y de Estudios

Superiores de Monterrey

Director.International Link Office /

Barcelona

Compte d'Urgell 187

08036 Barcelona, SPAIN

\section{ACADEMIC PREPARATION}

M.A. Education. Western Kentucky University, USA, (2001)

M.A. Education. California State University Fresno, (2000) Degree with Distinction

Certificate. CAST Program.(Certificate of Advanced Studies for Teachers) Instituto Tecnológico y de Estudios Superiores de Monterrey.

Mexico City campus, (2000)

B. S. Architecture. Instituto Tecnológico y de Estudios Superiores de Monterrey, Monterrey campus, México, (1982)

Certificate. English Language Instructor. Instituto Tecnológico y de Estudios Superiores de Monterrey. Monterrey campus, México, (1979)

\section{AREAS OF EXPERTISE}

English Language Consultant Student Teacher Supervisor Internationalization 


\section{PROFESSIONAL EXPERIENCE ON EDUCATION}

- Methodology Consultant for English Language for HMHarcourt Publishing Co. 2009 to the present.

- Creation and Supervision of Student Teacher Programs. Col-legi Reial Monestir de Santa Isabel Barcelona. 2009-2010

- Creation and Supervision of Student Teacher Programs. Col-legi Internacional SEK-Catalunya. Barcelona. 2008-2009

- Methodology Consultant for English Language to the schools part of Institución Educativa SEK at Madrid, Pontevedra and Almería and Catalunya, SPAIN. 2006-2009

- Creation and Direction of the English Language Library Classroom SEK (ELALCSEK) at Col-legi Internacional SEK-Catalunya. Barcelona, SPAIN. 2005-2007.

- Methodology Consultancy on English Language for Col-legi Internacional SEK Catalunya. Barcelona, SPAIN. 2004-2007.

- Creation and Direction of CLEPPT, Centro de Liderazgo y Estudios Pedagógicos de la Preparatoria del Instituto Tecnológico y de Estudios Superiores de Monterrey. Mexico City, MEXICO. 2001.

- Founder and Director of the Master Program of Arts in Education, taught by Western Kentucky University at Instituto Tecnológico y de Estudios Superiores de Monterrey, Mexico City campus. Mexico City, MEXICO. 2000-2002.

- Founder and Director of the CAST Program (Certificate of Advanced Studies for Teachers) at Instituto Tecnológico y de Estudios Superiores de Monterrey, Mexico City campus.Mexico City, MEXICO. 1998-2001.

- Founder and Consultant of the Technical Department on Instituto Motolinía. Monterrey, MEXICO. 1996-1998.

- President of the English Academy for the $64^{\text {th }}$ zone of Middle School. Monterrey, MEXICO. 1996-1997.

- Founder and Director of the Studies Team Project on Instituto Motolinía. Monterrey, MEXICO. 1995-1998.

- Manager and coordinator for the General Project on Instituto Motolinía. Monterrey, MEXICO. 1992-1998.

- Founder and Director of the English Department on Instituto Motolinía. Monterrey, MEXICO. 1990-1998.

- Coordinator of the English Language Academic Program on secondary level at Instituto Motolinía. Monterrey, Mexico. 1981-1984.

- English Language Professor on secondary level at Instituto Motolinía. Monterrey, MEXICO. 1978-1987.

- English Language Professor on particular courses for children and adults. Monterrey, MEXICO. 1977-1984. 


\section{PROGRAM EVALUATION EXPERIENCE}

- Educational Methodology on English Language for the schools part of the Institución Educativa SEK Alborán, Almería, Catalunya, Ciudalcampo, El Castillo y Santa Isabel, SPAIN. 2004-2009.

- General Academic Program of Instituto Motolinía, Monterrey, MEXICO. 1992-1998.

- Technical Department of Instituto Motolinía, Monterrey, MEXICO. 19961998.

- Educational Methodology on English Language for diverse locations schools of Instituto Motolinía: Mexico City, Poza Rica, Jalapa, Oaxaca, Montemorelos, and Monterrey. MEXICO. 1992-1994.

- Performance of English Language teachers on secondary level on Instituto Motolinía.

- Monterrey, MEXICO. 1990-1998.

\section{INTERNATIONAL WORK EXPERIENCE}

- Supervision of Student Teachers from Western Kentucky University doing a Student Teaching Program in Col-legi Reial Monestir de Santa Isabel Barcelona, SPAIN. 2009- 2010.

- Cognitive Leadership Workshop within the Master Universitario en Dirección de Empresas y Sistemas de Producción of Universidad Internacional de Catalunya, Barcelona, SPAIN. 2009.

- Supervision of Student Teachers from Western Kentucky University doing a Student Teaching Program in Col-legi Internacional SEKCatalunya. Barcelona, SPAIN. 2008- 2009.

- Supervision of Student Teachers from Western Kentucky University doing a Student Teaching Program in Col-legi Reail Monestir de Santa Isabel, Barcelona, SPAIN. 2008- 2009.

- Director. International Link Office - Barcelona of Sistema Tecnológico de Monterrey, México. Barcelona, SPAIN. Since 2007.

- Outreach Projects and Resident Director for Western Kentucky University in Spain and Europe. Bowling Green, KY, USA. Barcelona, SPAIN. Since 2007.

- Supervision of Student Teachers from Western Kentucky University doing a Student Teaching Program in Col-legi Internacional SEKCatalunya. Barcelona, SPAIN. 2004 - 2005.

- Educational Leadership Course to high school professors on Col-legi Internacional SEK-Catalunya. Barcelona, SPAIN. 2004.

- Educational Leadership Course to directive staff on Col-legi Internacional SEK-Catalunya. Barcelona, SPAIN. 2004. 
- Educational Leadership workshop to the staff on Col-legi Internacional SEK-Catalunya. Barcelona, SPAIN. 2003.

- Internationalization Process Manager of 10 professors of Instituto Tecnológico y de Estudios Superiores de Monterrey, campus Cd. de México. Mexico City, MEXICO. 2002.

- Teacher on SCATS Program on Western Kentucky University. Summer 2001.

- Internationalization Process Manager of 10 professors of Instituto Tecnológico y de Estudios Superiores de Monterrey, campus Cd. de México. Mexico City, MEXICO. 2000.

- Supervisor on education students from Western Kentucky University during Student Teaching Program on Mexico City, MEXICO. 2001.

- Committee Member on Funds obtaining for GATE Project, of Western Kentucky University. 2001.

- Auxiliary Teacher on Joyce M Huggins Early Education Center, California State University, Fresno. 2000.

- Internationalization Creator, Process Manager and coordinator of the internationalization for 60 professors of Instituto Tecnológico y de Estudios Superiores de Monterrey, campus Ciudad de México. Mexico City, MEXICO. 1999-2000.

- Internationalization Creator, Process Manager, and Coordinador for the Instituto Tecnológico y de Estudios Superiores de Monterrey, campus $\mathrm{Cd}$. de México. Mexico City, MEXICO. 1998-1999.

- Lecture presented on the National High School Association (NHSA) annual conference at Monterey, California. 1999.

- Lecture presented on the National High School Association (NHSA) annual conference at Nashville, Tennessee. 1998.

- Manager on the incorporation of the High School of Instituto Tecnológico y de Estudios Superiores de Monterrey, campus Cd. de México, on the National High school Association (NHSA). 1998

- Supervisor on education students from California State University, Fresno, during Student Teaching Program at Monterrey, MEXICO. 2001.

\section{CONSULTANCY}

- Educational Leadership and Cognitive Leadership Workshops on Col-legi Internacional SEK-Catalunya. Barcelona, SPAIN. 2003-2009.

- Educational Leadership and Cognitive Leadership Workshops on Col-legi Internacional SEK-Catalunya. Barcelona, SPAIN. 2003-2004.

- Educational Leadership Certificate to pre-scholar directive staff of Secretaría de Educación del Estado de Nuevo León, MEXICO. 20012002.

- Consultancy on English areas to Instituto Motolínia de Poza Rica, Veracruz. MEXICO. 2000.

- Workshops on: Assertive Discipline, Whole Language and Team work on diverse locations schools of Instituto Motolinía: Mexico City, Poza Rica, 
Jalapa, Oaxaca, Montemorelos, Monterrey. MEXICO. 1992-1994.

- Workshops and work sessions for teachers and directives on: Assertive Discipline, Whole Language and Team work to Instituto Brillamont. Monterrey. MEXICO. 1992.

- Workshops and work sessions for teachers and directives on: Assertive Discipline, Whole Language and Team work to Instituto San Roberto. Monterrey. MEXICO. 1992.

\section{INDIVIDUAL CONFERENCE PRESENTATIONS}

- Conference on First Childhood Education. Regio Emilia, ITALY. Summer 2000.

- Conference on Interprofessional Work. Fresno, California. 2000

- Conference on Interprofessional Work. Monterey, California. 2000

- Annual Conference of the American Association of Colleges in Teaching Education. Chicago, Illinois. 2000

- Conference on First Childhood Education. Mills College. Oakland, California.1999

- Conference "In Praise of Education" Seattle, Washington.1999

- CABE Annual Conference. San José, California. 1998

- MEXTESOL Annual Conference. Veracruz, Ver. MEXICO. 1997

- MEXTESOL Annual Conference.Zacatecas, Zac. MEXICO. 1996

- MEXTESOL Annual Conference. Acapulco, Gro. MEXICO. 1992

- Conference "Reading/Language Arts". University of Notre Dame. Indiana. 1992. 